\title{
NUTRIENT REMOVAL FROM CLARIFIED MUNICIPAL WASTEWATER USING MICROALGAE RACEWAY PONDS
}

\author{
A Thesis \\ presented to \\ the Faculty of California Polytechnic State University, \\ San Luis Obispo
}

\author{
In Partial Fulfillment \\ of the Requirements for the Degree \\ Master of Science in Civil and Environmental Engineering
}

by

Justin Andrew Kraetsch

March 2015 
(C) 2015

Justin Andrew Kraetsch

ALL RIGHTS RESERVED 


\section{COMMITTEE MEMBERSHIP}

TITLE:

AUTHOR: Justin Andrew Kraetsch

DATE SUBMITTED: $\quad$ March 2015

COMMITTEE CHAIR: $\quad$ Dr. Tryg Lundquist, Ph.D.

Associate Professor of Civil \& Environmental Engineering

COMMITTEE MEMBER: $\quad$ Dr. Tracy Thatcher, Ph.D.

Associate Professor of Civil \& Environmental Engineering

COMMITTEE MEMBER: $\quad$ Dr. Greg Schwartz, Ph.D.

Assistant Professor of BioResource and Agricultural

Engineering 


\begin{abstract}
Nutrient Removal From Clarified Municipal Wastewater Using Microalgae Raceway Ponds
\end{abstract}

Justin Andrew Kraetsch

Shallow, mixed raceway ponds can be used to grow microalgae for the dual purposes of wastewater treatment and biofuel feedstock production. To improve the environmental sustainability of microalgae biofuels and to alleviate resource limitations, nutrients remaining after biofuel production should be recycled for additional cultivation. This thesis considers three topics: wastewater treatment by algae, nitrogen and phosphorus assimilation by algae, and algae cell disruption to facilitate nutrient recovery.

The main experimental work was done in pilot raceway ponds growing polycultures of microalgae on clarified municipal wastewater. In addition, two lab-scale pretreatment technologies were tested for their ability to disrupt cells, as indicated by subsequent biomass organic nitrogen and particulate phosphorus degradation during sequential anaerobic and aerobic digestion. The two pretreatment technologies were sonication and high-pressure homogenization.

The raceway pond research was conducted at the City of San Luis Obispo Water Resource Recovery Facility (WRRF). Nine 30- $\mathrm{m}^{2}$, 0.3-m deep raceway ponds were operated continuously from March 1, 2013 to August 31, 2014. The ponds were arranged in three sets of triplicates. One set was operated at a 2-day hydraulic residence time (HRT) on clarified wastewater throughout the study. A second set ("Round 1" of pondsin-series) was operated at a 3-day HRT, also on clarified wastewater. Its effluent was 
clarified and then discharged into the third set ("Round 2" of ponds-in-series), which initially operated at a 4-day HRT but then later a 3-day HRT.

The nutrient removal and assimilation data were compared seasonally—summer (MarchOctober) and winter (November-February). The triplicate raceways operating at a 2-day HRT achieved average total ammonia nitrogen (TAN) removal efficiencies of $11 \%$ in the winter and $71 \%$ in the summer, while dissolved reactive phosphorus (DRP) removal remained similar throughout seasonality. In the first ponds-in-series experiment (3-day HRT followed by 4-day), average summer TAN removal efficiencies for Round 1 and 2 were $88 \%$ and nearly $100 \%$, respectively. Round 1 and 2 average summer DRP removal efficiencies were $29 \%$ and $67 \%$, respectively. The first ponds-in-series experiment was not conducted in the winter. In the second experiment, the Round 2 HRT was changed to 3 days. Average TAN removal efficiencies for Round 2 in the winter and summer were $88 \%$ and $100 \%$, respectively. DRP removal for Round 2 increased from $38 \%$ in the winter to $66 \%$ in the summer.

Total nitrogen (TN) mass balances on the raceway pond experiments were useful to illustrate the fate of influent nitrogen, including losses. In the first ponds-in-series experiment, $76 \%$ of the influent soluble nitrogen was converted to organic nitrogen by assimilation, while $6 \%$ of the influent ammonia was lost by volatilization. In the second ponds-in-series experiment, $81 \%$ of the influent soluble nitrogen was converted to organic nitrogen by assimilation and only $1 \%$ of the influent ammonia was lost by volatilization. The 2-day HRT raceway experiment achieved $41 \%$ conversion of influent soluble nitrogen to organic nitrogen by assimilation, with influent ammonia losses of $3 \%$ by volatilization. 
In addition to these pilot-scale raceway pond experiments, laboratory experiments were conducted on re-solubilization of algae biomass nutrients to support additional algae growth. Algae harvested from the pilot ponds was pre-treated with either sonication or high-pressure homogenization. The pretreated biomass was then subjected to anaerobic digestion and then aerobic digestion to increased nitrogen and phosphorus solubilization. The laboratory anaerobic digestion simulated pilot digestion, also conducted at the pilot facility, and the aerobic digestion was meant to simulate further re-solubilization that would occur when algae digestate was returned to the aerobic raceway ponds to promote further algae growth. Neither pre-treatment technologies had a significant impact on degradation of biomass organic nitrogen and particulate phosphorus compared to controls. It was found that simple anaerobic digestion followed by aerobic digestion resolubilized $90 \%$ of organic nitrogen and $50 \%$ of particulate phosphorus.

Keywords: microalgae, raceway pond, nitrification, denitrification, assimilation, volatilization, anaerobic degradation, aerobic degradation, nitrogen, phosphorus, pretreatment of algae, nutrient solubilization. 


\section{ACKNOWLEDGMENTS}

I would like to express my deepest gratitude to those who supported me during my research and throughout my time at Cal Poly.

To my family: Thank you for your unwavering love and support, my accomplishments would not have been possible with all of you.

To Dr. Tryg Lundquist: I consider myself very fortunate to have mentor as passionate and knowledgeable as you. You have made me a better engineer and student, and prepared me well for my next step as a professional engineer.

To Dr. Tracy Thatcher and Dr. Greg Schwartz: It has been such an honor to have such dedicated, intelligent advisors as you. I will always remember all that you two have taught me.

To Matt Hutton and Ian Woertz: Thank you for your continual guidance, motivation, and leadership during this project. It has been a very rewarding experience working with you.

To my fellow graduate students: Mike Chang, Alec Roberts, Carter Reiff, Alex Hill, Chad Boggess, and Eric Nicolai, thank you for your friendship and support. I wish all of you a successful and happy post-college life, and I hope to see you all in the future. To Mike Chang specifically, thank you for all of your help.

To Shelley Blackwell: Thank you for your impressive handling and organization of the ENVE 405 class.

To Aaron Carriedo, Dylan Robertson, Perry Ng, Brooke Favillo, Chase Perez, and Tiffany Racz: Thank you for sticking with this project for multiple quarters and helping us complete analytical tests. Without all of you, this thesis would not have been possible.

To Katie Johnston: Your support and encouragement during my time as a graduate student has helped me immensely.

To all ENVE 405 students: Without your commitment to this project, our research would not have been possible. I am forever grateful for your help.

To the San Luis Obispo Water Resource Recovery Facility: Thank you for providing us with the land and supplies to complete this research.

This project was funded by the United States Department of Energy. 


\section{TABLE OF CONTENTS}

Page

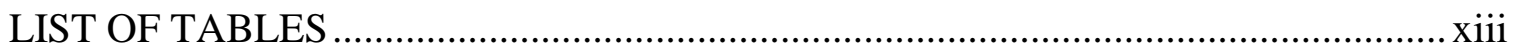

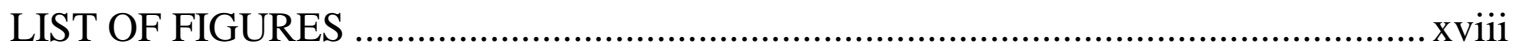

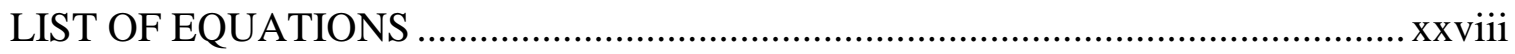

\section{CHAPTER}

1 Introduction .............................................................................................. 1

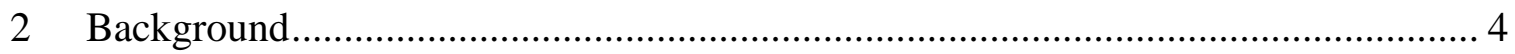

2.1 Sustainability Issues in Wastewater Treatment............................................ 4

2.2 Wastewater Treatment with Algae Raceway Ponds ...................................... 5

2.3 Nitrogen and Phosphorus Removal Mechanisms in Raceway Ponds ................ 8

2.3.1 Nitrogen Removal Mechanisms...................................................... 8

2.3.2 Phosphorus Removal Mechanisms ......................................................... 11

2.4 Improving Raceway Pond Performance and Sustainability .......................... 13

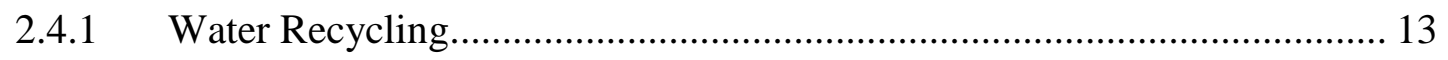

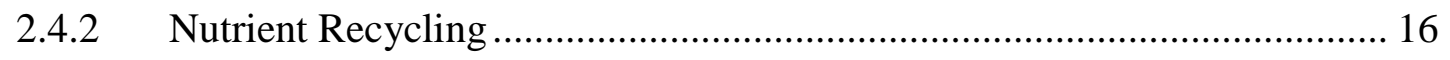

2.4.3 Anaerobic and Aerobic Degradation of Microalgae to Solubilize

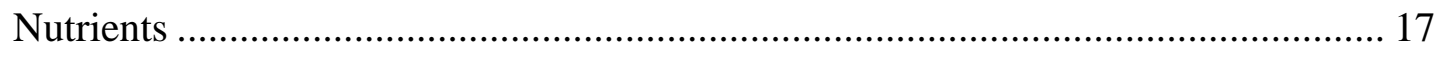

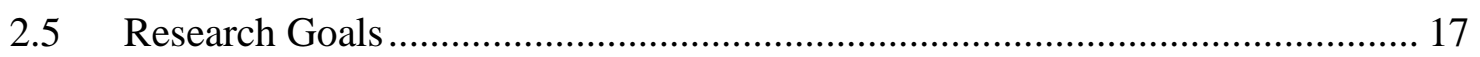

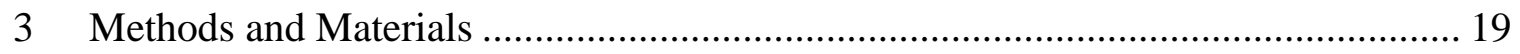

3.1 Algae Field Station: Location Layout ........................................................ 19 
3.2.1 Experimental Concept and Purpose ...................................................... 20

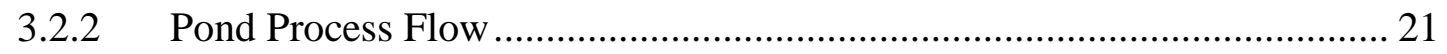

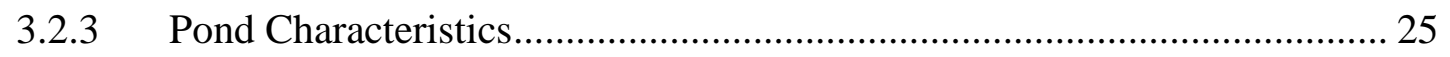

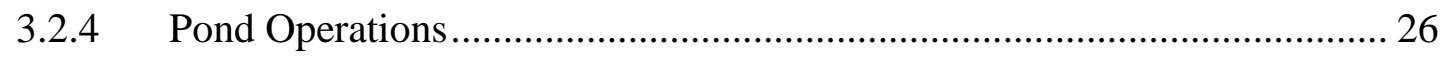

3.2.5 Description of Pond Experiments .................................................. 30

3.2.5.1 Nitrogen and Phosphorus Removal with Beta-to-Alpha Ponds in

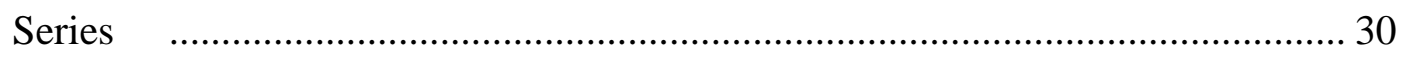

3.2.5.1.1 Beta to Alpha Ponds in Series Experiment I ............................... 31

3.2.5.1.2 Beta to Alpha Ponds in Series Experiment II ............................... 32

3.2.5.2 Nitrogen and Phosphorus Removal Performance from Raceway

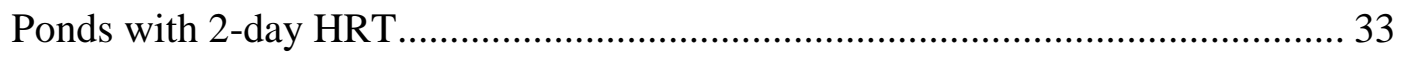

3.2.6 Weekly Pond Sampling Procedures ...................................................... 34

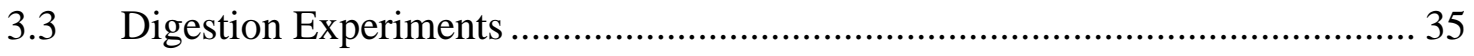

3.3.1 Collection and Storage of Settled Algal Sludge .................................. 38

3.3.2 Anaerobic Digestion Experiments ..................................................... 39

3.3.3 Aerobic Digestion Experiments …................................................ 42

3.3.3.1 Post Sonicated and Digestion Aerobic Degradation Experiment............ 42

3.3.3.2 Post Homogenized and Digested Aerobic Degradation Experiment ...... 43

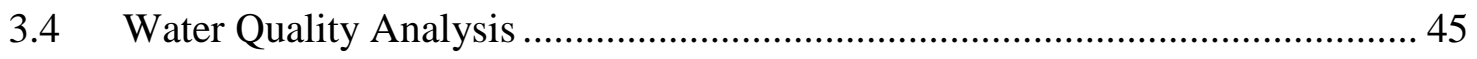




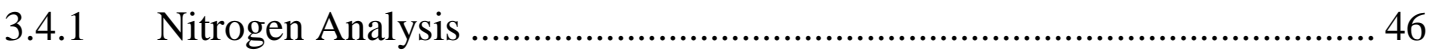

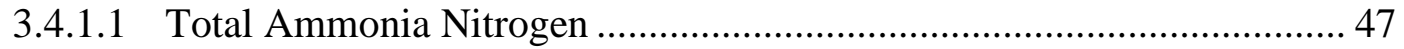

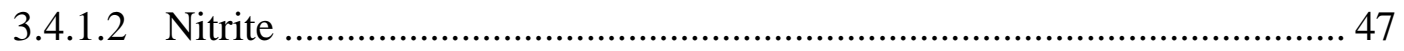

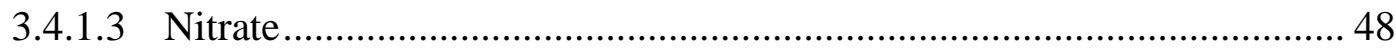

3.4.1.4 Total Kjeldahl Nitrogen .......................................................... 49

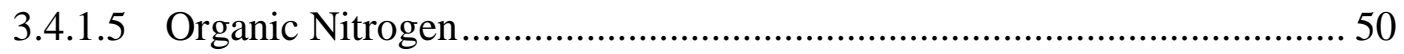

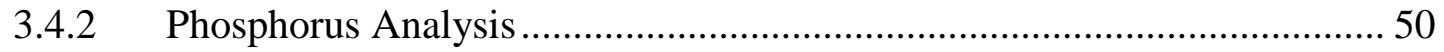

3.4.2.1 Dissolved Reactive Phosphorus ................................................... 50

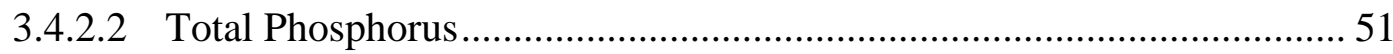

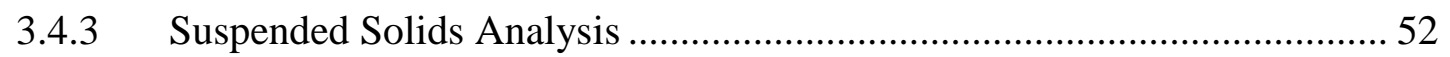

3.4.3.1 Pond Water Sample Homogenization for 0-hour Suspended Solids....... 52

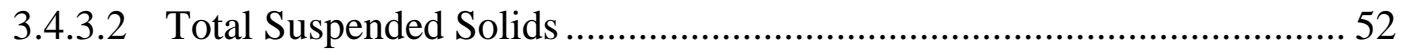

3.4.3.3 Volatile Suspended Solids.......................................................... 53

3.4.4 Total and Volatile Solids Analysis .................................................. 53

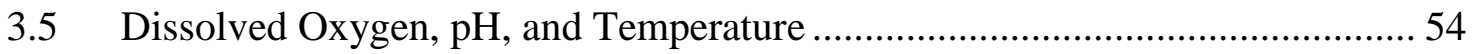

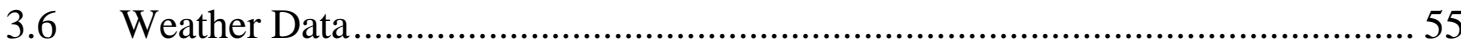

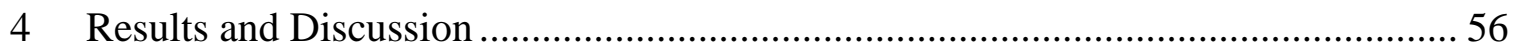

4.1 Pond Influent Water Characteristics ..................................................... 56

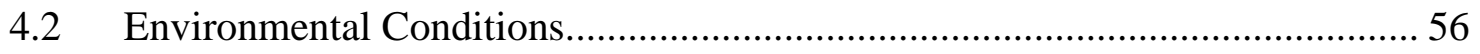

4.3 N and P Removal from Ponds in Series- Experiment I................................ 57 


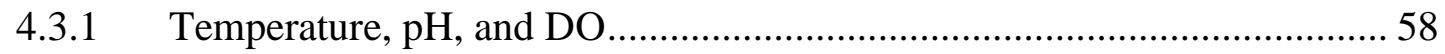

4.3.2 Nitrogen Removal .............................................................................. 58

4.3.3 Dissolved Reactive Phosphorus Removal .................................................... 64

4.4 N and P Removal from Ponds in Series- Experiment II ..................................... 66

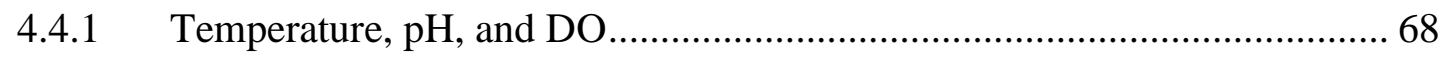

4.4.2 Nitrogen Removal in Series Experiment II.............................................. 71

4.4.3 Dissolved Reactive Phosphorus Removal in Series Experiment II ............ 86

4.5 N and P Removal from the Two-day HRT Raceway Ponds ............................. 88

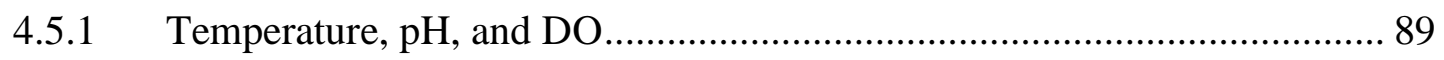

4.5.2 Nitrogen Removal .............................................................................. 91

4.5.3 Dissolved Reactive Phosphorus Removal ................................................. 98

4.6 Summary of sequential Anaerobic and Aerobic Digestion Experiments......... 101

4.6.1 Effect of Lysing Method on Organic Nitrogen Decay............................... 102

4.6.2 Effect of Lysing Method on Particulate Phosphorus Decay ...................... 103

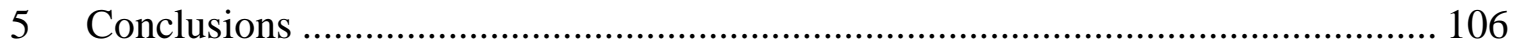

$5.1 \quad$ Experimental Conclusions.......................................................................... 106

5.1.1 N and P Removal from Ponds-in-Series Experiment I and II................... 106

5.1.1.1 N and P Removal from Ponds-in-Series Experiment I ......................... 106

5.1.1.2 N and P Removal from Ponds in Series Experiment II......................... 108

5.1.2 N and P Removal from Two-day HRT Raceway Ponds............................ 110 
5.1.3 Summary of sequential Anaerobic and Aerobic Digestion Experiments . 111

5.2 Limitations of Study ........................................................................... 113

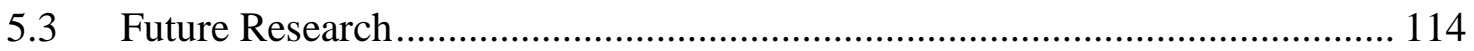

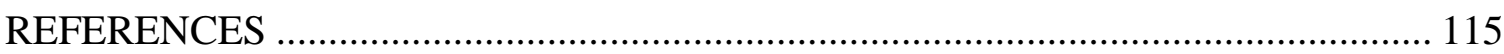

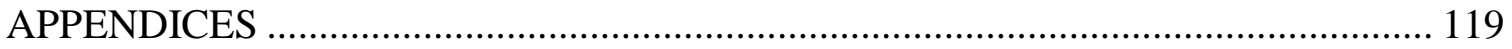

Appendix A: Pond pH, DO, and temperature graphs........................................ 120

Appendix B: San Luis Obispo monthly precipitation, solar radiation, and air temperature data recorded by the CIMIS weather station..................................... 126

Appendix C: Organic nitrogen and particulate phosphorus data from the sequential Anaerobic and Aerobic Digestion Experiments ................................................ 127

Appendix D: List of operational changes at the AFS........................................... 130 


\section{LIST OF TABLES}

Table

Page

Table 3-1: Target pond characteristics from June 2012 to June 13, 2013. *Channel

velocities obtained from Roberts, 2013 . ............................................................... 25

Table 3-2: Target pond characteristics from June 26, 2013 to August 28, 2014.

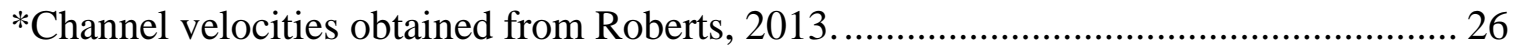

Table 3-3: Each analytical test performed on the different samples, and the required sample volume for each. The proper sample storage technique is list in the right

column (Hill, 2014).

Table 3-4: A list of the analytical method used to measure each constituent. Within each analytical method description, the APHA Standard Methods title is listed. 45

Table 4-1: Primary clarifier effluent characteristics, which served as the influent for the Beta (Round 1) ponds in the ponds in series experiments, and for the two-day HRT ponds

Table 4-2: TAN removal efficiencies in Round 1 and 2 ponds during March 6, 2013

to June 13, 2013.

Table 4-3: Nitrate nitrogen concentrations (mg/L-N) in the Round 1 and 2 pond effluent during March 3, 2013 to June 13, $2013 .$.

Table 4-4: Nitrite nitrogen concentrations (mg/L-N) in Round 1 and 2 effluent during March 6, 2013 to June 13, 2013. 62

Table 4-5: Dissolved reactive phosphorus (DRP) concentrations in Influent and

Round 1 and 2 effluent during March 6, 2013 to June 13, 2013. 65

Table 4-6: Winter and summer average TAN removal efficiencies and concentrations from the Influent and Round 1 and 2 effluent. The duration of the experiment was 
June 2013 - August 2014. Summer and winter months are March - October and November - February, respectively. 72

Table 4-7: TAN concentration (mg/L-N) percentiles for meeting the Stockton, Calif. ammonia discharge limit of $2 \mathrm{mg} / \mathrm{L}-\mathrm{N}$ in both summer and winter months. The 25 th and 75 th percentiles are also shown 73

Table 4-8: Winter and summer nitrate nitrogen concentrations $(\mathrm{mg} / \mathrm{L}-\mathrm{N})$ in the Influent and Round 1 and 2 effluent. The winter and summer months are NovemberFebruary and March - October, respectively. The duration of the experiment was June 2013 - August 2014. 77

Table 4-9: Winter and summer nitrite nitrogen concentrations (mg/L-N) of Influent and Round 1 and 2 effluent. Round 1 and 2 effluent values are averages of their respective triplicate ponds. Winter and summer months are November - February and March - October, respectively. The duration of the experiment was June 2013 August 2014 79

Table 4-10: The percent of time the Round 2 effluent would meet projected 10 $\mathrm{mg} / \mathrm{L}-\mathrm{N}$ total nitrogen discharge limits in both summer and winter months. The 25 th and 75 th percentiles $(\mathrm{mg} / \mathrm{L}-\mathrm{N})$ are also shown. 83

Table 4-11: Winter and summer dissolved reactive phosphorus concentrations (DRP in mg/L-P) in the Influent and Round 1 and 2 effluent during June 2013 - August 2014. The winter months were November, 2013 - February, 2014 and summer months were June, 2013 - October, 2013 and March, 2014 - August, 2014. 86 Table 4-12. Winter and summer TAN removal efficiencies and concentrations for Influent and Round 1 and 2. The duration of the experiment was March 62013 to 
August 28, 2014. Summer months were June 2013 - October 2013 and March 2014 August 2014, and the winter months were November 2013 - February 2014, respectively.

Table 4-13: Winter and summer data for nitrate nitrogen concentrations (mg/L-N) in the Influent and two-day HRT effluent during March 6, 2013 - August 28, 2014. Summer and winter months were March - October and November - February, respectively. 94

Table 4-14: Winter and summer nitrite nitrogen concentrations $(\mathrm{mg} / \mathrm{L}-\mathrm{N})$ for the Influent and two-day HRT effluent during March 6, 2013 - August 28, 2014. Winter months were November 2013- February 2014 and the summer months were June 2013 - October 2013 and March 2014 - August 2014. 96

Table 4-15: Summer and winter dissolved reactive phosphorus (DRP) concentrations and removal efficiencies in the Influent and two-day HRT effluent during March 6, 2013 - August 28, 2014

Table 5-1: Significant TAN effluent concentrations and removal efficiencies in the triplicate Round 1 and Round 2 ponds and Influent.

Table 5-2: Summer and winter TAN effluent concentrations and percent removals for Influent and Round 1 and 2 effluent. 109

Table 5-3: Winter and summer TAN effluent concentrations and removal efficiencies for the triplicate two-day HRT ponds, and the Influent.

Table 7-1: Monthly weather data recorded by the San Luis Obispo CIMIS weather station located approximately $6 \mathrm{~km}$ north of the AFS. 
Table 7-2: The mass of organic nitrogen in the anaerobic and aerobic digesters for the sequential anaerobic and aerobic digestion experiments in Section 4.6. The pretreatment technology was high-pressure homogenization. "Raw" refers to the pretreated sample in the anaerobic digestion on day 0. "Digestate" and "aerobic treatment" refers to the effluent of the anaerobic digesters and aerobic digesters, respectively.

Table 7-3: The mass of organic nitrogen in the anaerobic and aerobic digesters for the sequential anaerobic and aerobic digestion experiments in Section 4.6. No pretreatment technology was used for the control samples. "Raw" refers to the sample in the anaerobic digestion on day 0. "Digestate" and "aerobic treatment" refers to the effluent of the anaerobic digesters and aerobic digesters, respectively.

Table 7-4: The mass of organic nitrogen in the anaerobic and aerobic digesters for the sequential anaerobic and aerobic digestion experiments in Section 4.6. The pretreatment technology was sonication. "Raw" refers to the pre-treated sample in the anaerobic digestion on day 0. "Digestate" and "aerobic treatment" refers to the effluent of the anaerobic digesters and aerobic digesters, respectively.

Table 7-5: The mass of organic nitrogen in the anaerobic digesters for the sequential anaerobic and aerobic digestion experiments in Section 4.6. No pre-treatment technology was used for the control samples. "Raw" refers to the sample in the anaerobic digestion on day 0. "Digestate" refers to the effluent of the anaerobic digesters. 128

Table 7-6: The mass of particulate phosphorus in the anaerobic and aerobic digesters for the sequential anaerobic and aerobic digestion experiments in Section 4.6. The 
pre-treatment technology was high-pressure homogenization. "Raw" refers to the pre-treated sample in the anaerobic digestion on day 0. "Digestate" and "aerobic treatment" refers to the effluent of the anaerobic digesters and aerobic digesters, respectively. 128

Table 7-7: The mass of particulate phosphorus in the anaerobic and aerobic digesters for the sequential anaerobic and aerobic digestion experiments in Section 4.6. No pre-treatment technology was used for the control samples. "Raw" refers to the sample in the anaerobic digestion on day 0. "Digestate" and "aerobic treatment" refers to the effluent of the anaerobic digesters and aerobic digesters, respectively..... 128 Table 7-8: The mass of particulate phosphorus in the anaerobic digesters for the sequential anaerobic and aerobic digestion experiments in Section 4.6. The pretreatment technology was sonication. "Raw" refers to the pre-treated sample in the anaerobic digestion on day 0 . "Digestate" refers to the effluent of the anaerobic digesters. 129

Table 7-9: The mass of particulate phosphorus in the anaerobic digesters for the sequential anaerobic and aerobic digestion experiments in Section 4.6. No pretreatment technology was used for the control samples. "Raw" refers to the pretreated sample in the anaerobic digestion on day 0 . "Digestate" refers to the effluent of the anaerobic digesters.

Table 7-10: List of operational changes at the AFS during the course of the experiments (March 6, 2013 - August 28, 2014) 130 


\section{LIST OF FIGURES}

Figure

Page

Figure 2-1: A simplified version of the algal-bacterial relationship in raceway ponds for wastewater treatment (after Oswald et al, 1953). 6

Figure 2-2: Side view of a typical high rate algae pond with common dimensions, $\mathrm{CO}_{2}$ addition, and a $\mathrm{pH}$ sensor that triggers the $\mathrm{CO}_{2}$ release (Park et al, 2010). 7

Figure 2-3: Layout and cross section of an Advanced Integrated Wastewater Pond

System. (SSWM et al, n.d.)............................................................................... 8

Figure 2-4: The locations for potential pond sites that have the cost of water taken into account. The red/orange dots have the highest water cost as a percentage of

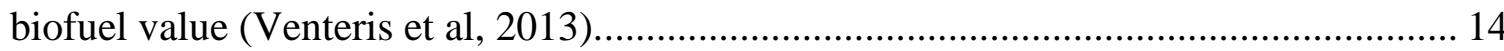

Figure 2-5: Map of solar radiation in the U.S. in units of $\mathrm{kWh} / \mathrm{m}^{2} / \mathrm{day}$ (NREL 2008).... 15 Figure 2-6: An algal biofuels production process flow using high rate ponds as the algal production source (Lundquist et al, 2010).

Figure 3-1: Aerial view of the AFS facility labeling the nine 33-m2 raceway ponds arranged in three sets of triplicates: Alpha, Beta, and Gamma. The primary clarifier was the influent source for the ponds. North arrow was included in the upper right hand corner. 19

Figure 3-2: The influent pump located in the western primary clarifier, as shown in Figure 3-1 (Chang, 2014).

Figure 3-3: Gamma constant head tank and distribution system with motor. Beta and Alpha head tanks operated identically (Chang, 2014) ............................................. 22 Figure 3-4: Side View of tube settlers showing the $60^{\circ}$ angle of tilt (Chang, 2014)....... 23 
Figure 3-5: Alpha constant head tank and distribution system. The top right photo shows how the tube settler effluent was fed into the head tank, there were six total feed lines with three on each side. The bottom picture shows the distribution pipe into each pond (Chang, 2014).

Figure 3-6: Ramp standpipe design installed in ponds 1, 2, 4, 5, 8, and 9 (Chang, 2014).

Figure 3-7: Four inch vertical standpipe design installed in ponds 3, 6, and 7 (Chang, 2014).

Figure 3-8: Neptune PM1 units for temperature and $\mathrm{pH}$ data acquisition. Identical set up in all three pump houses (Chang, 2014).

Figure 3-9: VFD for controlling water wheel and paddle wheel speed. The right most VFD controlled the water wheel and the left most VFD controlled the paddle wheel. Identical set up in all three pump houses (Chang, 2014).

Figure 3-10: Peristaltic pump set up in Beta pump house. Water entered from the right and pumped out the left side in the PVC and flexible tubing. Each pump pulled water from one pond and fed it into the two tube settlers for each Beta pond (Chang, 2014).

Figure 3-11: The PM3 unit that transmits DO readings from the probes in the ponds. Each pond has one located in a green water proof container. 28

Figure 3-12: A closed bottom ramp standpipe with a tube settler intake tube. This standpipe was one foot tall and controlled the depth of the raceway pond. 
Figure 3-13: The left photo shows the 50-1b CO2 cylinders secured in a shelving unit. The right photo shows the automated solenoid units that opened and closed CO2 distribution (Chang, 2014)

Figure 3-14a: The process flow schematic for the AFS ponds during Ponds in Series

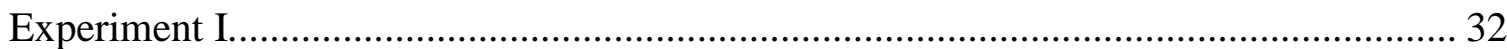

Figure 3-15b: The process flow schematic for the AFS ponds during Ponds in Series Experiment II

Figure 3-16: Sampling location for the Pond 6 tube settler supernatant. Identical set up for each tube settler (Chang, 2014). 35

Figure 3-17: A basic process flow for nutrient and water recycling with raceway ponds. The supernatant from the tube settler comprises the water recycling aspect, while the return disgestate is the nutrient recycle part. Also included are the inputs and outputs of system including energy required for the pretreatment technology, energy gained by anaerobic digestion, and sewage influent (Hill, 2014). 37

Figure 3-18: The angled tube settlers that the harvested algal biomass was collected from. The spigots at the bottom were the algal sludge collection point. The influent lines entered the settling units at 1/3 the depth (Ripley, 2013) 38 Figure 3-19: Serum bottles located inside the incubator which maintained a constant mesophilic temperature of $35 \pm 2^{\circ} \mathrm{C}$ (Hill, 2014).

Figure 3-20: Process flow for the set-up of the digesters. The collection and pretreatment of the algae samples is shown to the left and to the right is the collection of the seed (Hill, 2014). 
Figure 3-21: Triplcate 3.78-L polypropylene containers that served as the aerobic reactors with air lines that provided adequate aeration (Chang, 2014).......................... 43

Figure 3-22: A picture of the two sets of triplicate 3.78-L polypropylene aerobic reactors. The left picture is of the un-homogenized reactors, and the right photo is the homogenized reactors. Each set was placed in a water bath to maintain a constant temperature in the reactors (Chang, 2014)

Figure 3-23: The probe stand on each raceway pond. The $\mathrm{pH}$ and temperature probes are inserted through holes in the stand and the DO probe was connected to a green rod that is attached to the stand. 55

Figure 4-1: TAN removal from two rounds of treatment. The Influent line corresponds to the primary clarifier effluent distributed to Round 1 Beta ponds. Pond TAN values are the mean of triplicate ponds

Figure 4-2: Nitrate nitrogen concentrations in Round 1 and 2 effluent. The Influent nitrate nitrogen concentration varied between 0.1 to $2.0 \mathrm{mg} / \mathrm{L}-\mathrm{N}$. 61

Figure 4-3: Nitrite nitrogen concentrations in Round 1 and 2 effluent. The Influent nitrite nitrogen concentration varied between 0.1 and $<0.1 \mathrm{mg} / \mathrm{L}-\mathrm{N}$ 63 Figure 4-4: Nitrogen mass balance on the Round 1 and 2 pond sets during March 6 to June 13, 2013. The influent bar refers to the primary clarifier effluent, which served as the influent to Round 1 ponds. Oxidized nitrogen is the sum of the nitrate and nitrite concentrations. Round 2 received Round 1 effluent after solids separation (algae harvesting). The gap of about $0.8 \mathrm{~kg}$ was likely due to ammonia volatilization in the Round 1 ponds. The amount of organic nitrogen removed with the slurry 
harvested from the tube settlers was estimated from the difference in VSS

concentration across the tube settlers.

Figure 4-5: Dissolved reactive phosphorus (DRP) concentrations in Influent and

Round 1 and 2 effluent. 66

Figure 4-6: Monthly average solar radiation and air temperatures recorded by a CIMIS weather station in San Luis Obispo, Calif. See Methods chapter for details 68 Figure 4-7: Hourly DO measurements from Round 1 and 2. These values represent an average of the triplicates. This figure provides an example of two days of diel oscillations for both rounds. The Neptune data logger recorded these measurements.... 69 Figure 4-8: $\mathrm{pH}$ measurements taken at ten minute intervals from the Round 1 and 2 pond. These values represent an average of the triplicate ponds in each round. This figure only spans roughly two days to provide in example of the $\mathrm{pH}$ control provided by $\mathrm{CO}_{2}$ sparging. The $\mathrm{CO} 2$ was delivered by a $\mathrm{pH}$ reading of 8.5 , which prevented the $\mathrm{pH}$ levels from increasing to 9. Neptune data logger recorded these measurements.

Figure 4-9: Monthly average solar radiation and total ammonia nitrogen (TAN) concentrations of Influent and Round 1 and 2 effluents during June 2013 - August 2014 72

Figure 4-10: Probability plot for Round 1 effluent TAN concentrations in the summer months (June 2013 - October 2013, March 2014 - August 2014) operating at a three day residence time 
Figure 4-11: Probability plot for Round 1 effluent TAN concentrations during the winter months (November 2013 - February 2014) operating a three day residence time.

Figure 4-12: Probability plot for Round 2 effluent TAN concentrations in the summer months (June 2013 - October 2013, March 2014 - August 2014) operating at a three day residence time. 75

Figure 4-13: Probability plot for Round 2 effluent TAN concentrations during the winter months (November 2013 - February 2014) operating at a three day residence time. 76

Figure 4-14: Nitrate nitrogen concentrations in Round 1 and 2 effluent. The Influent nitrate nitrogen concentration varied between 0.2 to $3.6 \mathrm{mg} / \mathrm{L}-\mathrm{N}$. 78 Figure 4-15: Volatile suspended solids (VSS) concentrations in Round 1 and 2 effluent. 78

Figure 4-16: Nitrite nitrogen concentrations of Round 1 and 2 effluent during June 2013 - August 2014. The Influent nitrite nitrogen concentrations varied between 0.1 $\mathrm{mg} / \mathrm{L}-\mathrm{N}$ and $<0.1 \mathrm{mg} / \mathrm{L}-\mathrm{N}$ 80 Figure 4-17: Summer TN mass balance of Round 1 and 2 sets during June 2013 October 2013 and March 2014 - August 2014. The Influent bar refers to the primary clarifier effluent, which served as the influent to Round 1. Oxidized nitrogen is the sum of the nitrate and nitrite concentrations. Round 2 received Round 1 effluent after solids separation (algae harvesting). The small gaps were likely caused by sampling and analytical errors. The amount of organic nitrogen removed with the slurry harvested from the tube settlers was estimated from the difference 
in VSS concentration across the tube settlers. The masses shown reflect 30 out of 41 days of measurements taken during the summer period. The 11 days not included were dismissed because at least one form of nitrogen was not measured.

Figure 4-18: Winter TN mass balance on Influent, Round 1, and Round 2 effluent during November 2013 - February 2014. The Influent bar refers to the primary clarifier effluent, which served as the influent to Round 1. Oxidized nitrogen is the sum of the nitrate and nitrite concentrations. Round 2 received Round 1 effluent after solids separation. The amount of organic nitrogen removed from the influent into Round 2 was determined based on the biomass concentration in the tube settler supernatant, before entering Round 2. The masses shown reflect only 6 out of 14 days of measurements taken during the period of winter. The 8 days not included were dismissed because at least one form of nitrogen was not measured.

Figure 4-19: Summer time probability plot for Round 1 effluent soluble nitrogen concentrations (June 2013 - October 2013, March 2014 - August 2014) operating at a three day residence time 84

Figure 4-20: Winter time probability plot for Round 1 effluent soluble nitrogen concentrations (November 2013 - February 2014) operating at a three day residence time. 84

Figure 4-21: Summer time probability plot for Round 2 effluent soluble nitrogen concentrations (June 2013 - October 2013, March 2014 - August 2014) operating at a three day residence time. 85 
Figure 4-22: Winter time probability plot for Round 2 effluent soluble nitrogen concentrations (November 2013 - February 2014) operating at a three day residence time.

Figure 4-23: Monthly average solar radiation and dissolved reactive phosphorus (DRP) concentrations in the Influent and Round 1 and 2 effluent. 87

Figure 4-24: Monthly average air temperature and dissolved reactive phosphorus (DRP) concentrations in the Influent and Round 1 and 2 effluent. 88 Figure 4-25: Monthly average solar radiation and air temperatures recorded by a CIMIS weather station in San Luis Obispo, Calif. see the methods chapter for details. This is an extension of Figure 4-6 to show the data from March - May 2013 ... 89 Figure 4-26: Hourly DO measurements from the 2-day HRT ponds. These values represent an average of the triplicates. This figure only spans two days to provide an example of the diel oscillations for both rounds. The Neptune data logger recorded these measurements. 90

Figure 4-27: Monthly average solar radiation and total ammonia nitrogen (TAN) concentrations of the Influent and two-day HRT effluent during March 6, 2013 to August 28, 2014. 92

Figure 4-28: The effect of the pretreatment technologies on particulate phosphorus degradation during anaerobic digestion and aerobic digestion. The pretreatment technologies were high-pressure homogenization and sonication. "Digestate" refers to the effluent of the anaerobic digesters 105 Figure 5-1: TAN concentrations from Round 1 and 2 effluent and Influent, presented as a time series with monthly average solar radiation. 110 
Figure 7-1: Recorded hourly $\mathrm{pH}$ measurements for Round 1 and 2 ponds during November 1, 2013 - August 28, 2014 of Ponds in series- Experiment II. The values displayed are an average of the triplicate Round 1 and 2 ponds. The outlier values (below $\mathrm{pH} 5$ and above $\mathrm{pH}$ 12) correspond to time periods when the probes were down for maintenance or the data logger malfunctioned, and should be ignored. The Neptune data logger recorded these measurements. 120 Figure 7-2: Recorded hourly DO measurements for Round 1 and 2 ponds during September 28, 2013 - August 28, 2014 of Ponds in series- Experiment II. The values displayed are an average of the triplicate Round 1 and 2 ponds. The Neptune data logger recorded these measurements.

Figure 7-3: Recorded hourly temperature measurements for Round 1 and 2 ponds during September 29, 2013 - August 28, 2014 of Ponds in series- Experiment II. The values displayed are an average of the triplicate Round 1 and 2 ponds. The outlier values (temperatures of $0^{\circ} \mathrm{C}$ ) correspond to time periods when the probes were down for maintenance or the data logger malfunctioned, and should be ignored. The Neptune data logger recorded these measurements. 122 Figure 7-4: Recorded hourly $\mathrm{pH}$ measurements for the two-day HRT ponds during November 1, 2013 - August 28, 2014 of the Two-day HRT Raceway Ponds experiment. The values displayed are an average of the two-day HRT ponds. The outlier values (below pH 5) correspond to time periods when the probes were down for maintenance or the data logger malfunctioned, and should be ignored. The Neptune data logger recorded these measurements. 
Figure 7-5: Recorded hourly DO measurements for the two-day HRT ponds during September 28, 2013 - August 28, 2014 of the Two-day HRT Ponds experiment. The values displayed are an average of the triplicate two-day HRT ponds. The Neptune data logger recorded these measurements. 124 Figure 7-6: Recorded hourly temperature measurements for two-day HRT ponds during September 29, 2013 - August 28, 2014 of the Two-day HRT Ponds experiment. The values displayed are an average of the triplicate two-day HRT ponds. The outlier values (temperatures of $0^{\circ} \mathrm{C}$ ) correspond to time periods when the probes were down for maintenance or the data logger malfunctioned, and should be ignored. The Neptune data logger recorded these measurements 


\section{LIST OF EQUATIONS}

Equation $\quad$ Page

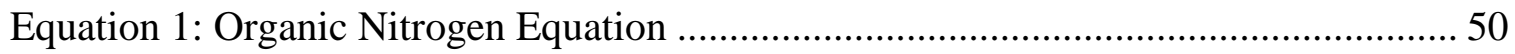




\section{Introduction}

As urban populations increase in the United States and the demand for water grows, the energy required to produce drinking water and treat wastewater also grows, this is known as the water-energy nexus (U.S. GAO, 2011). According to the California Energy Commission (CEC), water-related energy use consumes 19\% of the state's electricity, $30 \%$ of its natural gas, and 88 billion gallons of diesel fuel every year. With water and electricity demand growing rapidly, provisions for the future must be established to ensure failure of its electricity infrastructure and water system reliability does not occur (CEC, 2005). California's State Water Resource Control Board (SWRCB) enacted its Recycled Water Policy in 2009 aimed at relieving a portion of the state's water use, which the Regional Water Quality Control Boards (RWQCB) are committed to enforcing. This increased funding by the state produces an opportunity for advancements in the sustainability of water and wastewater treatment technologies (SWRCB, 2010). Increasingly strict nutrient removal regulations, along with battling the high cost of commercial biological treatment systems, has increased the attention on using more energy efficient wastewater systems such has high rate algae ponds (Sutherland et al, 2014). High rate algae ponds, or raceway ponds, utilize the symbiotic relationship between the microalgae and bacteria to provide a cost effective, sustainable biological wastewater treatment system. First investigated by Dr. Oswald and colleagues in the 1950 's as an alternative to facultative ponds, raceway ponds have been shown to provide improved and more consistent wastewater treatment (Park et al, 2010). Along with wastewater treatment, raceway ponds may also be a viable source for algal biofuel production. 
The algal biomass grown as a by-product of wastewater treatment can be used as the source for algal biofuels, essentially producing free feedstock (Parks et al, 2010). Microalgae grown in wastewater fed raceway ponds have an advantage over traditional agricultural crops due to high growth rates, ability to grow throughout the year, and a lower water and land footprint (Sutherland et al, 2014). The potentially huge upside of algal biofuels has also inspired the Department of Energy's (DOE) Office of Energy Efficiency \& Renewable Energy (EERE) to create an Algae Program under the Bioenergy Technologies Office (BETO). The Algae Program's strategy is to provide long-term applied research and development opportunities to achieve affordable, scalable, and sustainable algal biofuels (EERE, n.d.).

Raceway pond systems also provide the added benefit of nutrient recovery from wastewater via algal biomass. These recovered nutrients can be used in a variety of applications, such as fertilizer or to promote further algal productivity (Sutherland et al, 2014). Anaerobic digestion is a common method to recover nutrients from harvested algal biomass and produce biogas. As the biomass decomposes during digestion, nutrients such as nitrogen and phosphorus resolubilize (Hill, 2014). These resolubilized nutrients (i.e. ammonia) can be added to nutrient depleted raceway ponds as a feed to promote further algal growth (Sutherland et al, 2014).

From a cost comparison to commercial biological treatment systems, raceway pond operation and maintenance expenses are minimal compared to activated sludge systems (Park et al, 2010). The nutrient removal efficiencies of raceway ponds are enhanced with $\mathrm{CO}_{2}$ addition and provide $\mathrm{GHG}$ abatement benefits. According to a study done by Ian Woertz and Dr. Tryg Lundquist, a 100-ha $\mathrm{CO}_{2}$-raceway pond/digestion facility had a 
potential energy surplus of $330 \mathrm{kWh} / \mathrm{ML}$ from biogas-derived electricity and greenhouse gas abatement of $660 \mathrm{~kg} \mathrm{CO} 2 \mathrm{eq} / \mathrm{ML}$ compared to a typical active sludge facility with nitrification/denitrification (2009).

Although there are several economic and environmental advantages to using raceway ponds for wastewater treatment and algal biofuel production, there are disadvantages as well. The land footprint is much higher than commercial treatment systems and treatment performance varies with seasons. Also, harvesting the algal biomass for biofuel purposes is dependent on bioflocculation, settling, and harvesting equipment, which can be troublesome if settling efficiency is poor. (Woertz et al, 2009).

The studies presented in this thesis discuss the nitrogen and phosphorus removal performance of triplicate raceway ponds fed primary clarifier effluent, with two sets operating in series and another at a 2-day HRT. The organic nitrogen and particulate phosphorus degradation results from the anaerobic and aerobic digestion experiments presented in Hill, 2014 and Chang, 2014, respectively, will be summarized and discussed. 


\section{Background}

This section discusses the need to increase wastewater treatment sustainability. Further discussion entails a description of wastewater treatment with raceway ponds, their nutrient removal mechanisms, and how to improve treatment and sustainability.

\subsection{Sustainability Issues in Wastewater Treatment}

Implementation of increasingly stringent wastewater regulations in the United States has required treatment plants to upgrade their nutrient removal capabilities. Centralized activated sludge (AS) plants became the primary nutrient removal technology for municipal wastewater because of their small land footprint and effectiveness. Eventually, greater nutrient removal regulations required these plants to upgrade with systems that have higher nitrogen and phosphorus removal capabilities. The Modified Ludzack Ettinger (MLE) process was one of the most popular upgrades to AS plants to achieve higher nitrogen removal (Metcalf \& Eddy, 2014). However, some AS plants do not have the extra land needed for use the MLE process to meet treatment demands. This increased the need for more expensive upgrades such as a membrane bioreactor activated sludge (MBRAS) and integrated fixed-film activated sludge (IFAS). Each new advanced upgrade accompanied an increased energy demand, cost, maintenance, etc. (Hu et al, 2012). The biggest energy consumer across all of the different AS plants is the oxygen supply. Depending on the size of the basin, aeration can require $0.0015-0.0025 \mathrm{kWh}$ per gallon of raw sewage. Typically, that results in around $60 \%$ of the total energy demand for the entire treatment plant (Pitas et al, 2010). In-situ anaerobic digestion of sludge cannot recover that amount of energy. Additionally, the electricity generated to operate these aerators release significant amounts of carbon dioxide into the environment. This is 
the most detrimental operation to the sustainability of a municipal wastewater treatment plant.

These energy intensive biological treatment technologies may become unaffordable for many communities trying to abide strict regulations. The demand continues to grow for a sustainable, cost-effective nutrient removal technology that satisfies the regulations set by the USEPA and SWRCB.

\subsection{Wastewater Treatment with Algae Raceway Ponds}

When well-designed raceway ponds are fed wastewater rich in nutrients and organic matter, they can cultivate microalgae, aerobic bacteria, and anaerobic bacteria. The resulting algal-bacterial symbiotic relationship creates an energy efficient system using the sun's solar radiation to drive algal photosynthesis. This relationship involves the aerobic bacteria consuming degradable organic material found in wastewater, and creating soluble nutrients and $\mathrm{CO}_{2}$ as byproducts. The photoautotrophic microalgae consume these byproducts, along with the soluble nutrients and $\mathrm{CO}_{2}$ from the wastewater loading (Woertz et al, 2009). Microalgae utilize these $\mathrm{CO}_{2}$ loadings as their primary carbon source. $\mathrm{CO}_{2}$ supplementation via sparging into raceway ponds has been proven to promote higher algae growth by providing excess inorganic carbon concentrations (Sutherland et al, 2014). The microalgae release dissolved oxygen as a byproduct, which is used by the aerobic bacteria to promote further removal of organics (Figure 2-1). This

decreases the need for electrical-driven blowers to provide oxygen to the bacteria, as seen in AS systems (Woertz et al, 2009). 


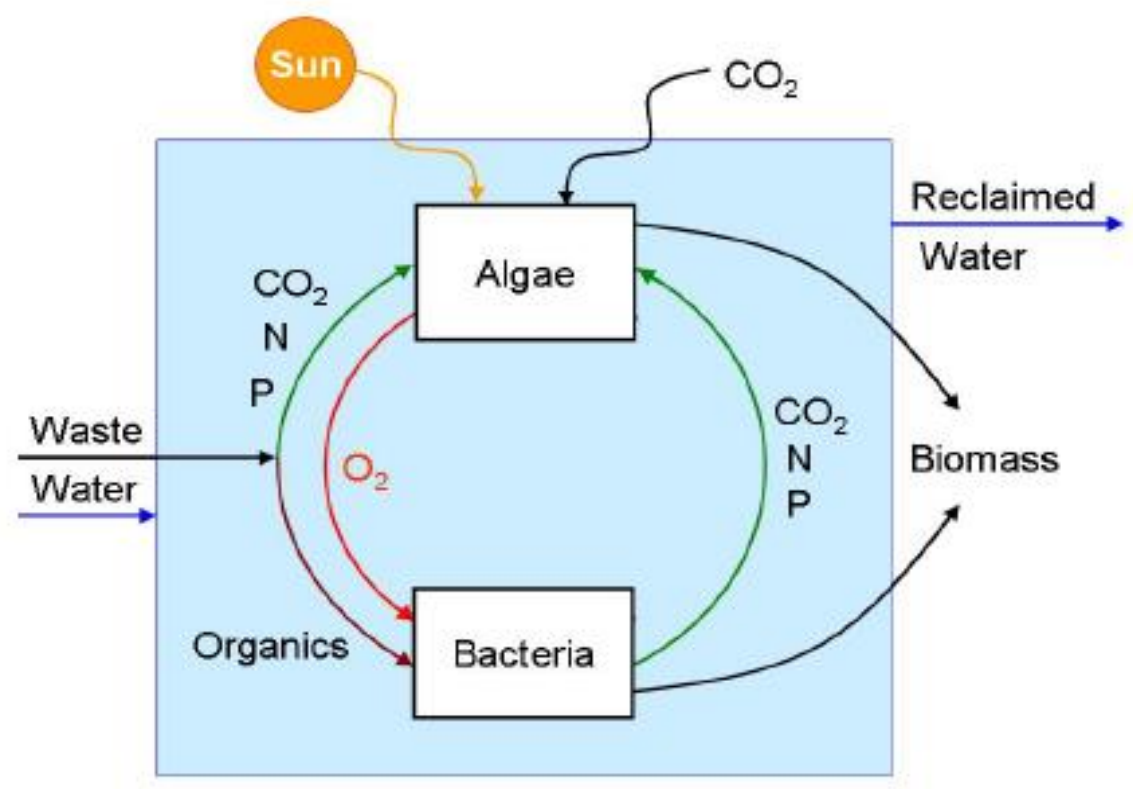

Figure 2-1: A simplified version of the algal-bacterial relationship in raceway ponds for wastewater treatment (after Oswald et al, 1953).

Raceway ponds use a low-energy motorized paddle wheel and a shallow depth to create a channel velocity $(0.15-0.3 \mathrm{~m} / \mathrm{s})$ that will provide gentle mixing (Figure 2-2). The configuration may be a single loop or multiple loops around central dividing walls, also referred to as baffles, which promote the raceway flow. Raceway ponds have a typical hydraulic residence time (HRT) of 3-10 days. (Chinnasamy et al, 2014). Proper mixing in the pond channels provides a biological system capable of treating primary or secondary effluent wastewater (Park et al, 2010). The key variables affecting algae growth are light intensity, temperature, nutrients, $\mathrm{pH}$, pond depth and hydraulic residence time (Kendrick, 2011). The treatment performance can also be limited if reduced biomass growth from grazing by herbivorous zooplankton occurs (Porter, 1976). 


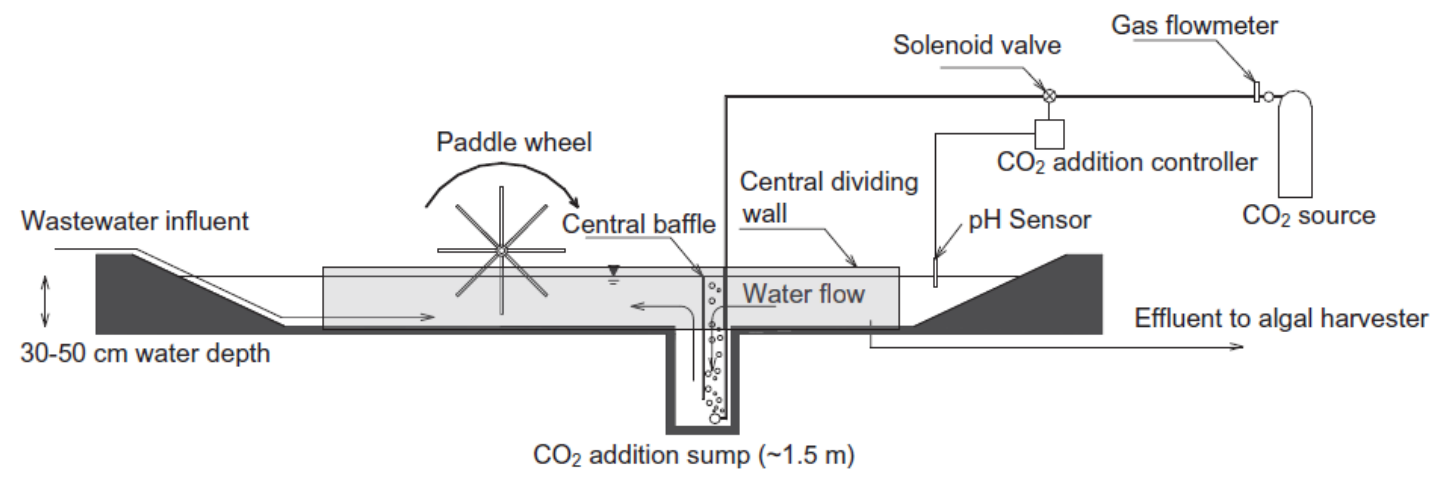

Figure 2-2: Side view of a typical high rate algae pond with common dimensions, $\mathrm{CO}_{2}$ addition, and a $\mathrm{pH}$ sensor that triggers the $\mathrm{CO}_{2}$ release (Park et al, 2010).

Prior to the recent push for research on the feasibility of wastewater treatment with raceway ponds, their performance had been evaluated within advanced integrated wastewater pond systems (AIWPS). AIWPS technology was most effective when operating as a series of at least four ponds: facultative, raceway (or high rate pond), settling, and maturation (Figure 2-3). Each pond was designed to perform at least one of the basic treatment processes (Oswald, 1990).

According to Dr. Oswald, a pioneer in the algae pond research field, the energy required to power the paddle wheel mixers in raceway ponds to a velocity of 0.15 meters per second is roughly five kilowatt hours per hectare per day. This results in a dissolved oxygen production of more than 100 kilograms per hectare per day, and an energy demand of 20 kilograms of oxygen per kilowatt hour. Compare this to mechanical aeration used in AS systems which normally transfers one kilogram of oxygen per kilowatt hour, and the energy savings are more than 10 fold (Oswald, 1990). 


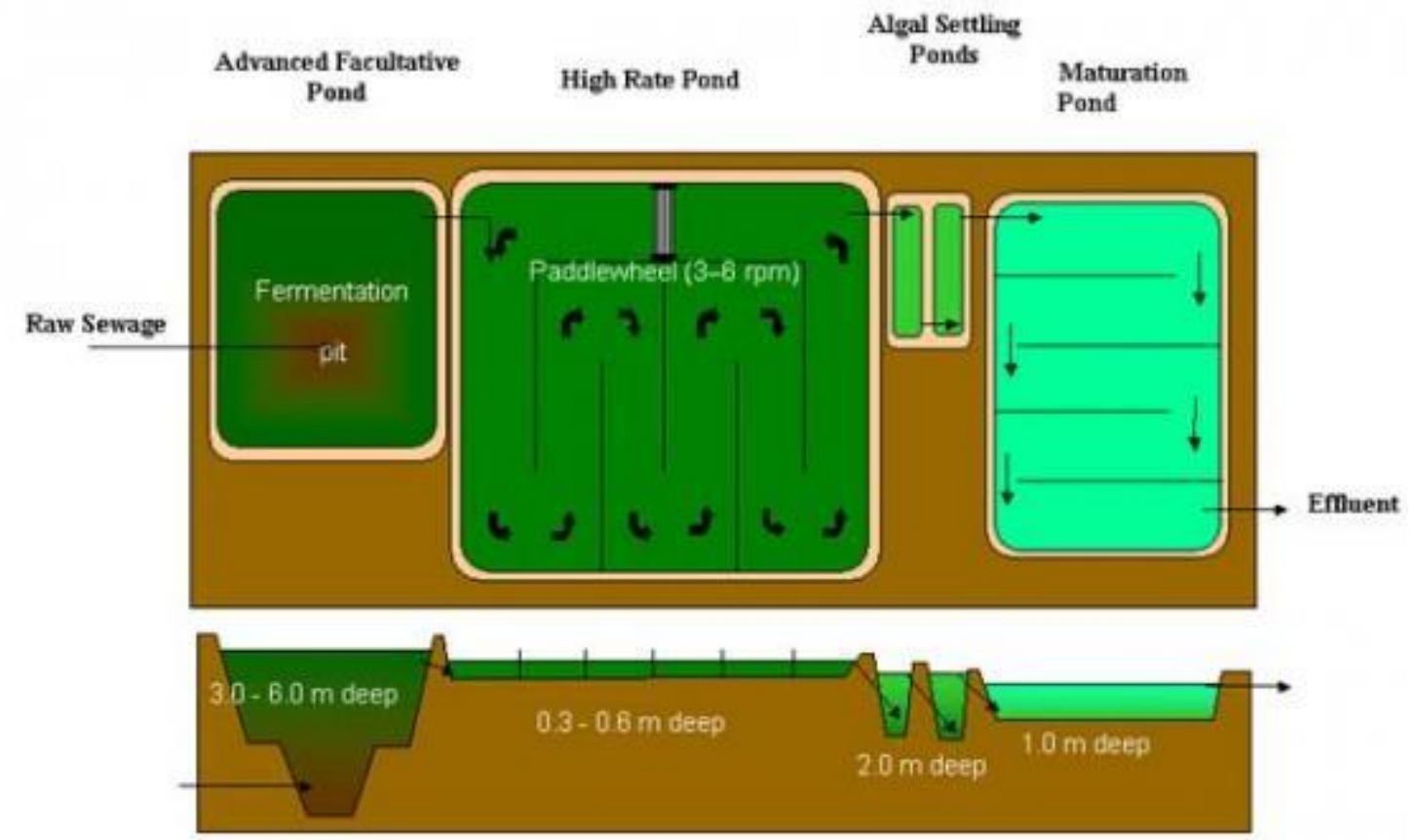

Figure 2-3: Layout and cross section of an Advanced Integrated Wastewater Pond System. (SSWM et al, n.d.)

\subsection{Nitrogen and Phosphorus Removal Mechanisms in Raceway Ponds}

The following subsections outline the nitrogen and phosphorus removal mechanisms by the autotrophic microalgae and heterotrophic bacteria present in raceway ponds fed primary effluent wastewater.

\subsubsection{Nitrogen Removal Mechanisms}

Raceway ponds have been proven to achieve adequate nitrogen removal from wastewater if operated at their most suitable hydraulic residence time (HRT) based on the loading. The removal mechanisms in suspended growth processes such as raceway ponds are achieved though: assimilation, sedimentation, volatilization, nitrification, and denitrification (Mayo \& Mutamba, 2005). 
Assimilation, or uptake, of nitrogen by algae cells and bacteria increases proportionally with biomass concentration, as algae cells contain $6 \%$ to $11 \%$ nitrogen. This percentage varies upon based upon species of the algae and growth conditions (Oswald, 1968). Ammonia removal via assimilation occurs before nitrates are used because algae prefer ammonia as their nitrogen source (Mayo \& Mutamba, 2005). Under the optimal environmental conditions for algae growth, assimilation can be a significant contributor to nitrogen removal. While assimilation removes soluble nitrogen, it does not remove nitrogen from the system but converts it to organic nitrogen. Sedimentation, or settling, is required to remove organic nitrogen from the system (Chinnasamy et al, 2014). Settling efficiencies are dependent on algae strains and harvesting technology (Park et al, 2011). Ammonia $\left(\mathrm{NH}_{3}-\mathrm{N}\right)$ volatilization is an indirect nitrogen removal mechanism that increases proportionally with temperature and $\mathrm{pH}$ (Mayo \& Mutamba, 2005). The fraction of ammonia to ammonium in total ammonia nitrogen (TAN) is dependent on $\mathrm{pH}$. With a pond temperature of $20^{\circ} \mathrm{C}$ and $\mathrm{pH}$ of 9.4 , ammonia gas and ammonium ions are equal in concentration. If $\mathrm{pH}$ exceeds 9.4, ammonia gas begins to dominate and volatilization potential increases (Mayo \& Mutamba, 2005). In raceway ponds with no $\mathrm{CO}_{2}$ supplementation, algae cells consume $\mathrm{CO}_{2}$ and $\mathrm{HCO}_{3}{ }^{-}$during daytime photosynthesis often increasing the $\mathrm{pH}$ to 11 or greater (Park et al, 2010). $\mathrm{CO}_{2}$ supplementation into raceway ponds has become a standard modification to enhance algal productivity, maintain a steady $\mathrm{pH}$ at the optimum level of 8 , and create a suitable environment for nitrification (Park et al, 2010).

Nitrification is a fundamental process in biological wastewater treatment because of the strict regulations for ammonia and total nitrogen removal. Ammonia nitrogen is the most 
abundant nitrogen species in municipal wastewater at levels in the range of 25 to 45 mg/L-N based on a loading rate of 380 L/capita-day (Metcalf \& Eddy, 2014). In suspended growth systems, nitrification occurs when certain genera of autotrophic bacteria are in the presence of high concentrations of ammonia. The first oxidation step during nitrification converts ammonia to nitrite (Equation 2-1) with Nitrosomonas and Nitrosospira acting as the ammonia-oxidizing bacteria (AOB). The second oxidation step converts nitrite to nitrate (Equation 2-2) with Nitrobacter acting as the main nitriteoxidizing bacteria (NOB). Based on the stoichiometry in Equation 2-3, the amount of oxygen required to complete the two-step oxidation process is approximately $4.57 \mathrm{~g} \mathrm{O}_{2} / \mathrm{g}$ $\mathrm{NH}_{3}-\mathrm{N}$ oxidized (Metcalf \& Eddy, 2014).

Nitroso-bacteria:

$$
2 \mathrm{NH}_{4}{ }^{+}+3 \mathrm{O}_{2} \rightarrow 2 \mathrm{NO}_{2}^{-}+4 \mathrm{H}^{+}+2 \mathrm{H}_{2} \mathrm{O}
$$

Nitro-bacteria:

$$
2 \mathrm{NO}_{2}^{-}+\mathrm{O}_{2} \rightarrow 2 \mathrm{NO}_{3}^{-}
$$

Total oxidation reaction:

$$
\mathrm{NH}_{4}^{+}+2 \mathrm{O}_{2} \rightarrow \mathrm{NO}_{3}^{-}+2 \mathrm{H}^{+}+\mathrm{H}_{2} \mathrm{O}
$$

Denitrification is necessary in wastewater treatment plants that must remove nitrate from its effluent to meet a total nitrogen discharge limit. This is an anoxic process that reduces nitrate into nitrogen gas through several steps (Equation 2-4). Nitrate ions serve as the electron accepter and organic carbon as the electron donor. Conventional wastewater treatment plants most commonly use the Modified Ludzak-Ettinger (MLE) process for biological nitrogen removal involving nitrification and denitrification. The MLE process consists of a preanoxic tank for denitrification followed by an aeration basin for 
nitrification. An internal recycle from the aeration basin supplies nitrate-rich water to the preanoxic basin, which receives primary effluent for its carbon source. The preanoxic denitrification process uses a wide range of heterotrophic bacteria for nitrate reduction (Metcalf \& Eddy, 2014).

Nitrate reduction process:

$$
\mathrm{NO}_{3}{ }^{-} \rightarrow \mathrm{NO}_{2}{ }^{-} \rightarrow \mathrm{NO} \rightarrow \mathrm{N}_{2} \mathrm{O} \rightarrow \mathrm{N}_{2}(\mathrm{~g}) \quad \text { Equation 2-4 }
$$

\subsubsection{Phosphorus Removal Mechanisms}

Phosphorus in wastewater can be found in three forms: organic phosphorus, orthophosphate, and polyphosphate. Orthophosphate formation results from the complete hydrolysis of polyphosphates and the decomposition of organic phosphorus, making it the dominant form of total phosphorus $(\sim 80 \%)$ found in raceway ponds (Nurdogan \& Oswald, 1995). Microalgae consume phosphorus during growth to obtain cellular constituents such as phospholipids, nucleic acid, and nucleotides. Thus, because phosphorus is essential for algae growth, it must be removed from wastewater to prevent algal blooms and eutrophication in creeks and lakes that receive the effluent (Powell et al, 2008).

Since the phosphorus content in microalgae typically falls in the $0.5 \%-1 \%$ range, assimilation cannot remove enough of it from highly concentrated wastewater. (Powell et al, 2008). Common upgrade options to increase phosphorus removal are typically expensive such as chemical dosing and installing an enhanced biological phosphorus removal (EBPR) form of AS systems. Chemical dosing is effective but results in a chemical precipitate that must be disposed of, also limiting the recovery of phosphorus. (Powell et al, 2009). Natural phosphorus precipitation can also happen from 
autoflocculation. This occurs during periods of high $\mathrm{pH}$ levels that promote the formation of phosphate complexes with metal ions found in wastewater such as calcium, magnesium and iron. Naturally high $\mathrm{pH}$ levels typically occur during sunny days in the afternoon when high microalgae productivity consumes inorganic carbon at a faster rate than replenishment via the wastewater loading or absorption from the atmosphere (Powell et al, 2008). Although for many regions, that high growth rate may not occur due to environmental inhibition, and many small scale treatment plants cannot afford upgrading to an AS system with EBPR or using chemical dosing. A second biological mechanism termed 'luxury uptake of phosphorus' has been proven to optimize biological phosphorus removal potential with microalgae.

Luxury uptake is the term used to describe the storage of phosphorus in the form of polyphosphate, within the biomass. Polyphosphate can be found as either the acidinsoluble form (AISP) or acid-soluble form (ASP). ASP is used actively in the metabolism of microalgae, and AISP is stored for when the growth medium becomes phosphorus limited (Powell et al, 2008). Experiments led by Nicola Powell at the Centre for Environmental Technology and Engineering in New Zealand (2009) were aimed at investigating the dynamics of the luxury uptake mechanism. Their studies found a correlation between phosphate concentration in the wastewater, light intensity, and temperature, to the accumulation and utilization of both ASP and AISP. Luxury uptake was triggered when the microalgae ponds were fed wastewater containing high phosphate concentrations $(15-30 \mathrm{mg} / \mathrm{L})$. Increases in temperature and light intensity also correlated with an increase in luxury uptake. The maximum percentage of phosphorus found in the 
biomass after luxury uptake was $3.16 \%$, roughly 3-3.5 times higher than the amount needed for growth (Powell et al, 2008; Powell et al 2009).

An advantage of promoting biological phosphorus removal as opposed to chemical precipitation is the ability to harvest the biomass after sedimentation. If chemical dosing is used, the phosphorus precipitate cannot be reused and must be disposed of (Powell et al, 2009). Harvesting energy-rich algal-biomass is essential for promoting the sustainability of algal biofuels (Park et al, 2010).

\subsection{Improving Raceway Pond Performance and Sustainability}

The following subsections outline research performed on several methods of optimizing the sustainability and performance of raceway ponds and algal biofuels. These methods include pond water recycling, anaerobic and aerobic degradation of algal biomass to solubilize nutrients, and recycling these captured nutrients.

\subsubsection{Water Recycling}

Reducing the water footprint for raceway ponds is a continuing goal to improve the overall sustainability of algal biofuel and wastewater treatment industries. Preserving freshwater sources has become of utmost importance for states prone to droughts such as California. As described in Chang 2014, very few locations in the U.S. with high average annual solar insolation (Figure 2-5) match with locations that have water available for algae production (Figure 2-4). This issue reduces the feasibility of implementing a large scale microalgae biofuel production pond. Changing the water source from freshwater to wastewater or seawater, and recycling this water, can greatly reduce the water footprint and cost. A LCA on microalgae biofuel production determined using seawater or wastewater instead of freshwater as the growth medium improved the life-cycle 
freshwater usage as much as $90 \%$ (Yang et al, 2011). Water recycling can also benefit the microalgae wastewater treatment industry as well as biofuel.

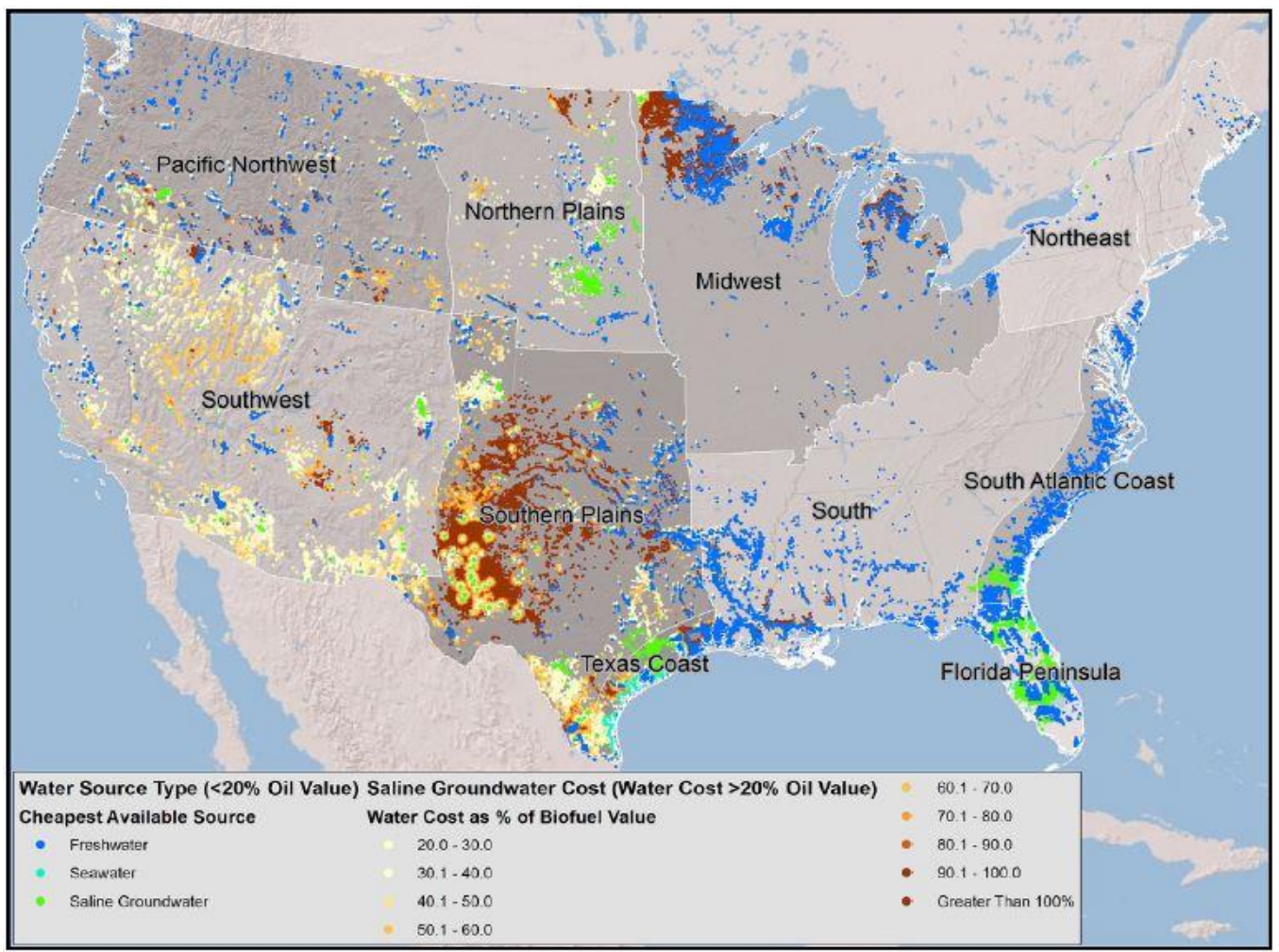

Figure 2-4: The locations for potential pond sites that have the cost of water taken into account. The red/orange dots have the highest water cost as a percentage of biofuel value (Venteris et al, 2013). 


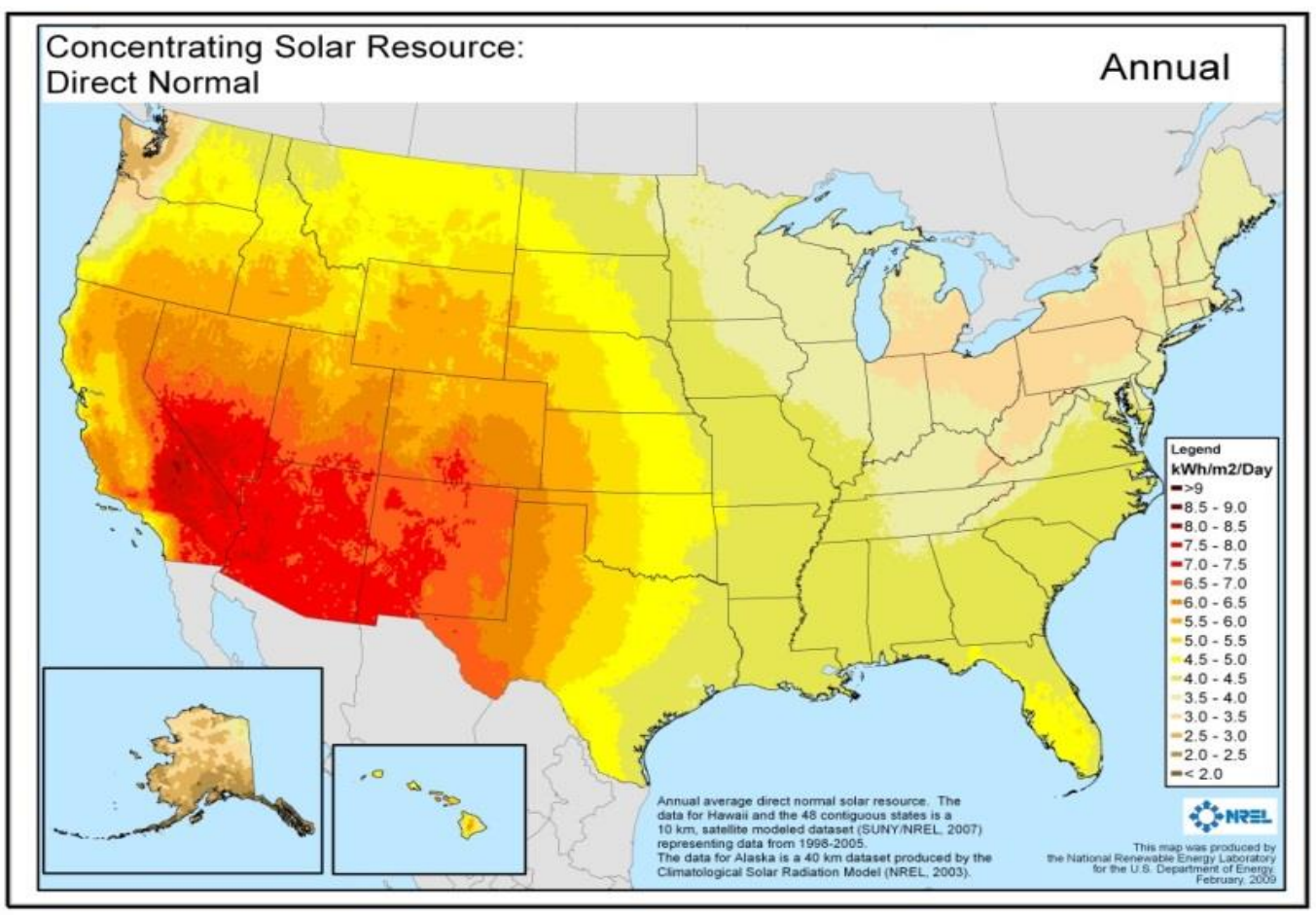

Figure 2-5: Map of solar radiation in the U.S. in units of $\mathrm{kWh} / \mathrm{m}^{2} /$ day (NREL 2008).

Recycling raceway pond effluent post biomass harvesting into the same pond or into another set (i.e. raceway ponds operating in series) can provide additional wastewater treatment and microalgae growth. However, recycling the growth media has resulted in reduced algal productivity, likely from an accumulation of inhibitory compounds, algal pathogens, and/or nutrient limitations (Park et al, 2010). Operating raceway ponds in series with water recycling improved total ammonia nitrogen (TAN) and biological oxygen demand (BOD) removal significantly in both the summer and winter. Two rounds of treatment at 3-day and 4-day HRT achieved TAN removal efficiencies of $99 \%$ and $98 \%$ in the summer and winter, respectively. Additionally, annual average BOD removal remained above $97 \%$ (Rodrigues, 2013). 


\subsubsection{Nutrient Recycling}

Recapturing nutrients from harvested algal biomass can be very useful if there is a local demand for biofuel or fertilizer production. Not only is there an economic benefit, but also a $\mathrm{CO}_{2}$ abatement benefit as well (Woertz et al, 2009). Recycling the nutrients into nutrient depleted raceway ponds to supplement further microalgae production also increases the sustainability of algal biofuels. Supplying raceway ponds with nitrogen and phosphorus can potentially increase algal productivity and amount of harvested biomass.

Figure 2-6 shows a theoretical algal biofuel process flow with raceway ponds fed wastewater. The anaerobic digester degrades the organic nitrogen and particulate phosphorus to produce resolubilized nutrients. Therefore, the performance of the digesters will determine the amount of soluble nutrients that can be captured. Lab scale anaerobic digestion experiments are helpful to predict the performance of full scale digesters and solubilization rates.

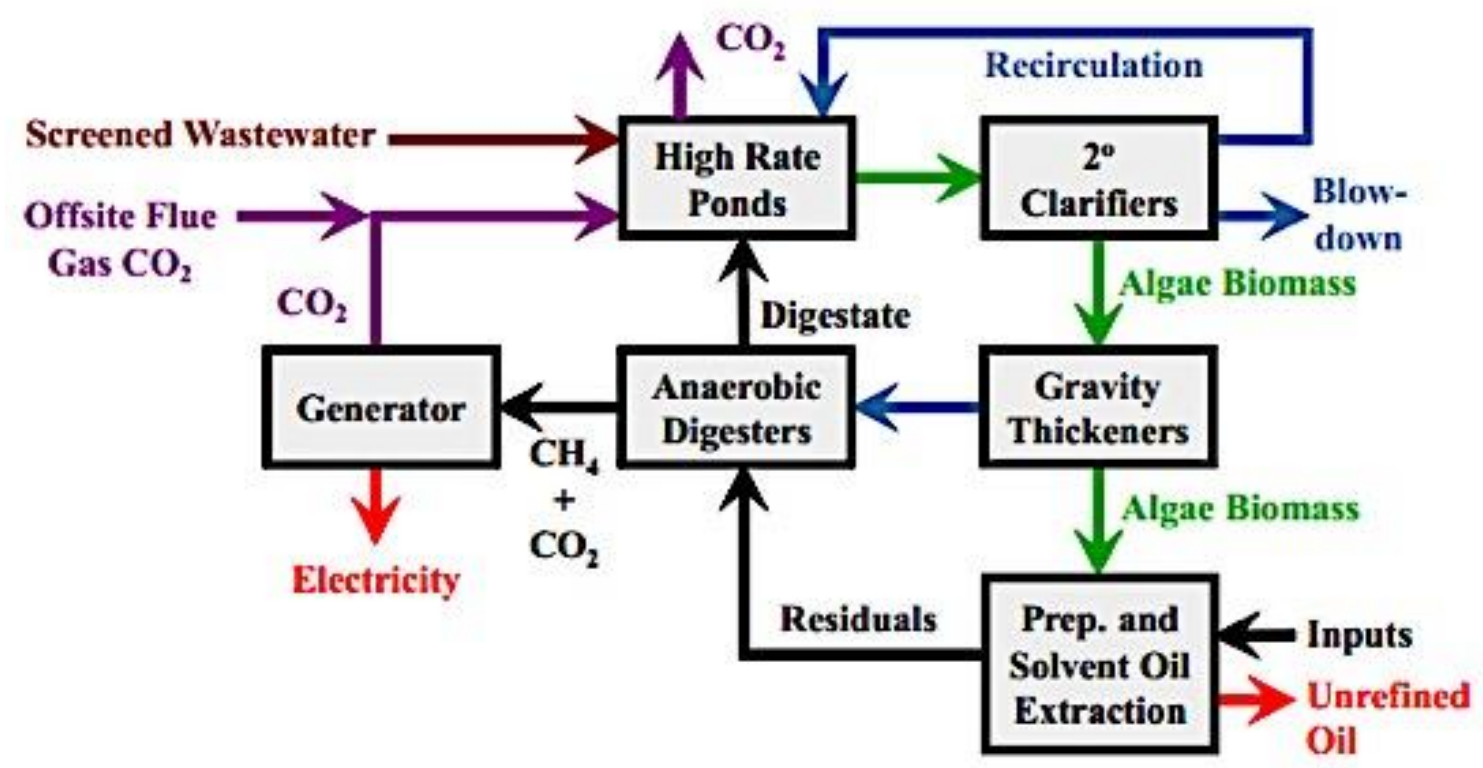

Figure 2-6: An algal biofuels production process flow using high rate ponds as the algal production source (Lundquist et al, 2010). 


\subsubsection{Anaerobic and Aerobic Degradation of Microalgae to Solubilize Nutrients}

It is important to quantify the rate and extent of soluble nutrient regeneration from degrading algal biomass to determine the amount of expected algal regrowth these recycled nutrients will provide (Jewell \& McCarty, 1971). Algal biomass degradation occurs during anaerobic and aerobic environments. Degrading the biomass in anaerobic digesters adds the benefit of producing and capturing biogas along with resolubilized nutrients (Bohutskyi et al, 2014). The fraction of algal biomass that is biodegradable and non-biodegradable from anaerobic and aerobic digestion is dependent on the microalgae cultures present in the sample (Jewell \& McCarty, 1971). For a complete analysis of the background on the performance of anaerobic digestion with algal biomass refer to Hill,

2014. For a complete analysis of the background research performed on aerobic degradation of microalgae refer to Chang, 2014.

\subsection{Research Goals}

Questions investigated in this thesis:

1. What is the fate of influent nitrogen and phosphorus in two sets of triplicate raceway ponds operating in series, each at a 3-day HRT?

2. What is the fate of nitrogen and phosphorus in Round 1 (3-day HRT) and Round 2 (4-day HRT) triplicate ponds operating in series?

3. What is the fate of nitrogen and phosphorus in triplicate raceway ponds with a 2day HRT? 
4. What percentage of organic nitrogen and particulate phosphorus in algal sludge was degradable during anaerobic and aerobic digestion? Also, did the pretreatment lysing technologies increase the fraction of degradable biomass? 


\section{Methods and Materials}

This chapter provides a description of the Algae Field Station (AFS), raceway pond experiments, the operation and maintenance, sampling methods, experimental procedures, and water quality analyses methods. In addition, the bench-scale anaerobic and aerobic digestion lab experiments, their sampling methods, procedures, and water quality analyses methods are discussed.

\subsection{Algae Field Station: Location Layout}

The nine raceway style ponds are located at the AFS within the City of San Luis Obispo Water Resource Recovery Facility (WRRF) and next to the western primary clarifier (Figure 3-1). At the time of testing for this thesis, the WRRF was designed to process 5.2 million gallons of wastewater per day. The AFS consists of nine $33-\mathrm{m}^{2}$ raceway ponds arranged in three sets of triplicates: Alpha, Beta, and Gamma.

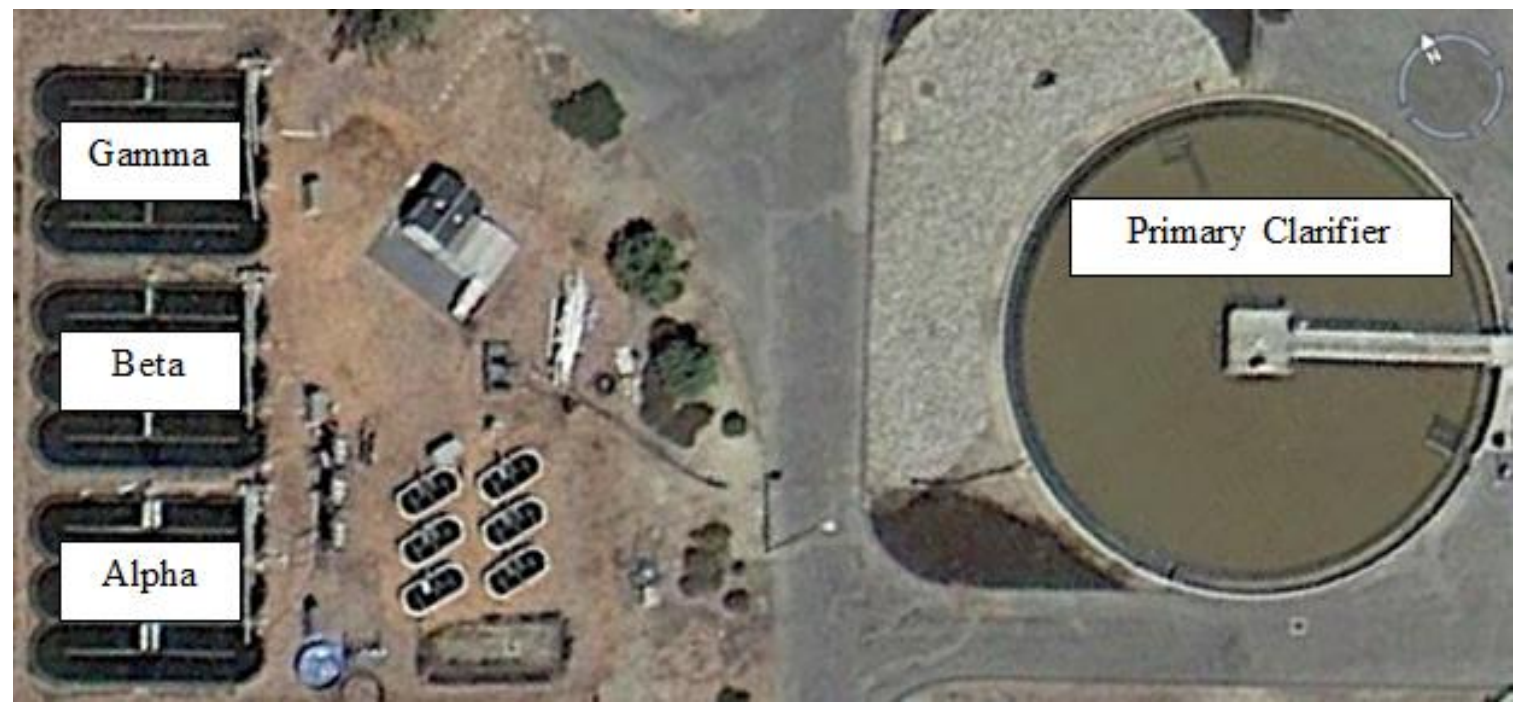

Figure 3-1: Aerial view of the AFS facility labeling the nine 33-m2 raceway ponds arranged in three sets of triplicates: Alpha, Beta, and Gamma. The primary clarifier was the influent source for the ponds. North arrow was included in the upper right hand corner. 


\subsection{Raceway Pond Experiments}

The experiments conducted with the ponds were: (1) nitrogen and phosphorus removal with Beta to Alpha ponds operating in series, and (2) nitrogen and phosphorus removal with Gamma ponds operating at a 2-day HRT. These experiments were designed to address questions one, two, and three of the research goals.

\subsubsection{Experimental Concept and Purpose}

Two ponds-in-series experiments were conducted from March 6, 2013 - August 28, 2014. The purpose of these experiments was to test the ability of raceway ponds operating in series to achieve low nitrogen and phosphorus levels. For these experiments, the triplicate Beta ponds are referred to as "Round 1" and the triplicate Alpha ponds as “Round 2." Round 1 ponds received primary clarifier effluent wastewater, and Round 2 ponds received Round 1 pond effluent after solids separation. Separation of biomass from triplicate Round 1 ponds was completed using tube settlers (see Section 3.2.2). All of the pond water from Round 1 was collected and sent to Round 2, ensuring none was lost in the process. Some biomass was present at the top of the tube settlers during periods of poor settling efficiency. The total treatment times for the wastewater from the first and second ponds in series experiment were seven and six days, respectively.

The Gamma ponds received primary clarifier effluent wastewater, similar to Beta. The main goal was to determine the extent of nitrogen and phosphorus removal from triplicate ponds operating at a two-day HRT.

For each pond experiment, the fate of the nitrogen during treatment was closely monitored. During treatment, the ammonia in the influent nitrified to form oxidized nitrogen, and assimilation by microalgae converted soluble nitrogen to organic nitrogen. 
Also, because typical pond $\mathrm{pH}$ levels were greater than 7 , ammonia volatilization may have occurred.

\subsubsection{Pond Process Flow}

The triplicate sets of raceway ponds were labelled as Alpha (Round 2) being ponds 1-3; Beta (Round 1) being ponds 4-6; and Gamma (two-day HRT) being ponds 7-9.

Ponds 4-9 were fed influent water pumped from the primary clarifier between the scum baffle and overflow weir (Figure 3-2).

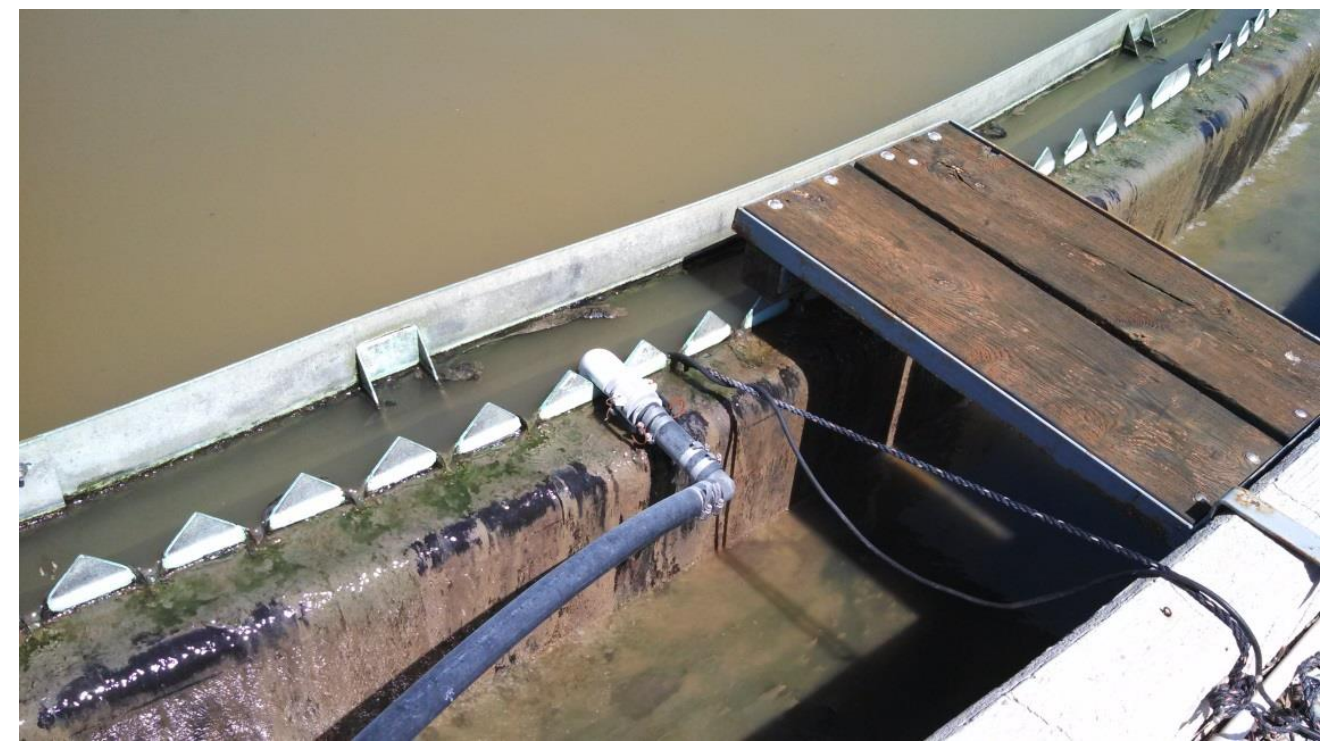

Figure 3-2: The influent pump located in the western primary clarifier, as shown in Figure 3-1 (Chang, 2014).

The primary clarifier effluent was continuously pumped to the Beta and Gamma head tanks. The wastewater was then distributed to each pond by a constantly rotating scoop and distribution system (Figure 3-3). The water level in the head tanks was kept constant, and the speed and depth of the scoops was varied to adjust the flow rate into the ponds. Gravitational flow distributed the water to each pond from the distribution system. 


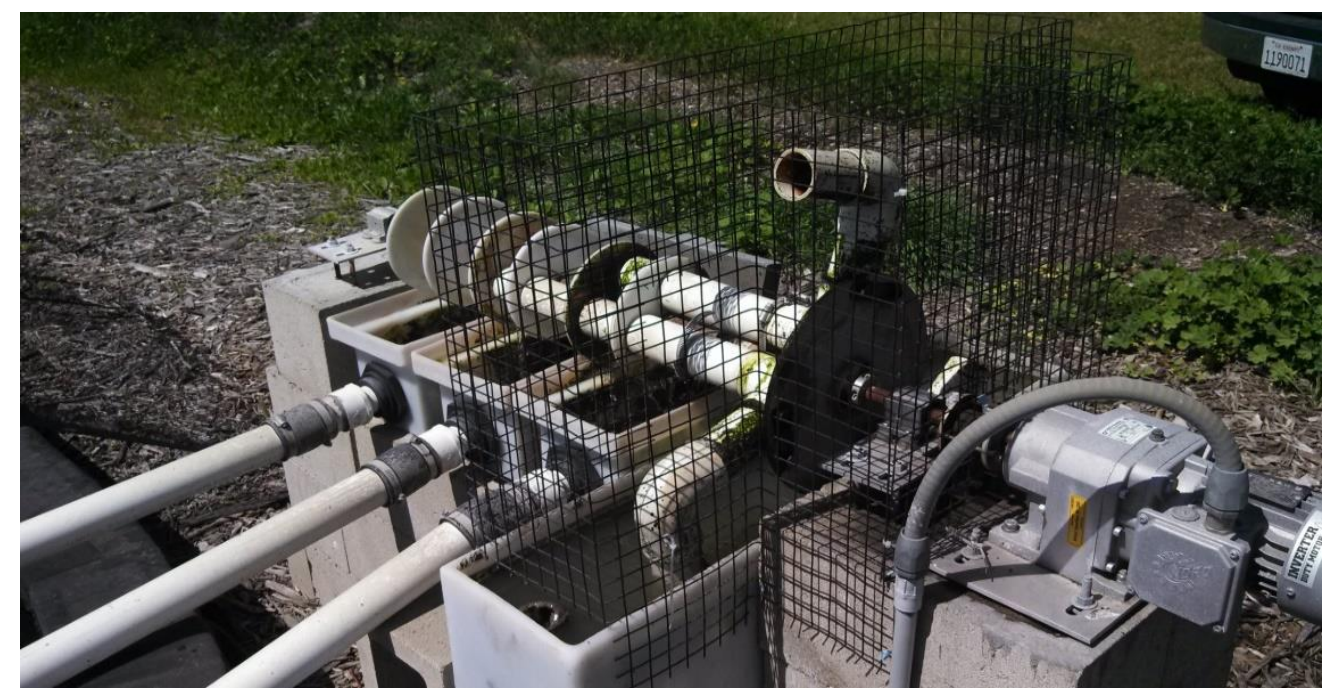

Figure 3-3: Gamma constant head tank and distribution system with motor. Beta and Alpha head tanks operated identically (Chang, 2014).

From June 2012 to July 2013, the Beta (Round 1) and Alpha (Round 2) sets operated as follows: supernatant from the Pond 4 tube settler gravity drained into Pond 1, Pond 5 into Pond 2, and Pond 6 into Pond 3. Water from each Beta pond was continuously pumped into tube settlers by peristaltic pumps for algae settling and the supernatant was fed into the corresponding Alpha pond previously mentioned. All of the tube settlers were set at an angle of $60^{\circ}$ (Figure 3-4). 


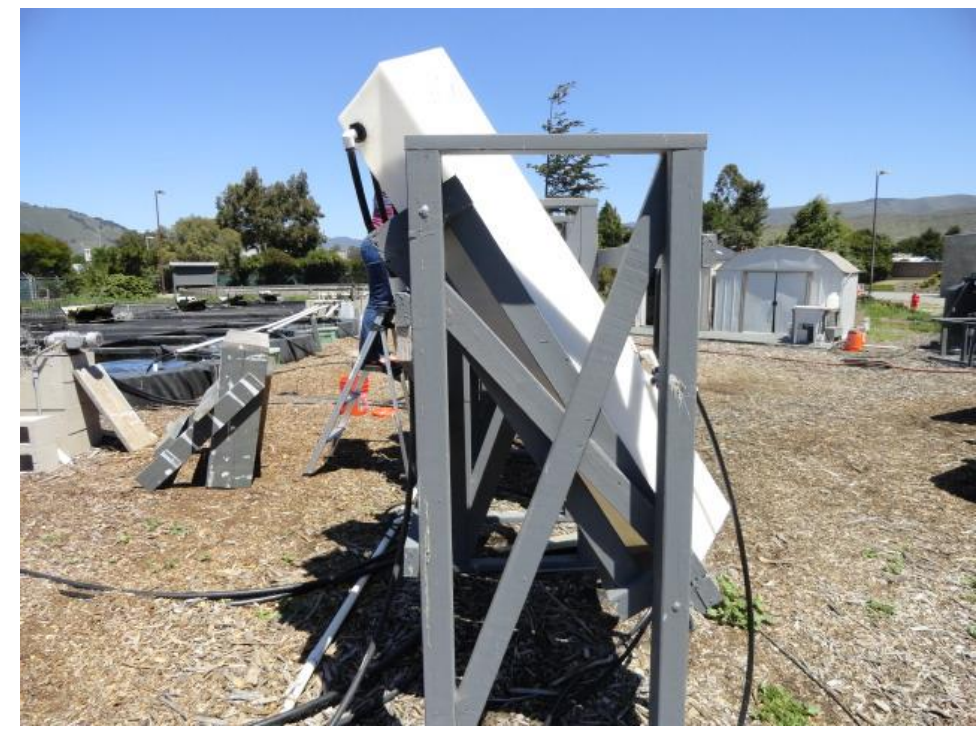

Figure 3-4: Side View of tube settlers showing the $60^{\circ}$ angle of tilt (Chang, 2014).

On July 2013, the configuration changed to replicate a water recycling project. The supernatant from all of the Beta tube settlers flowed into the Alpha head tank, mixed with an aquarium mixer, and distributed evenly into the Alpha ponds via a constantly rotating scoop and distribution system set to deliver a 3-day HRT flow (Figure 3-5). The tube settler flow and speed of the rotating scoops were adjusted to ensure all of the supernatant was collected into the Alpha head tank and distributed to each pond without losing any water. This was especially important to maintain the water recycling aspect. 

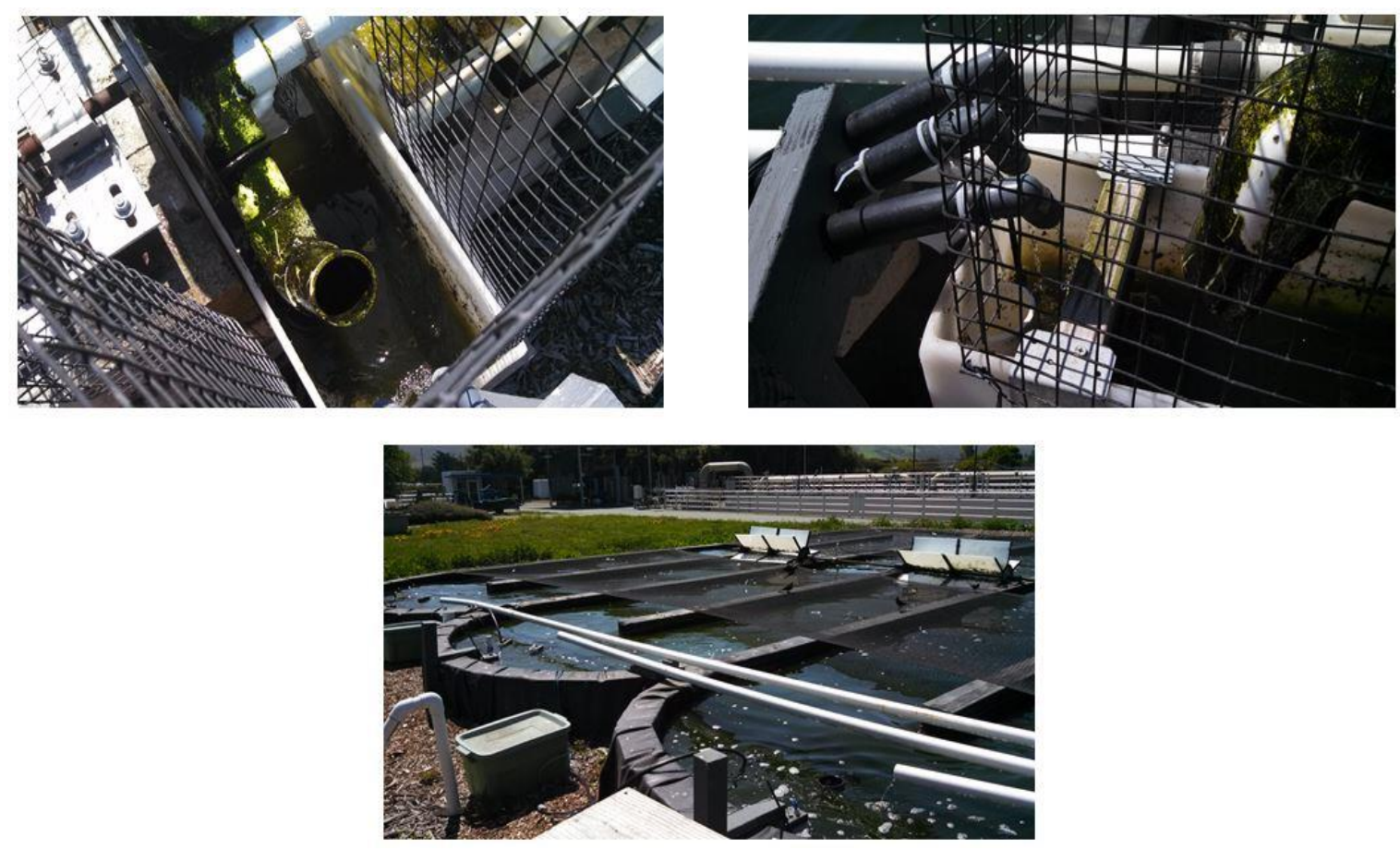

Figure 3-5: Alpha constant head tank and distribution system. The top right photo shows how the tube settler effluent was fed into the head tank, there were six total feed lines with three on each side. The bottom picture shows the distribution pipe into each pond (Chang, 2014).

The water in Alpha and Gamma leave the ponds by flowing into either a two inch ramp standpipe (Figure 3-6) or four inch vertical standpipe (Figure 3-7). The standpipes are one foot tall to maintain a constant pond depth.

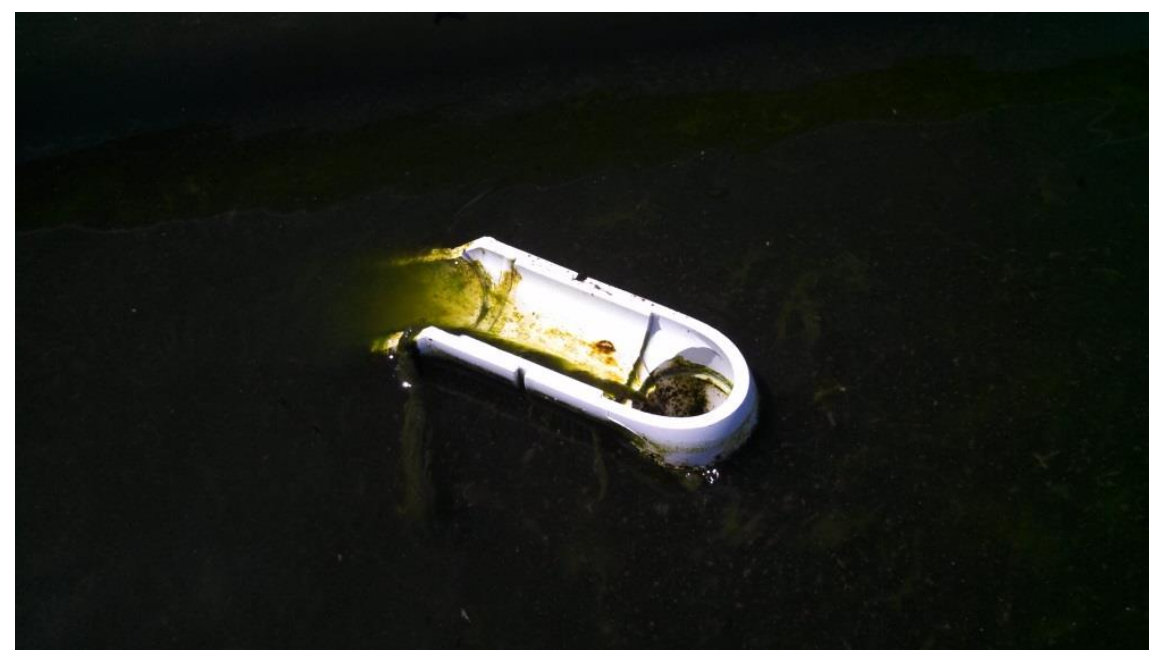

Figure 3-6: Ramp standpipe design installed in ponds 1, 2, 4, 5, 8, and 9 (Chang, 2014). 


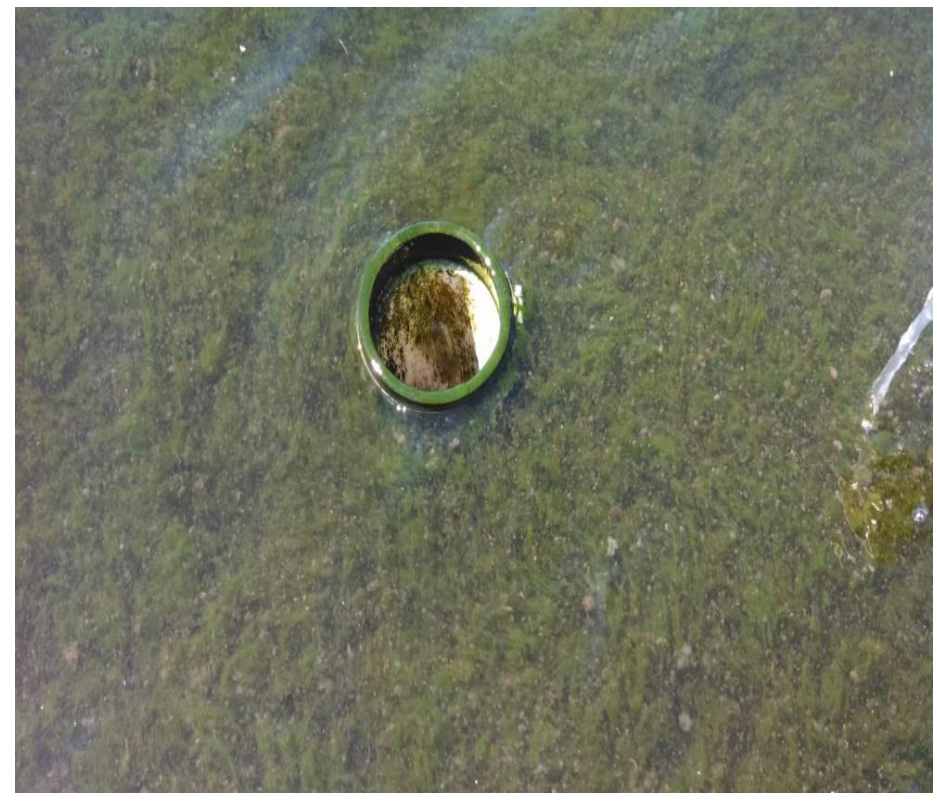

Figure 3-7: Four inch vertical standpipe design installed in ponds 3, 6, and 7 (Chang, 2014). Refer to Chang 2014 thesis for a complete detailed description of the entire AFS pond and tube settler process flow.

\subsubsection{Pond Characteristics}

The pond depth, area, and channel velocity remained unchanged during the course of the pond experiments. However, the HRT, influent flow, tube settler flow and configuration changed. These details are outlined in Table 3-1 and Table 3-2.

Table 3-1: Target pond characteristics from June 2012 to June 13, 2013. *Channel velocities obtained from Roberts, 2013.

\begin{tabular}{cccc} 
& \multicolumn{3}{c}{ Triplicate Set } \\
\hline Specification & Alpha & Beta & Gamma \\
\hline Ponds in Set & $1,2,3$ & $4,5,6$ & $7,8,9$ \\
Depth (m) & 0.3 & 0.3 & 0.3 \\
Channel Velocity & 19.8 & 19.2 & 19.5 \\
$(\mathrm{~cm} / \mathrm{sec})^{*}$ & 1.65 & 2.25 & 3.30 \\
Influent (L/min) & 0.80 & 1.65 & 0.80 \\
Tube Settler Flow (L/min) & 4.0 & 3.0 & 2.0 \\
HRT (days) & &
\end{tabular}


Table 3-2: Target pond characteristics from June 26, 2013 to August 28, 2014. *Channel velocities obtained from Roberts, 2013.

\begin{tabular}{cccc} 
& \multicolumn{3}{c}{ Triplicate Set } \\
\hline Specification & Alpha & Beta & Gamma \\
\hline Ponds in Set & $1,2,3$ & $4,5,6$ & $7,8,9$ \\
Depth (m) & 0.3 & 0.3 & 0.3 \\
Channel Velocity & 19.8 & 19.2 & 19.5 \\
(cm/sec)* & 2.25 & 2.25 & 3.30 \\
Influent (L/min) & 2.25 & 2.25 & N/A \\
Tube Settler Flow (L/min) & 3.0 & 3.0 & 2.0 \\
HRT (days) & 3.0
\end{tabular}

\subsubsection{Pond Operations}

Pond operations involved maintenance of the paddle and water wheels, data recorders for $\mathrm{pH}$, temperature, and dissolved oxygen (DO), and peristaltic pumps that pumped Beta pond effluent to tube settlers. Each pond set had an identical pump house that contained the $\mathrm{pH}$ and temperature controls units (Figure 3-8), and variable frequency drives (VFD) that controlled the water wheel and paddle wheel speed (Figure 3-9). The Beta pump house was the only one with peristaltic pumps, and it contained three of them (Figure 310). The dissolved oxygen (DO) control unit was located in a separate plastic box located next to each pond (Figure 3-11) 


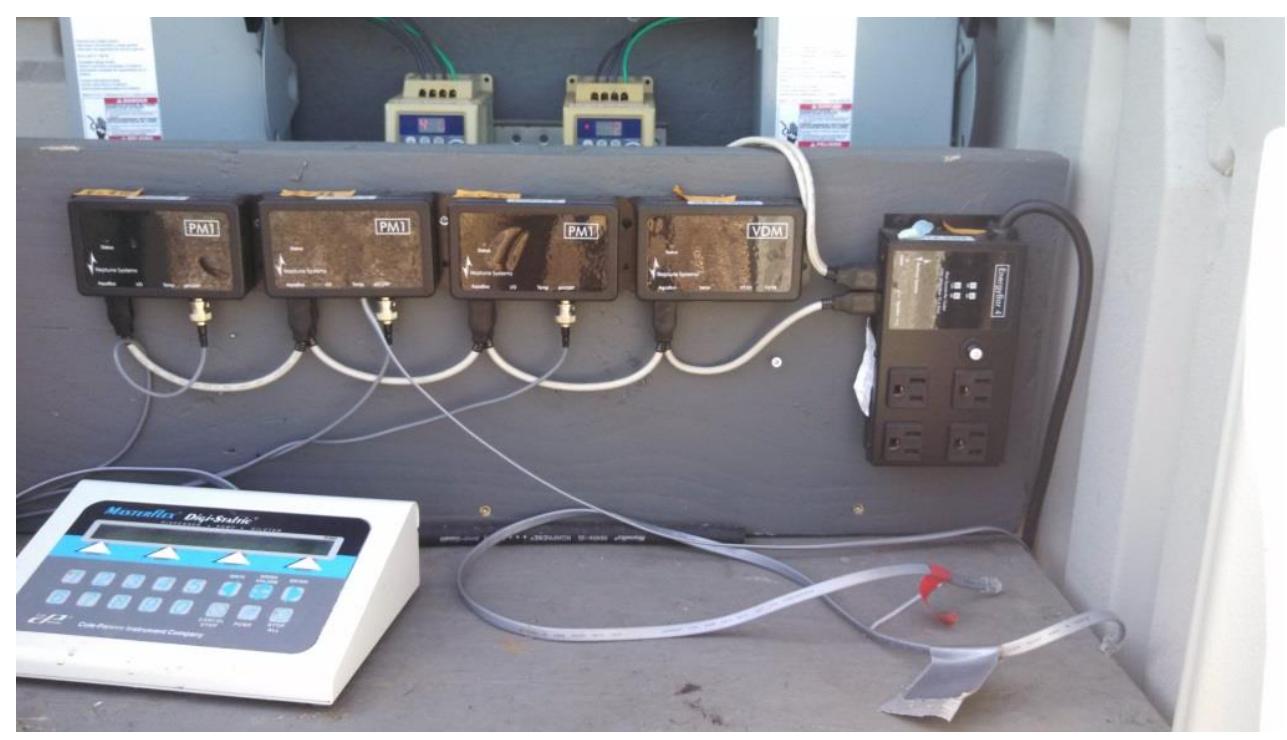

Figure 3-8: Neptune PM1 units for temperature and $\mathrm{pH}$ data acquisition. Identical set up in all three pump houses (Chang, 2014).

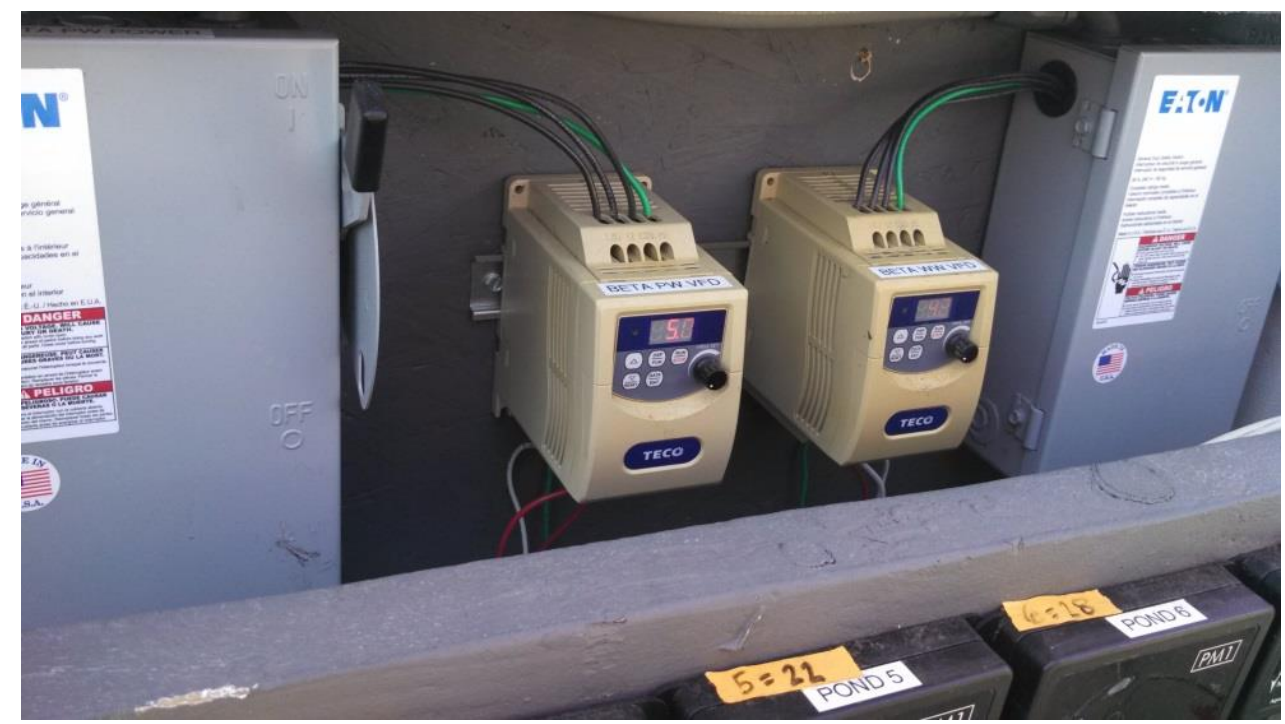

Figure 3-9: VFD for controlling water wheel and paddle wheel speed. The right most VFD controlled the water wheel and the left most VFD controlled the paddle wheel. Identical set up in all three pump houses (Chang, 2014). 


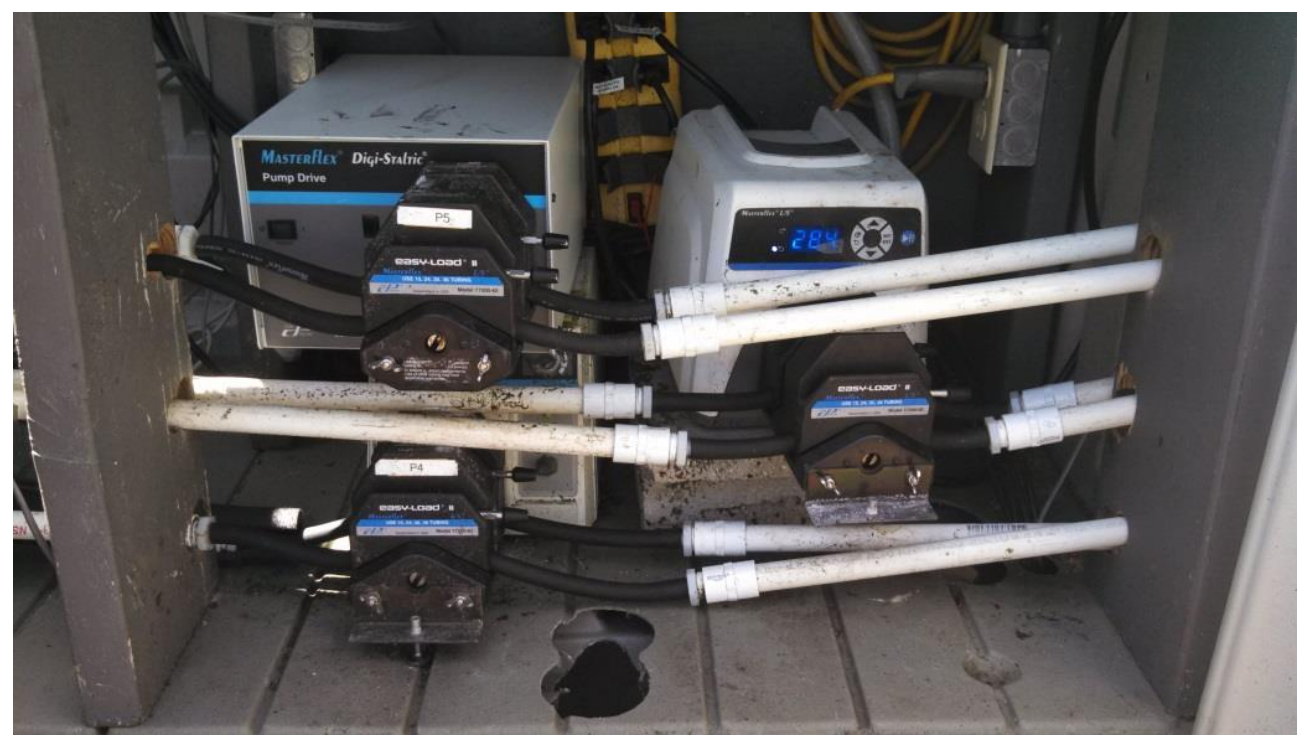

Figure 3-10: Peristaltic pump set up in Beta pump house. Water entered from the right and pumped out the left side in the PVC and flexible tubing. Each pump pulled water from one pond and fed it into the two tube settlers for each Beta pond (Chang, 2014).

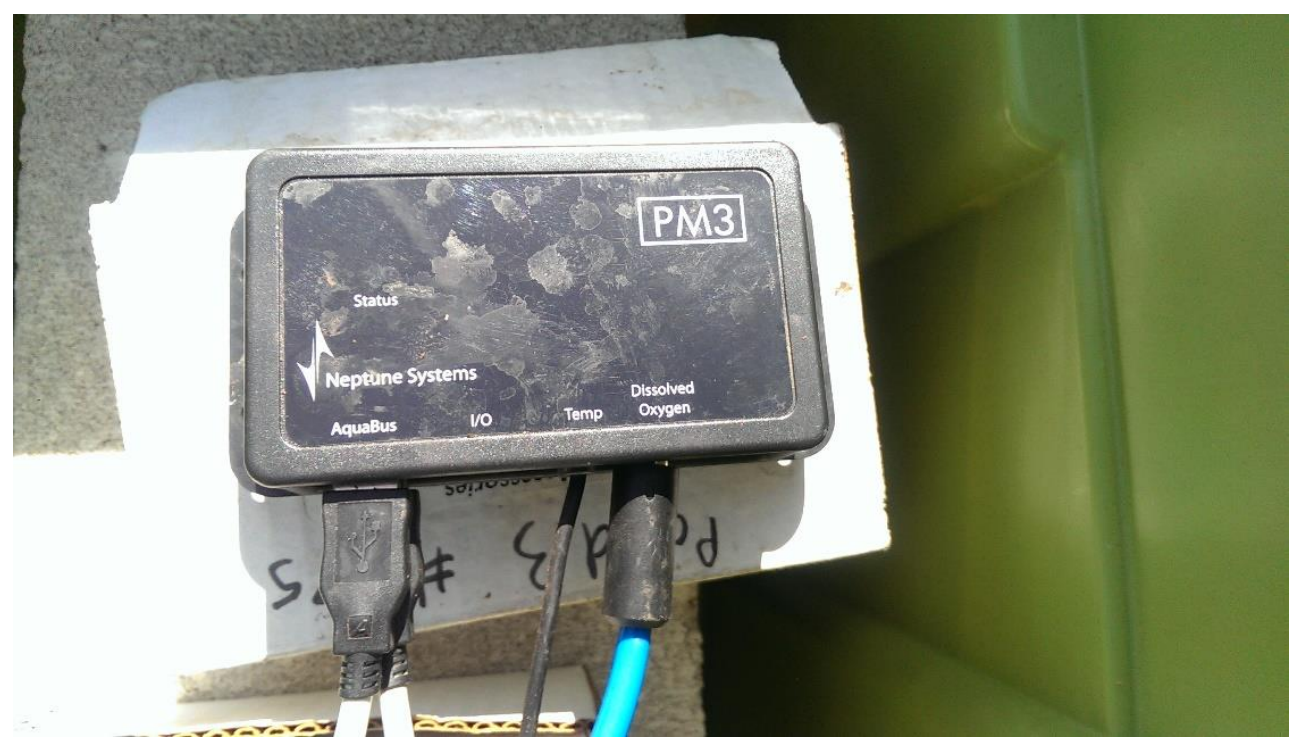

Figure 3-11: The PM3 unit that transmits DO readings from the probes in the ponds. Each pond has one located in a green water proof container.

The intake tubing for the tube settlers was placed in a separate closed bottom standpipe which maintained the target depth (1ft) of each pond (Figure 3-12). 


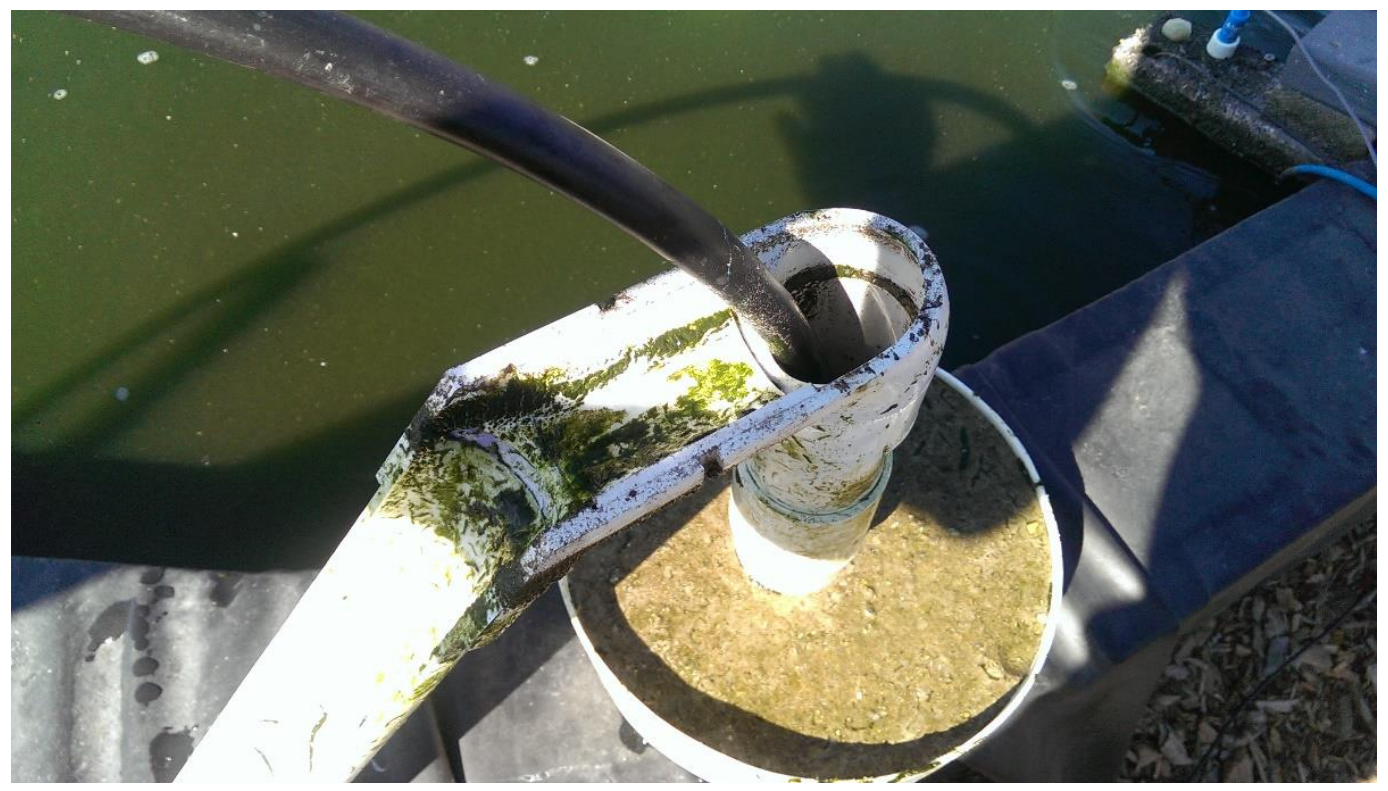

Figure 3-12: A closed bottom ramp standpipe with a tube settler intake tube. This standpipe was one foot tall and controlled the depth of the raceway pond.

The Alpha and Beta ponds were $\mathrm{pH}$ controlled by an external carbon dioxide source.

Triggered by the $\mathrm{pH}$ recordings, each pond was sparged with $\mathrm{CO}_{2}$ to achieve a consistent $\mathrm{pH}$ level of 8.4 to 8.5 . The $\mathrm{CO}_{2}$ was supplied from 50-lb pressurized cylinder $(99.5 \%$ purity, 750 psi, Airgas). Automated solenoid switches opened and closed the $\mathrm{CO}_{2}$ delivery based on the pond $\mathrm{pH}$ recordings. (Figure 3-13). 

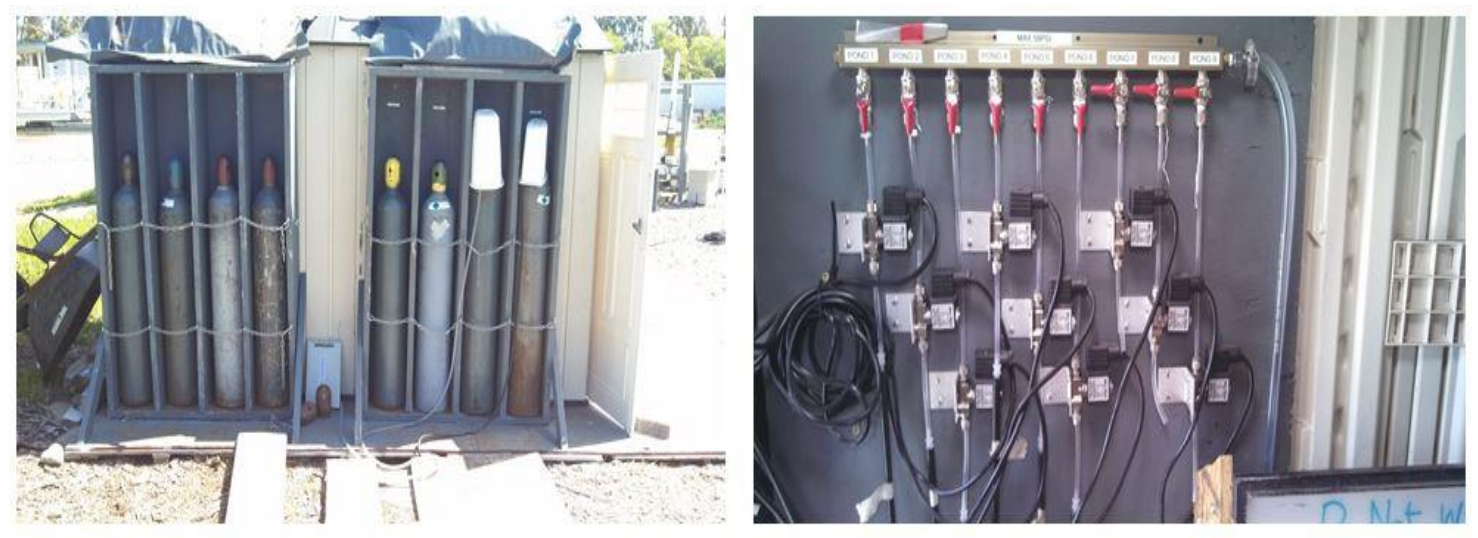

Figure 3-13: The left photo shows the 50-1b CO2 cylinders secured in a shelving unit. The right photo shows the automated solenoid units that opened and closed CO2 distribution (Chang, 2014).

Refer to Chang 2014 thesis for a detailed description of the daily tube settler operations and other AFS maintenance tasks to ensure a smooth operation and aesthetic appeal.

\subsubsection{Description of Pond Experiments}

The section outlines the pond experiments performed for this thesis, previously introduced at the beginning of Section 3.2. Pond experiments included nitrogen and phosphorus removal with Beta (Round 1) to Alpha (Round 2) ponds operating in series and nitrogen and phosphorus removal with Gamma ponds at a 2-day HRT.

\subsubsection{Nitrogen and Phosphorus Removal with Beta-to-Alpha Ponds in Series}

This experiment was designed to determine the nitrogen and phosphorus removal capabilities from two sets of triplicate raceway ponds operating in series. The triplicate Beta ponds were Round 1 of treatment and the triplicate Alpha ponds were round 2. Two of these experiments were performed with Alpha changing HRT conditions from four days to three days, while Beta stayed constant at three days HRT. For the rest of the ponds in series analysis in this thesis, the Beta ponds will be referred to as Round 1 and Alpha ponds will be Round 2. 


\subsection{Beta to Alpha Ponds in Series Experiment I}

For the first experiment, Round 1 ponds received primary clarifier effluent and operated at 3-day HRT, while Round 2 ponds operated at 4-day HRT. The process flow went as follows: Pond 4 effluent was pumped into a tube settler and the supernatant gravity drained into Pond 1, Pond 5 into Pond 2, and Pond 6 into Pond 3. The total treatment time for the primary clarifier effluent after Round 2 was seven days. The main goal was to test the ability of raceway ponds operating in series to achieve low nitrogen and phosphorus levels. The duration of data collection for this experiment was March 06, 2013 to June 13, 2013. 


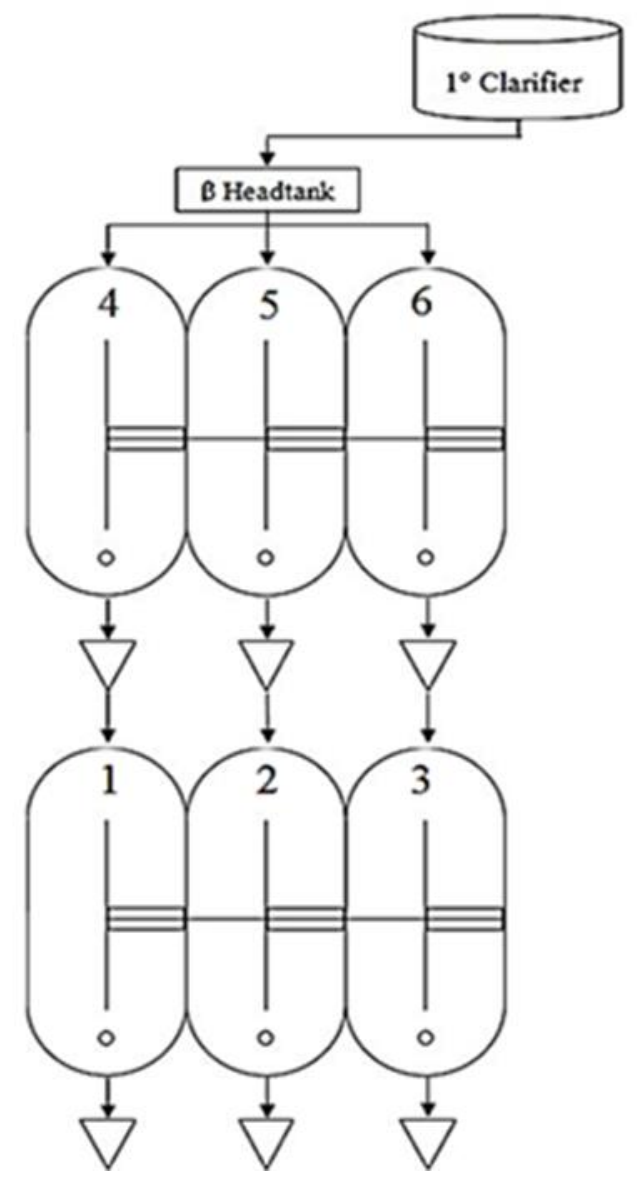

Figure 3-14a: The process flow schematic for the AFS ponds during Ponds in Series Experiment I.

\subsection{Beta to Alpha Ponds in Series Experiment II}

June 26, 2013 marked the start of the second ponds-in-series experiment. The Round 2 ponds switched to a 3-day HRT while Round 1 characteristics remained unchanged.

Round 1 effluent was pumped into tube settlers and the supernatant gravity drained into the Round 2 head tank for complete mixing. The constantly rotating scoop evenly distributed the mixed Round 1 biomass-separated effluent into the triplicate Round 2 ponds (Figure 3-14). This differed from Experiment 1 which did not mix the Round 1 ponds tube settler effluent prior to distribution to the Round 2 ponds for the second round of treatment. The tube settler effluent lines and Round 2 head tank were monitored daily 
to ensure no water was lost and it all reached the Round 2 ponds, extremely vital for a water recycle project. The main goal was to determine the nitrogen and phosphorus removal performance from raceway ponds operating in series for one year. Both Round 1 and Round 2 ponds operated at a 3-day HRT, for a total of six days of treatment.

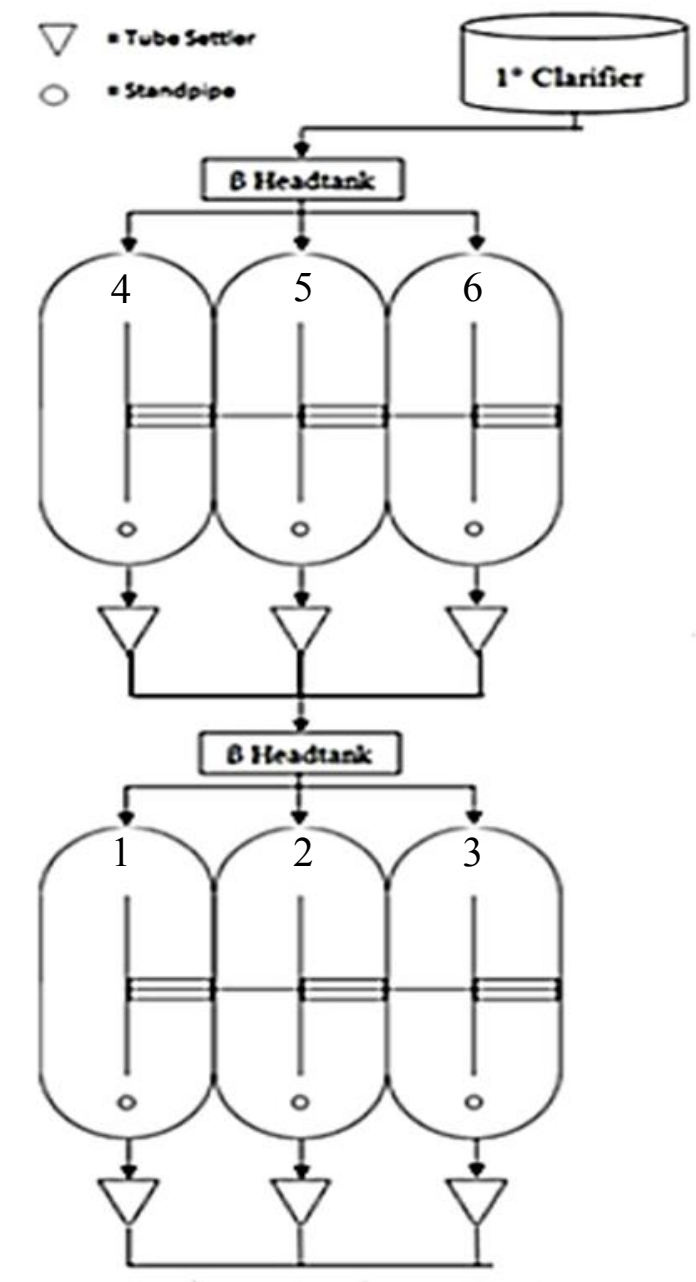

Figure 3-15b: The process flow schematic for the AFS ponds during Ponds in Series Experiment II.

\subsubsection{Nitrogen and Phosphorus Removal Performance from Raceway Ponds with 2-day HRT}

This experiment addressed the nitrogen and phosphorus removal capabilities from raceway ponds fed primary clarifier effluent operating at a 2-day HRT. This was 
conducted in the triplicate Gamma ponds at the AFS. Optimizing raceway pond performance with shorter HRTs is of utmost importance for the feasibility of this technology. Shorter HRTs allow for a reduction in land requirement, which is one of the biggest disadvantages for full-scale raceway pond implementation. Another goal of this experiment was to determine the maximum and minimum seasonal nitrogen and phosphorus removal performance.

\subsubsection{Weekly Pond Sampling Procedures}

Grab samples were collected for water quality analysis on a weekly basis between 7-8am. The one gallon sample bottles were inserted into the ponds upside down until midelevation, then turned right side up to collect the pond sample into the bottle. The sampling location was upstream from the standpipe. Tube settler supernatant was also collected. The sample location was located at the downspout at the top of the tube settler before it gravity drained into the Alpha head tank (Figure 3-15). The pond and tube settler samples were stored in closed coolers to prevent light exposure from generating algae growth. 


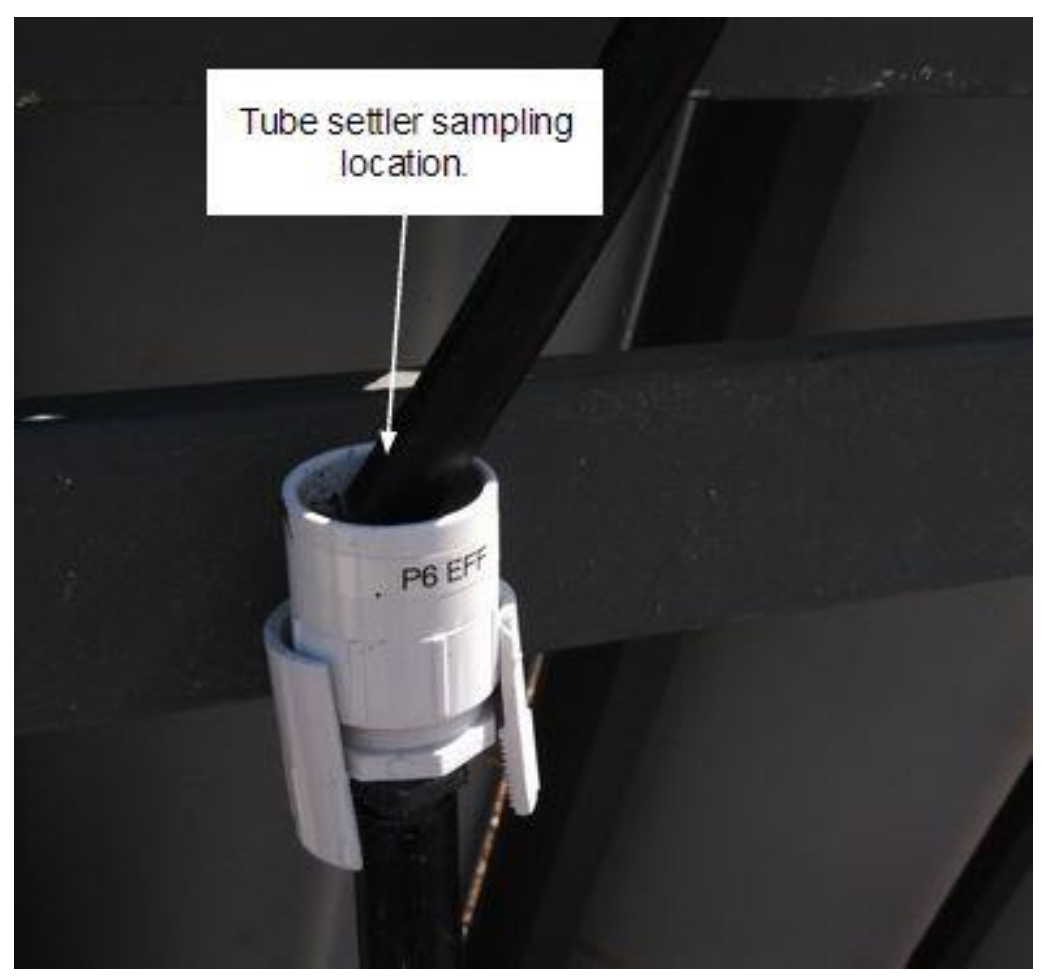

Figure 3-16: Sampling location for the Pond 6 tube settler supernatant. Identical set up for each tube settler (Chang, 2014).

The samples were taken to the Cal Poly lab immediately after collection to begin the analytical water quality tests. These are explained in detail in Section 3.4.

\subsection{Digestion Experiments}

Effectively recycling nutrients is an essential requirement for sustainable algal biofuels production. Re-capturing the nitrogen and phosphorus in settled algal sludge has many benefits, such as recycling them back into a raceway pond to promote microalgae productivity. If successful, nutrients from outside sources (i.e fertilizer) will not need to be purchased, consequently decreasing costs and promoting sustainability. For these experiments, this goal was achieved by organic nitrogen and particulate phosphorus degradation via lab scale anaerobic digestion and aerobic digestion experiments. Anaerobic digestion decomposed the algal cells resulting in a release of soluble nitrogen 
and phosphorus previously in the organic form. Once the digested algal biomass is returned to the raceway ponds, the re-solubilized nutrients are available to support further microalgae growth. The digested algal biomass will decompose further in the aerobic pond environment, providing more re-solubilized nutrients for algae growth. Lab scale aerobic digestion experiments were conducted on the post-anaerobically digested sludge to determine the extent of further degradation and nutrient solubilization in the aerobic raceway ponds.

Several pretreatment technologies were tested to promote an increase of nutrient solubilization by increasing the fraction of degradable biomass during anaerobic digestion. The four technologies were: sonication, high-pressure homogenization, autoclaving, and boiling. Only sonication and high-pressure homogenization will be discussed in this thesis, refer to Hill, 2014 for anaerobic digestion results on autoclaving and boiling. The goal of these pretreatment technologies is to rupture, or "lyse" algal cells to possibly aid the nutrient solubilization process during digestion.

A conceptual process flow of the pilot scale raceway pond, cultivation, digestion, and nutrient recycle all working in combination is described in Figure 3-16. The pretreatment step is also shown, but can be dismissed if it did not increase solubilization enough to warrant the extra costs associated with its implementation. 


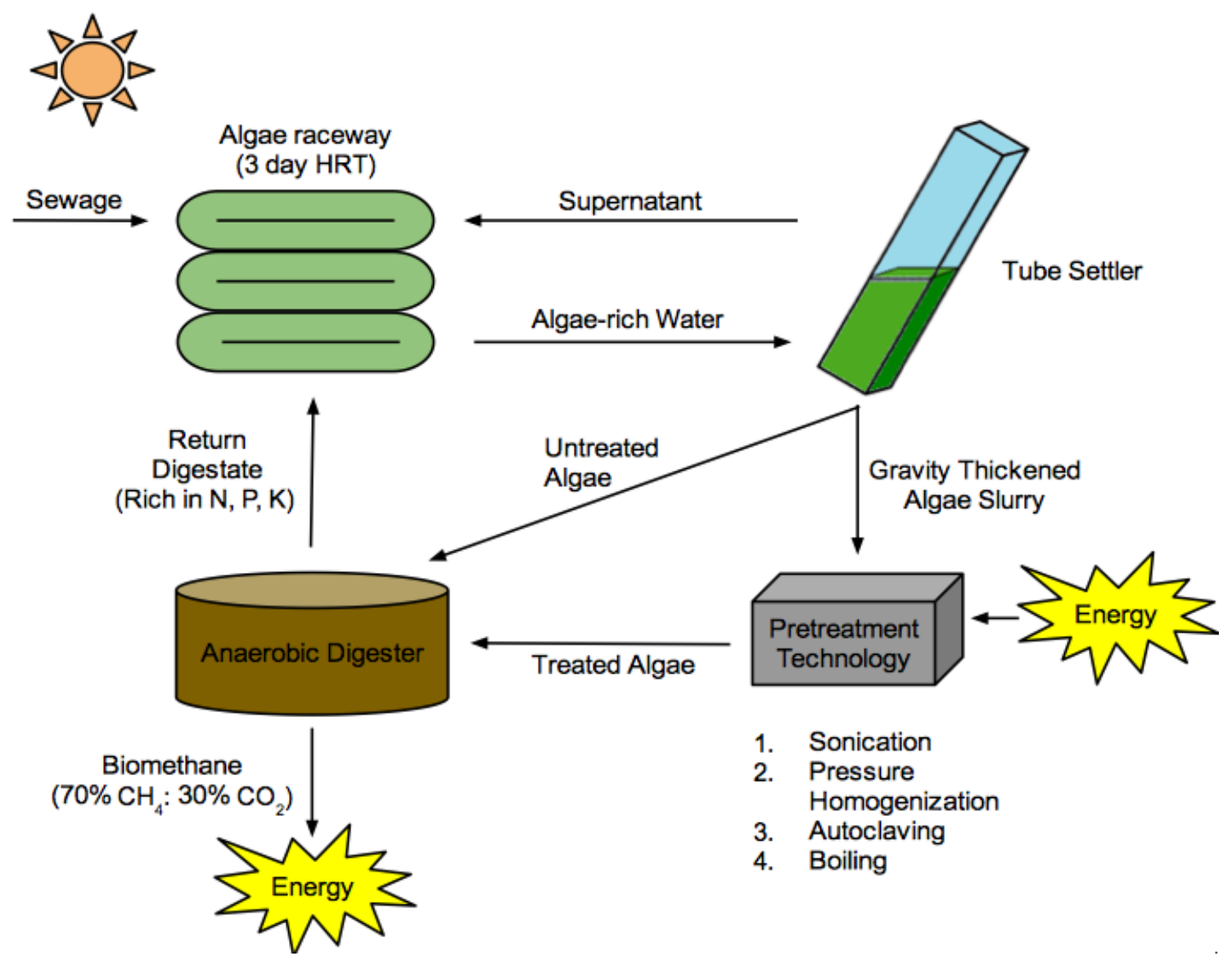

Figure 3-17: A basic process flow for nutrient and water recycling with raceway ponds. The supernatant from the tube settler comprises the water recycling aspect, while the return disgestate is the nutrient recycle part. Also included are the inputs and outputs of system including energy required for the pretreatment technology, energy gained by anaerobic digestion, and sewage influent (Hill, 2014).

This thesis will summarize the following results from the sonication and posthomogenization digestion experiments: (1) the fraction of organic nitrogen and particulate phosphorus degradation occurred from sequential anaerobic and aerobic digestion, (2) the fraction of non-biodegradable organic nitrogen and particulate phosphorus (3) the effect of the pre-treatment technologies (i.e. sonication and highpressure homogenization) on the fraction biodegradable organic nitrogen and particulate phosphorus. 


\subsubsection{Collection and Storage of Settled Algal Sludge}

The algae samples were collected from the Alpha set of tube settlers located adjacent to the Beta ponds at the AFS. Beta pond effluent after solids separation was the growth medium for the Alpha ponds, and primary clarifier effluent was the growth medium for the Beta ponds. The tube settlers operated via gravity separation of the algae, no chemical flocculants were added (Figure 3-17). The settled algal biomass was collected from the bottom of the tube settlers and stored in 1-L HDPE bottles. The collected sludge was then transported to the Cal Poly labs and briefly stored in a refrigerator $\left(4^{\circ} \mathrm{C}\right)$ while the experimental set up was completed.

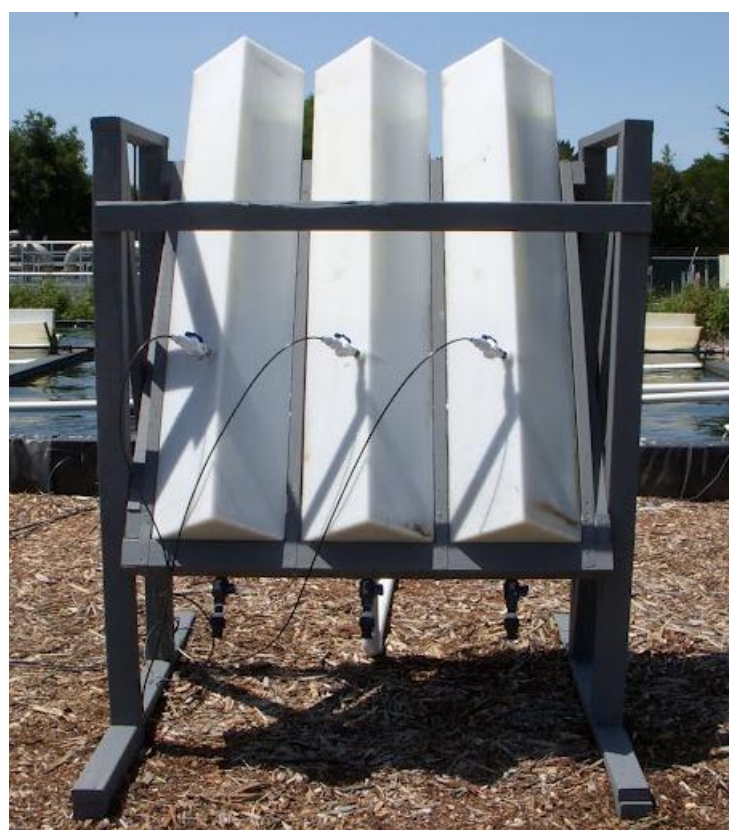

Figure 3-18: The angled tube settlers that the harvested algal biomass was collected from. The spigots at the bottom were the algal sludge collection point. The influent lines entered the settling units at $1 / 3$ the depth (Ripley, 2013).

Since primary clarifier effluent was the growth medium for the ponds, the algal populations were always poly-cultural. Microscopy was performed weekly on all of the raceway ponds at the AFS to record present and dominant microalgae species. 


\subsubsection{Anaerobic Digestion Experiments}

The purpose of these batch-digestion experiments was to determine the extent of organic nitrogen and particulate phosphorus degradation and the resulting nutrient solubilization. Additionally, the effectiveness of the pretreatment technologies were compared to each other and to non-pretreated digesters. Sonication was a bench-scale cell disruption technology that could not be scaled-up easily at the Cal Poly pilot plant. High-pressure homogenization, autoclaving, and boiling were considered scalable to implement at the pilot plant. For each experiment, the four types of digesters tested were: (1) pre-treated algae + seed digesters, (2) non-pretreated algae + seed digesters (control), (3) raw untreated algae (control), and (4) digester seed (control). The controls were important to determine the effectiveness of the pretreatment method and any affect caused by the seed. Municipal sludge digester effluent was used as a seed in the batch digestion experiments. It came from the WRRF which operates three anaerobic digesters in series at a temperature of $32^{\circ} \mathrm{F}$ and 60 days total hydraulic residence time.

Serum bottles of either $125 \mathrm{~mL}$ or $1.2 \mathrm{~L}$ were used as the anaerobic digesters and placed in a gravity convection incubator (Precision, Chicago, Ill) that maintained a constant mesophilic temperature of $35 \pm 2{ }^{\circ} \mathrm{C}$ for the duration of each experiment (Hill, 2014). The serum bottles within the incubator are shown in Figure 3-18. Excluding the sonication experiment, extra identical pretreated and non-pretreated digesters were prepared to be used in the aerobic digestion experiments outlined in Section 3.3.3. 


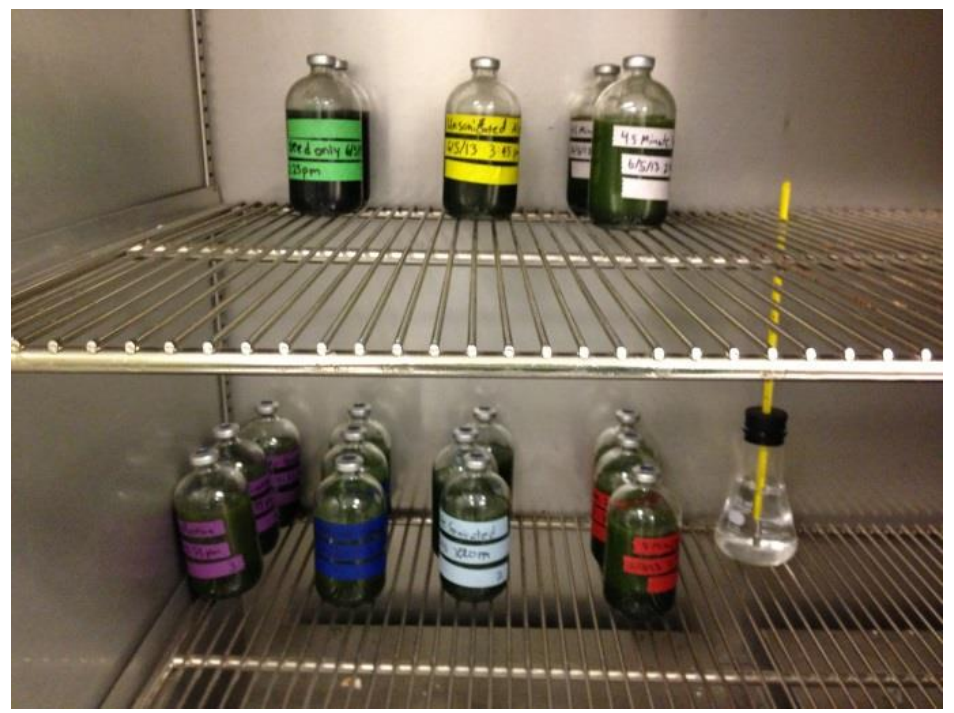

Figure 3-19: Serum bottles located inside the incubator which maintained a constant mesophilic temperature of $35 \pm 2{ }^{\circ} \mathrm{C}$ (Hill, 2014).

The process flow of the digester set up was identical for each experiment (Figure 3-19), and the same analytical tests were performed on each experiment (Table 3-3). 


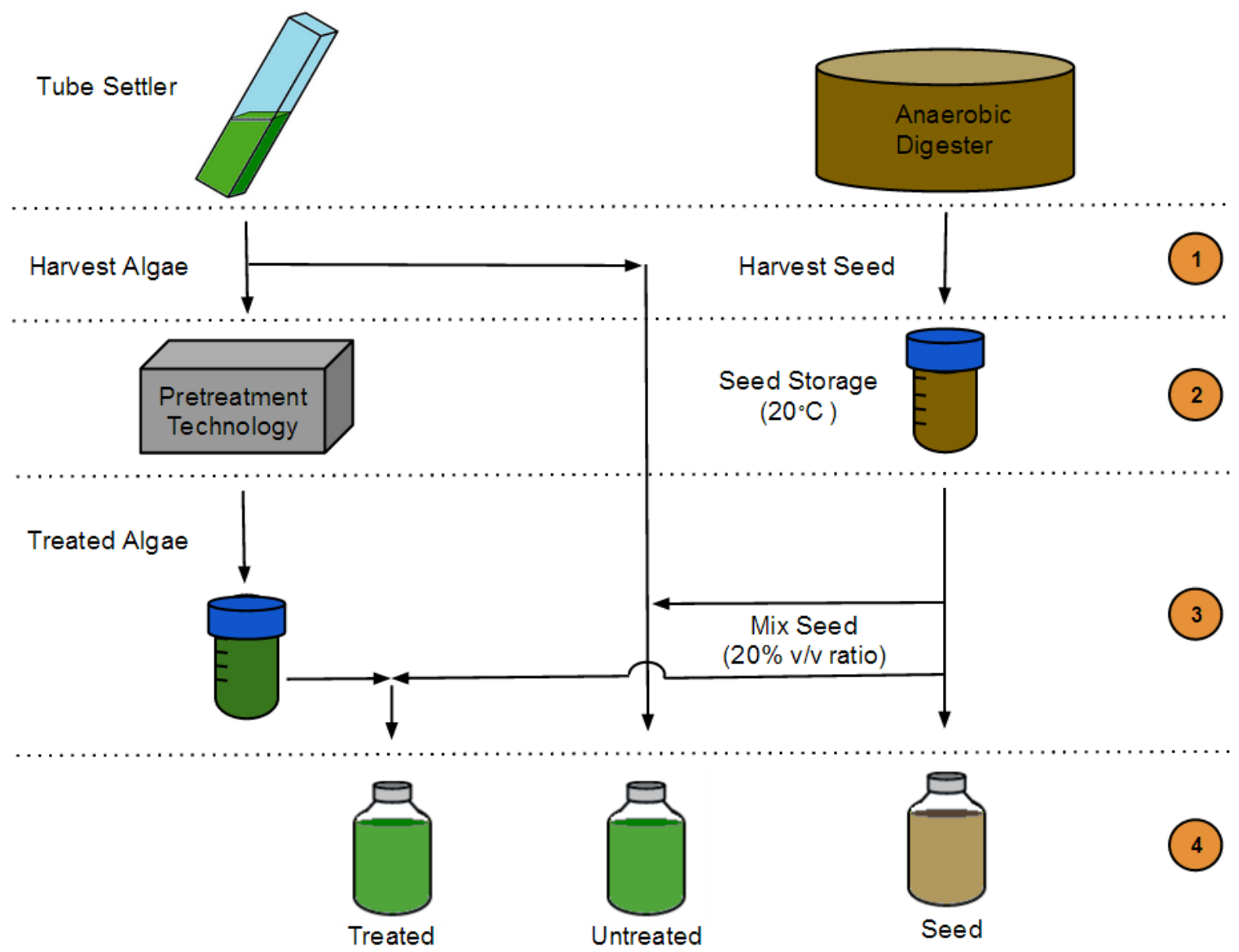

Figure 3-20: Process flow for the set-up of the digesters. The collection and pretreatment of the algae samples is shown to the left and to the right is the collection of the seed (Hill, 2014).

Table 3-3: Each analytical test performed on the different samples, and the required sample volume for each. The proper sample storage technique is list in the right column (Hill, 2014).

\begin{tabular}{|c|c|c|c|c|c|c|c|}
\hline Analytical Test & $\begin{array}{c}\text { Raw, } \\
\text { untreated } \\
\text { algae }\end{array}$ & $\begin{array}{c}\text { Digester } \\
\text { Seed Only }\end{array}$ & $\begin{array}{c}\text { Treated } \\
\text { Algae }\end{array}$ & $\begin{array}{c}\text { Untreated } \\
\text { Algae + Seed }\end{array}$ & $\begin{array}{c}\text { Treated } \\
\text { Algae + Seed }\end{array}$ & $\begin{array}{l}\text { Required } \\
\text { Sample Size }\end{array}$ & $\begin{array}{l}\text { Sample } \\
\text { Storage }\end{array}$ \\
\hline TS/VS & $\mathrm{x}$ & $\mathrm{x}$ & $\mathrm{x}$ & $\mathrm{x}$ & $x$ & $15 \mathrm{~mL}$ & None \\
\hline pH/Alkalinity & & $x$ & $\mathrm{x}$ & $\mathrm{x}$ & $\mathrm{x}$ & $20 \mathrm{~mL}$ & None \\
\hline tCOD & $\mathrm{x}$ & $x$ & $\mathrm{x}$ & $\mathrm{x}$ & $\mathrm{x}$ & $10 \mathrm{~mL}$ & $\mathrm{H}_{2} \mathrm{SO}_{4}$ \\
\hline sCOD & $\mathrm{x}$ & $\mathrm{x}$ & $\mathrm{x}$ & $\mathrm{x}$ & $\mathrm{x}$ & $30 \mathrm{~mL}$ & $\mathrm{G} 4, \mathrm{H}_{2} \mathrm{SO}_{4}$ \\
\hline TKN & & $\mathrm{x}$ & $\mathrm{x}$ & $\mathrm{x}$ & $\mathrm{x}$ & $25 \mathrm{~mL}$ & $\mathrm{H}_{2} \mathrm{SO}_{4}$ \\
\hline TAN & & $x$ & $x$ & $\mathrm{x}$ & $\mathrm{x}$ & $20 \mathrm{~mL}$ & $\mathrm{H}_{2} \mathrm{SO}_{4}$ \\
\hline Total P & & $\mathrm{x}$ & $\mathrm{x}$ & $\mathrm{x}$ & $x$ & $15 \mathrm{~mL}$ & Frozen \\
\hline DRP & & $\mathrm{x}$ & $\mathrm{x}$ & $\mathrm{x}$ & $\mathrm{x}$ & $10 \mathrm{~mL}$ & $\begin{array}{c}\mathrm{G} 4,0.45 \mu \mathrm{m}, \\
\mathrm{H}_{2} \mathrm{SO}_{4}\end{array}$ \\
\hline Total Potassium & & $\mathrm{x}$ & & $\mathrm{x}$ & $x$ & $100 \mathrm{~mL}$ & $\mathrm{HNO}_{3}$ \\
\hline Soluble Potassium & & $\mathrm{x}$ & & $\mathrm{x}$ & $\mathrm{x}$ & $100 \mathrm{~mL}$ & $\begin{array}{c}\mathrm{G} 4,0.45 \mu \mathrm{m}, \\
\mathrm{HNO}_{3}\end{array}$ \\
\hline
\end{tabular}


The results section of this thesis will only cover the sonication and high-pressure homogenization experiments. For a detailed description of all four anaerobic digestion experiments, their experimental set-up, results, and all other logistical information, refer to Hill, 2014.

\subsubsection{Aerobic Digestion Experiments}

The purpose these experiments was to determine the extent of organic nitrogen and particulate phosphorus degradation in an aerobic environment, and the resulting nutrient solubilization on the post anaerobically digested algal sludge. For the aerobic digestion experiments, only the high pressure homogenization experiment included both homogenized and non-homogenized samples. The sonication aerobic digestion experiment did not include the non-sonicated sample, because extra digesters were not prepared prior to the start of the anaerobic digestion experiment.

\subsubsection{Post Sonicated and Digestion Aerobic Degradation Experiment}

The sonication aeration experiment used triplicate aerobic reactors (Figure 3-20). 3.78-L polypropylene juice pitchers served as the reactors. Adequate aeration was provided by two $3.5 \mathrm{~cm}$ long, $1 \mathrm{~cm}$ diameter fine bubble ceramic diffuser stones. Each reactor was stirred with Hanna Instrument, HI 190M stir plates. To replicate the environment of a raceway pond, the post anaerobically digested algal sludge was diluted with dechlorinated tap water and added a specific amount of recycled activated sludge (RAS) from the WRRF to provide microbes found in wastewater. 

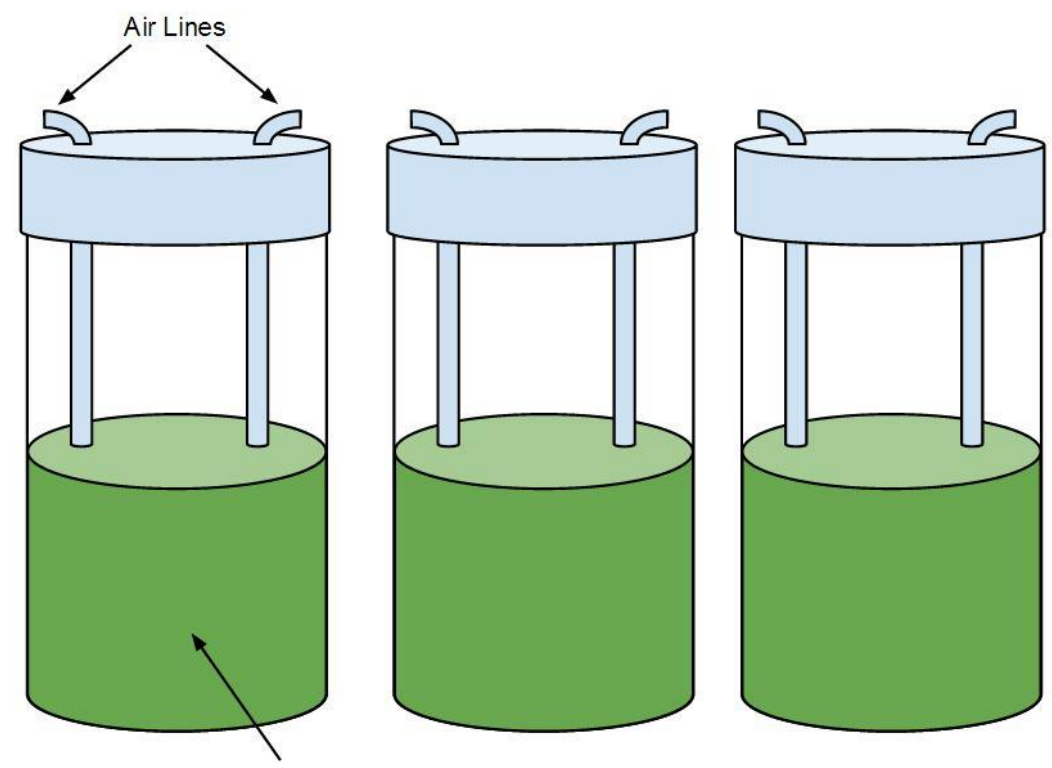

Digested Sludge

Figure 3-21: Triplcate 3.78-L polypropylene containers that served as the aerobic reactors with air lines that provided adequate aeration (Chang, 2014).

The following water quality analyses were performed on the reactors: temperature, $\mathrm{pH}$, dissolved oxygen, volatile suspended solids, ammonia, nitrate, nitrite, total kjeldahl nitrogen, and DRP. Dissolved oxygen was measured with an YSI Digital Professional Series ProODO meter equipped with a YSI ProBOD probe. Temperature and $\mathrm{pH}$ were measured using an Oakton waterproof $\mathrm{pH} / \mathrm{mV} /{ }^{\circ} \mathrm{C} /{ }^{\circ} \mathrm{F}$ data meter 310 series with an Oakton $\mathrm{pH}$ probe. All nutrient data were measured using methods outlined in Section 3.4. For a complete and detailed experimental set up and sampling procedure, refer to Chang 2014.

\subsubsection{Post Homogenized and Digested Aerobic Degradation Experiment}

The high pressure homogenization aeration digestion experiment was prepared with the same dilution factor and RAS ratio used for the sonication experiment. This experiment included triplicate reactors of homogenized, post anaerobically digested algal sludge and 
non-homogenized, post anaerobically digested algal sludge (Figure 3-21). This was important to determine if high pressure homogenization aided in further biomass degradation.
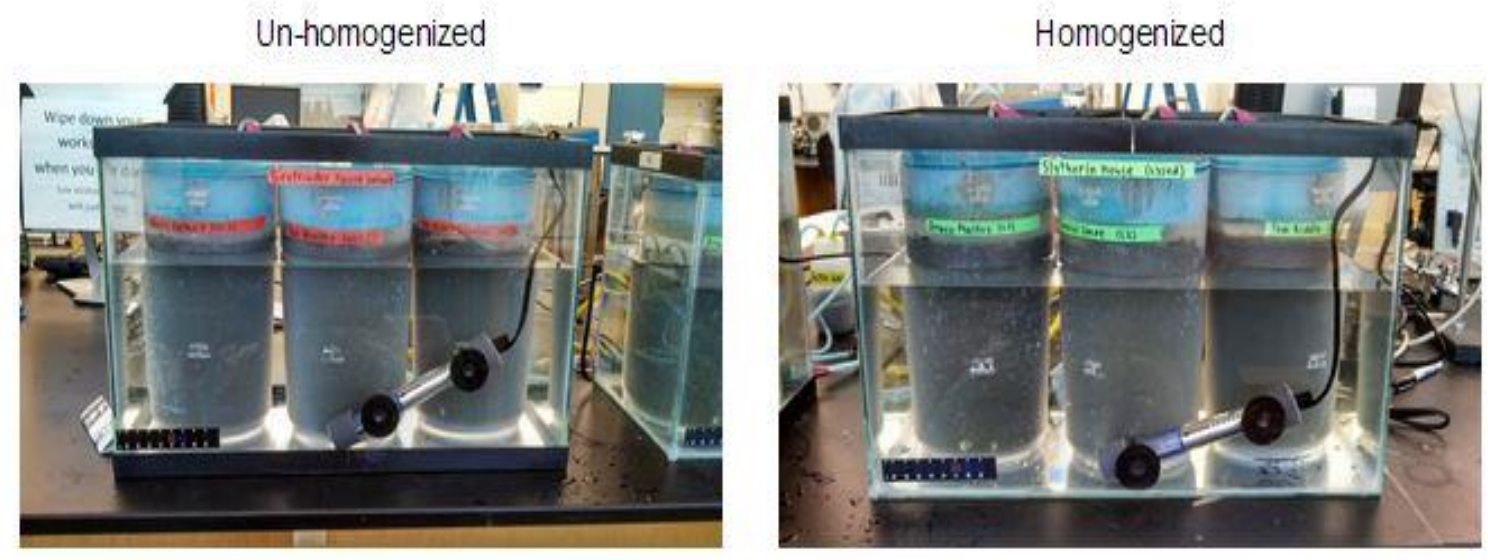

Figure 3-22: A picture of the two sets of triplicate 3.78-L polypropylene aerobic reactors. The left picture is of the un-homogenized reactors, and the right photo is the homogenized reactors. Each set was placed in a water bath to maintain a constant temperature in the reactors (Chang, 2014).

Based on observations from the sonication experiment, stir plates were deemed unnecessary because sufficient aeration provided adequate mixing. A water bath was used to stabilize the reactor temperatures. The influent air was filtered with activated carbon prior to entering the reactors because of unwanted oil and dirt in the air supply. Due to the highly reactive nature of nitrogen observed in the sonication experiment, VSS, ammonia, nitrate, and nitrite were measured each sample day, while DRP was measured on a weekly basis. TKN, TP, and COD were measured periodically throughout the duration of the experiment. For a detailed, complete experimental set up and sampling procedure, refer to Chang 2014. 


\subsection{Water Quality Analysis}

On a weekly basis, the same water quality tests were performed on grab samples from all nine ponds. Table 3-4 outlines the tests performed on each sample type. Analysis in Cal Poly labs immediately followed sample collection and completed within ten hours, with the exception of Total Kjeldahl Nitrogen (TKN) and Total Phosphorus (TP), which were acidified and preserved. Unless otherwise stated, all tests and sample preservation techniques were performed in accordance with Standard Methods for the Examination of Water and Wastewater 1995 (Table 3-4)

Table 3-4: A list of the analytical method used to measure each constituent. Within each analytical method description, the APHA Standard Methods title is listed.

\section{Constituent}

Nutrients

Total Ammonia Nitrogen

Nitrite

Nitrate

Total Kjeldahl Nitrogen

Dissolved Reactive Phosphorus

Total Phosphorus

\section{Organics}

Total and Volatile Suspended Solids

\section{Analytical Method}

Ammonia Selective Electrode (APHA Method 4500$\left.\mathrm{NH}_{3} \mathrm{D}\right)$

Colorimetric, Fisherbrand $0.45 \mu \mathrm{m}$ Multiple Cellulose Ester filtration (APHA Method $4500-\mathrm{NO}_{2}{ }^{-} \mathrm{B}$ )

Nitrate Ion Selective Electrode with Interference Suppression Solution (APHA Method $4500-\mathrm{NO}_{3}{ }^{-} \mathrm{D}$ )

Macro-Kjeldahl and manual titration (APHA Method $4500-\mathrm{N}_{\text {org }} \mathrm{B}$ )

Ascorbic Acid, Fisherbrand $0.45 \mu \mathrm{m}$ Multiple Cellulose Ester filtration (APHA Method 4500-P E)

Vanadomolybdophosphoric Acid Colorimetric (APHA Method 4500-P C)

Gravimetric with Fisherbrand G4 Glass Fiber filters filtration (APHA Method 2540 D and E) 
Total and Soluble

Carbonaceous Biochemical

Oxygen Demand

\section{Other}

Microscopy for Algae ID

Alkalinity 5-day with $20{ }^{\circ} \mathrm{C}$ incubation, Fisherbrand G4 Glass

Fiber filtration (APHA Method 5210 B)
Selected Taxonomic References, Optical Microscope (Method 10900 E. 2.)

Sulfuric Acid Titration (APHA Method 2320 B)

Every analytical test involved at least two of the following quality analysis/quality control (QA/QC) checks: blank, standard check, split, matrix spike. If a QA/QC sample failed in a test, that batch was either re-run or otherwise removed from the data set. All reagents and stock solutions were either prepared by graduate students, research supervisors, or purchased from Fisher Scientific. Calibration curves were required for several tests to convert the output to concentration, as described in the following sections. If sample concentrations were outside the calibration curve, they were either diluted more or less, and ran again. All samples were prepared with DI water, and glassware was rinsed thoroughly with DI water before and after the test.

\subsubsection{Nitrogen Analysis}

Nitrogen analyses were performed on the pond, aeration digestion, and anaerobic digestion samples. The different forms of nitrogen tested were: total ammonia nitrogen (TAN), nitrite, nitrate, and total Kjeldahl nitrogen (TKN). Organic nitrogen concentrations were calculated from Equation 1 displayed in a following section. TAN, nitrite, and nitrate tests required calibration curves to convert their respective output to 
known concentrations. The pond and aeration samples received all four of the nitrogen tests listed above, but anaerobic digestion samples only received TAN and TKN testing because oxidized nitrogen is not present in anaerobic samples.

\subsubsection{Total Ammonia Nitrogen}

Total ammonia nitrogen (TAN) concentrations were obtained following APHA Method 4500-NH3 D. An ammonia gas selective electrode (Thermo Scientific, RS1-121618) was used a $\mathrm{pH} /$ ion analyzer meter (Corning Model 355) for taking potentiometric measurements on a millivolt scale. A calibration curve with standards of $0.1,1,10$, and $50 \mathrm{mg} / \mathrm{L}-\mathrm{NH}_{3}$ concentrations was prepared with each set of samples. The standards were created by diluting a $2500 \mathrm{ppm}$ as $\mathrm{NH}_{3}$ stock ammonium chloride standard (Aqua Solutions).

The room temperature samples were adjusted to $\mathrm{pH} 11$ or higher using Alkaline Reagent (Orion 951011) before measurement to convert all of the ammonia/ammonium to ammonia. This was necessary because the electrode was selective to only ammonia, not ammonium.

The probe was rinsed with deionized (DI) water in between each sample, and DI water was also used for creating the standard dilutions. Acidified pond and influent samples were stored at $4^{\circ} \mathrm{C}$ for preservation.

\subsubsection{Nitrite}

Nitrite $\left(\mathrm{NO}_{2}^{-}\right)$concentrations were attained using a colorimetric reagent, in accordance with APHA Method 4500- $\mathrm{NO}_{2}{ }^{-}$B. The colorimetric reagent consisted of $85 \%$ phosphoric acid, sulfanilamide, and N-(1-napthyl)-ethylenediamine. Influent and pond 
samples were filtered through $0.45-\mu \mathrm{m}$ mixed cellulose ester membrane filters

(Fisherbrand, Catalog No. 09-719-2E) prior to the start of the test. A calibration curve with standards of $0,0.05,0.10,0.15$, and $0.20 \mathrm{mg} / \mathrm{L}-\mathrm{N}$ concentrations was prepared with each set of samples. The standards were created by diluting a $250 \mathrm{mg} / \mathrm{L}-\mathrm{N}$ sodium nitrite solution. Fifteen minutes after the addition of the coloring reagent to each sample, absorbances of the samples were measured at $543 \mathrm{~nm}$ using $1-\mathrm{cm}$ path length cuvettes (Plastibrand, Catalog No. 759076D) on a UV-VIS spectrophotometer (Shimadzu UV1700 PharmaSpec).

\subsubsection{Nitrate}

Nitrate analysis was completed in accordance to APHA Method 4500-NO $3-\mathrm{D}$. A nitrate ion selective electrode (Orion Model RO1-14563) was used to obtain a millivolt reading output from a Corning Model 355 ion analyzer. An Interference Suppression Solution (ISS) was added to each sample due to the presence of interfering ions such as nitrite, carbonate, bicarbonate, and phosphorus. ISS was added in a ratio of $10.1 \mathrm{~mL}$ ISS per 90.9 $\mathrm{mL}$ of sample, in accordance to the APHA Method 4500-NO3-D. The ISS was prepared in lab by graduate students, and was made according to the Orion preparation procedure. A low-level calibration curve method was used to convert the millivolt readings to nitrate concentrations, because several ponds contained low nitrate concentrations. A five-point calibration curve with concentrations of $0.2,0.6,1.0,2.9$ and $4.7 \mathrm{mg} / \mathrm{L}-\mathrm{N}$ was created by performing five additions of a $100 \mathrm{mg} / \mathrm{L}-\mathrm{N}$ standard to a blank sample containing $100 \mathrm{~mL}$ DI and $11.1 \mathrm{~mL}$ of ISS. The $100 \mathrm{mg} / \mathrm{L}-\mathrm{N}$ standard was created prior to each analysis completing a 10x dilution of a $1000 \mathrm{mg} / \mathrm{L}-\mathrm{N}$ sodium nitrate stock standard. 
Pond samples with nitrate concentrations in excess of $1.2 \mathrm{mg} / \mathrm{L}-\mathrm{N}$ required a DI water dilution prior to testing to achieve a concentration within the proper range. Dilutions were performed with $50 \mathrm{~mL}$ volumetric flasks and DI water. Dilution factors varied due to seasonal variations of treatment performance, but the same low-level calibration method was used for each test. Once the millivolt readings became stable, they were recorded. The probe was rinsed thoroughly with DI water between each sample. The detection limit for the nitrate ion selective electrode was $0.1 \mathrm{mg} / \mathrm{L}-\mathrm{N}$.

\subsubsection{Total Kjeldahl Nitrogen}

Total Kjeldahl Nitrogen (TKN) was performed in accordance with APHA Standard Methods 4500-- $\mathrm{N}_{\mathrm{ORG}} \mathrm{B}$ using an 18-burner digestion-distillation combination fume hood (Labconco, No. 2117803) and $800 \mathrm{~mL}$ Kjeldahl flasks. TKN analysis was always performed on acidified, preserved samples that were kept in a refrigerator at $4{ }^{\circ} \mathrm{C}$. The samples were run before the one month preservation deadline, in accordance to APHA

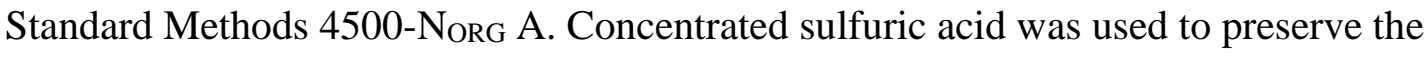
samples to a $\mathrm{pH}$ of $1.7-2$.

On analysis day, the acidified samples were blended to achieve homogenization. This was deemed necessary due to big algae flocs in certain samples. After homogenization, $50 \mathrm{~mL}$ of the sample was poured into the $800 \mathrm{~mL}$ Kjeldahl flasks and mixed with $250 \mathrm{~mL}$ of DI water. The lab analysts took extra precaution to prevent biomass from settling prior to sample pouring, thus ensure the $50 \mathrm{~mL}$ sample represented its respective pond sample. TKN analysis was consisted of the following QC checks: a 20 or $40 \mathrm{mg} / \mathrm{L}-\mathrm{N}$ standard check, a blank sample (DI water), a split and a spike. TKN analysis using this particular method did not require a calibration curve. The standard check and spike used the same 
$2500 \mathrm{ppm}$ as $\mathrm{NH}_{3}$ stock ammonium chloride standard (Aqua Solutions) that Total Ammonia Nitrogen analysis used. Manual acid titration was performed at the end using $0.02 \mathrm{~N}$ sulfuric acid.

\subsubsection{Organic Nitrogen}

Organic nitrogen concentrations were calculated using Equation 1

Equation 1: Organic Nitrogen Equation

$$
\text { Organic Nitrogen }=T K N-T A N
$$

\subsubsection{Phosphorus Analysis}

The two forms of phosphorus tested were: total phosphorus (TP), and dissolved reactive phosphorus (DRP). Pond, aeration, and anaerobic samples all received these two phosphorus tests. To reduce phosphorus contamination, special precautions were taken to all of the glassware and filters that came into contact with the samples. First, all glassware was acid washed by soaking it in a $10 \% \mathrm{v} / \mathrm{v}$ sulfuric acid bath for at least 20 minutes followed by a DI water bath. This method varied from Standard Methods, which suggested using hydrochloric acid instead of sulfuric acid. Sulfuric acid was chosen for safety and hazardous waste reasons. Glassware was acid washed every $2-3$ months, in accordance to Standard Methods. Also, the $0.45-\mu \mathrm{m}$ membrane filters were soaked in DI water for 24 hours prior to sample filtration.

\subsubsection{Dissolved Reactive Phosphorus}

Dissolved reactive phosphorus (DRP) analysis was performed in accordance to APHA Standard Methods 4500-P E. Similar to the nitrite method, DRP was a colorimetric test and required samples to be filtered through the same $0.45-\mu \mathrm{m}$ membrane filters. The 
coloring reagent was made with potassium antimonyl tartrate, ammonium molydbate, and ascorbic acid to create a blue color change in samples. Filtered samples were diluted in $50 \mathrm{~mL}$ volumetric flasks and added to $250 \mathrm{~mL}$ Erlenmeyer flasks. $8 \mathrm{~mL}$ of the color reagent was added to each sample and was given at least 15 minutes to react before spectrophotometer analysis. The spectrophotometer procedure was the same as nitrite, except the wavelength was $880 \mathrm{~nm}$ for DRP.

\subsubsection{Total Phosphorus}

Total Phosphorus (TP) testing was performed in accordance to APHA Standard Methods 4500-P B \& C using the same 18-burner Kjeldahl apparatus described in the TKN section above. TP analysis was always performed on acidified, preserved samples, kept at $4{ }^{\circ} \mathrm{C}$ in a refrigerator. Preserved samples were run before the 1 month expiration date, in accordance to the APHA method. Concentrated hydrochloric acid was used to preserve the samples to a $\mathrm{pH}$ of $1.7-2$.

On analysis day, $50 \mathrm{~mL}$ of sample was added to the acid washed $800 \mathrm{~mL}$ Kjeldahl flasks along with $25 \mathrm{~mL}$ concentrated nitric acid and $5 \mathrm{~mL}$ concentrated sulfuric acid. The samples then began the acid digestion step, in which nitric and sulfuric acid converts particulate phosphorus to dissolved phosphorus. The samples were digested until the nitric acid boiled away, indicated by a color change of brown to white in the smoke. Afterward, a vanadomolybdophosphoric acid color reagent was added to each sample and given at least 15 minutes to react before spectrophotometric analysis. This color reagent was made of ammonium molybdate tetra-hydrate, ammonium metavanadate, and concentrated hydrochloric acid. The spectrophotometric analysis was the same as described in the nitrite section. 
As with DRP, all glassware was acid washed to prevent phosphorus contamination.

\subsubsection{Suspended Solids Analysis}

Total suspended solids (TSS) and volatile suspended solids (VSS) were performed on samples from the ponds and aeration digesters. All TSS and VSS samples were run in duplicate, and the results averaged. A Mettler Toledo AG245 five-point balance was used for weight measurement and set to read $0.00001 \mathrm{~g}$, with results rounded to $0.0001 \mathrm{~g}$. First, the procedure for homogenizing 0-hour pond water samples prior to TSS and VSS is described.

\subsubsection{Pond Water Sample Homogenization for 0-hour Suspended Solids}

The pipettes used for capturing the suspended solids samples strain out large flocs because of their small diameter opening. Therefore, sample homogenization via blending was deemed necessary to capture a sample volume that is representative to the concentration found in the ponds. The samples were poured into a square beaker (Phipps and Bird Beaker ${ }^{2}$ ) and blended using a two speed immersion blender (Proctor Silex, Model No. 59738) until flocs greater than a quarter centimeter were absent.

\subsubsection{Total Suspended Solids}

Total suspended solids (TSS) analysis was performed according to APHA Standard Methods 2540 D using G4 glass fiber filters with 1.2- $\mu \mathrm{m}$ nominal pore size (Fisherbrand G4 filters, Cat No. 09-804-42C). Prior to TSS testing, all G4 filters used were preconditioned by performing a DI water rinse to each once and placed in a muffle furnace set to $550^{\circ} \mathrm{C}$ for 15 minutes. This was necessary because volatile suspended solids analysis was also performed on the same filters. After the tare weights were recorded, a selective sample volume was dispensed onto the filter and drained through via a vacuum 
pump. All suspended solids remained on top the filter while the filtrate was collected in an Erlenmeyer flask. They were then carefully removed and placed onto an aluminum tray (Fisherbrand). After completion, they were placed in a gravity convection oven (VWR Symphony, Part No. 414005-110) for at least two hours to remove all moisture. Before recording final weights, the filters cooled to room temperature in a desiccator.

All filters were stored in desiccators to prevent the accumulation of moisture in the air onto the filters. Color-indicating desiccant (Agros Organics Drierite) was present in each desiccator to absorb intruding moisture.

\subsubsection{Volatile Suspended Solids}

Volatile suspended solids (VSS) analysis was performed according to APHA Standard Methods 2540 E. VSS was tested on the same filters used for TSS. After the final weights were recorded for TSS analysis, they were placed in a muffle furnace (Fisherbrand Isotemp oven, Model No 550-58) set to $550^{\circ} \mathrm{C}$ for 15 minutes to remove volatile biomass. The filters then cooled to room temperature in a desiccator before final weights were recorded.

\subsubsection{Total and Volatile Solids Analysis}

Total solids (TS) analysis was performed following APHA Standard Methods 2540 B and volatile solids (VS) followed APHA Standard Methods 2540 E. All samples were measured on a mass per volume basis and run in triplicate. The reported values were the average of the triplicate set. In sampling, 3-5 mL of well-mixed sample was collected from a 50-mL beaker using a 3-5 $\mathrm{mL}$ syringe and expelled onto the a Fisherbrand aluminum dish. The aluminum dishes were tared. The total solids concentration was determined by drying the sample in a gravity convection oven (VWR Symphony, Part 
No. $414005-110)$ at $105^{\circ} \mathrm{C}$. Volatile solids concentration was determined by ashing the samples for 15 minutes in the muffle furnace (Fisherbrand Isotemp oven, Model No 55058) set at $550^{\circ} \mathrm{C}$.

\subsection{Dissolved Oxygen, $\mathrm{pH}$, and Temperature}

A Neptune SCADA system was used at the AFS to monitor pH (Sensorex, Garden Grove, Calif.), dissolved oxygen (Neptune Systems, Morgan Hill, Calif.), and temperature (Neptune Systems) in the ponds. Temperature, $\mathrm{pH}$, and dissolved oxygen data were stored in data-loggers (Apex Aqua Controllers, Neptune Systems). From March 2013 to June 2014, the pH system was programmed to record values every 10 minutes. On July 2014 the programming changed to record $\mathrm{pH}$ values every hour to be consistent with the DO and temperature recordings. Each week, the recorded field data were stored on an external hard drive for future use. Dissolved oxygen and temperature were always recorded every hour. The $\mathrm{pH}$, temperature, and dissolved oxygen probes were located on the eastern edge of the ponds, upstream of the influent pipe (Figure 322). They were cleaned daily with a jet of DI water from a squeeze bottle and calibrated weekly with $\mathrm{pH} 7$ and 10 standard buffers. 


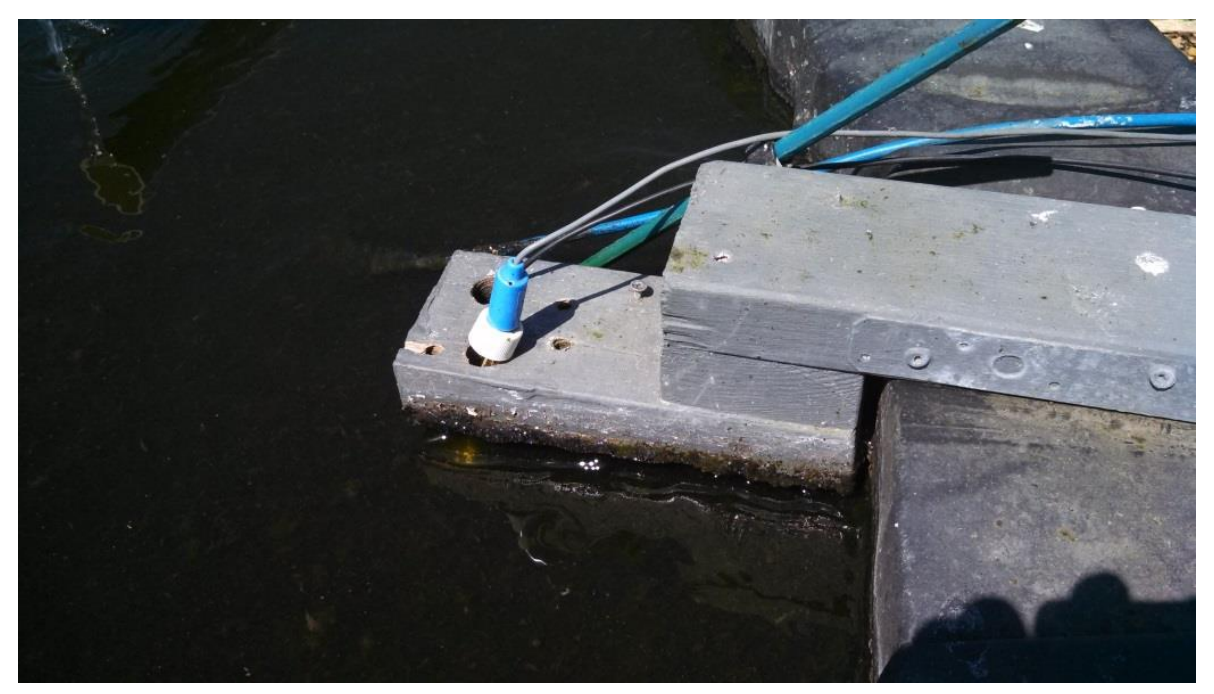

Figure 3-23: The probe stand on each raceway pond. The $\mathrm{pH}$ and temperature probes are inserted through holes in the stand and the DO probe was connected to a green rod that is attached to the stand.

From March 2013 to September 2013, the Neptune system malfunctioned and prevented the storage of data. No field data were recorded from this time period. The DO and temperature system were fixed in September 2013, but the pH system was not fixed until November 2013.

\subsection{Weather Data}

Daily weather data were collected from the California Irrigation Management Information System (CIMIS), as described in Chang (2014). This weather station was located on the California Polytechnic San Luis Obispo campus, nearly six kilometers north of the AFS. 


\section{Results and Discussion}

The results for nitrogen and phosphorus removal from the two separate ponds-in-series experiments (Round 1 ponds to Round 2 ponds) are presented first. Then the nitrogen and phosphorus removal from Gamma ponds (operating at a two-day HRT) will be discussed.

Finally, a summary of the organic nitrogen and particulate phosphorus degradation results from the sequential anaerobic digestion and aerobic digestion experiments will be presented.

\subsection{Pond Influent Water Characteristics}

Primary clarifier effluent was obtained from just inside of the weir and continuously pumped to the Beta and Gamma constant head tanks. The influent constituents for the duration of all the pond experiments (Table 4-1) showed that total ammonia nitrogen (TAN) was the main nitrogen source and substantial suspended solids were present, averaging $64 \mathrm{mg} / \mathrm{L}$. This influent VSS was subtracted from effluent VSS to determine net productivity.

Table 4-1: Primary clarifier effluent characteristics, which served as the influent for the Beta (Round 1) ponds in the ponds in series experiments, and for the two-day HRT ponds.

\begin{tabular}{cccccccccc} 
& TAN & $\mathrm{NO}_{2}^{-}$ & $\mathrm{NO}_{3}{ }^{-}$ & Org N & DRP & TP & TSS & VSS & TBOD $_{5}$ \\
\hline Average (mg/L) & 36.6 & 0.0 & 1.1 & 8.2 & 3.7 & 5.8 & 64 & 46 & 122 \\
Standard Dev. & 6.9 & 0.0 & 0.7 & 5.2 & 0.4 & 1.2 & 25 & 8 & 23 \\
Min. (mg/L) & 22.2 & 0.0 & 0.2 & 0.3 & 1.8 & 3.5 & 33 & 31 & 82 \\
Max. (mg/L) & 53.0 & 0.3 & 3.6 & 21.5 & 4.5 & 8.3 & 183 & 76 & 177 \\
\hline
\end{tabular}

\subsection{Environmental Conditions}

San Luis Obispo is located on the California central coast in a climatic region classified as Mediterranean. Precipitation, solar radiation, and air temperatures were the main weather conditions analyzed in this thesis. Although annual precipitation is usually 
around 38 centimeters, throughout the course of pond experimentation (March 2013 August 2014), the total precipitation was 25 centimeters. Over half of that total occurred in February 2014 with 13 centimeters. The average monthly solar radiation peaked at 335 $\mathrm{W} / \mathrm{m}^{2}$ in June 2014 and reached a minimum of $126 \mathrm{~W} / \mathrm{m}^{2}$ in December 2013. Monthly average air temperatures ranged from $12-19^{\circ} \mathrm{C}$. Weather data were acquired from the Department of Water Resources California Irrigation Management Information Systems (CIMIS) measured at Station (lat. 35.31, long. -120.66). This weather station was located on the California Polytechnic San Luis Obispo campus, roughly six kilometers north of the AFS. Appendix B provides time series data of San Luis Obispo's precipitation, solar radiation, and air temperatures.

\subsection{N and P Removal from Ponds in Series- Experiment I}

The Ponds in Series- Experiment I in this thesis was a continuation of the Ponds in Series experiment in Rodrigues (2013) thesis titled: Experiment II: Ponds in Series. As discussed in Section 3.2.5.1.1, the objective was to evaluate the nitrogen and phosphorus removal performance from raceway ponds operating in series. The triplicate Round 1 ponds (Beta ponds) served as the first round of treatment, which had a 3-day HRT, and received primary clarifier effluent as its influent. The triplicate Round 2 ponds (Alpha ponds) served as the second round of treatment. They operated at a 4-day HRT, and received Round 1 pond effluent after solids separation (see Figure 3-14a for a process flow schematic). Round 2 ponds were expected to have higher nutrient removal efficiencies compared to Round 1.

Round 2 ponds received $\mathrm{CO}_{2}$ supplementation via sparging but Round 1 ponds did not. The spargers were located roughly 0.3 meters upstream of the paddlewheels. The $\mathrm{CO}_{2}$ 
diffusers functioned on independent solenoids programmed to turn on at a $\mathrm{pH}$ of 8.5 and turn off when $\mathrm{pH}$ reached 8.4 .

The duration of this experiment was March 6, 2013 to June 13, 2013. Across these months the average solar radiation was $276 \mathrm{~W} / \mathrm{m}^{2}$, with a maximum and minimum monthly average of 308 and $215 \mathrm{~W} / \mathrm{m}^{2}$, respectively. Monthly average air temperatures ranged from $12-17^{\circ} \mathrm{C}$.

\subsubsection{Temperature, $\mathrm{pH}$, and DO}

The Neptune data-logging system malfunctioned and no data were collected during this experiment. The temperatures of the ponds during March 2013 - June 2013 were estimated by comparing months with similar average ambient temperatures that had recorded SCADA pond temperature data.

The $\mathrm{pH}$ of the ponds was not recorded for the same issue stated above. However, the SCADA system was still successfully controlling $\mathrm{CO}_{2}$ addition using $\mathrm{pH}$ setpoints of 8.4 to 8.5 in the Round 2 set. Based on the initial $\mathrm{pH}$ values recorded during alkalinity testing, the $\mathrm{pH}$ values in the Round 1 and 2 ponds ranged between 7.0 and 8.5.

Dissolved oxygen also was not recorded.

\subsubsection{Nitrogen Removal}

Round 1 achieved an average TAN removal efficiency of $88 \%$ throughout the experiment, with a maximum of 93\% measured on March 13, April 18, and June 13, 2013. The lowest solar radiation measurement of $215 \mathrm{~W} / \mathrm{m}^{2}$ occurred on March 6, 2013 when the lowest Round 1 removal efficiency of $75 \%$ was measured corresponding to a concentration of $9.1 \mathrm{mg} / \mathrm{L}-\mathrm{N}$. Round 2 achieved an average TAN removal efficiency of 
nearly $100 \%$, a $12 \%$ increase from Round 1 . The maximum TAN concentration in Round 2 effluent was $0.8 \mathrm{mg} / \mathrm{L}-\mathrm{N}$, measured on April 25, 2013 (Table 4-2). Out of the 14 weeks of data collection, Round 2 achieved nearly $100 \%$ removal efficiencies for 11 weeks with TAN concentrations of less than $0.2 \mathrm{mg} / \mathrm{L}-\mathrm{N}$ (Figure 4-1). The Round 2 effluent TAN concentrations did not increase during spikes in the influent measured on March 13 and April 4, 2013. This lack of sensitivity to influent spikes demonstrated the reliability of the TAN removal performance for this experiment.

Table 4-2: TAN removal efficiencies in Round 1 and 2 ponds during March 6, 2013 to June 13, 2013.

\begin{tabular}{lccc} 
& Influent & Round 1 & Round 2 \\
\hline Avg. TAN (mg/L-N) & 39 & 4.8 & 0.1 \\
Avg. \% Removal & - & $88 \%$ & $\sim 100 \%$ \\
Standard Deviation & 5 & $4.8 \%$ & $0.6 \%$ \\
of \% Removal & - & 4.53 & 0.02 \\
25th Percentile & - & 5.85 & 0.16 \\
75th Percentile & 31 & 2.3 & $<0.1$ \\
Min. TAN (mg/L-N) & 49 & 9.1 & 0.8 \\
Max. TAN (mg/L-N) & & & \\
\hline
\end{tabular}




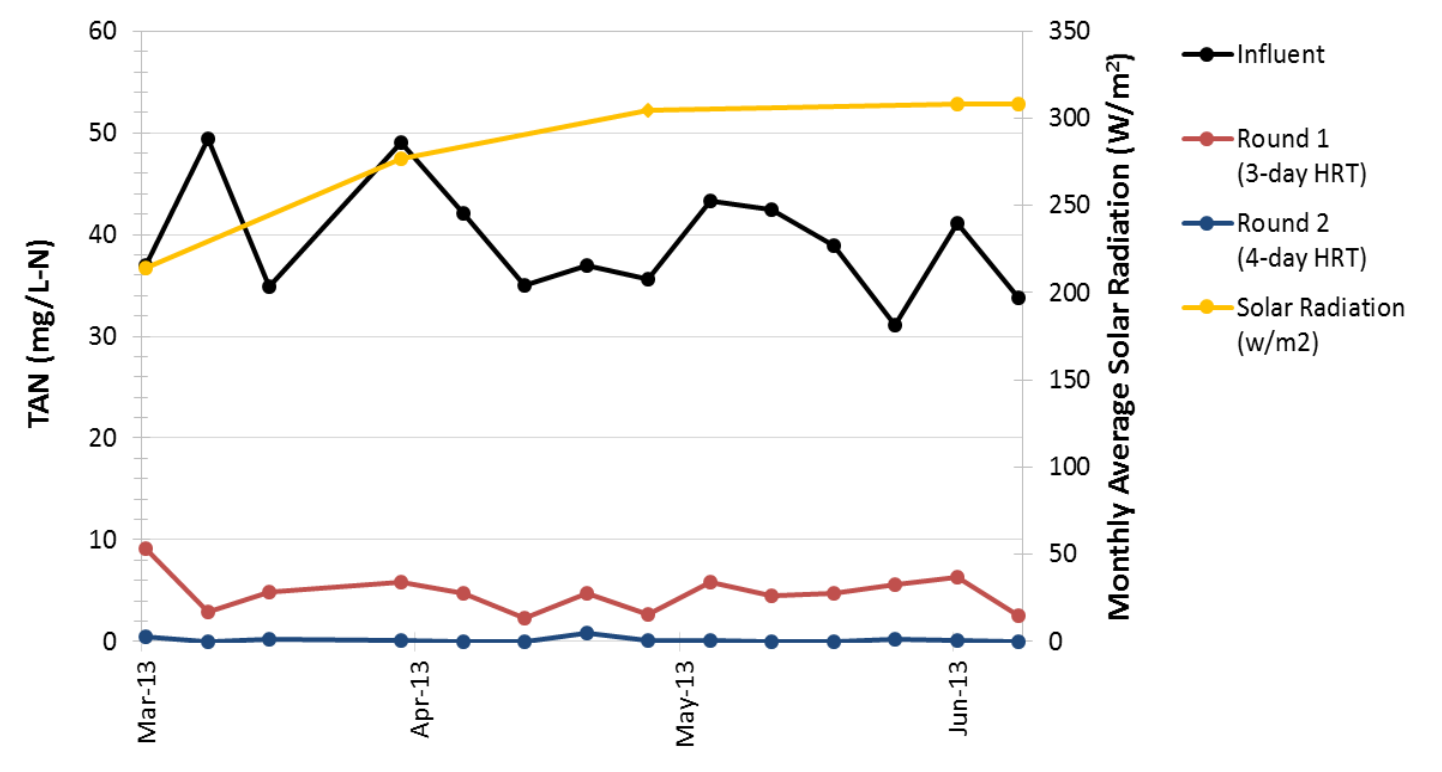

Figure 4-1: TAN removal from two rounds of treatment. The Influent line corresponds to the primary clarifier effluent distributed to Round 1 Beta ponds. Pond TAN values are the mean of triplicate ponds.

Average nitrate nitrogen $\left(\mathrm{NO}_{3}{ }^{-}-\mathrm{N}\right)$ concentrations in Round 2 effluent remained lower than Round 1, with the exception of the March 6 and June 6, 2013 samples (Table 4-3). For seven out of the fourteen weeks of experimentation, average Round 2 effluent concentrations were at least $25 \%$ less than Round 1 (Figure 4-2).

Potential nitrate removal processes were denitrification or assimilation. The potential for denitrification increased at night when photosynthetic oxygenation ceased, allowing DO to drop, potentially to anoxic levels. Although DO data were not recorded in this experiment due to data-logger malfunction (Section 4.3.1), the recorded nighttime DO levels in the Round 1 ponds during September 2013 - August 2014, under the same loading conditions, were used to determine if Round 1 ponds became anoxic at night. The September 2013 - August 2014 DO data showed Round 1 ponds consistently reached 0\% 
saturation from $10 \mathrm{pm}$ to $5 \mathrm{am}$. The continuous feed of primary clarifier effluent into Round 1 ponds provided BOD loading at night that could have fueled denitrification. Round 2 ponds remained above 30\% saturation at night in the September 2013 to August 2014 data set suggesting that denitrification was unlikely. Thus, the nitrate removal in Round 2 was likely caused by assimilation.

Table 4-3: Nitrate nitrogen concentrations $(\mathrm{mg} / \mathrm{L}-\mathrm{N})$ in the Round 1 and 2 pond effluent during March 3, 2013 to June 13, 2013.

\begin{tabular}{lcc} 
& Round 1 & Round 2 \\
\hline Avg. $\mathrm{NO}_{3}-\mathrm{N}$ & 12.8 & 10.1 \\
Standard Deviation & 3.0 & 2.5 \\
25th Percentile & 11.0 & 9.7 \\
75th Percentile & 14.8 & 11.5 \\
Min. $\mathrm{NO}_{3}^{-}-\mathrm{N}$ & 7.8 & 4.3 \\
Max. $\mathrm{NO}_{3}{ }^{-}-\mathrm{N}$ & 18.1 & 14.1 \\
\hline
\end{tabular}

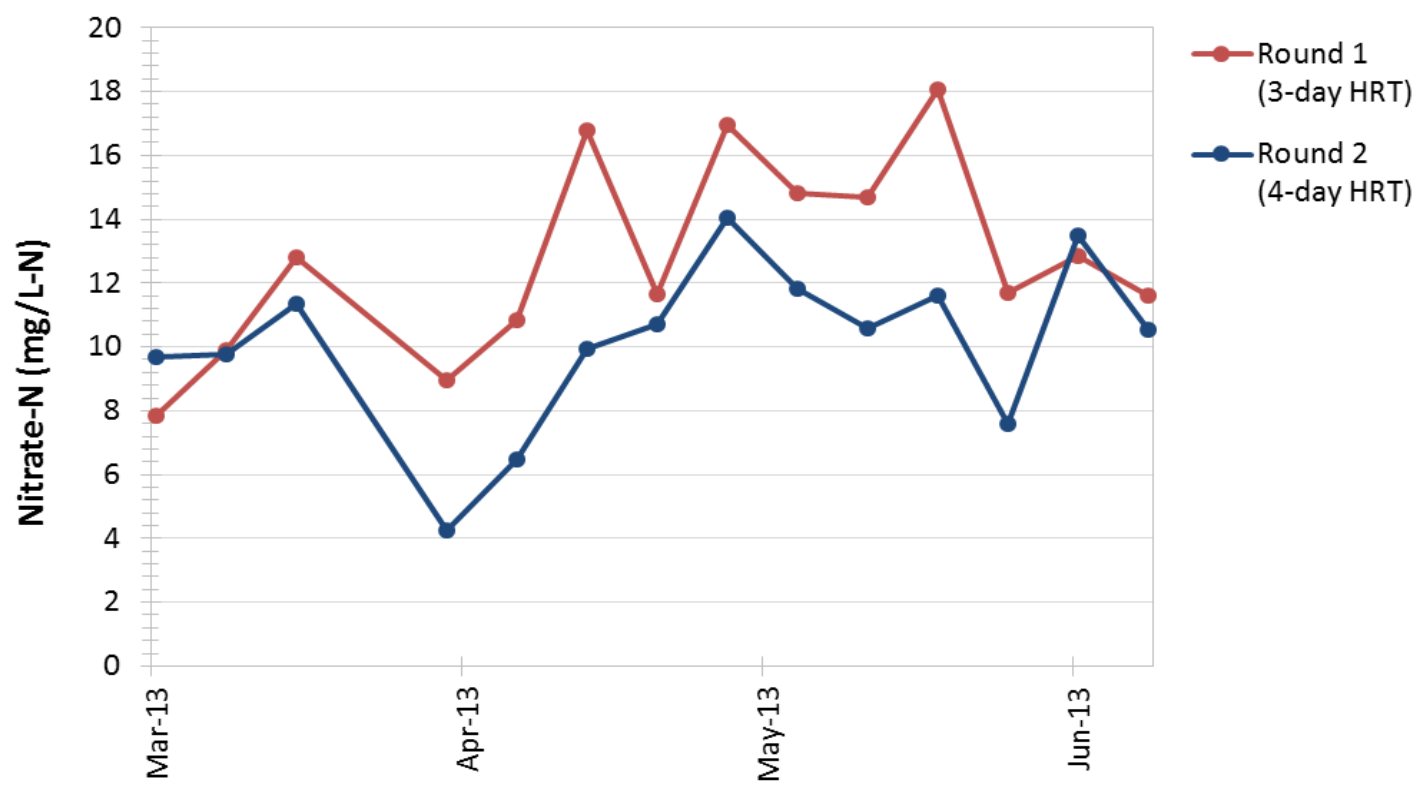

Figure 4-2: Nitrate nitrogen concentrations in Round 1 and 2 effluent. The Influent nitrate nitrogen concentration varied between 0.1 to $2.0 \mathrm{mg} / \mathrm{L}-\mathrm{N}$. 
The average nitrite nitrogen $\left(\mathrm{NO}_{2}^{-}-\mathrm{N}\right)$ concentrations in Round 2 remained lower than Round 1 throughout the experiment (Table 4-4 below). Average concentrations in Round 2 were at least 2.5-times less than Round 1, with the exception of April 18, 2013 when Round 2 was $23 \%$ less. On that date, Round 2 average nitrite concentration spiked at 0.5 mg/L-N, while Round 1 decreased concentration from the previous week. The June 6 , 2013 spike in Round 1 to $3.2 \mathrm{mg} / \mathrm{L}-\mathrm{N}$ corresponded with a small increase in Round 2 of $0.5 \mathrm{mg} / \mathrm{L}-\mathrm{N}$ (Figure 4-3). The decreased nitrite nitrogen concentrations in Round 2 were likely caused by further nitrification from nitrite to nitrate within the Round 2 ponds.

Table 4-4: Nitrite nitrogen concentrations (mg/L-N) in Round 1 and 2 effluent during March 6, 2013 to June 13, 2013.

\begin{tabular}{lcc} 
& Round 1 & Round 2 \\
\hline Avg. $\mathrm{NO}_{2}-\mathrm{N}$ & 1.2 & 0.2 \\
Standard Deviation & 0.8 & 0.1 \\
25th Percentile & 0.7 & 0.1 \\
75th Percentile & 1.3 & 0.3 \\
Min. $\mathrm{NO}_{2}^{-}-\mathrm{N}$ & 0.5 & 0.1 \\
Max. $\mathrm{NO}_{2}^{-}-\mathrm{N}$ & 3.2 & 0.5 \\
\hline
\end{tabular}




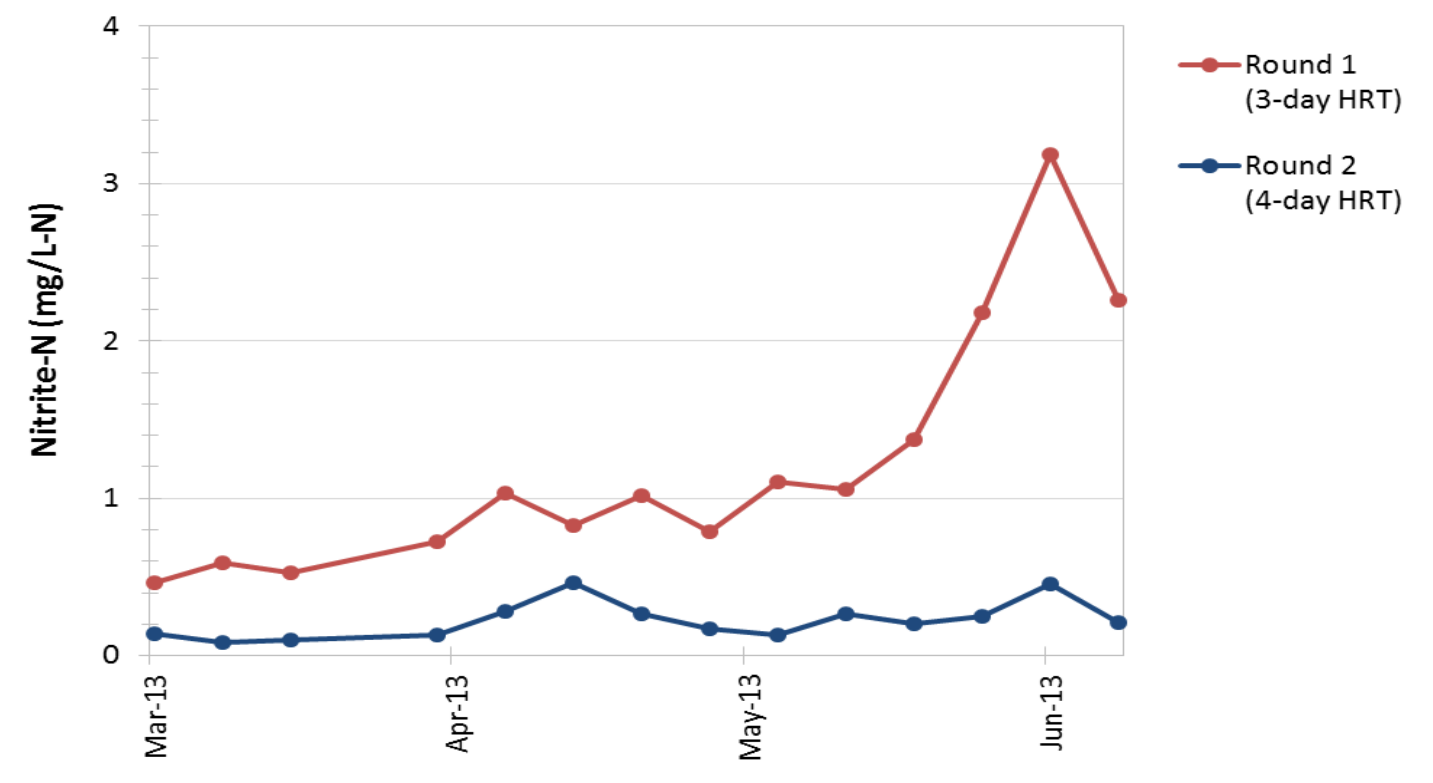

Figure 4-3: Nitrite nitrogen concentrations in Round 1 and 2 effluent. The Influent nitrite nitrogen concentration varied between 0.1 and $<0.1 \mathrm{mg} / \mathrm{L}-\mathrm{N}$.

Organic nitrogen was calculated using TAN and TKN results (Section 3.4.1.5). With all forms of nitrogen measured, a nitrogen mass balance for the Round 1 and 2 ponds was useful to illustrate the fate of influent nitrogen, including losses. $76 \%$ of the influent soluble nitrogen was converted to organic nitrogen via assimilation by algae (Figure 44).

Nitrogen losses occur from ammonia volatilization and denitrification processes. Mass balance bar graphs were used to determine if nitrogen losses occurred from these two processes, indicated by a gap between in the Influent bar and Round 1 and 2 effluent bars. Ammonia volatilization potential is affected by $\mathrm{pH}$ values, which were in the 8.4 to 8.5 range. Nighttime DO levels of $0 \%$ and a continuous BOD loading in Round 1 fueled the potential for denitrification to occur. Denitrification in Round 2 was deemed unlikely due to residual nighttime DO and low BOD. Total influent nitrogen losses of $6 \%$ occurred in 
Round 1 . Relatively no further losses occurred in Round 2, which was $\mathrm{pH}$ controlled by $\mathrm{CO}_{2}$ supplementation. (Figure 4-4). The amount of organic nitrogen removed from the Round 1 effluent by the tube settlers was estimated from the difference in the VSS concentration across the tube settlers.

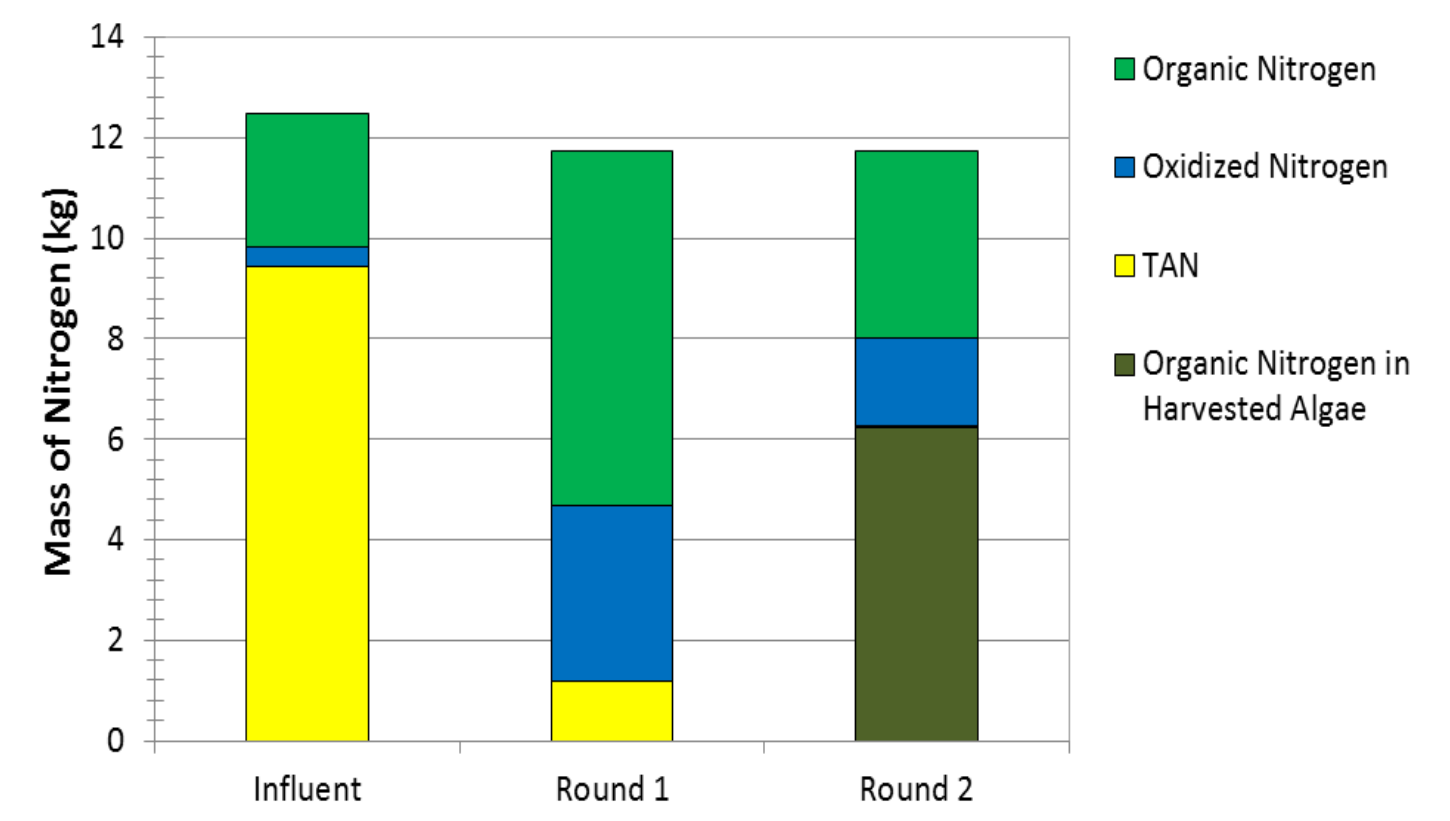

Figure 4-4: Nitrogen mass balance on the Round 1 and 2 pond sets during March 6 to June 13, 2013. The influent bar refers to the primary clarifier effluent, which served as the influent to Round 1 ponds. Oxidized nitrogen is the sum of the nitrate and nitrite concentrations. Round 2 received Round 1 effluent after solids separation (algae harvesting). The gap of about $0.8 \mathrm{~kg}$ was

likely due to ammonia volatilization in the Round 1 ponds. The amount of organic nitrogen removed with the slurry harvested from the tube settlers was estimated from the difference in VSS concentration across the tube settlers.

\subsubsection{Dissolved Reactive Phosphorus Removal}

Dissolved reactive phosphorus (DRP) was the form of soluble phosphorus measured for the experiments in this thesis. Total phosphorus was not measured during this particular experiment. 
The primary phosphorus removal mechanism in raceway ponds is assimilation by microalgae. Since the pond volume and influent flow remained constant during the experiment, DRP concentration removal was directly proportional to new growth (VSS $\mathrm{Vet}_{\text {ne }}$. The phosphorus content in algae cells typically falls in the $0.5 \%$ to $1 \%$ range (Powell et al, 2008).

Round 1 achieved an average percent removal of 29\% from March 6 to June 13, 2013, resulting in an average DRP removal of $1.1 \mathrm{mg} / \mathrm{L}-\mathrm{P}$ (Table 4-5). The removal efficiencies increased to $40-50 \%$ in the last three weeks of the experiment, with removals of roughly $1.8 \mathrm{mg} / \mathrm{L}-\mathrm{P}$ (Figure 4-5). This $0.7 \mathrm{mg} / \mathrm{L}-\mathrm{P}$ increase in DRP removal did not correlate with a proportional increase in net VSS growth on the same sample days, suggesting that the phosphorus content in the biomass increased. The overall phosphorus percentage in the algae growth $\left(\mathrm{VSS}_{\text {net }}\right)$ was $0.5 \%$.

Round 2 achieved an average percent removal of $67 \%$ during this experiment, a $38 \%$ average removal increase over Round 1. This resulted in an average DRP removal of 1.3 mg/L-P from the Round 1 effluent. Unlike Round 1, this DRP removal of $1.3 \mathrm{mg} / \mathrm{L}-\mathrm{P}$ correlated with a proportional increase in Round 2 net VSS growth of roughly $130 \mathrm{mg} / \mathrm{L}$ from March 6, 2013 to June 13, 2013. The resulting ratio of P:VSS was 1\%, which is typical of algae biomass. The overall phosphorus percentage in the algae growth was 1.0\%. (Table 4-5).

Table 4-5: Dissolved reactive phosphorus (DRP) concentrations in Influent and Round 1 and 2 effluent during March 6, 2013 to June 13, 2013.

\begin{tabular}{lccc} 
& Influent & Round 1 Effluent & Round 2 Effluent \\
\hline Avg. DRP (mg/L-P) & 3.6 & 2.5 & 1.2 \\
Avg. \% Removal & - & $29 \%$ & $67 \%$ \\
Standard Deviation of \% & 0.2 & $11 \%$ & $21 \%$
\end{tabular}


Removal

25th Percentile (mg/L-P)

$\begin{array}{lll}- & 2.5 & 0.5\end{array}$

75th Percentile (mg/L-P)

2.7

1.8

Min DRP (mg/L-P)

3.2

1.8

0.4

Max DRP (mg/L-P)

4.1

2.9

2.4

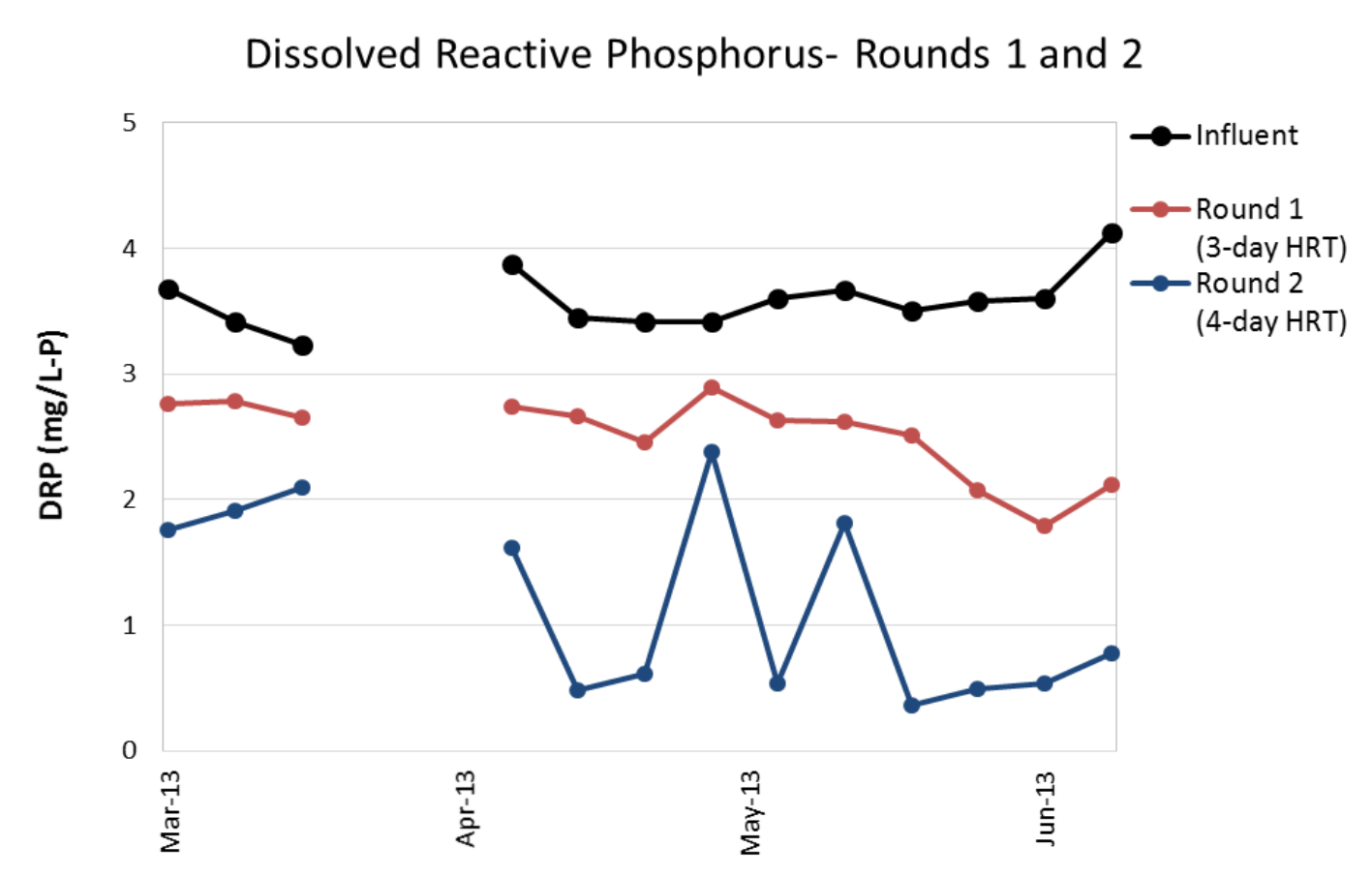

Figure 4-5: Dissolved reactive phosphorus (DRP) concentrations in Influent and Round 1 and 2 effluent.

\subsection{N and P Removal from Ponds in Series- Experiment II}

As in Experiment I, the objective of Experiment II was to determine the nitrogen and phosphorus removal performance by raceway ponds operating in series, but, unlike Experiment I, in Experiment II, the Round 2 residence time was three days instead of four days. Another difference in Experiment II, was that the effluents from the three Beta (Round 1) tube settlers were intermixed in the Alpha head tank prior to being distributed to the triplicate Alpha (Round 2) ponds. In Experiment I, the effluent from individual 
ponds in the Round 1 set were passed through tube settlers and into individual Round 2 ponds (see Figure 3-14b for process flow schematic). The $\mathrm{pH}$ setpoint for $\mathrm{CO}_{2}$ supplementation remained the same for the Round 2 ponds from Experiment I to Experiment II, but unlike Experiment I, the Round 1 ponds now also received $\mathrm{CO}_{2}$. The $\mathrm{pH}$ set points of 8.4 - 8.5 for $\mathrm{CO}_{2}$ supplementation remained unchanged.

Other nitrogen removal performance goals for Experiment II were to achieve consistent, year round TAN and soluble nitrogen (SN) effluent concentrations that comply with typical discharge limits set by the RWQCBs.

The data presented for Experiment II span June 26, 2013 to August 28, 2014. The rest of the Experiment II data will be reported in Reiff, 2015 (in preparation). For the present analysis, the data were separated into summer (June - October 2013, March - August 2014) and winter (November 2013 - February 2014).

For the winter months, the average solar radiation and air temperature were $136 \mathrm{~W} / \mathrm{m}^{2}$ and $13^{\circ} \mathrm{C}$, respectively. February 2014 was the only month that experienced significant precipitation at $13.4 \mathrm{~cm}$. For the summer months, the average solar radiation and air temperature were $275 \mathrm{~W} / \mathrm{m}^{2}$ and $17^{\circ} \mathrm{C}$, respectively. March 2014 was the only month that experienced significant precipitation at $6.0 \mathrm{~cm}$ (Figure 4-6). 


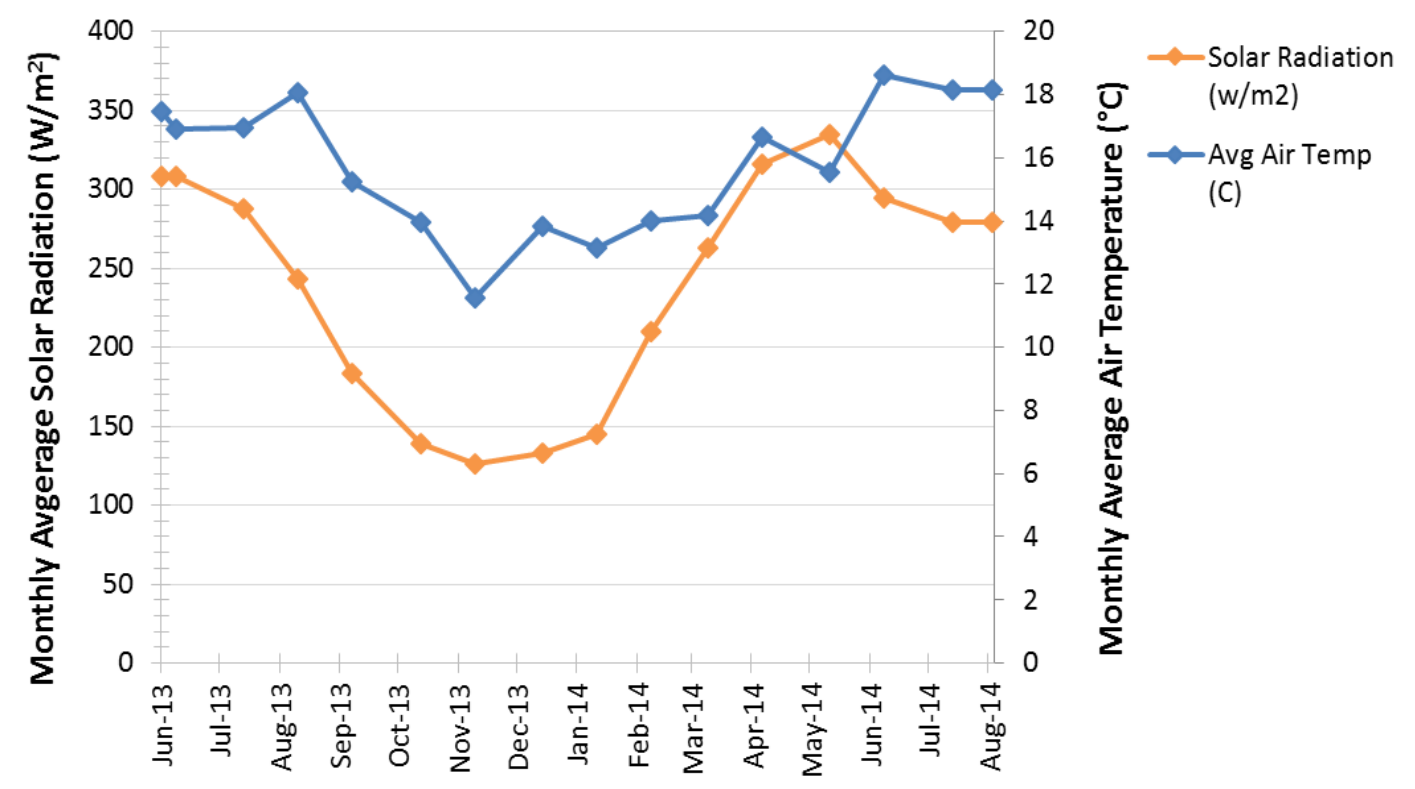

Figure 4-6: Monthly average solar radiation and air temperatures recorded by a CIMIS weather station in San Luis Obispo, Calif. See Methods chapter for details.

\subsubsection{Temperature, $\mathrm{pH}$, and DO}

A Neptune technician began fixing the data logging problems (Section 4.3.1.1) in September 2013, allowing the first collection of hourly DO and temperature readings. The $\mathrm{pH}$ data logging was fixed in November 2013. Although the data logging was fixed, the $\mathrm{pH}$ and $\mathrm{DO}$ probes periodically malfunctioned. This resulted in missing periods of recorded $\mathrm{pH}$ and $\mathrm{DO}$ measurements until new parts were installed. However, calibrated data were collected for over $80 \%$ of the duration of Experiment II and manual probe checks were performed for verification of the automatic recordings.

Temperatures in the Round 1 and Round 2 ponds remained similar to each other through seasonal variations. Average water temperatures in both sets varied ranged between 18 $23^{\circ} \mathrm{C}$ in the summer months (July-October 2013, March-August 2014) and dropped to the $13-17^{\circ} \mathrm{C}$ range in winter months (November 2013-Febuary 2014). 
DO saturation levels in the ponds experienced diel oscillations (Figure 4-7). Average DO saturation in the afternoon varied between 150\% - 250\% and 250\%-350\% in Round 1 and Round 2 ponds, respectively. DO in the Round 1 ponds were typically consumed within two to three hours after sunset, while DO in the Round 2 ponds remained at 30\% - 80\% saturation overnight. Filamentous flocs often grew in Round 1 ponds, occasionally sticking to the DO membrane, possibly lowering the recorded measurements. Round 2 ponds did not produce large enough flocs to interfere with the probe.

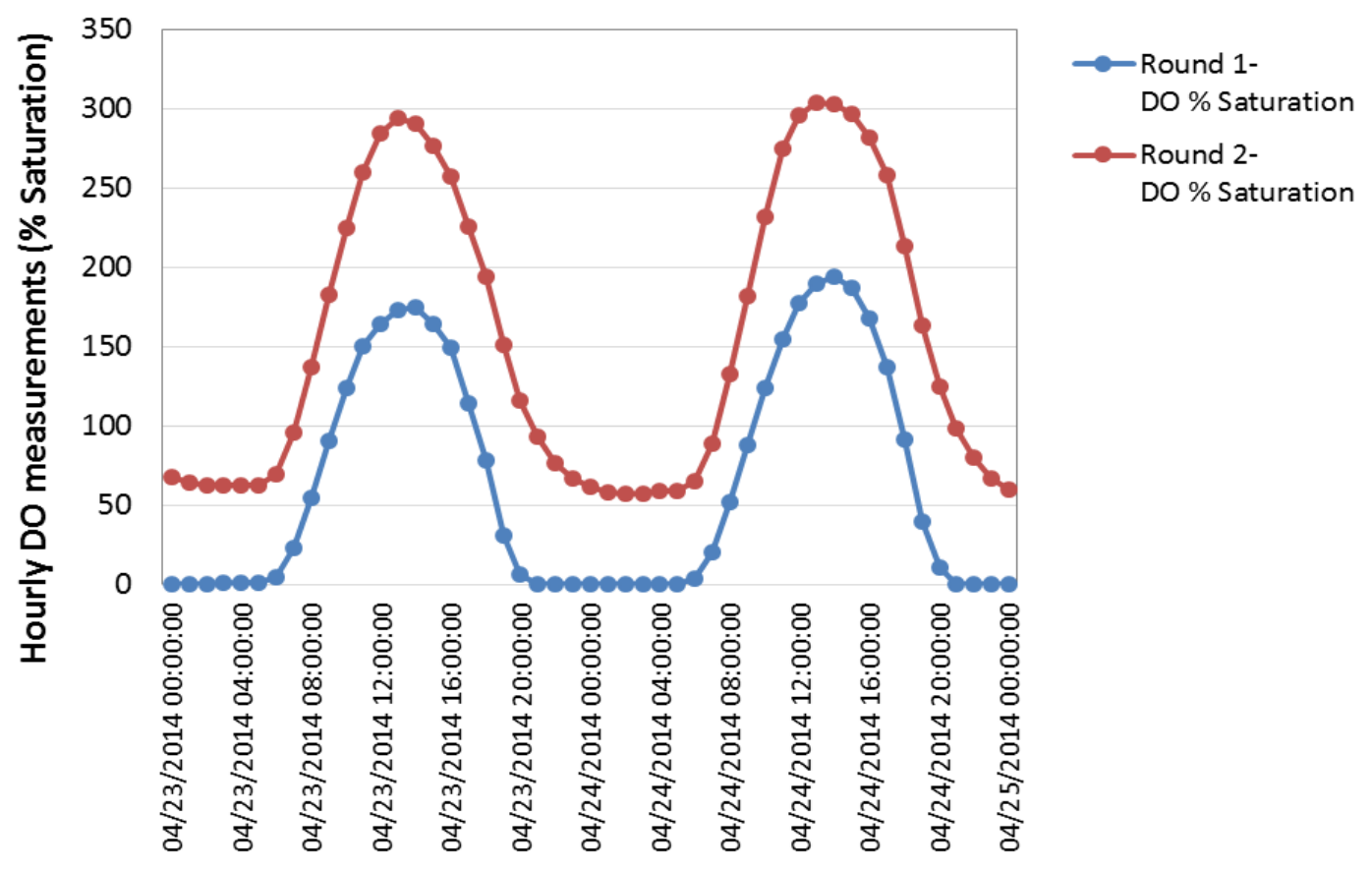

Figure 4-7: Hourly DO measurements from Round 1 and 2. These values represent an average of the triplicates. This figure provides an example of two days of diel oscillations for both rounds. The Neptune data logger recorded these measurements.

Round 1 and Round 2 ponds received $\mathrm{CO}_{2}$ supplementation at $\mathrm{pH}$ set points of 8.4 and 8.5 , triggered by the readings from the probes located in the ponds. The $\mathrm{pH} 8.5$ set point turned on the $\mathrm{CO}_{2}$ delivery, and 8.4 turned it off. Software problems, and fouled or damaged membranes occasionally produced unreliable readings. This issue often 
occurred to only one pond in the triplicate set at a time, and was resolved within a week. The unreliable recordings were dismissed from the data set. This typically occurred at least once a month. On rare occasions, these software problems resulted in delivering too much $\mathrm{CO}_{2}$ or not enough to the ponds, causing them to reach $\mathrm{pH}$ values of $6.0-6.5$. From the end of January 2014 to the beginning of March, a Neptune software issue resulted in Pond 3 receiving more $\mathrm{CO}_{2}$ than Ponds 1 and 2 (Ponds 1, 2, and 3 are the triplicate Round 2 ponds). This had a significant impact on net productivity between Pond 3 and Ponds 1 and 2, but not nutrient removal (see Chang, 2014 for net productivity comparison). During periods of no $\mathrm{CO}_{2}$ supplementation to the ponds, daytime $\mathrm{pH}$ levels, primarily in the summer, reached 9, with maximums as high as 9.5. However, when the software and probes worked correctly, $\mathrm{pH}$ levels did not increase above 8.6 - 8.7.

(Figure 4-8).

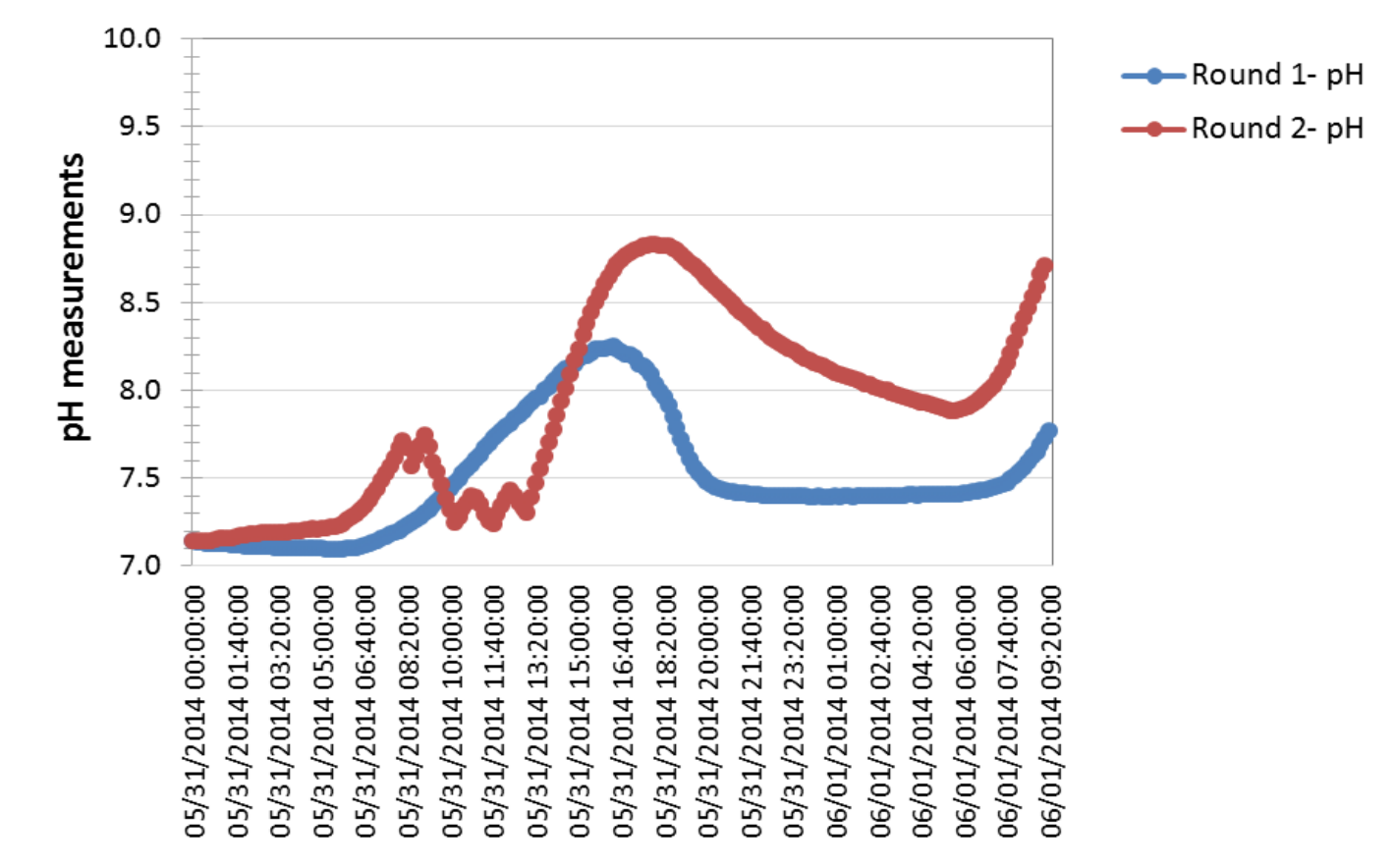

Figure 4-8: $\mathrm{pH}$ measurements taken at ten minute intervals from the Round 1 and 2 pond. These values represent an average of the triplicate ponds in each round. This figure only spans roughly two days to provide in example of the $\mathrm{pH}$ control provided by $\mathrm{CO}_{2}$ sparging. The $\mathrm{CO} 2$ was 
delivered by a $\mathrm{pH}$ reading of 8.5 , which prevented the $\mathrm{pH}$ levels from increasing to 9 . Neptune data logger recorded these measurements.

\subsubsection{Nitrogen Removal in Series Experiment II}

The Rounds 1 and 2 cumulative total ammonia nitrogen (TAN) summer removal efficiencies averaged $84 \%$ and nearly 100\%, respectively (Table 4-6). Round 2 in the summer achieved consistently high TAN removal efficiencies with an average pond effluent TAN concentration of $0.1 \mathrm{mg} / \mathrm{L}-\mathrm{N}$, and minimums of $<0.1 \mathrm{mg} / \mathrm{L}-\mathrm{N}$ recorded for 13 out of the 41 weeks of summer operation. The maximum Round 1 and 2 pond TAN concentrations peaked at 10.1 and $1.2 \mathrm{mg} / \mathrm{L}-\mathrm{N}$, respectively on July 17,2014 . This correlated with $\mathrm{pH}$ controller malfunction leading to unusually low $\mathrm{pH}$ levels of roughly 7.5 in the ponds, which may have decreased ammonia volatilization.

Decreased TAN removal performance in the winter correlated with lower solar radiation and air temperatures (Figure 4-9 and Figure 4-10). In Round 1, decreased winter TAN removal also correlated with lower DO concentrations and pond temperatures. Nitrification is, in part, a function of DO concentration and water temperature, thus low DO concentrations can reduce the amount of net nitrite and nitrate produced from ammonia. Round 2 ponds maximum daytime DO levels consistently stayed above $200 \%$ saturation, while Round 1 dropped to below 100\%. Assimilation and ammonia volatilization were likely the other primary mechanisms for ammonia removal besides nitrification. 
Table 4-6: Winter and summer average TAN removal efficiencies and concentrations from the Influent and Round 1 and 2 effluent. The duration of the experiment was June 2013 - August 2014. Summer and winter months are March - October and November - February, respectively.

Influent

Round 1

Round 2

\begin{tabular}{lcccccc}
\hline & Winter & Summer & Winter & Summer & Winter & Summer \\
\hline Avg. TAN (mg/L-N) & 34 & 37 & 20.1 & 5.6 & 3.7 & 0.15 \\
$\begin{array}{l}\text { Avg. \% Removal } \\
\text { Standard Deviation }\end{array}$ & - & - & $41.4 \%$ & $84 \%$ & $88 \%$ & $100 \%$ \\
of \% Removal & 4 & 8 & $20.5 \%$ & $7.6 \%$ & $13.8 \%$ & $0.7 \%$ \\
25th Percentile & - & - & 14.7 & 3.9 & 1.0 & 0.04 \\
75th Percentile & - & - & 24.3 & 7.2 & 4 & 0.13 \\
Min. TAN (mg/L-N) & 27 & 22 & 9.1 & 2.1 & 0.3 & 0.0 \\
Max. TAN (mg/L-N) & 42 & 53 & 34 & 10.1 & 15.2 & 1.2 \\
\hline
\end{tabular}

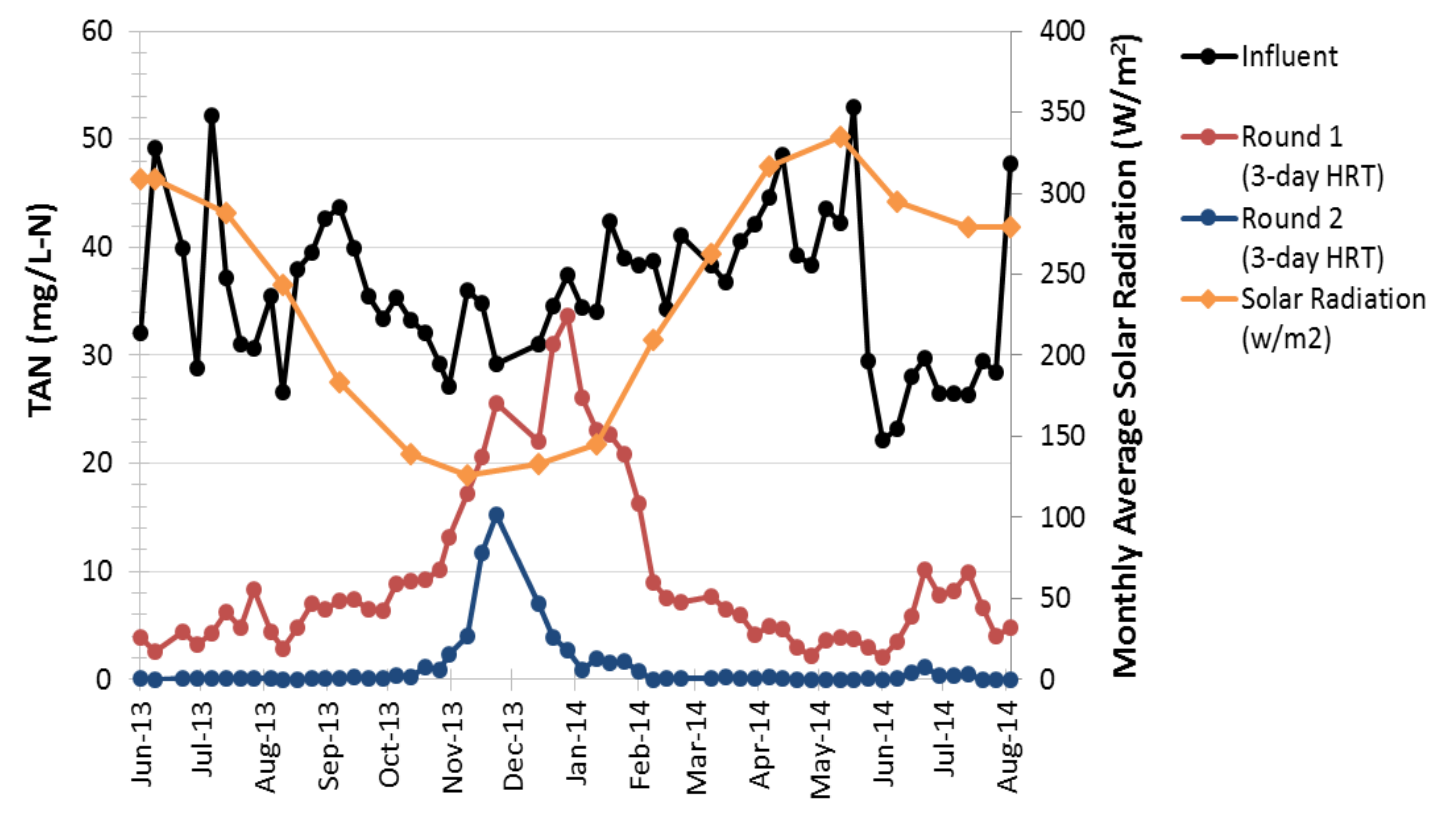

Figure 4-9: Monthly average solar radiation and total ammonia nitrogen (TAN) concentrations of Influent and Round 1 and 2 effluents during June 2013 - August 2014. 


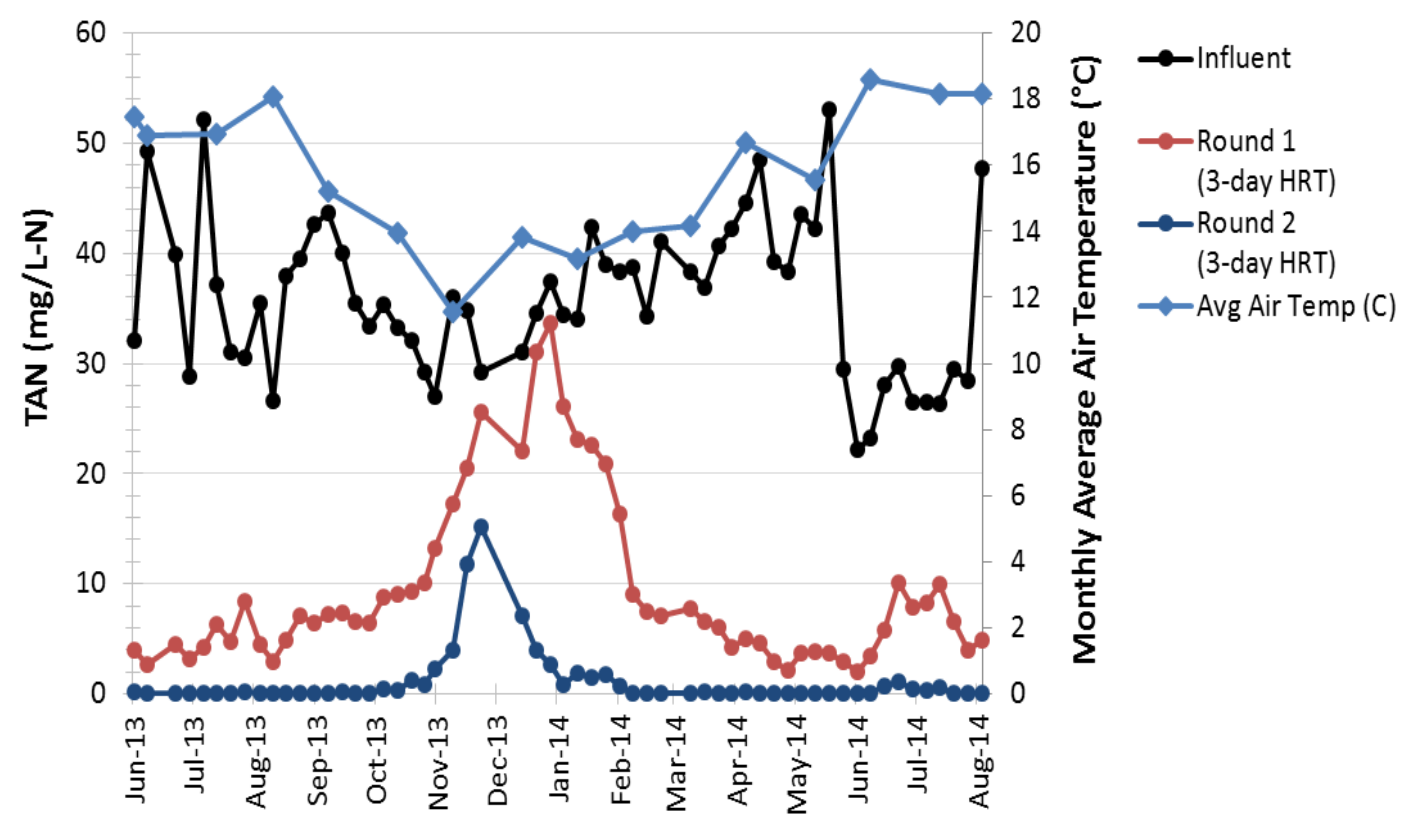

Figure 4-10: Monthly average air temperature and total ammonia nitrogen (TAN) concentrations of Influent and Round 1 and 2 effluents during June 2013 - August 2014.

A goal for Experiment II was to achieve consistent, year round TAN effluent

concentrations that complied with typical ammonia discharge limits set by a RWQCB.

For example, the City of Stockton, Calif., currently has an ammonia discharge limit of 2 mg/L-N (RWCF, n.d.). The Round 2 effluent succeeded at meeting this discharge limit for nearly $100 \%$ and $50 \%$ of the experimental duration in summer and winter, respectively (Table 4-7). Round 1 effluent did not meet this limit at any point during experimentation. The percentile graphs displayed in Figures 4-10 to 4-13 provide a quick reference to determine the seasonal probability of meeting a TAN discharge limit with one and/or two rounds of treatment each operating at a 3-day HRT.

Table 4-7: TAN concentration (mg/L-N) percentiles for meeting the Stockton, Calif. ammonia discharge limit of $2 \mathrm{mg} / \mathrm{L}-\mathrm{N}$ in both summer and winter months. The 25 th and 75 th percentiles are also shown.

\begin{tabular}{ccccc} 
& \multicolumn{2}{c}{ Round 1 Effluent } & \multicolumn{2}{c}{ Round 2 Effluent } \\
\hline & Winter & Summer & Winter & Summer \\
\hline 25th Percentile & 14.7 & 3.9 & 1.0 & 0.04
\end{tabular}


75th Percentile

24.3

7.2

4

0.13

Percentage meeting an example TAN discharge limit of $2 \mathrm{mg} / \mathrm{L}-\mathrm{N}$

$0 \%$

$0 \%$

$50 \%$

$\sim 100 \%$

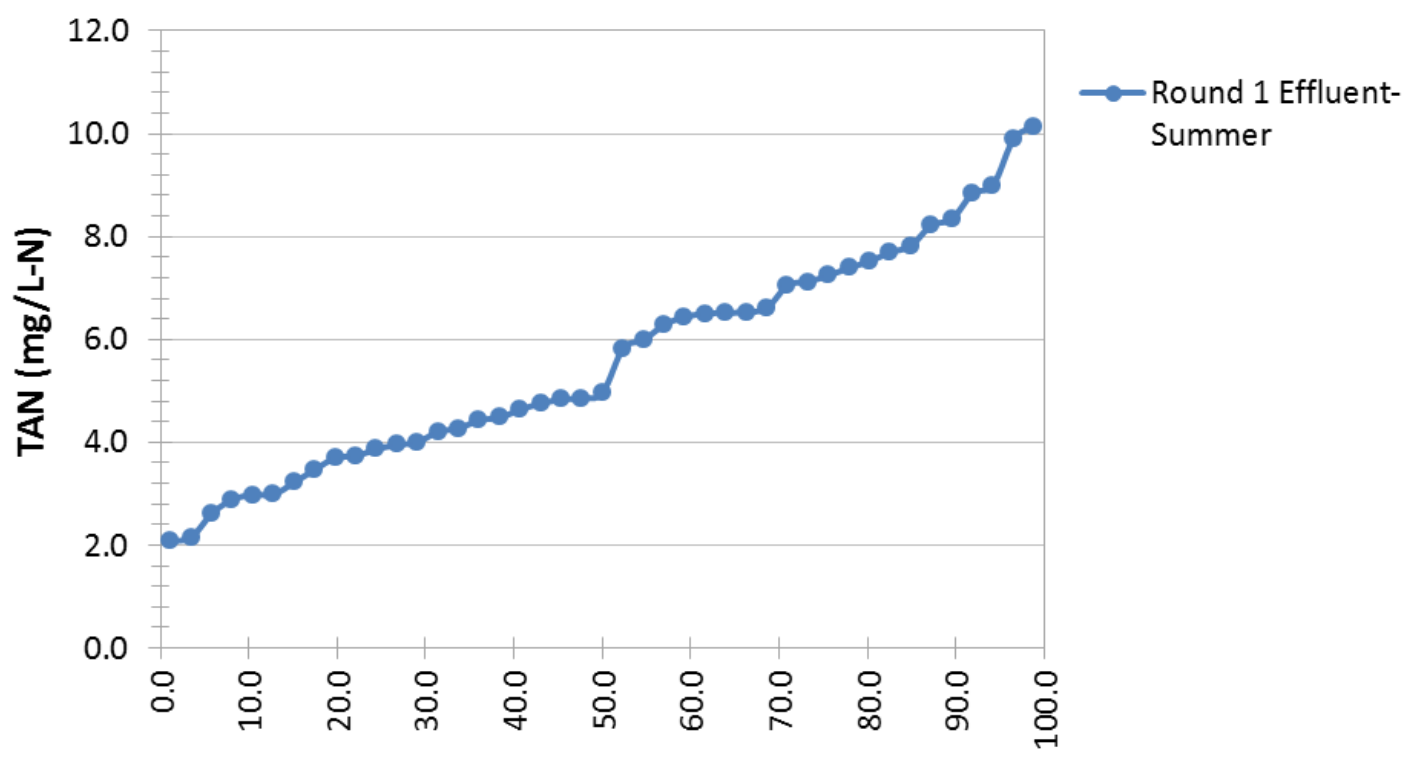

Percentage of values equal or less than indicated value

Figure 4-10: Probability plot for Round 1 effluent TAN concentrations in the summer months (June 2013 - October 2013, March 2014 - August 2014) operating at a three day residence time. 


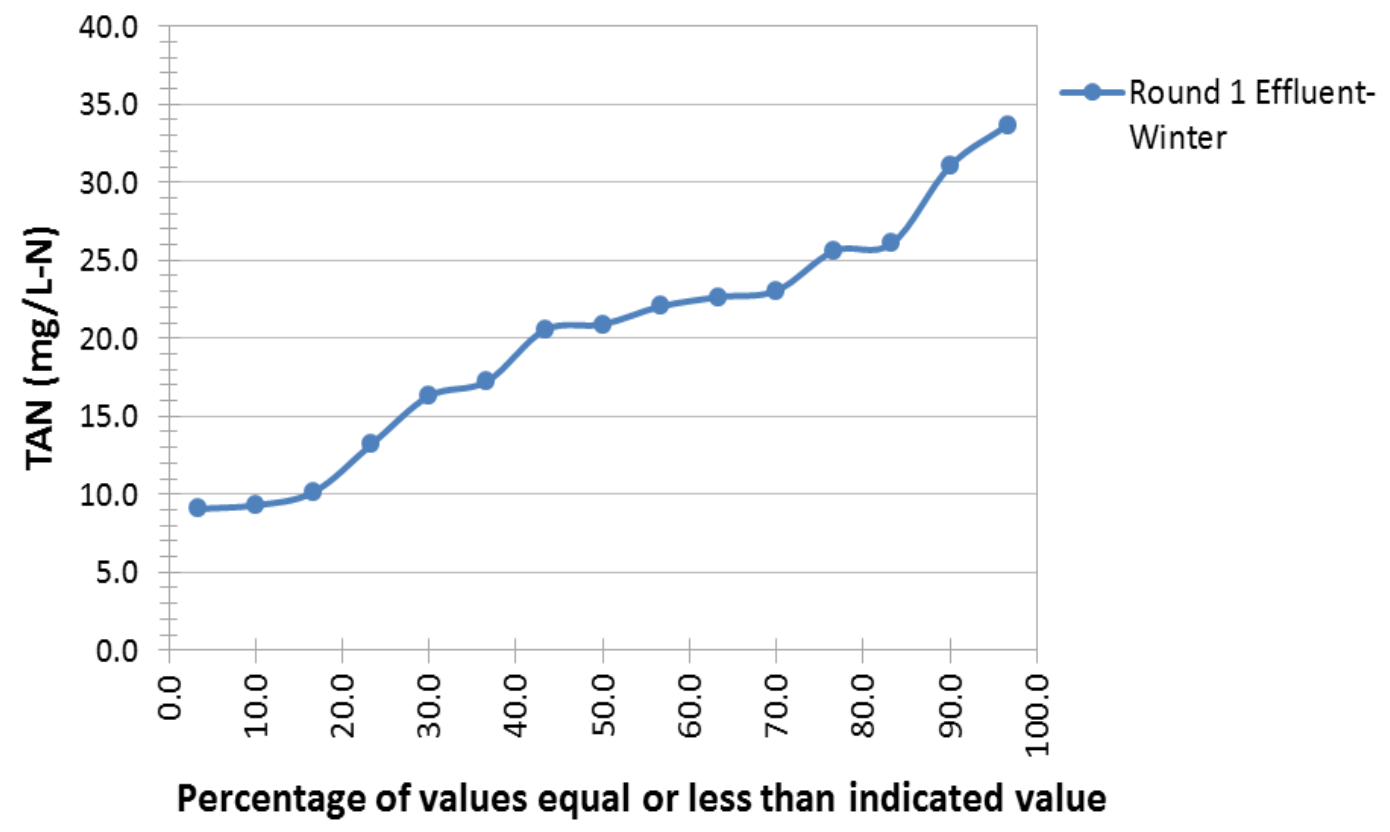

Figure 4-11: Probability plot for Round 1 effluent TAN concentrations during the winter months (November 2013 - February 2014) operating a three day residence time.

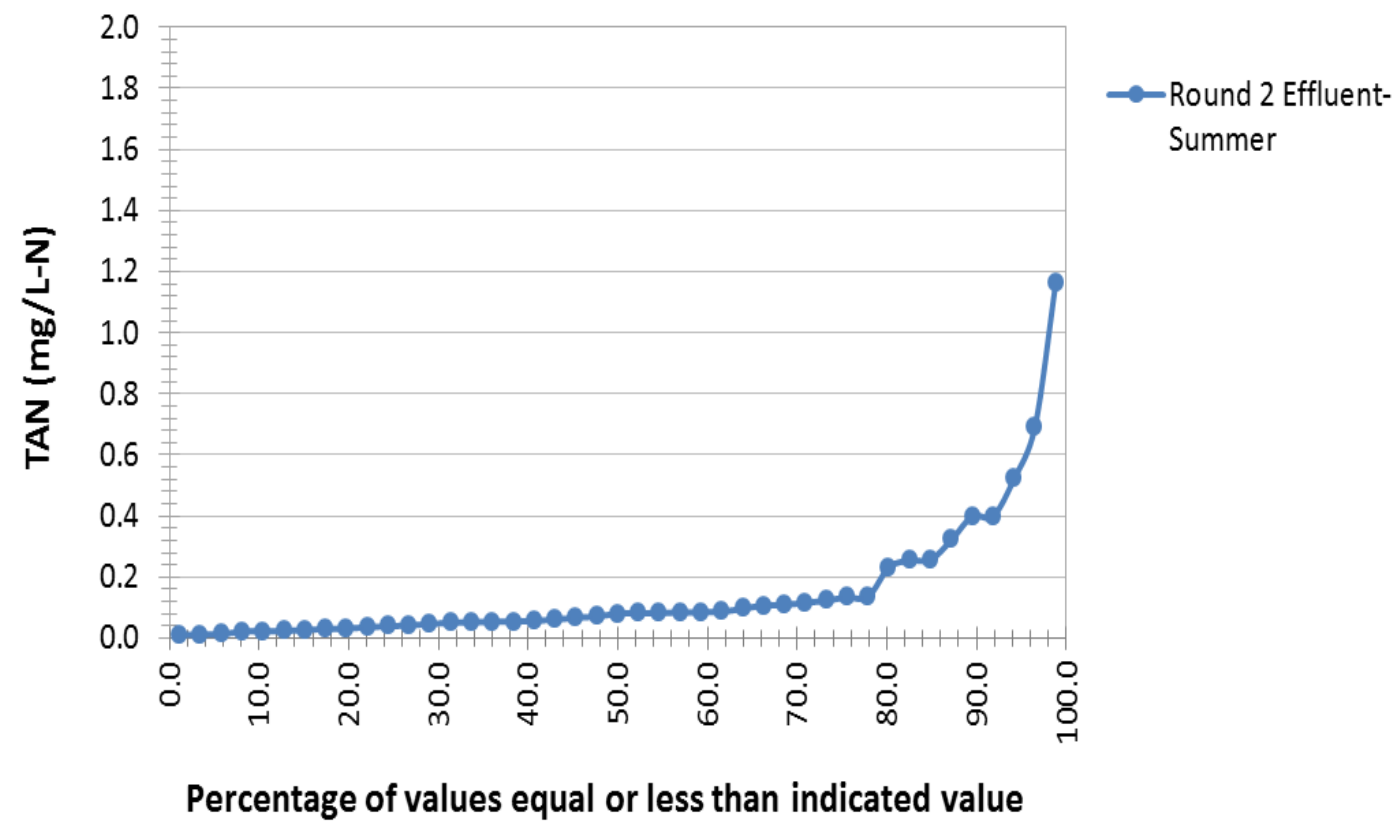

Figure 4-12: Probability plot for Round 2 effluent TAN concentrations in the summer months (June 2013 - October 2013, March 2014 - August 2014) operating at a three day residence time. 


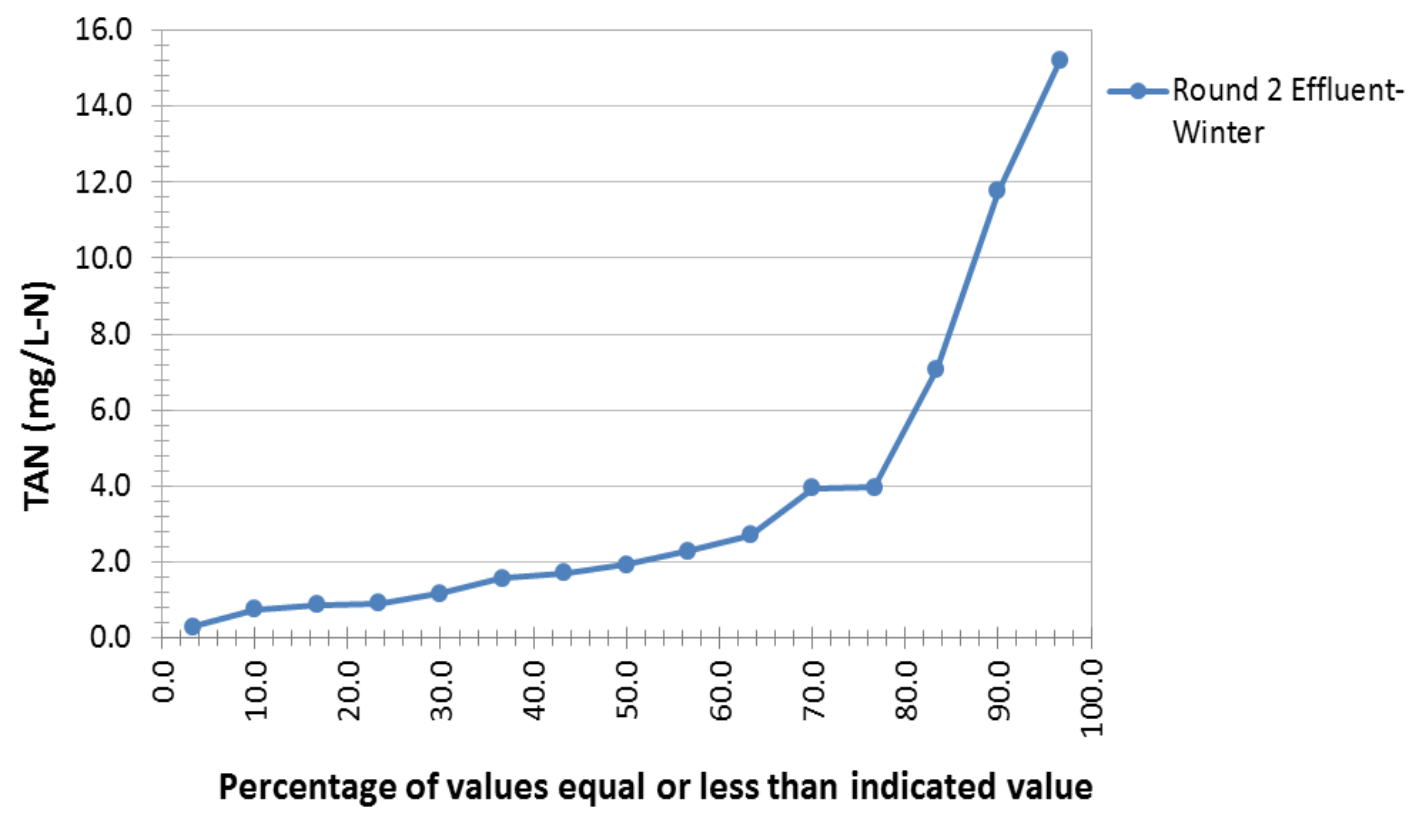

Figure 4-13: Probability plot for Round 2 effluent TAN concentrations during the winter months (November 2013 - February 2014) operating at a three day residence time.

The average summer nitrate nitrogen concentrations in Round 2 and Round 1 effluent were respectively 6.4 and $10.3 \mathrm{mg} / \mathrm{L}-\mathrm{N}$, resulting in an average increased removal of $61 \%$ from Round 2 (Table 4-8). The nitrate nitrogen concentrations in Round 2 effluent exceeded Round 1 effluent concentrations for a total of four measurements during the summer months (June 2013 - October 2013, March 2014 - August 2014) (Figure 4-14).

In the winter months (November 2013 - February 2014), the average nitrate nitrogen concentration in the Round 2 effluent was $4.5 \mathrm{mg} / \mathrm{L}-\mathrm{N}$ higher than the Round 1 effluent. It should be noted that the nitrate nitrogen concentrations in the Influent, Round 1, and Round 2 were not measured for five weeks out of the fifteen weeks of winter experimentation. During those five weeks, the nitrate ion selective electrode (Orion Model RO1-14563) was undergoing troubleshooting. 
The mechanisms of nitrate removal in raceway ponds are denitrification and assimilation. Denitrification was possible in the Round 1 ponds because DO was typically consumed by respiration within two hours after sunset, and the continuous feed of primary clarifier effluent into the ponds provided BOD loading at night. However, Round 2 ponds likely did not achieve denitrification because their nighttime DO levels never decreased below $30 \%$ saturation and its BOD loading was minimal. Thus ruling out denitrification in Round 2, the additional average nitrate removal of $61 \%$ in summer was likely from assimilation by microalgae. Microalgae prefer ammonia over nitrate as their nitrogen source, but Round 2 TAN concentrations were consistently below $0.5 \mathrm{mg} / \mathrm{L}-\mathrm{N}$, with a majority of the weeks measured at $<0.1 \mathrm{mg} / \mathrm{L}-\mathrm{N}$. With no ammonia to consume, nitrate was the next nitrogen source for microalgae to continue growth. The average concentration of volatile suspended solids (VSS) in Round 2 ponds remained close to Round 1 ponds, which was ammonia-rich (Figure 4-15), which probably indicates that generally the algae grew up to light limitation in both the Round 1 and 2 sets.

Table 4-8: Winter and summer nitrate nitrogen concentrations (mg/L-N) in the Influent and Round 1 and 2 effluent. The winter and summer months are November - February and March October, respectively. The duration of the experiment was June 2013 - August 2014.

\begin{tabular}{lcccccc} 
& \multicolumn{2}{c}{ Influent } & \multicolumn{2}{c}{ Round 1 Effluent } & Round 2 Effluent \\
\hline & Winter & Summer & Winter & Summer & Winter & Summer \\
\hline Avg. $\mathrm{NO}_{3}{ }^{-}-\mathrm{N}$ & 0.6 & 1.2 & 7.5 & 10.3 & 12.0 & 6.4 \\
Standard Deviation & 0.1 & 0.9 & 3.9 & 3.5 & 3.4 & 4.3 \\
25th Percentile & - & - & 4.6 & 7.7 & 11.6 & 2.8 \\
75th Percentile & - & - & 9.6 & 12.7 & 13.2 & 10.0 \\
Min. $\mathrm{NO}_{3}{ }^{-}-\mathrm{N}$ & 0.4 & 0.2 & 0.6 & 4.0 & 4.0 & 0.5 \\
Max. $\mathrm{NO}_{3}-\mathrm{N}$ & 0.8 & 5.0 & 14.7 & 17.6 & 17.9 & 15.6 \\
\hline
\end{tabular}




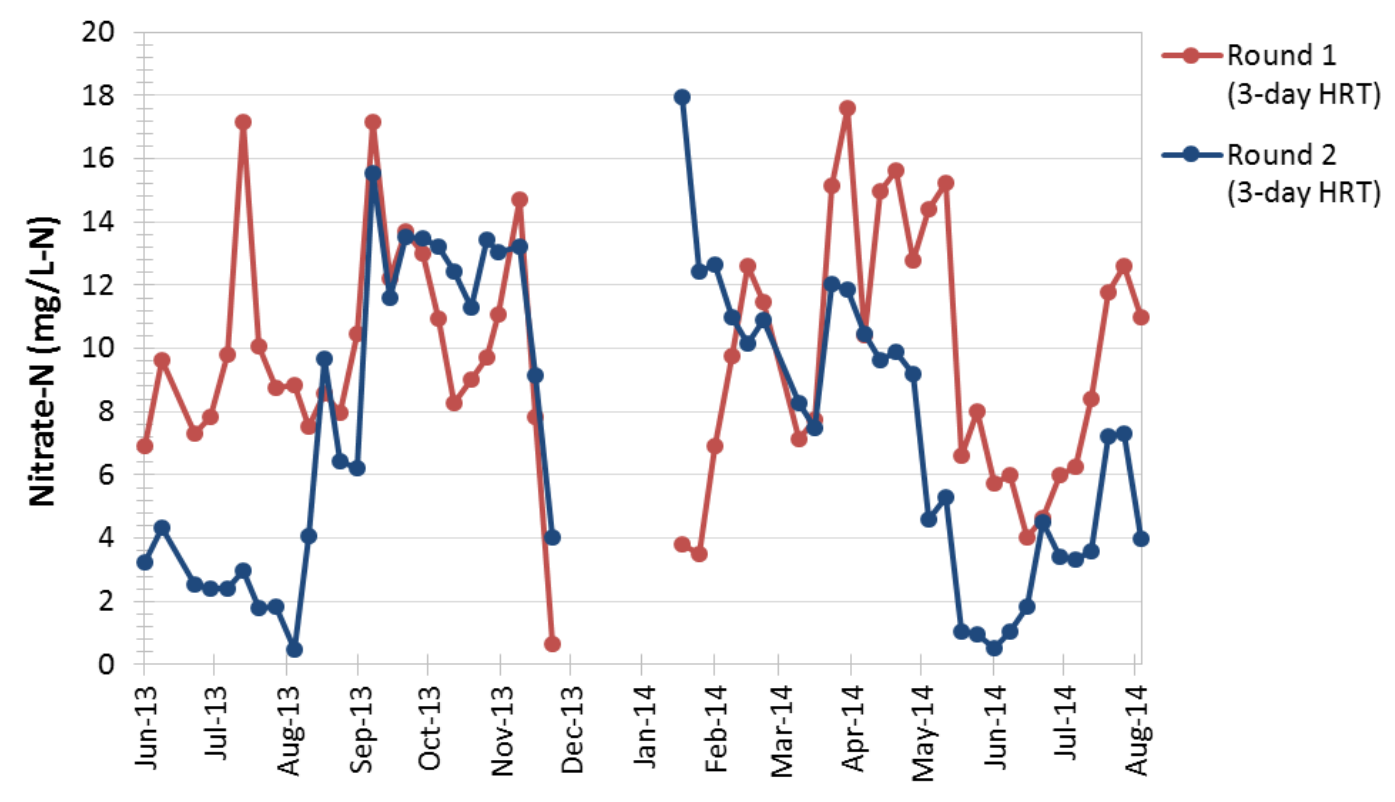

Figure 4-14: Nitrate nitrogen concentrations in Round 1 and 2 effluent. The Influent nitrate nitrogen concentration varied between 0.2 to $3.6 \mathrm{mg} / \mathrm{L}-\mathrm{N}$.

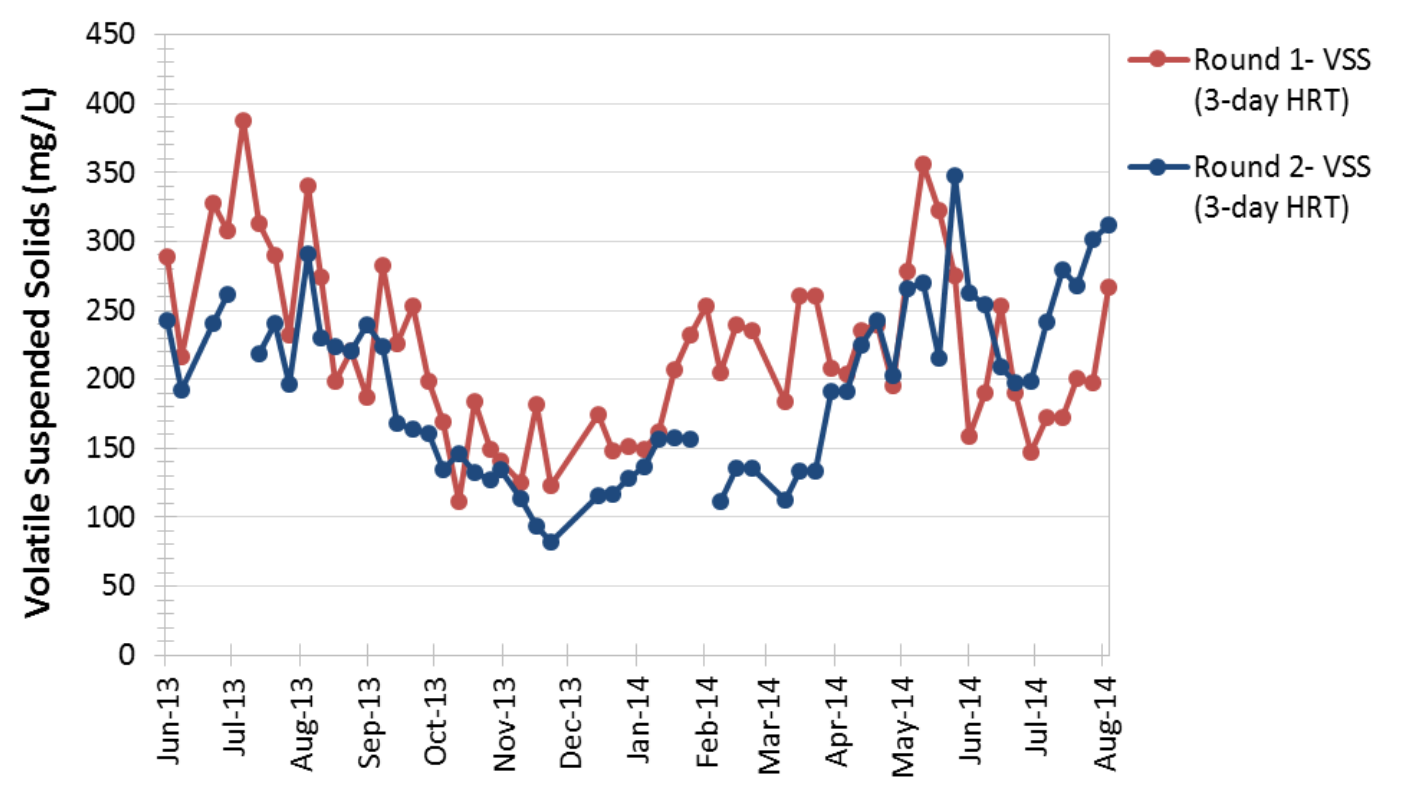

Figure 4-15: Volatile suspended solids (VSS) concentrations in Round 1 and 2 effluent. 
The average summer Round 2 effluent nitrite nitrogen concentration was 5-times lower than Round 1 effluent, while in winter it was 2.6-times lower (Table 4-9). The spikes in Round 1 effluent corresponded to low DO concentrations, during periods of decline in algae productivity (Figure 4-16). Without sufficient oxygen, incomplete nitrification can occur resulting in nitrite accumulation. The additional in nitrite removal from the second round of treatment was likely caused by further nitrification to nitrate. The DO in the Round 2 ponds was in excess, with levels rarely decreased below $150 \%$ saturation, with the average roughly $250 \%$ in both summer and winter.

Table 4-9: Winter and summer nitrite nitrogen concentrations (mg/L-N) of Influent and Round 1 and 2 effluent. Round 1 and 2 effluent values are averages of their respective triplicate ponds. Winter and summer months are November - February and March - October, respectively. The duration of the experiment was June 2013 - August 2014.

\begin{tabular}{lcccccc} 
& \multicolumn{2}{c}{ Influent } & \multicolumn{2}{c}{ Round 1 Effluent } & Round 2 Effluent \\
\hline & Winter & Summer & Winter & Summer & Winter & Summer \\
\hline Avg. $\mathrm{NO}_{2}{ }^{-}-\mathrm{N}$ & 0.0 & 0.0 & 1.3 & 1.0 & 0.5 & 0.2 \\
Standard Deviation & 0.0 & 0.0 & 0.9 & 0.6 & 0.2 & 0.2 \\
25th Percentile & - & - & 0.5 & 0.7 & 0.4 & 0.1 \\
75th Percentile & - & - & 2.1 & 1.1 & 0.5 & 0.2 \\
Min. $\mathrm{NO}_{2}-\mathrm{N}$ & 0.0 & 0.0 & 0.4 & 0.3 & 0.1 & 0.0 \\
Max. $\mathrm{NO}_{2}-\mathrm{N}$ & 0.1 & 0.3 & 3.5 & 3.4 & 0.8 & 1.2 \\
\hline
\end{tabular}




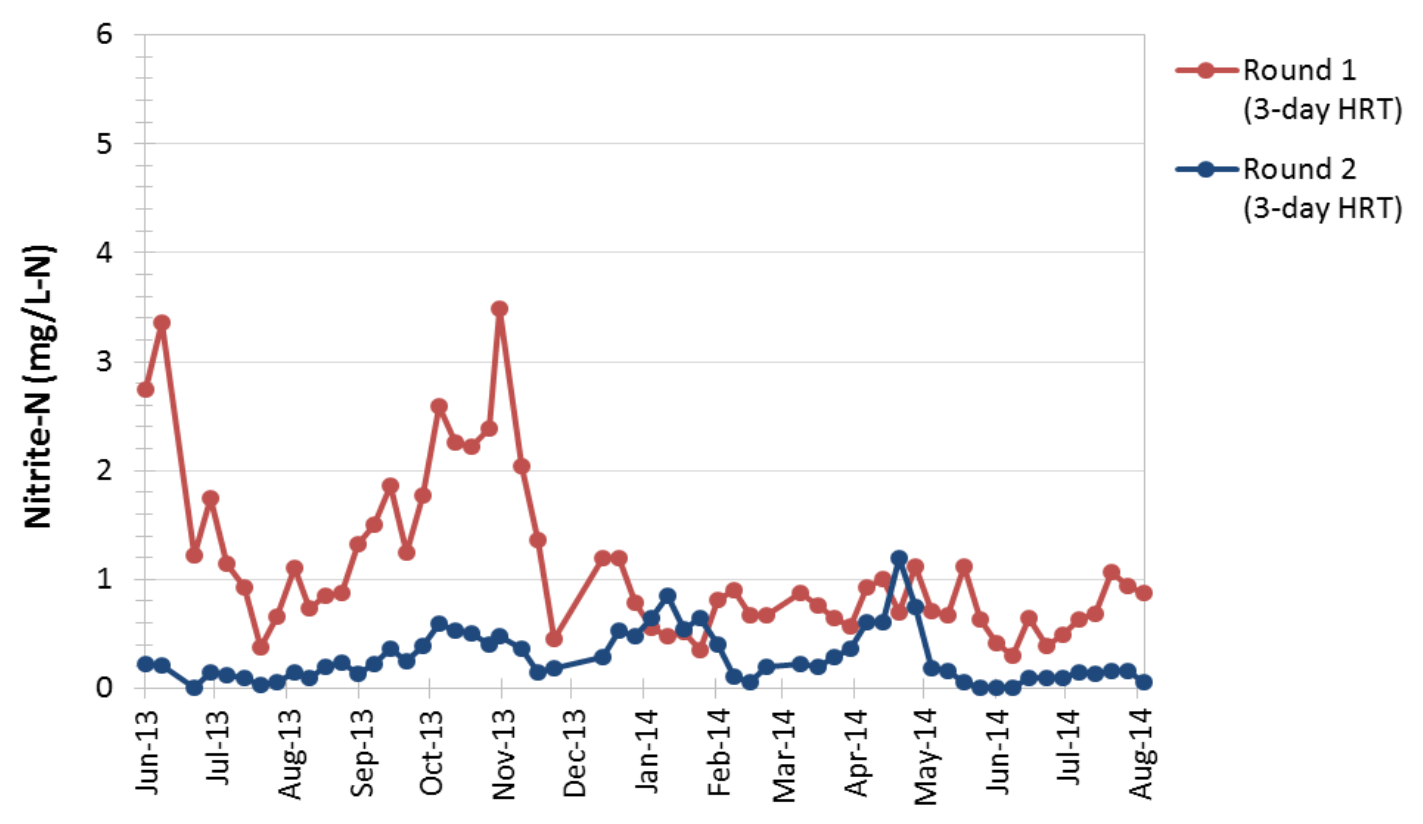

Figure 4-16: Nitrite nitrogen concentrations of Round 1 and 2 effluent during June 2013 August 2014. The Influent nitrite nitrogen concentrations varied between $0.1 \mathrm{mg} / \mathrm{L}-\mathrm{N}$ and $<0.1$ $\mathrm{mg} / \mathrm{L}-\mathrm{N}$.

Organic nitrogen was calculated as the difference of TKN and TAN concentrations

(Section 3.4.1.5). With all major forms of nitrogen measured, a total nitrogen (TN) mass balance was calculated for the Round 1 and 2 sets to illustrate the fate of influent nitrogen, including losses. Additionally, a summer and winter nitrogen mass balance was used to evaluate the seasonality of the fate of influent nitrogen (Figure 4-17 and Figure 4-18).

In the summer months, the Round 1 ponds converted 55\% of the influent soluble nitrogen (TAN \& oxidized nitrogen) into organic nitrogen and oxidized $30 \%$ of the influent TAN into oxidized nitrogen (nitrite and nitrate). The Round 2 ponds converted an additional $26 \%$ of the influent soluble nitrogen into organic nitrogen by assimilation. In total, $81 \%$ of the influent soluble nitrogen was assimilated to create organic nitrogen in the biomass. 
Maximizing this assimilation efficiency increases the feasibility of algal biofuels (Figure 4-17).

The gap between the Round 1 and 2 nitrogen mass balance bar graphs indicates nitrogen losses from denitrification and/or ammonia volatilization. The TN in Round 1 effluent was 3\% higher than Influent on a mass basis, and Round 2 effluent was $1 \%$ lower than Influent. This small apparent increase and decrease was likely caused by sampling and analytical errors. Based on this mass balance, significant ammonia volatilization and denitrification did not occur in the Round 1 and 2 sets.

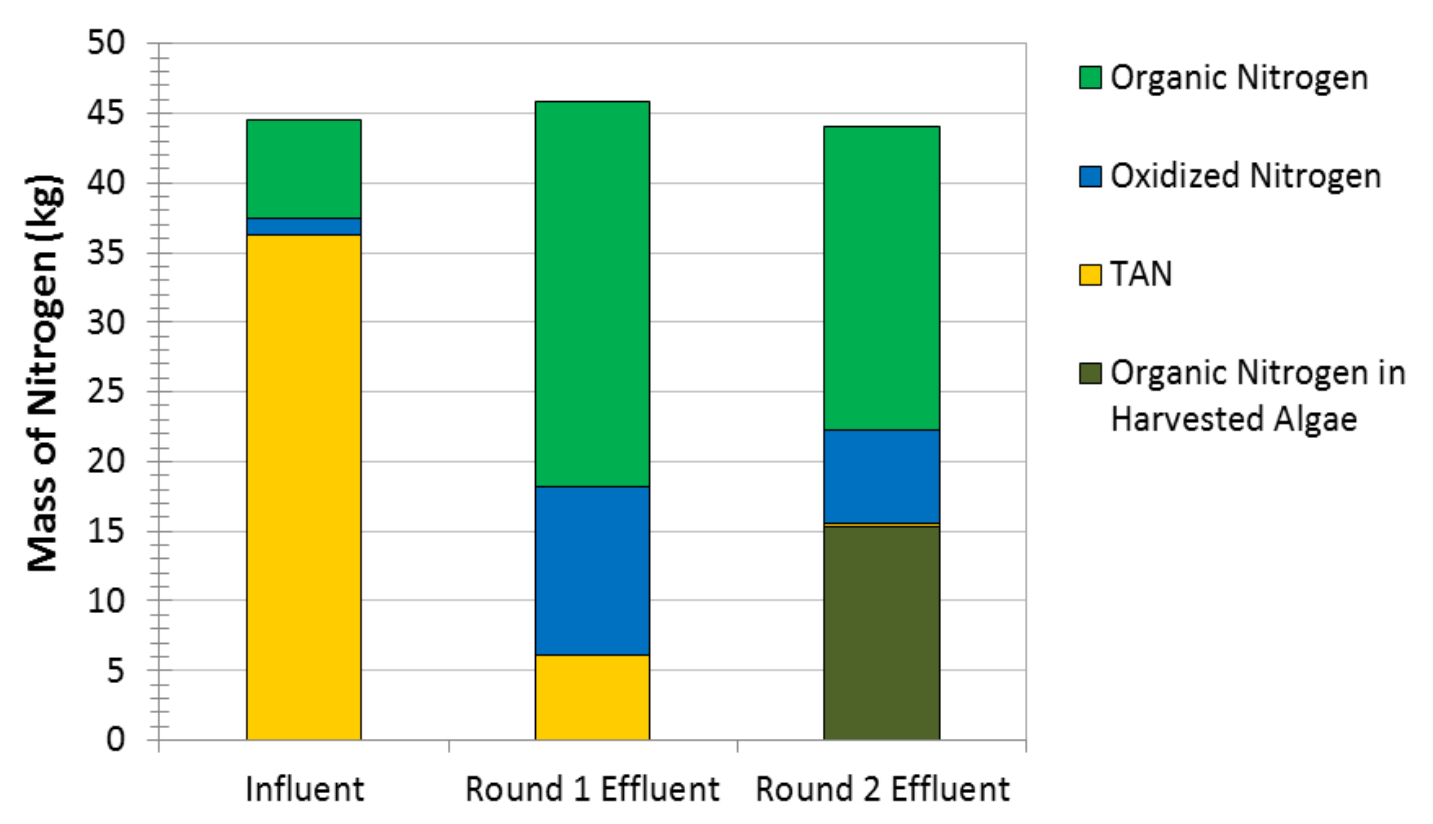

Figure 4-17: Summer TN mass balance of Round 1 and 2 sets during June 2013 - October 2013 and March 2014 - August 2014. The Influent bar refers to the primary clarifier effluent, which served as the influent to Round 1. Oxidized nitrogen is the sum of the nitrate and nitrite concentrations. Round 2 received Round 1 effluent after solids separation (algae harvesting). The small gaps were likely caused by sampling and analytical errors. The amount of organic nitrogen removed with the slurry harvested from the tube settlers was estimated from the difference in

VSS concentration across the tube settlers. The masses shown reflect 30 out of 41 days of measurements taken during the summer period. The 11 days not included were dismissed because at least one form of nitrogen was not measured. 
During the winter, the Round 1 and 2 raceway ponds did not remove the influent SN or achieve the net organic nitrogen increase to the same extent as summer. The Round 1 ponds converted $24 \%$ of the influent SN into organic nitrogen, and oxidized $23 \%$ of the influent TAN into oxidized nitrogen. The Round 2 ponds converted an additional $24 \%$ of the influent soluble nitrogen to organic nitrogen by assimilation. In total, $47 \%$ of the influent soluble nitrogen was converted to biomass organic nitrogen by assimilation (Figure 4-18). The Round $1 \mathrm{TN}$ was $3 \%$ lower than influent on a mass basis. With $\mathrm{pH}$ values in the $7.5-8.5$ range for a majority of the winter months, and pond temperatures ranging from $13-16^{\circ} \mathrm{C}$, significant ammonia volatilization in Round 1 was unlikely to occur. No further nitrogen losses occurred in the Round 2 ponds.

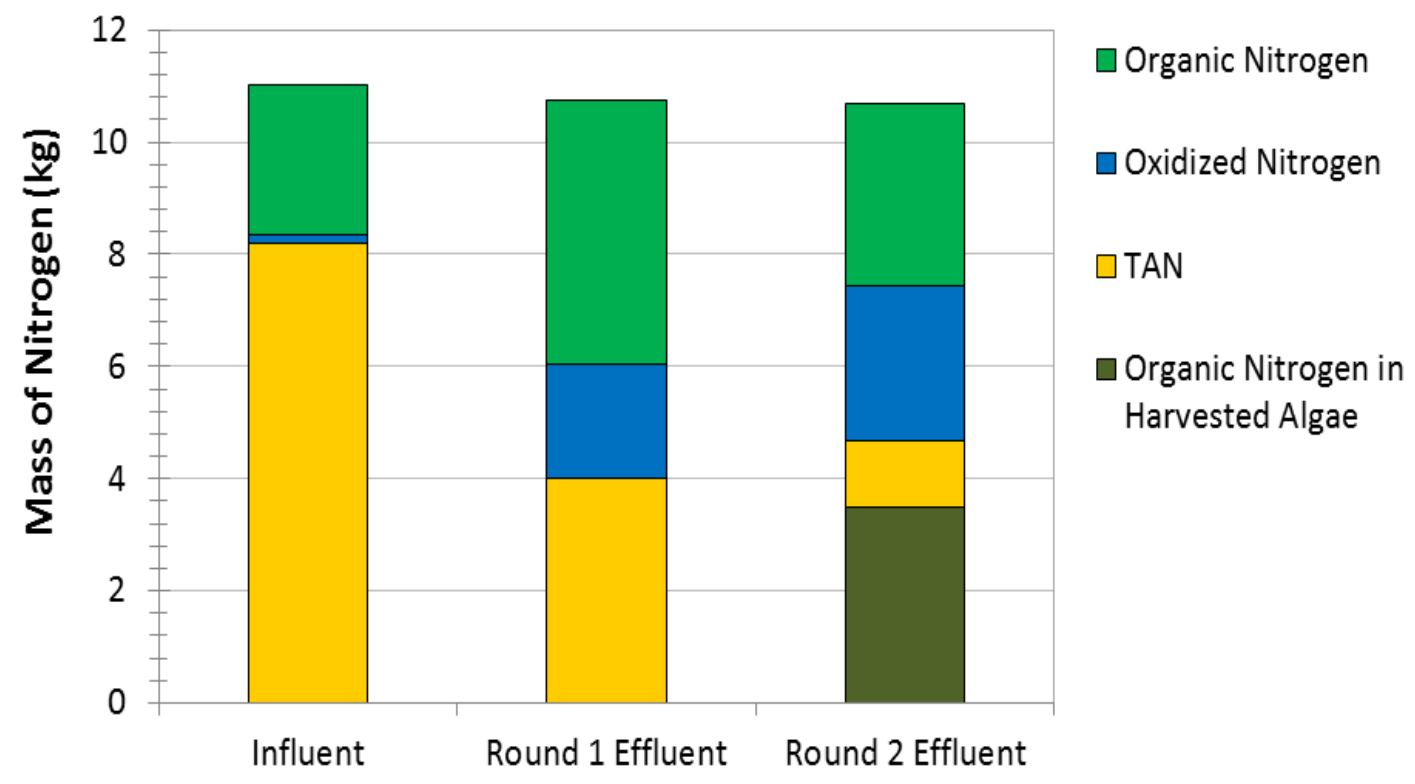

Figure 4-18: Winter TN mass balance on Influent, Round 1, and Round 2 effluent during November 2013 - February 2014. The Influent bar refers to the primary clarifier effluent, which served as the influent to Round 1. Oxidized nitrogen is the sum of the nitrate and nitrite concentrations. Round 2 received Round 1 effluent after solids separation. The amount of organic nitrogen removed from the influent into Round 2 was determined based on the biomass concentration in the tube settler supernatant, before entering Round 2. The masses shown reflect 
only 6 out of 14 days of measurements taken during the period of winter. The 8 days not included were dismissed because at least one form of nitrogen was not measured.

Another goal for Experiment II was to achieve consistent, year-round effluent TN concentrations that comply with typical TN discharge limits set by the California Regional Water Quality Control Boards-<10 mg/L-N (e.g., Keeling, 2011). For the following analysis, it is presumed that future pond-based treatment plans will use coagulation and filtration to remove $100 \%$ of the organic nitrogen. Thus, $\mathrm{TN}$ is assumed to equal SN.

Round 2 effluent met the $10 \mathrm{mg} / \mathrm{L}-\mathrm{N}$ discharge limit $69 \%$ of the time in summer and $0 \%$ in the winter months (Table 4-10). Round 1 effluent met this limit only 5\% of the time in summer and $0 \%$ in the winter. Thus, a substantial amount of additional treatment would be needed to meet discharge limits such as the use of additional ponds or other treatment technology. The probability graphs displayed in Figures 4-19 to 4-22 provide a quick reference to determine the seasonal probability of meeting a SN discharge limit with one and/or two rounds of treatment, each operating at a three day HRT.

Table 4-10: The percent of time the Round 2 effluent would meet projected $10 \mathrm{mg} / \mathrm{L}-\mathrm{N}$ total nitrogen discharge limits in both summer and winter months. The 25 th and 75 th percentiles $(\mathrm{mg} / \mathrm{L}-\mathrm{N})$ are also shown.

\begin{tabular}{lcccc} 
& \multicolumn{2}{c}{ Round 1 } & \multicolumn{2}{c}{ Round 2 } \\
\hline & Winter & Summer & Winter & Summer \\
\hline 25th Percentile & 23.1 & 14.4 & 13.8 & 3.2 \\
75th Percentile & 28.8 & 19.7 & 19.4 & 0.13 \\
Percentage meeting an example TN discharge & $0 \%$ & $5 \%$ & $0 \%$ & $69 \%$ \\
limit of 10 mg/L-N & & & & \\
\hline
\end{tabular}




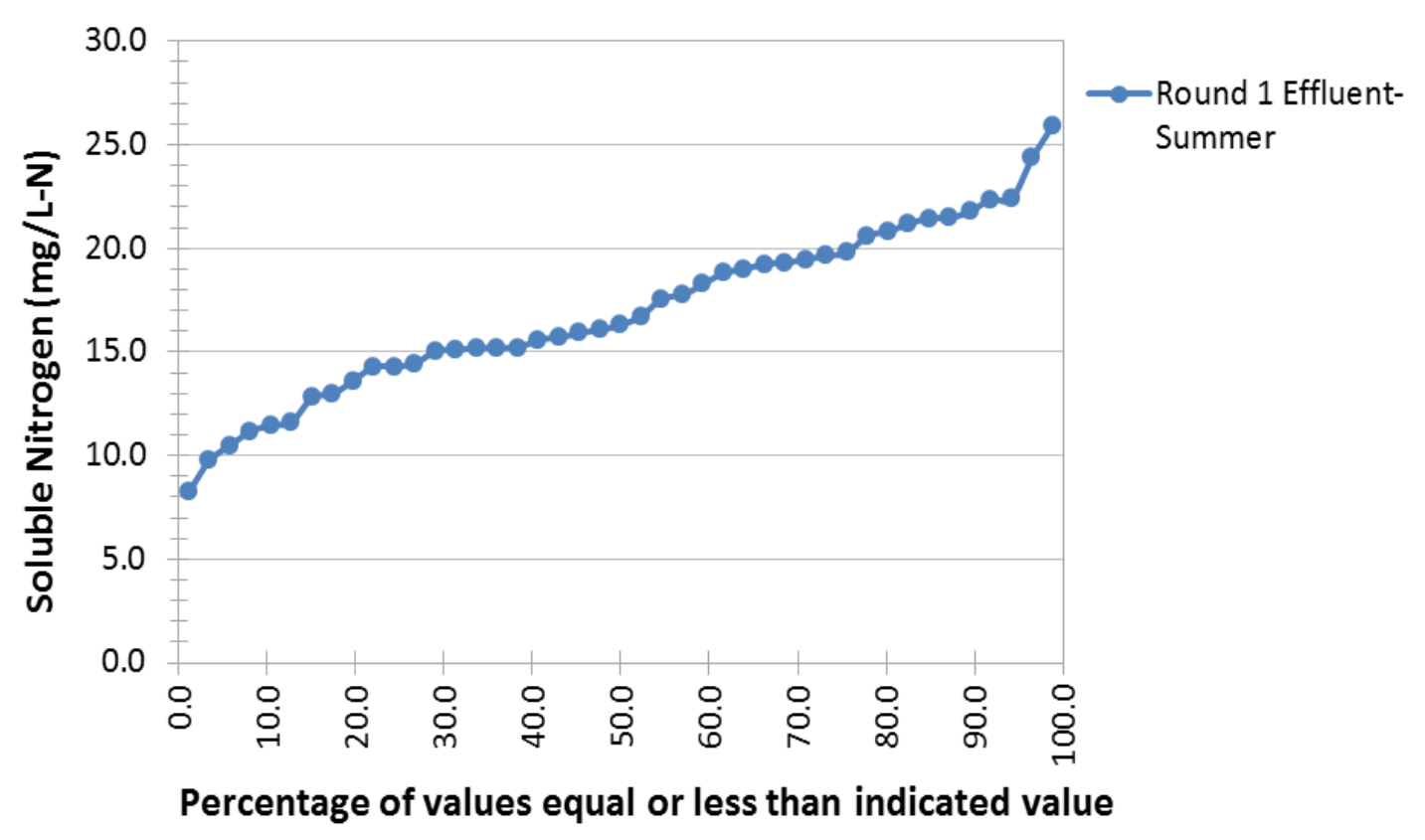

Figure 4-19: Summer time probability plot for Round 1 effluent soluble nitrogen concentrations (June 2013 - October 2013, March 2014 - August 2014) operating at a three day residence time.

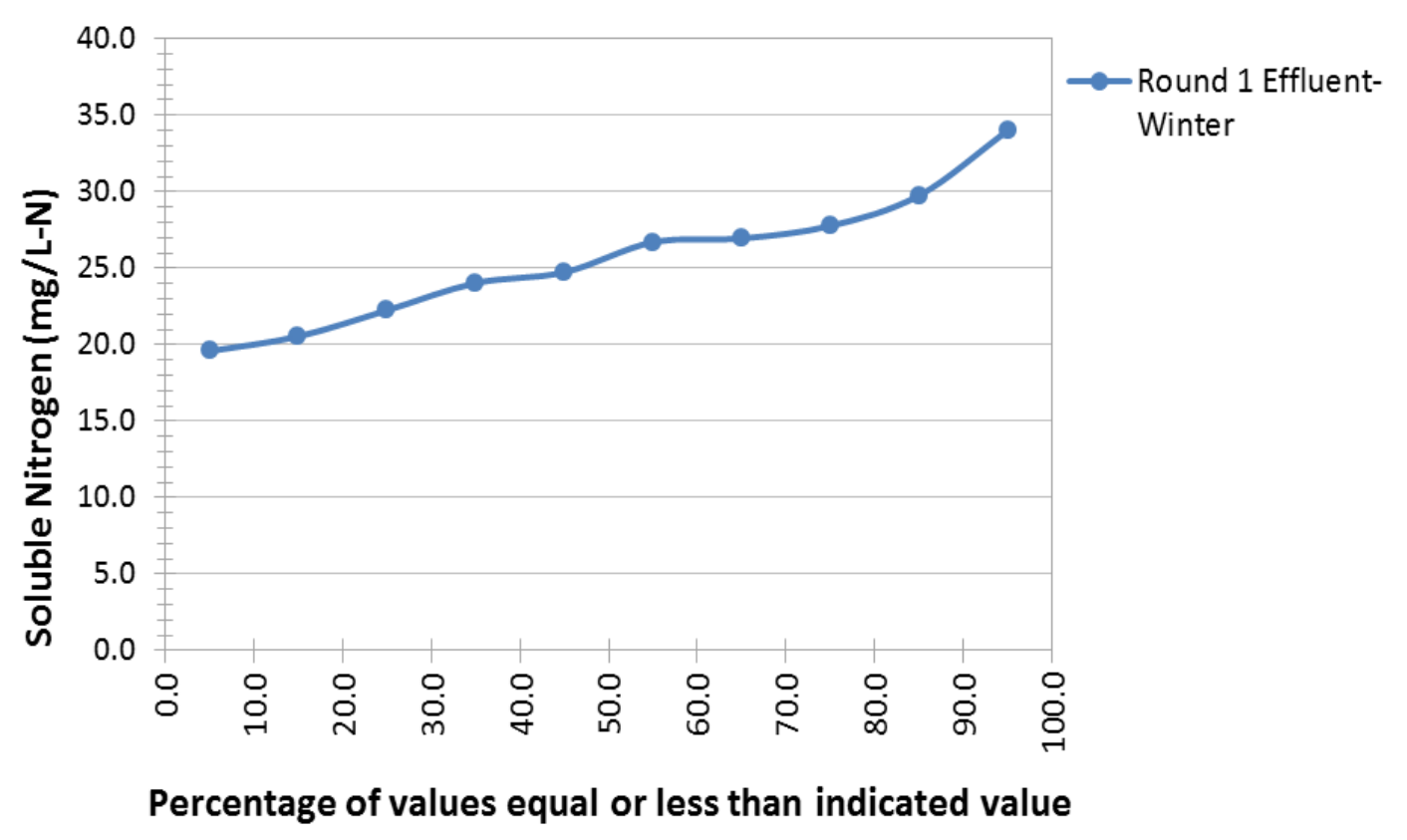

Figure 4-20: Winter time probability plot for Round 1 effluent soluble nitrogen concentrations (November 2013 - February 2014) operating at a three day residence time. 


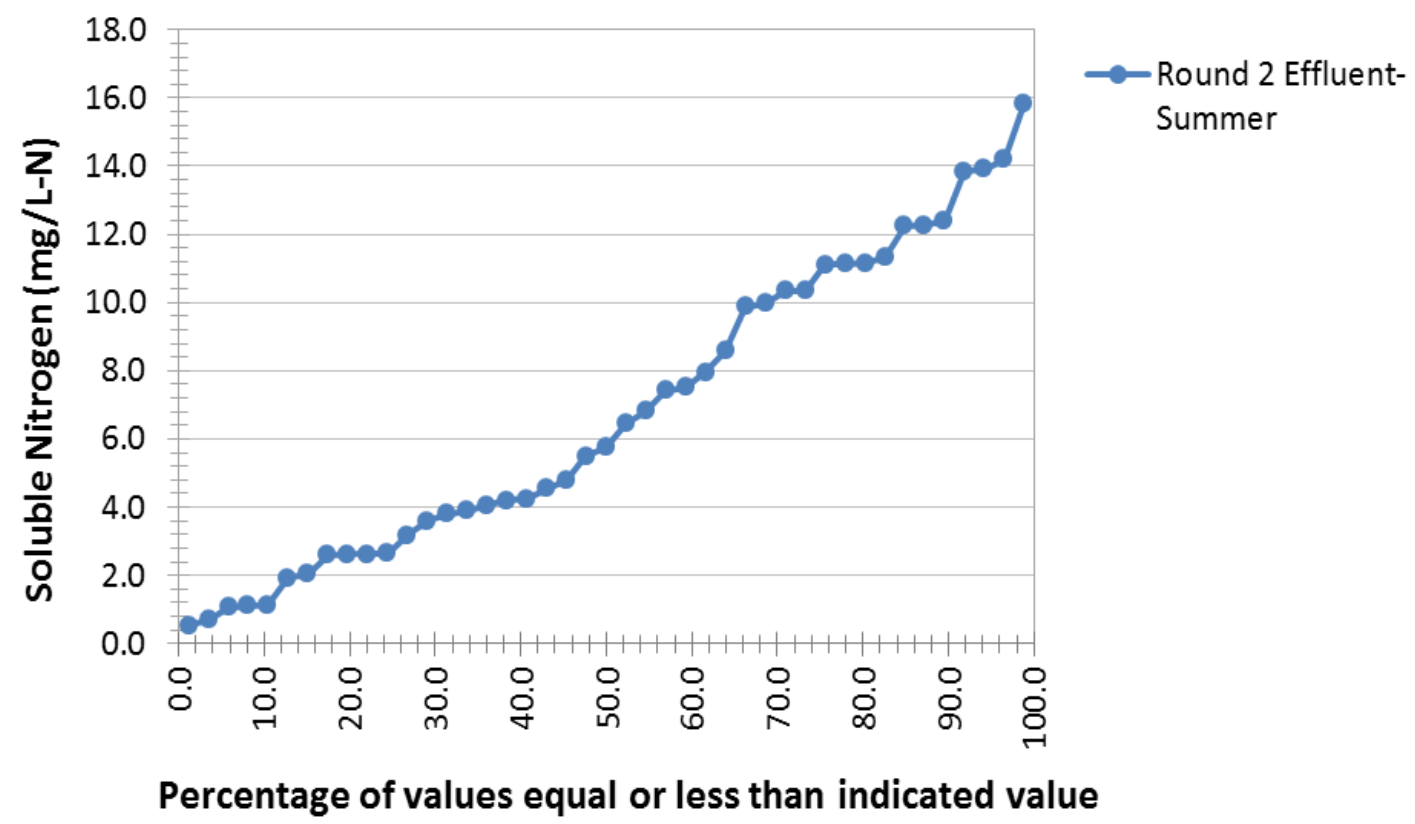

Figure 4-21: Summer time probability plot for Round 2 effluent soluble nitrogen concentrations (June 2013 - October 2013, March 2014 - August 2014) operating at a three day residence time.

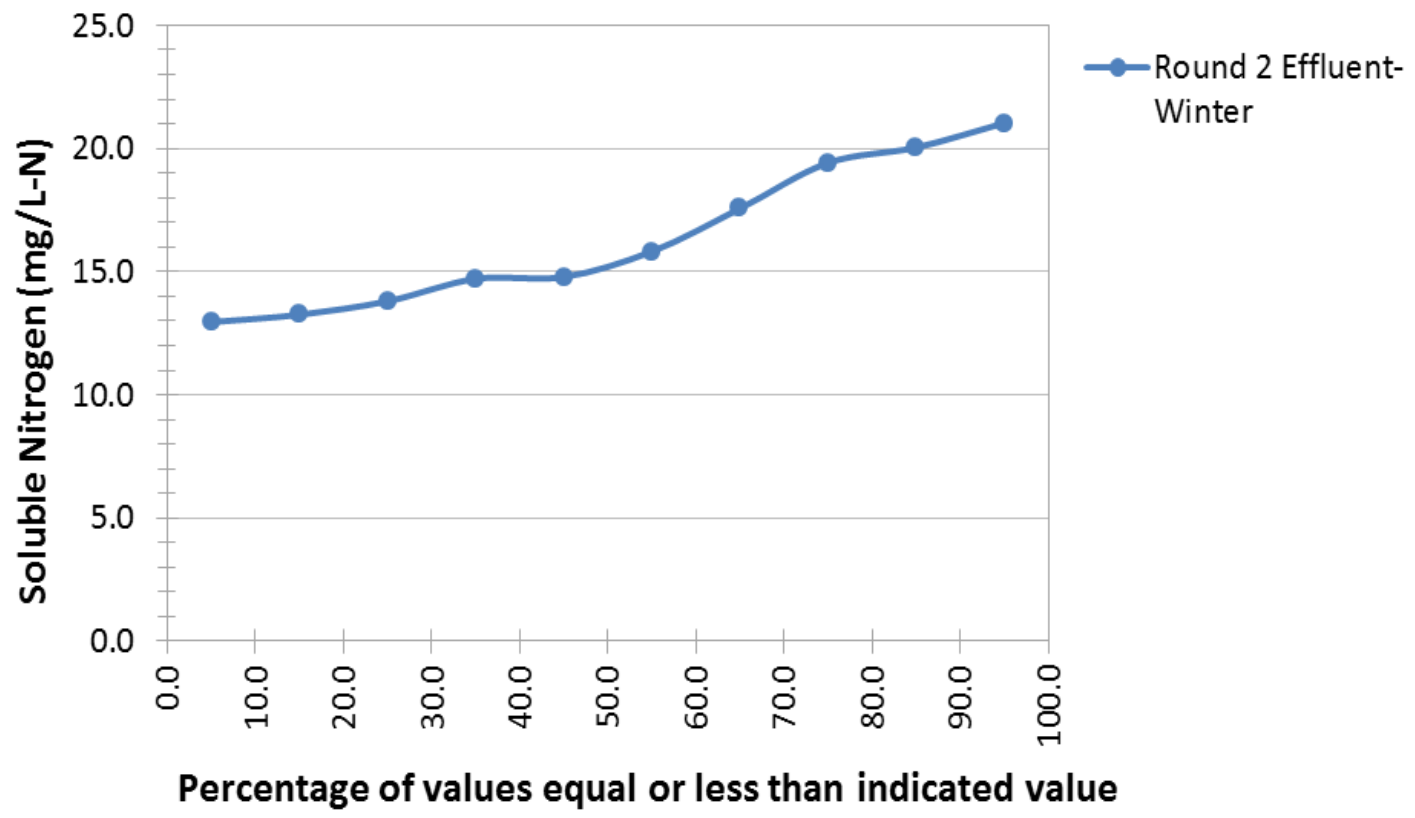

Figure 4-22: Winter time probability plot for Round 2 effluent soluble nitrogen concentrations (November 2013 - February 2014) operating at a three day residence time. 


\subsubsection{Dissolved Reactive Phosphorus Removal in Series Experiment II}

Dissolved reactive phosphorus (DRP) was the only form of soluble phosphorus measured in this experiment. The following DRP analysis is separated into summer and winter months. As described in Section 4.3.2, the summer and winter months were March October and November - February, respectively.

The second round of treatment during the summer months had $28 \%$ better DRP removal compared to the winter months (Table 4-11). Round 2 effluent achieved DRP concentrations of less than $1 \mathrm{mg} / \mathrm{L}-\mathrm{P}$ during 19 of the 43 weeks of summer operation. With the exception of May and June 2014, increased DRP removal correlated with increased average solar radiation and air temperatures (Figure 4-23 and Figure 4-24). DRP removal in the Round 1 and 2 ponds decreased to minimums of $3 \%$ and $10 \%$, respectively, during periods of low solar radiation and temperature in the winter.

Assimilation by algae is the primary DRP removal mechanism in raceways because $\mathrm{pH}$ values do not often rise to a level that would cause phosphate precipitation. Increased DRP removal was expected during the summer when microalgae growth is higher due to warmer temperatures and higher solar radiation. The overall phosphorus percentage in the Round 1 algae growth was $0.52 \%$ in the summer and $0.40 \%$ in the winter. For Round 2, the overall phosphorus percentage in the algae growth was $1.15 \%$ in both summer and winter.

Table 4-11: Winter and summer dissolved reactive phosphorus concentrations (DRP in mg/L-P) in the Influent and Round 1 and 2 effluent during June 2013 - August 2014. The winter months were November, 2013 - February, 2014 and summer months were June, 2013 - October, 2013 and March, 2014 - August, 2014.

\begin{tabular}{cccccc}
\multicolumn{2}{c}{ Influent } & Round 1 Effluent & Round 2 Effluent \\
\hline Winter & Summer & Winter & Summer & Winter & Summer \\
\hline
\end{tabular}


Avg. DRP

Avg. \% Removal

Standard Deviation of \%

Removal

25th Percentile

75th Percentile

Min. DRP

3.7

\section{7}

3.2

2.7

2.3

1.3

Max. DRP

$0.3 \quad 0.4$

$14 \%$

$28 \%$

$38 \%$

$66 \%$

-

$7 \%$

$13 \%$

$14 \%$

$19 \%$

-

3.4

1.8

3.1

2.5

2.0

0.8

3.3

3.0

2.7

1.9

4.5

4.5

2.7

1.0

1.5

0.0

3.5

3.4

3.0

2.9

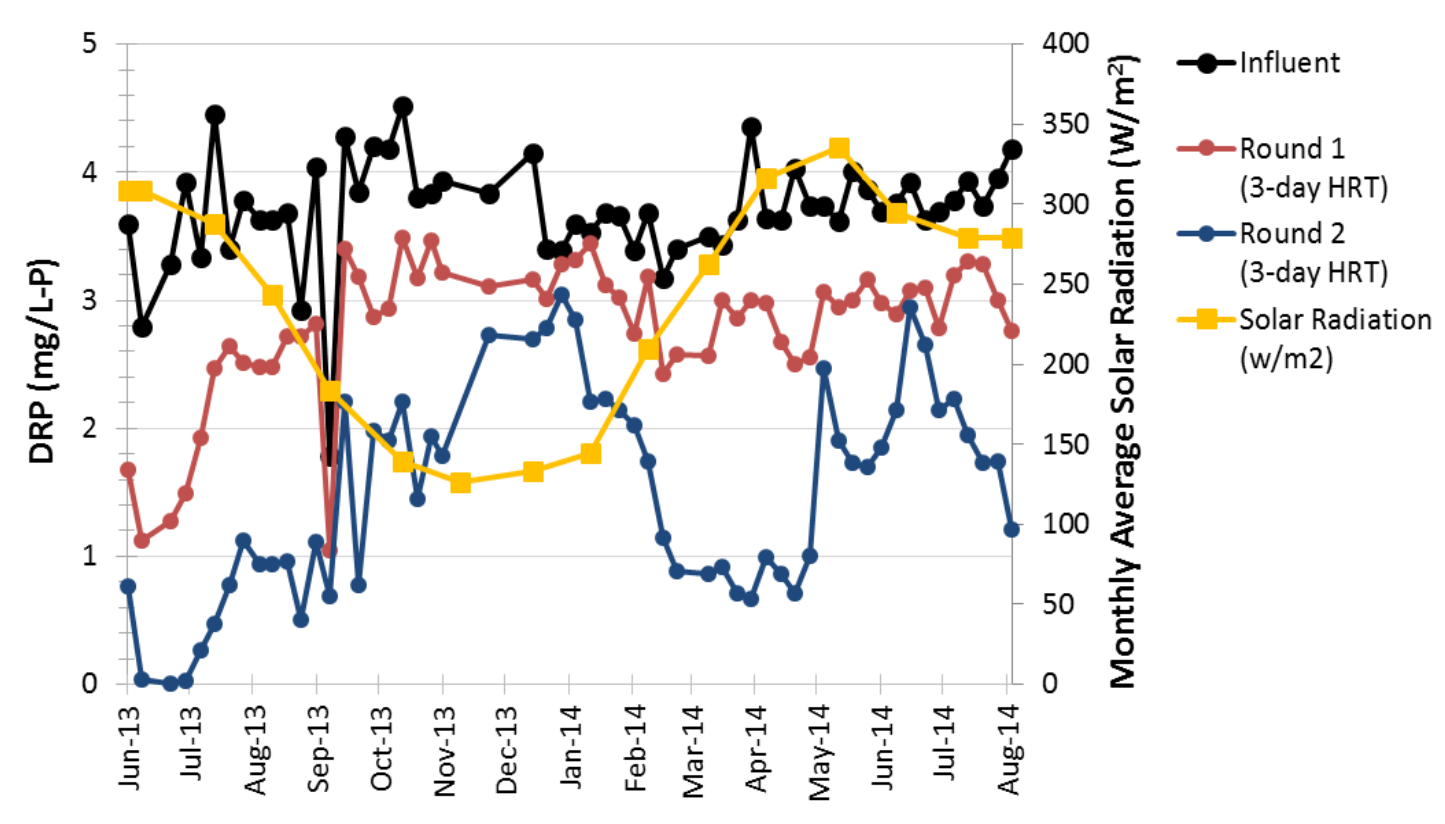

Figure 4-23: Monthly average solar radiation and dissolved reactive phosphorus (DRP) concentrations in the Influent and Round 1 and 2 effluent. 


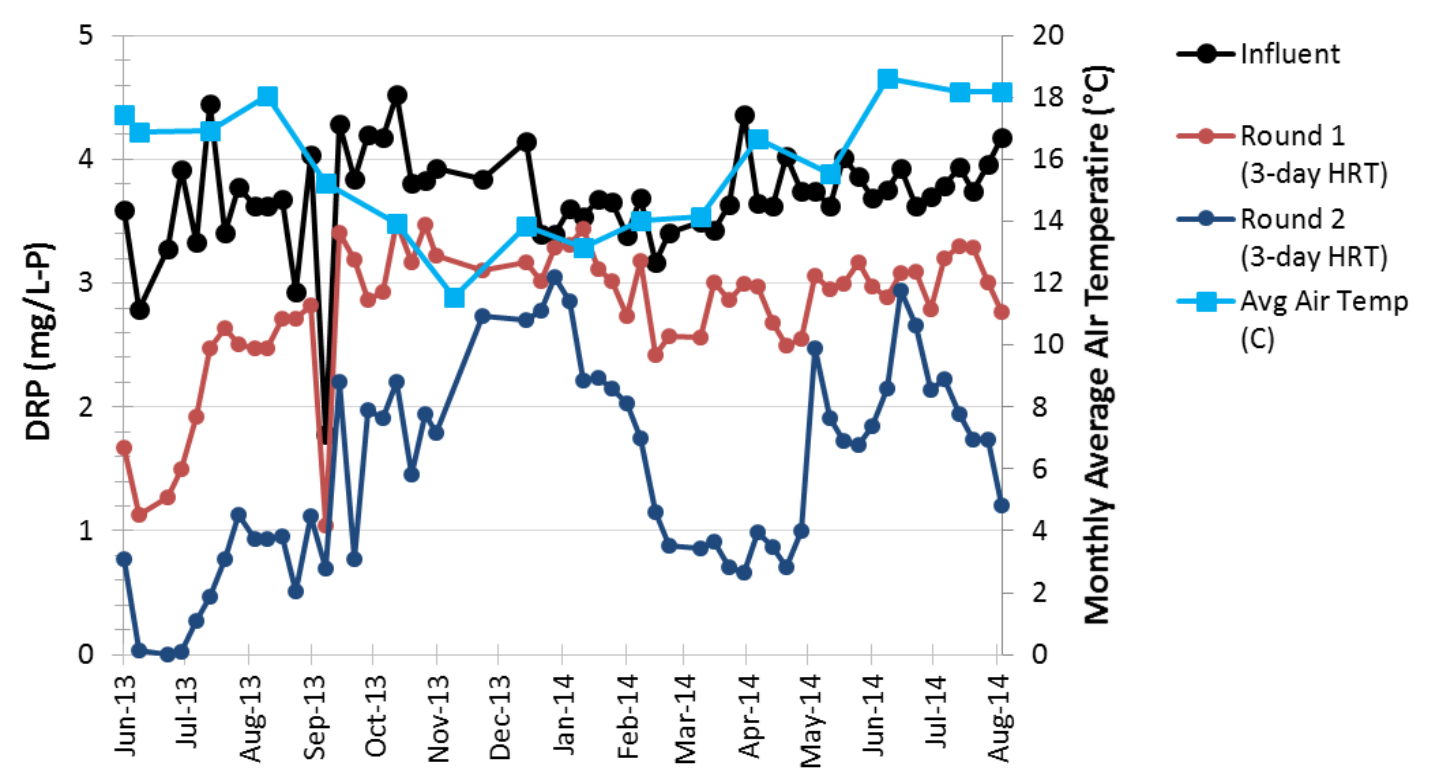

Figure 4-24: Monthly average air temperature and dissolved reactive phosphorus (DRP) concentrations in the Influent and Round 1 and 2 effluent.

\subsection{N and P Removal from the Two-day HRT Raceway Ponds}

This 18-month experiment was conducted in the triplicate Gamma ponds during March 2013 - August 2014. Throughout experimentation, the ponds were fed primary clarifier effluent wastewater rich in total ammonia nitrogen (TAN), dissolved reactive phosphorus (DRP) and biological oxygen demand (BOD). The goal was to determine the incidental nutrient removal by the raceway ponds when operated for secondary treatment only, with a short 2-day HRT. The results from each pond in the triplicate set were averaged to show one value.

As with the Ponds in Series- Experiment II, the summer months spanned March 2013 October 2013 and March 2014 - August 2014, and the winter months spanned November 2013 - February 2013. For the summer months, the average solar radiation was 273 $\mathrm{W} / \mathrm{m}^{2}$ with a maximum of $335 \mathrm{~W} / \mathrm{m}^{2}$ in June 2014 . March 2014 was the only month that 
experienced significant precipitation with $6.0 \mathrm{~cm}$. For the winter months, the average solar radiation was $136 \mathrm{~W} / \mathrm{m}^{2}$ with a maximum of $145 \mathrm{~W} / \mathrm{m}^{2}$. February 2014 was the only month that experienced significant precipitation with $13.4 \mathrm{~cm}$. Average 24-hour air temperature never decreased below $11^{\circ} \mathrm{C}$ throughout experimentation, and the maximum of $19^{\circ} \mathrm{C}$ occurred in July 2014 (Figure 4-25).

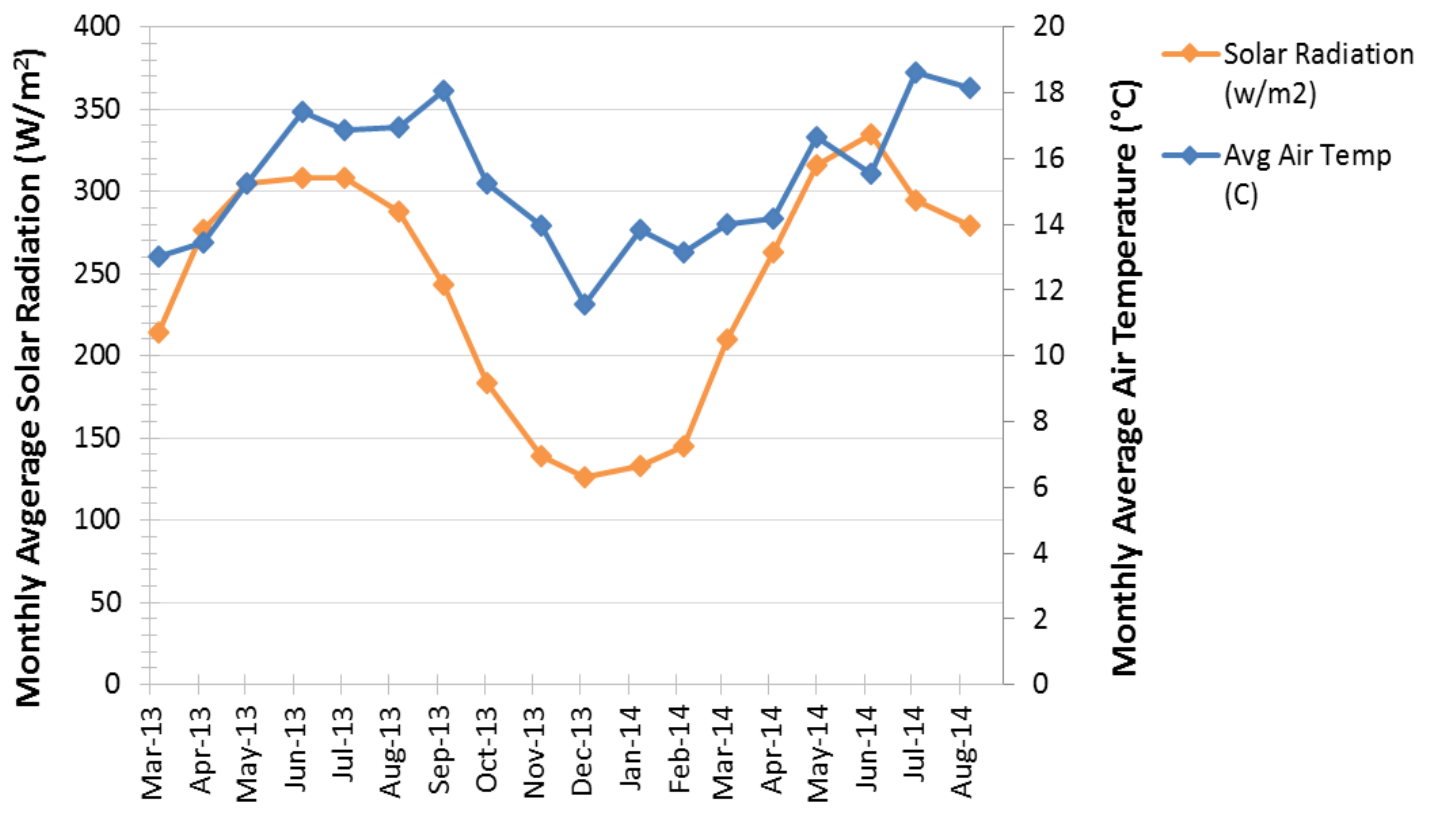

Figure 4-25: Monthly average solar radiation and air temperatures recorded by a CIMIS weather station in San Luis Obispo, Calif. see the methods chapter for details. This is an extension of

Figure 4-6 to show the data from March - May 2013.

\subsubsection{Temperature, $\mathrm{pH}$, and DO}

As described in Section 4.4.1, the Neptune data logger experienced several problems preventing the storage of hourly temperature, $\mathrm{pH}$, and $\mathrm{DO}$ readings in the ponds. The $\mathrm{pH}$ data logger was fixed in November 2013. The 2-day HRT Gamma ponds were not pH 
controlled with $\mathrm{CO}_{2}$ sparging. Accurate and calibrated data were collected for over $50 \%$ of the experiment.

With no $\mathrm{pH}$ control in these ponds, the $\mathrm{pH}$ ranged from 6.5 to 10.5 . The $\mathrm{pH}$ measurements greater in the 9.5 - 10.5 range were recorded on May 6 and 8, and June 14 . However, a majority of the measurements were in the 7.5 to 8.5 range.

DO saturation levels experienced diel oscillations with the maximum concentrations in the afternoon and minimums overnight (Figure 4-26). During the winter months, the maximum daytime DO concentrations were at least $30 \%$ lower than the summer months. The maximum daytime levels reached 160-180\% saturation during the summer months, but the DO was typically consumed within two to three hours after sunset.

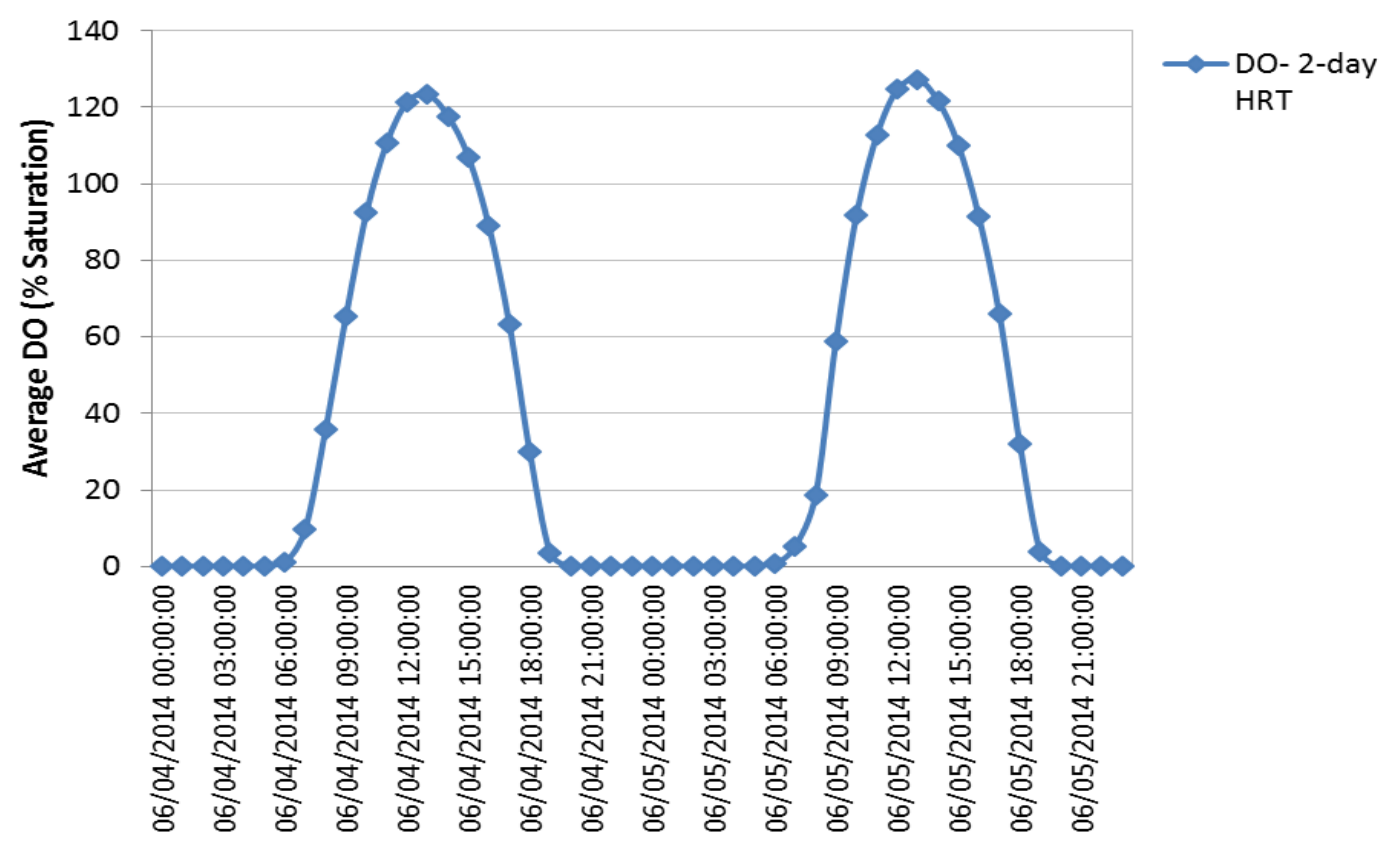

Figure 4-26: Hourly DO measurements from the 2-day HRT ponds. These values represent an average of the triplicates. This figure only spans two days to provide an example of the diel oscillations for both rounds. The Neptune data logger recorded these measurements. 
The average pond temperatures during the winter and summer were $16^{\circ} \mathrm{C}$ and $20^{\circ} \mathrm{C}$, respectively. The minimum daytime pond temperatures correlated with low daytime DO levels.

\subsubsection{Nitrogen Removal}

Higher solar radiation and air temperature correlated with increased TAN removal, as seen during the summer months (Figure 4-27 \& Figure 4-28). Higher solar radiation and air temperatures in the summer also correlated with increased algal productivity and DO concentrations in the ponds. Increased DO concentrations can potentially increase nitrification rates (Metcalf \& Eddy, 2014).

The two-day HRT cumulative summer and winter total ammonia nitrogen (TAN) removal efficiencies averaged $71 \%$ and $11 \%$, respectively (Table 4-12). The high standard deviation for the average summer removal efficiency resulted from poor treatment performances during periods of declining biomass concentrations. These declines occurred either during a pond crash or in the weeks leading to winter. The high standard deviation for winter removal resulted from four weeks in January when the effluent had a higher TAN concentration than influent. Although QA/QC passed on those measurements, effluent TAN concentrations should not exceed influent if a positive net growth of volatile suspended solids (VSS) was present. In each of those four weeks, a net growth of at least $70 \mathrm{mg} / \mathrm{L}$ VSS was measured. The resulting organic nitrogen to VSS ratio for those four weeks were within the $0.05-0.12$ range, typical ratios for algal cells (Park et al, 2010). No net production of oxidized nitrogen was measured in those four weeks. 
Table 4-12. Winter and summer TAN removal efficiencies and concentrations for Influent and Round 1 and 2. The duration of the experiment was March 62013 to August 28, 2014. Summer months were June 2013 - October 2013 and March 2014 - August 2014, and the winter months were November 2013 - February 2014, respectively.

\begin{tabular}{lcccc} 
& \multicolumn{2}{c}{ Influent } & \multicolumn{2}{c}{$\begin{array}{c}\text { Two-day HRT } \\
\text { effluent }\end{array}$} \\
\hline & Winter & Summer & Winter & Summer \\
\hline \hline Average TAN (mg/L-N) & 34 & 37 & 30.4 & 10.4 \\
Average \% Removal & - & - & $11 \%$ & $71 \%$ \\
Standard Deviation of \% & 4 & 7 & $20 \%$ & $15 \%$ \\
Removal & & & & \\
25th Percentile (mg/L-N) & - & - & 25.1 & 6.3 \\
75th Percentile (mg/L-N) & - & - & 37.2 & 13.8 \\
Min. TAN (mg/L-N) & 27 & 22 & 17.5 & 0.6 \\
Max. TAN (mg/L-N) & 42 & 53 & 43 & 22.5 \\
\hline
\end{tabular}

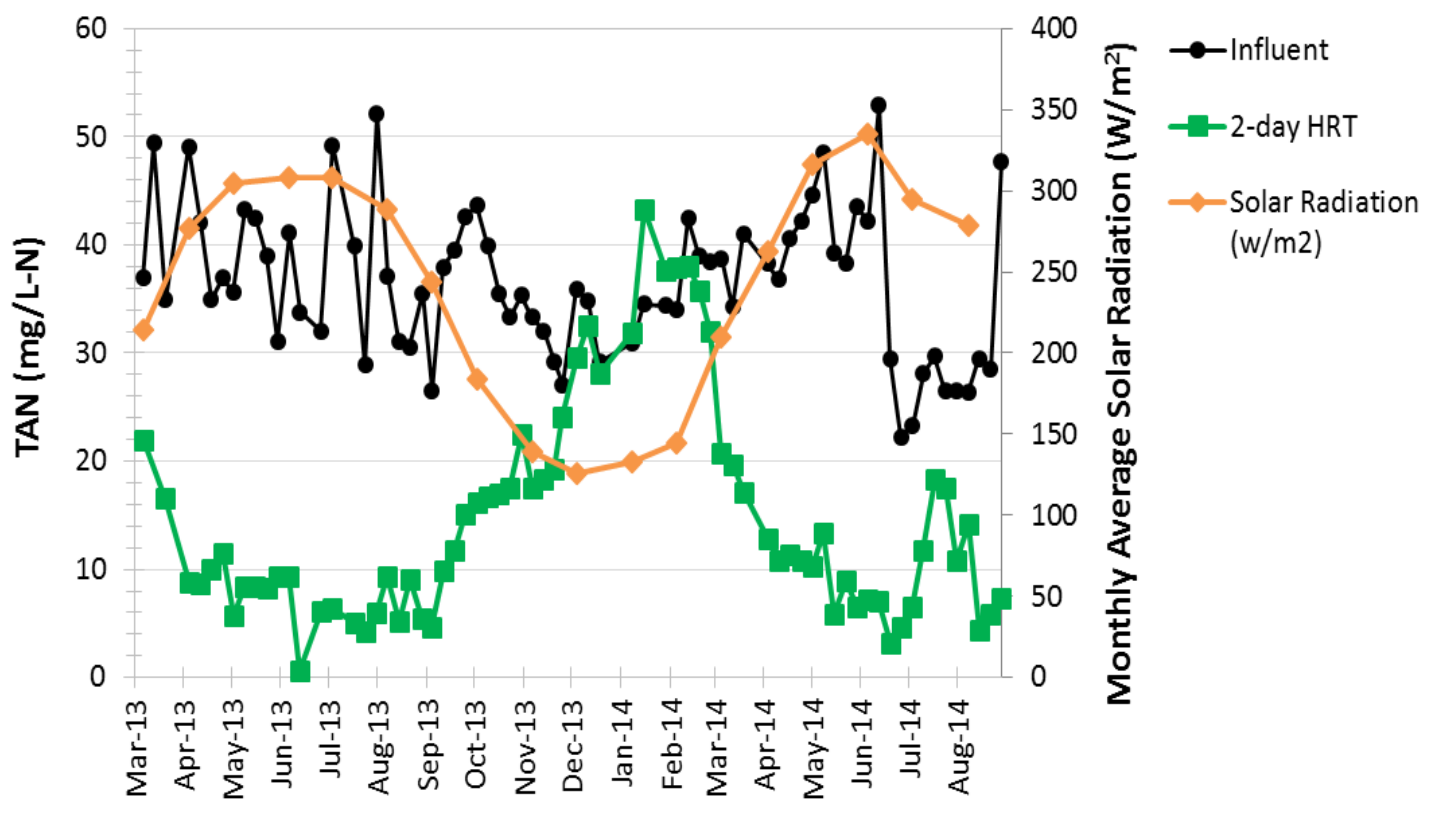

Figure 4-27: Monthly average solar radiation and total ammonia nitrogen (TAN) concentrations of the Influent and two-day HRT effluent during March 6, 2013 to August 28, 2014. 


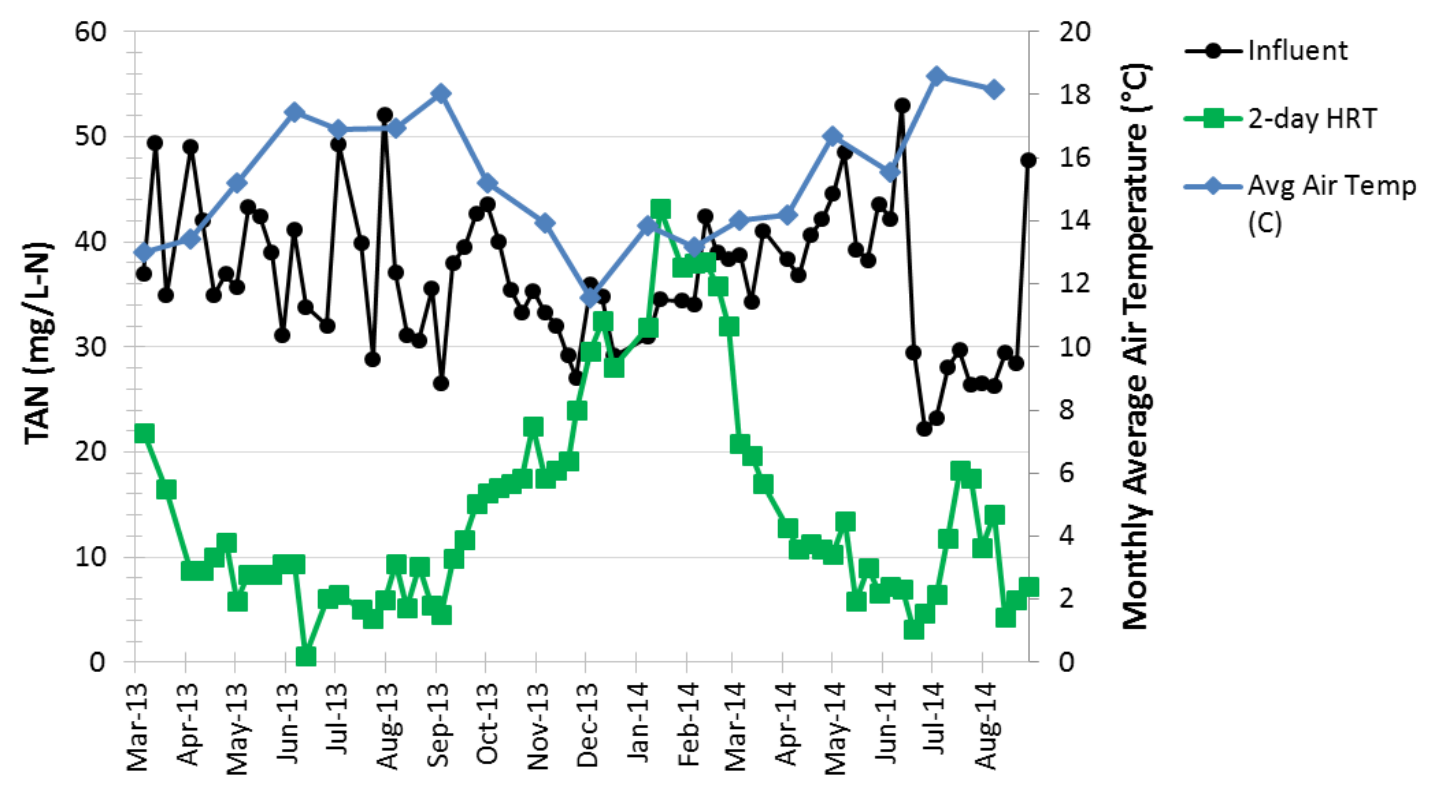

Figure 4-28: Monthly average air temperature and total ammonia nitrogen (TAN) concentrations of the Influent and two-day HRT effluent during March 62013 to August 28, 2014.

The average nitrate nitrogen $\left(\mathrm{NO}_{3}{ }^{-} \mathrm{N}\right)$ concentration was 5-times higher in the summer compared to winter, with values of $5.0 \mathrm{mg} / \mathrm{L}-\mathrm{N}$ and $1.3 \mathrm{mg} / \mathrm{L}-\mathrm{N}$, respectively (Table 413). The average concentration peaked at $15.4 \mathrm{mg} / \mathrm{L}-\mathrm{N}$ on August 7, 2013 (Figure 4-29 and Figure 4-30). This seasonal increase in net nitrate production correlated with higher pond DO concentrations and temperatures. The daily maximum DO saturation levels in the summer were $1.5-2$ times higher, and average pond temperatures $3-10^{\circ} \mathrm{C}$ higher, than in winter. These results match expectations in that higher DO concentrations and temperatures generally increase nitrification rates (EPA, 2002). Nitrate removal via algal assimilation might have been low because TAN concentrations remained above $2 \mathrm{mg} / \mathrm{L}$ $\mathrm{N}$ for every week except one, and algae prefer their nitrogen source in the form of ammonia over nitrate (Mayo \& Mutamba, 2005). 
Denitrification was possible because the pond DO was typically consumed two to three hours after sunset, and they received a constant BOD loading. Nitrate was not measured for five weeks in the winter because the nitrate ion selective electrode (Orion Model RO1-14563) was malfunctioning.

Table 4-13: Winter and summer data for nitrate nitrogen concentrations $(\mathrm{mg} / \mathrm{L}-\mathrm{N})$ in the Influent and two-day HRT effluent during March 6, 2013 - August 28, 2014. Summer and winter months were March - October and November - February, respectively.

\begin{tabular}{lcccc} 
& \multicolumn{2}{c}{ Influent } & \multicolumn{2}{c}{$\begin{array}{c}\text { Average two-day } \\
\text { HRT Effluent }\end{array}$} \\
\hline Avg. $\mathrm{NO}_{3}{ }^{-}-\mathrm{N}$ & Winter & Summer & Winter & Summer \\
Standard Deviation & 0.6 & 1.2 & 1.3 & 5.0 \\
25th Percentile & 0.1 & 0.7 & 1.0 & 3.0 \\
75th Percentile & - & - & 0.5 & 2.8 \\
Min. $\mathrm{NO}_{3}{ }^{-} \mathrm{N}$ & - & - & 1.5 & 6.5 \\
Max. $\mathrm{NO}_{3}{ }^{-}-\mathrm{N}$ & 0.4 & 0.2 & 0.5 & 0.4 \\
\hline
\end{tabular}

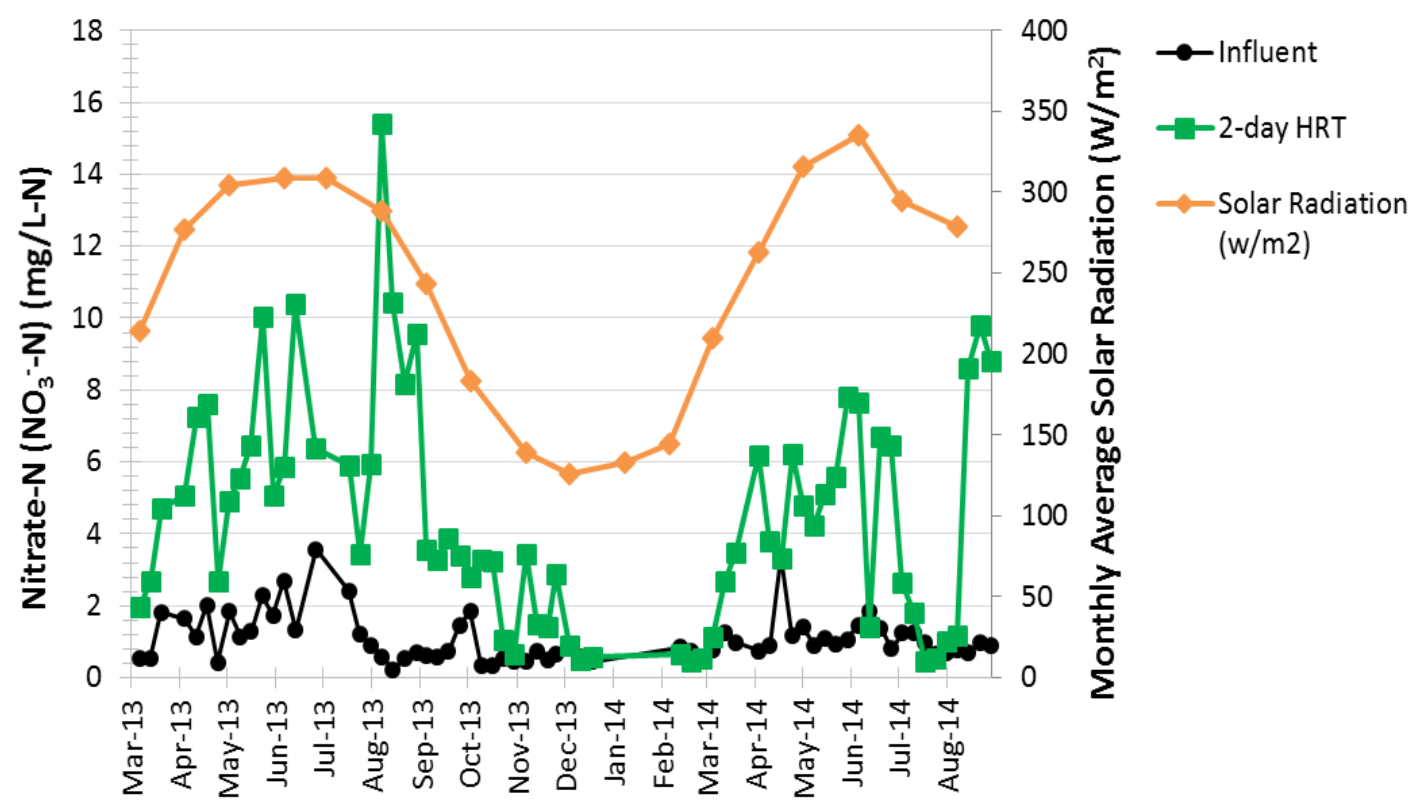

Figure 4-29: Monthly average solar radiation and average nitrate nitrogen concentrations of the Influent and two-day HRT effluent during March 6, 2013 - August 28, 2014. 


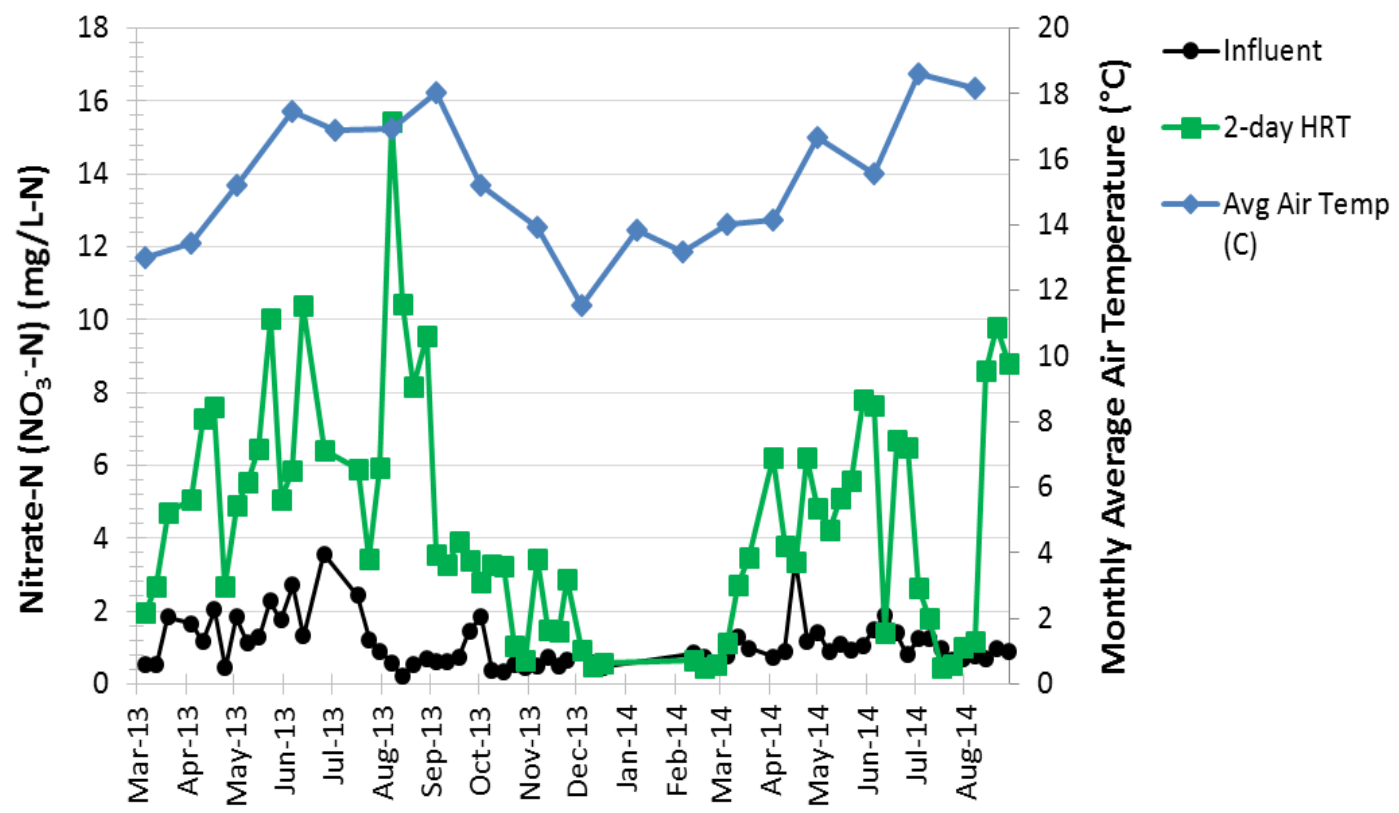

Figure 4-30: Monthly average air temperature and average nitrate nitrogen concentrations of the Influent and two-day HRT effluent during March 6, 2013 - August 28, 2014.

The average summer nitrite nitrogen $\left(\mathrm{NO}_{2}{ }^{-}-\mathrm{N}\right)$ concentration in the two-day HRT effluent was 3-times higher than the average concentration in the winter (Table 4-14). As previously stated in the nitrate analysis, the DO concentration in the ponds during summer months was consistently at least 1.5-times higher, promoting ammonia oxidation.

Low DO in the ponds during winter correlated to a reduction in algae growth during periods of low solar radiation and colder temperatures. The low DO levels, low solar radiation and air temperature, and high ammonia concentrations in December, January, and February correlated with very low nitrite levels (Figure 4-31 and Figure 4-32). 
Table 4-14: Winter and summer nitrite nitrogen concentrations $(\mathrm{mg} / \mathrm{L}-\mathrm{N})$ for the Influent and two-day HRT effluent during March 6, 2013 - August 28, 2014. Winter months were November 2013- February 2014 and the summer months were June 2013 - October 2013 and March 2014 August 2014.

\begin{tabular}{lcccc} 
& \multicolumn{2}{c}{ Influent } & \multicolumn{2}{c}{$\begin{array}{c}\text { Two-day HRT } \\
\text { Effluent }\end{array}$} \\
\hline & Winter & Summer & Winter & Summer \\
\hline Average $\mathrm{NO}_{2}-\mathrm{N}$ & 0.0 & 0.0 & 0.3 & 1.0 \\
Standard Deviation & 0.0 & 0.0 & 0.5 & 0.5 \\
25th Percentile & - & - & 0.03 & 0.7 \\
75th Percentile & - & - & 0.3 & 1.2 \\
Minimum $\mathrm{NO}_{2}^{-}-\mathrm{N}$ & 0.0 & 0.0 & 0.0 & 0.0 \\
Maximum $\mathrm{NO}_{2}^{-}-\mathrm{N}$ & 0.1 & 0.3 & 2.0 & 2.0 \\
\hline
\end{tabular}

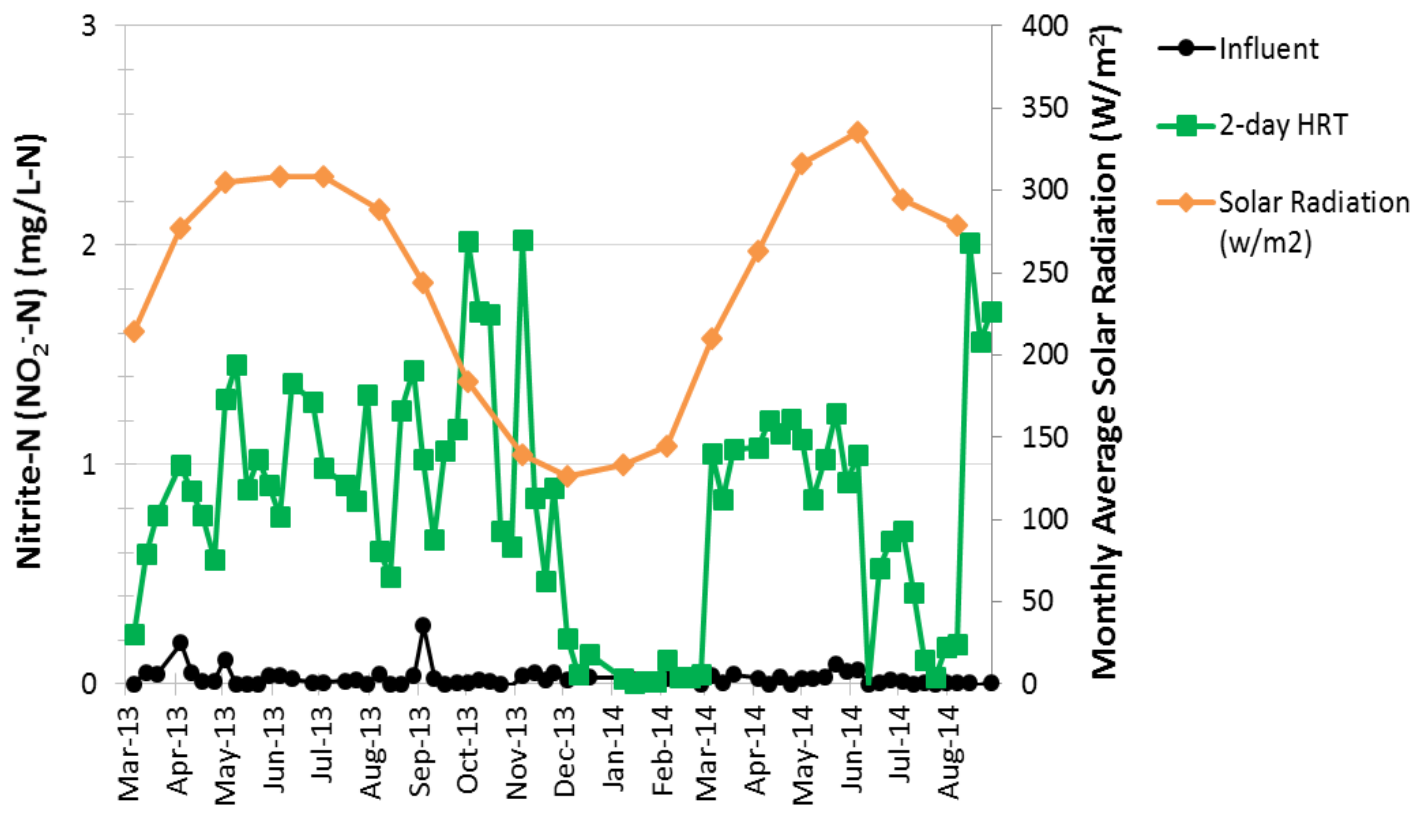

Figure 4-31: Monthly average solar radiation and nitrite nitrogen concentrations in the Influent and two-day HRT effluent during March 6, 2013 - August 28, 2014. 


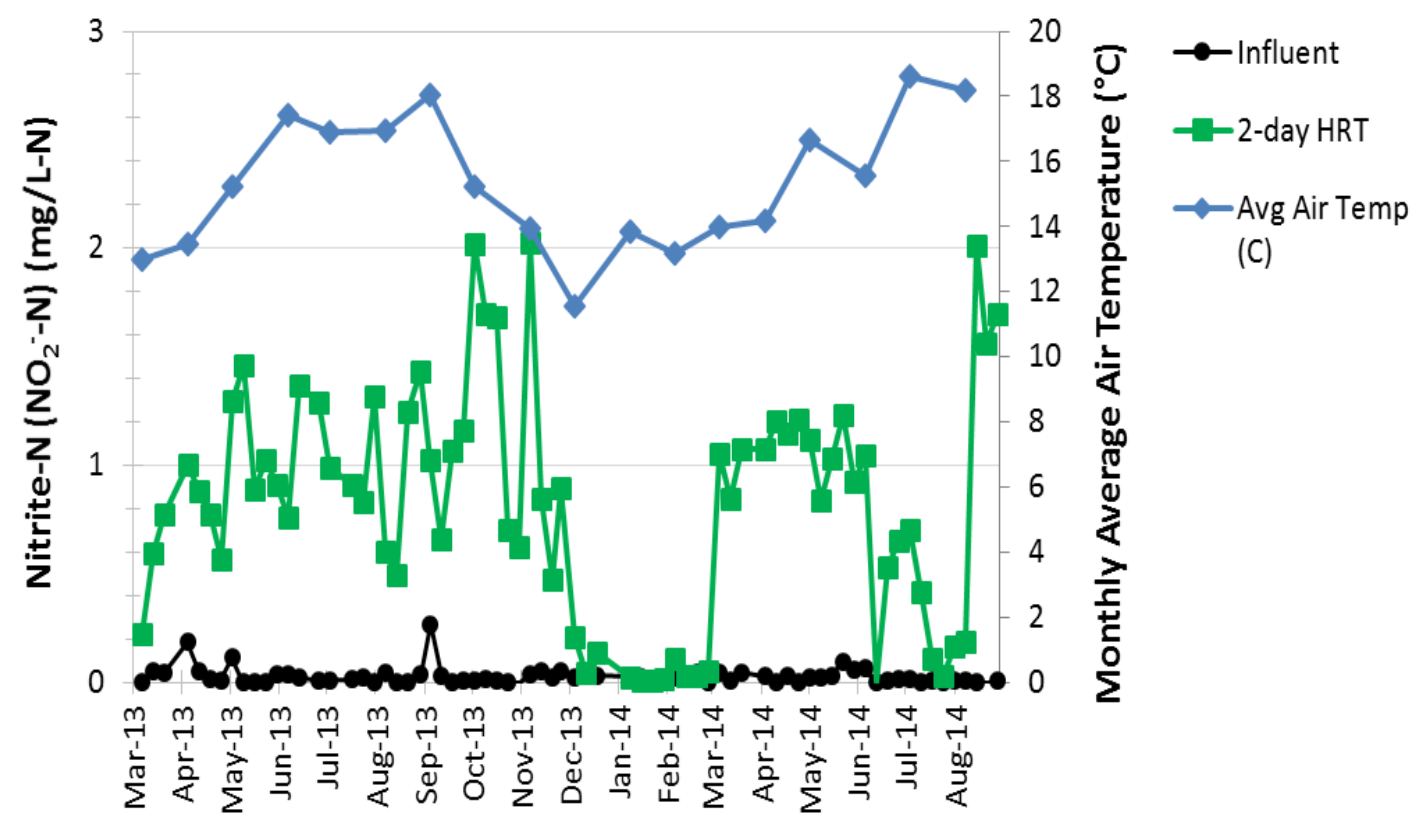

Figure 4-32: Monthly average air temperature and nitrite nitrogen concentrations in the Influent and two-day HRT ponds during March 6, 2013 - August 28, 2014.

The two-day HRT ponds converted $44 \%$ of the influent soluble nitrogen (TAN, nitrite, nitrate) into organic nitrogen and oxidized $15 \%$ of the influent TAN into oxidized nitrogen (nitrite and nitrate) (Figure 4-33).

Total nitrogen mass balance was used to quantify influent nitrogen losses that may have occurred via ammonia volatilization and/or denitrification. Only $3 \%$ of the influent total nitrogen was lost from the triplicate two-day HRT effluent. This may have resulted from ammonia volatilization during the rare occasions when pond $\mathrm{pH}$ reached its maximum of 9.8 for a couple hours. However, while the data logger properly recorded the levels, the $\mathrm{pH}$ was under 8 for nearly $80 \%$ of the experiment. Denitrification was possible during the summer months with significant nitrate levels, nighttime DO levels of $0 \%$, and a continuous supply of BOD. With such a low loss percentage, it was deemed safe to assume that neither significant denitrification nor ammonia volatilization occurred. 


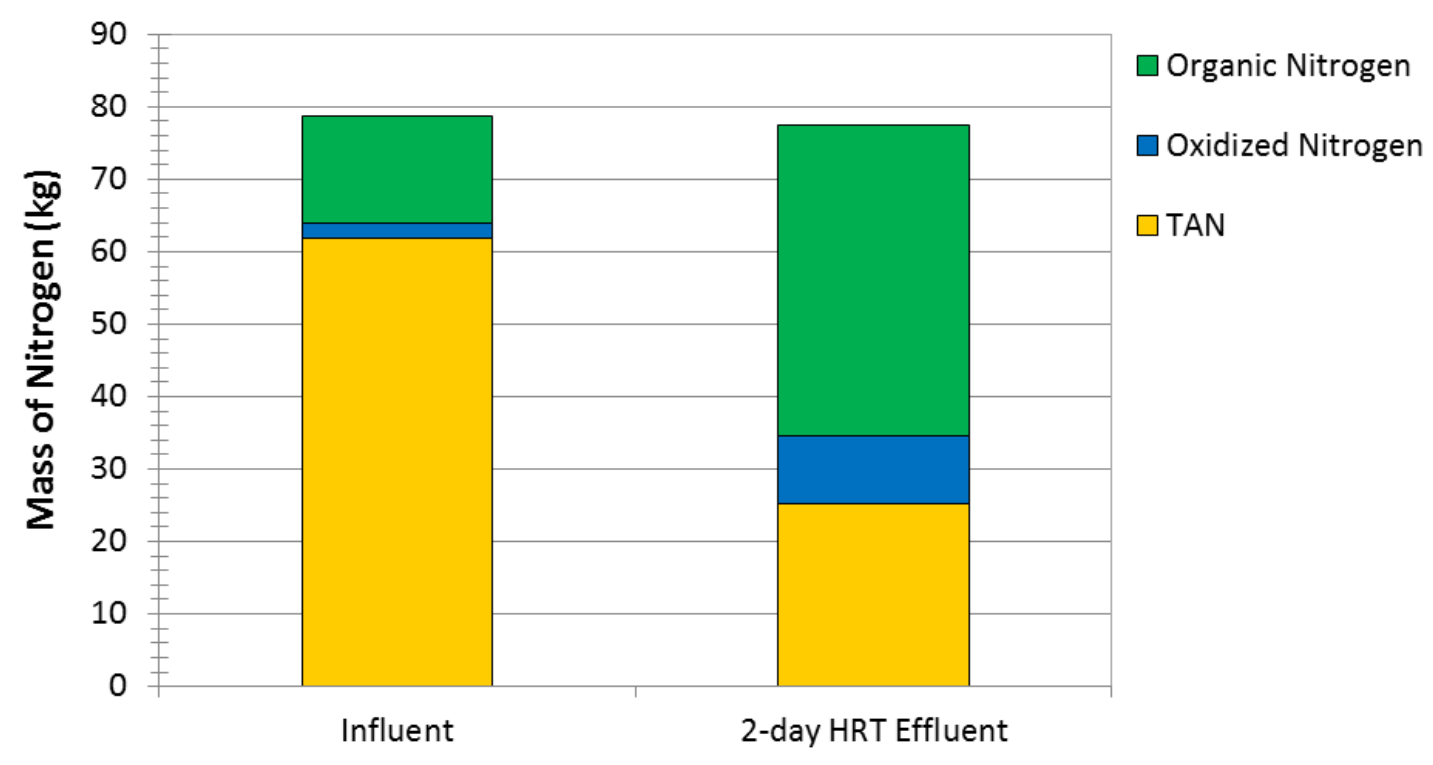

Figure 4-33: Total nitrogen mass balance on the Influent and two-day HRT effluent during March 6, 2013 - August 28, 2014. The Influent bar refers to the primary clarifier effluent, which served as the influent to the two-day HRT ponds. Oxidized nitrogen is the sum of nitrate and nitrite concentrations. The masses shown reflect 53 out of 71 days of measurements taken. The 18 weeks not included were dismissed because at least one form of nitrogen was not measured

\subsubsection{Dissolved Reactive Phosphorus Removal}

Dissolved reactive phosphorus (DRP) was the only form of phosphorus measured in this experiment. The following DRP removal analysis will be separated into summer and winter months. As described in Section 4.5, the summer and winter months were March October and November- February, respectively. Additionally, the weekly results from the triplicate Gamma ponds were averaged to show one two-day HRT value.

Two days of treatment time did not provide much DRP removal. The average percent removal in the summer and winter periods was $17 \%$ and 10\%, respectively (Table 4-15). Unlike TAN removal as described in Section 4.4.2, DRP removal performance did not significantly improve with higher solar radiation and air temperature (Figure 4-34 and 
Figure 4-35). Removal efficiencies had significant standard deviations because several weeks in both summer and winter had essentially no DRP removal.

DRP removal in raceway ponds occurs primarily through algal assimilation, in which phosphorus is typically $1 \%$ by mass. To properly explain why several weeks in summer had $0 \%$ DRP removal with high biomass concentration, it is necessary to measure all forms of soluble phosphorus, such as polyphosphate, which was not done in this study.

Table 4-15: Summer and winter dissolved reactive phosphorus (DRP) concentrations and removal efficiencies in the Influent and two-day HRT effluent during March 6, 2013 - August 28, 2014.

\begin{tabular}{|c|c|c|c|c|}
\hline & \multicolumn{2}{|c|}{ Influent } & \multicolumn{2}{|c|}{$\begin{array}{c}\text { Average two-day } \\
\text { HRT }\end{array}$} \\
\hline & Winter & Summer & Winter & Summer \\
\hline Avg. DRP (mg/L-P) & 3.7 & 3.7 & 3.4 & 3.0 \\
\hline Avg. \% Removal & - & - & $10 \%$ & $17 \%$ \\
\hline $\begin{array}{l}\text { Standard Deviation of \% } \\
\text { removal }\end{array}$ & 0.3 & 0.4 & $8 \%$ & $12 \%$ \\
\hline 25th Percentile (mg/L-P) & - & - & 3.2 & 2.8 \\
\hline 75th Percentile (mg/L-P) & - & - & 3.5 & 3.2 \\
\hline Min. DRP (mg/L-P) & 3.4 & 1.8 & 2.9 & 1.3 \\
\hline Max. DRP (mg/L-P) & 4.5 & 4.5 & 3.8 & 3.9 \\
\hline
\end{tabular}




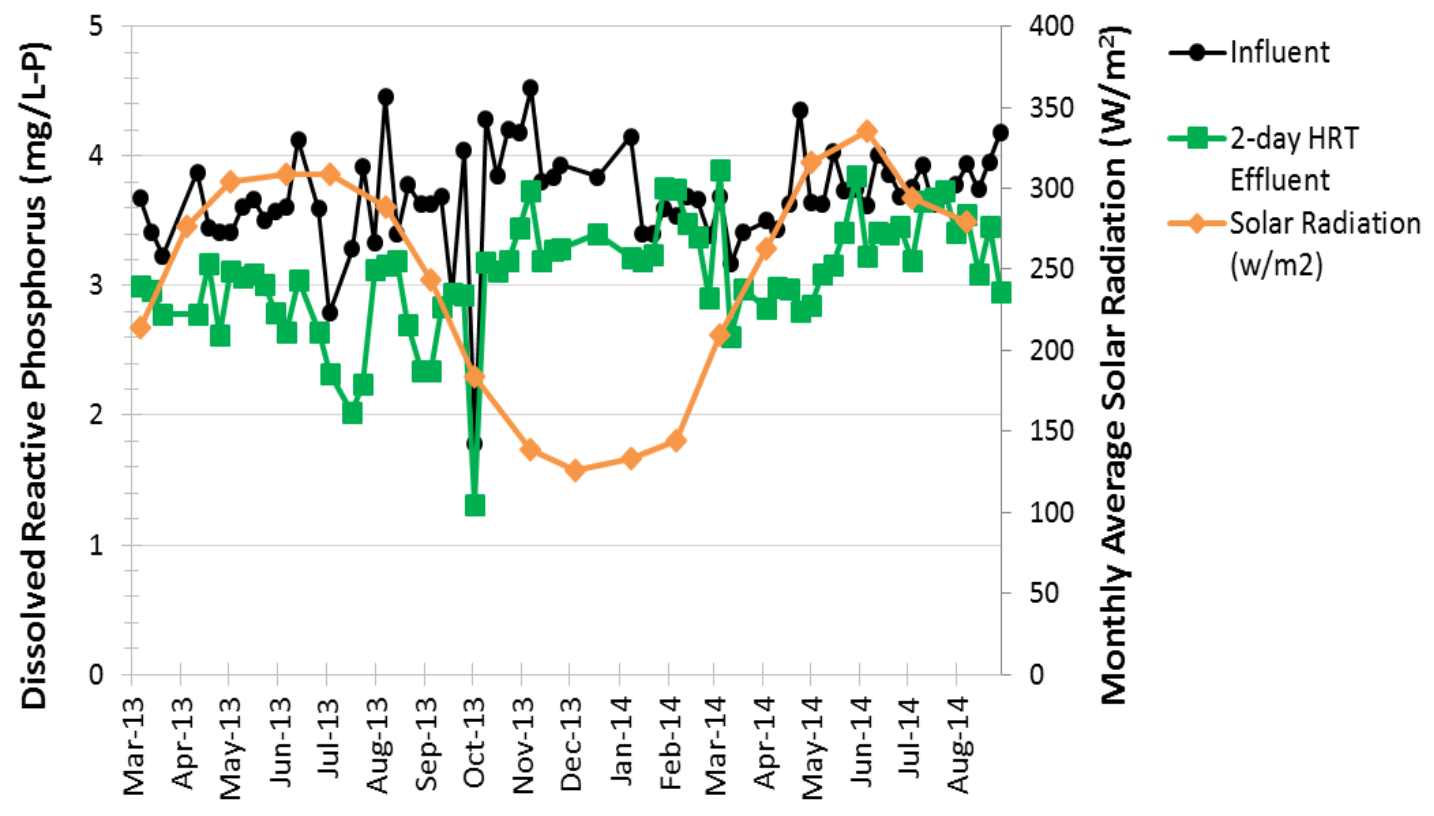

Figure 4-34: Monthly average solar radiation and DRP concentrations in the Influent and twoday HRT effluent during March 6, 2013 - August 28, 2014.

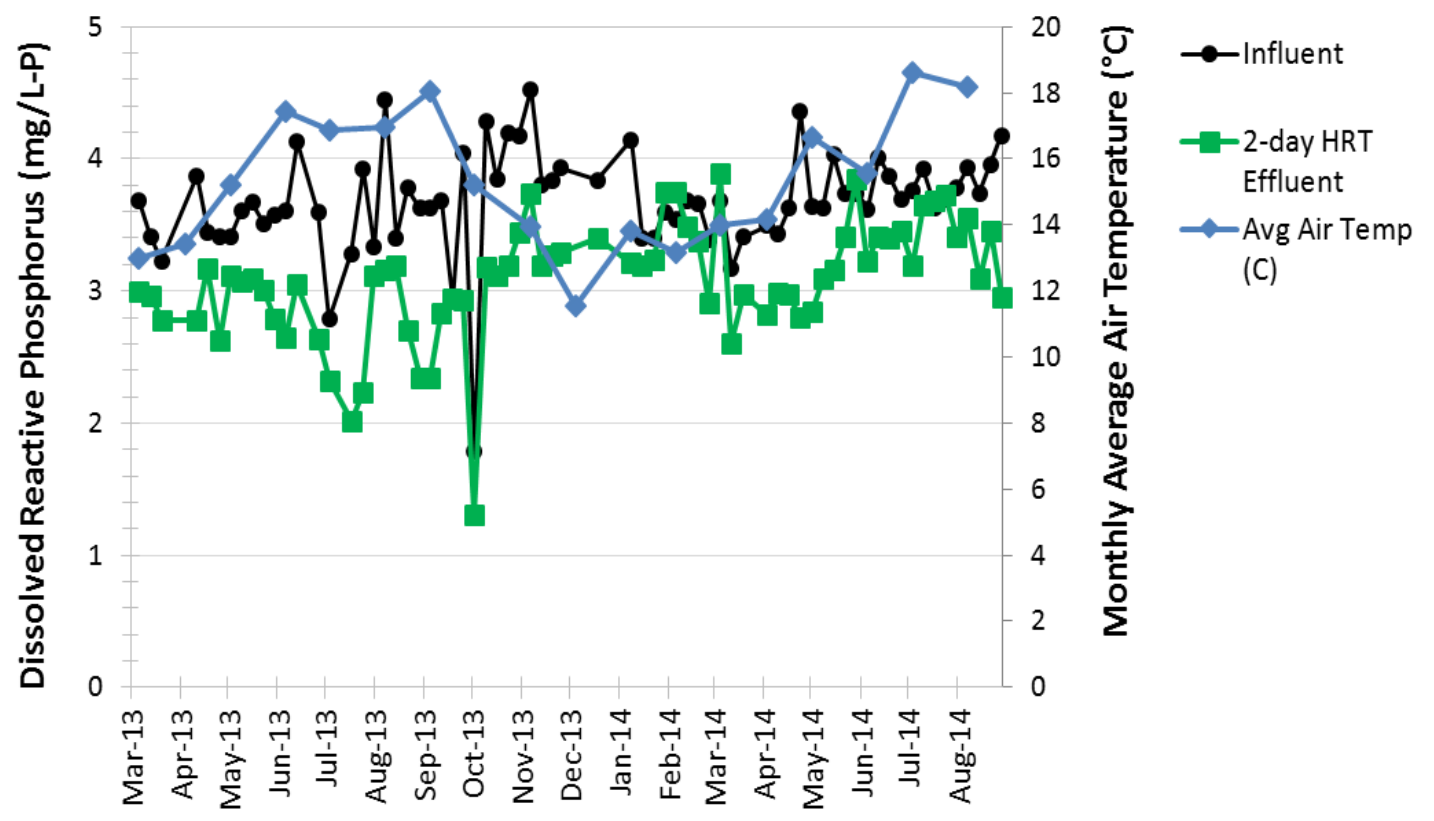

Figure 4-35: Monthly average air temperature and DRP concentrations in the Influent and twoday HRT effluent, with during March 6, 2013 - August 28, 2014. 


\subsection{Summary of sequential Anaerobic and Aerobic Digestion Experiments}

This section covers the total organic nitrogen and particulate phosphorus degradation results from the lab-scale anaerobic and aerobic digestion experiments outlined in Section 3.3. The resulting nitrogen and phosphorus solubilization from organic degradation will be discussed. Refer to Hill (2014) for specific results on solids, nitrogen, and phosphorus data trends, and methane generation results from anaerobic digestion experiments. Refer to Chang (2014) for specific solids, nitrogen, and phosphorus data trends from aerobic digestion experiments.

The purpose of these experiments was to determine the extent of organic nitrogen and particulate phosphorus degradation from a sequence of anaerobic digestion followed by aerobic digestion. As described earlier, this sequence of conditions mimicked conditions to be imposed on algae biomass in later experiments at pilot scale. In those experiments, the digestate pilot digesters will be fed to the raceway ponds to provide nitrogen and phosphorus for algae growth. Wastewater nutrients will not be provided during those experiments.

In the present lab studies, the most important variables to determine were the fraction of organic nitrogen and particulate phosphorus that were degraded, releasing soluble nitrogen and phosphorus for growth of new algae. Such nutrient recycling should improve the environmental sustainability of algae biofuels.

The cell-lysing pretreatment technologies described in Hill (2014) were designed to increase the fraction of organic nitrogen and particulate phosphorus that is readily degradable during anaerobic digestion. The two lysing methods were high-pressure homogenization and sonication. Each experiment included control reactors fed algae that 
had not been pretreated prior to anaerobic digestion. Refer to Hill (2014) for a detailed analysis on the effects of these two lysing methods in the anaerobic digestion experiments. Refer to Chang (2014) for a detailed analysis on the effects of these two lysing methods in the aerobic digestion experiments. Sections 4.5.1 and 4.5.2 below combine the results from those two master's theses to provide a complete analysis of the total organic nitrogen and particulate phosphorus decay in the algal sludge due to pretreatment followed by anaerobic digestion followed by aerobic digestion.

\subsubsection{Effect of Lysing Method on Organic Nitrogen Decay}

The following analysis compares the effects that high-pressure homogenization and sonication had on organic nitrogen decay and resulting solubilization during lab scale anaerobic and aerobic digestion experiments. The amount of organic nitrogen degradation and solubilization is discussed in terms of the fraction of organic nitrogen remaining after anaerobic and aerobic digestion.

Figure 4-36 highlights the fraction of organic nitrogen remaining after each digestion step for the two lysing methods and their respective controls. "Digestate" refers to the anaerobic digester samples. High-pressure homogenization reduced the fraction of organic nitrogen remaining by $19 \%$ in the anaerobic digestion reactors, increasing the amount of resolubilized nitrogen that can be recycled into the raceways for regrowth. After aerobic digestion, the fraction of organic nitrogen remaining was lower in the control reactors than the homogenized. The excess $19 \%$ of organic nitrogen remaining in the high-pressure homogenization control reactors degraded in an aerobic environment. In the sonication test, organic nitrogen degradation in the anaerobic digestion reactors was $9 \%$ lower compared to the control. Thus indicating that after 120 days of aerobic 
treatment, high-pressure homogenization and sonication had no significant impact on total organic nitrogen degradation and solubilization compared to the controls. The sonication control reactors were not aerobically digested because of insufficient sample volume after anaerobic digestion.

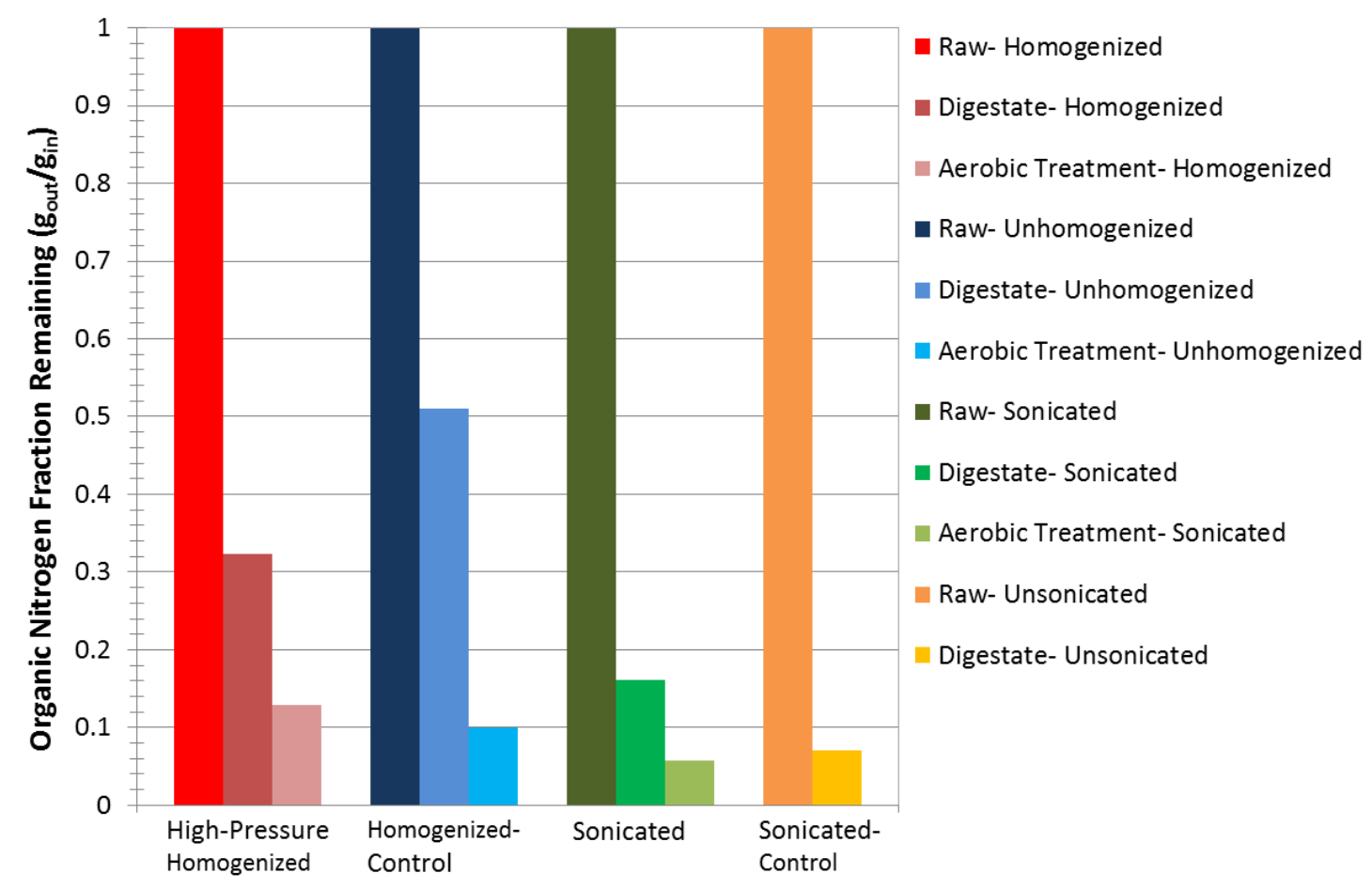

Figure 4-36: The effect of the pretreatment technologies on organic nitrogen degradation during anaerobic digestion and aerobic digestion compared to untreated controls. The pretreatment technologies were high-pressure homogenization and sonication. "Digestate" refers to the effluent of the anaerobic digesters.

\subsubsection{Effect of Lysing Method on Particulate Phosphorus Decay}

The following analysis compares the effects that high-pressure homogenization and sonication had on particulate phosphorus decay and solubilization during lab scale anaerobic and aerobic digestion experiments. The amount of particulate phosphorus 
degradation and solubilization will be discussed in terms of the fraction of particulate phosphorus remaining after anaerobic and aerobic digestion.

Figure 4-37 highlights the fraction of particulate phosphorus remaining after each digestion step for the two lysing methods and their respective controls. High-pressure homogenization had no significant effect on increasing the particulate phosphorus decay. The high pressure homogenization reactors and their control reactors only achieved 5\% and $1 \%$ degradation, respectively, during anaerobic digestion. The sonication reactors and their control reactors achieved $47 \%$ and $48 \%$ degradation, respectively. As described in Hill (2014), the dissolved phosphorus data for the high-pressure homogenization experiment was deemed incorrect because phosphorus precipitation occurred in the reactors. He concluded that this was the cause for low degradation results. The aerobic digestion stage achieved further particulate phosphorus degradation of $48 \%$ in both the high-pressure homogenized and control reactors, thereby providing further resolubilized phosphorus in an aerobic environment (i.e. raceway ponds). Due to the roughly equal results in the high pressure homogenized reactors and their controls, the lysing step appears to have had no significant impact on degradation and solubilization. Total phosphorus was not run on the aerobic treatment sonication reactors, therefore particulate phosphorus could not be calculated. However, based on the roughly equal degradation in the digestate, sonication had no impact on particulate phosphorus decay and solubilization during anaerobic digestion. 


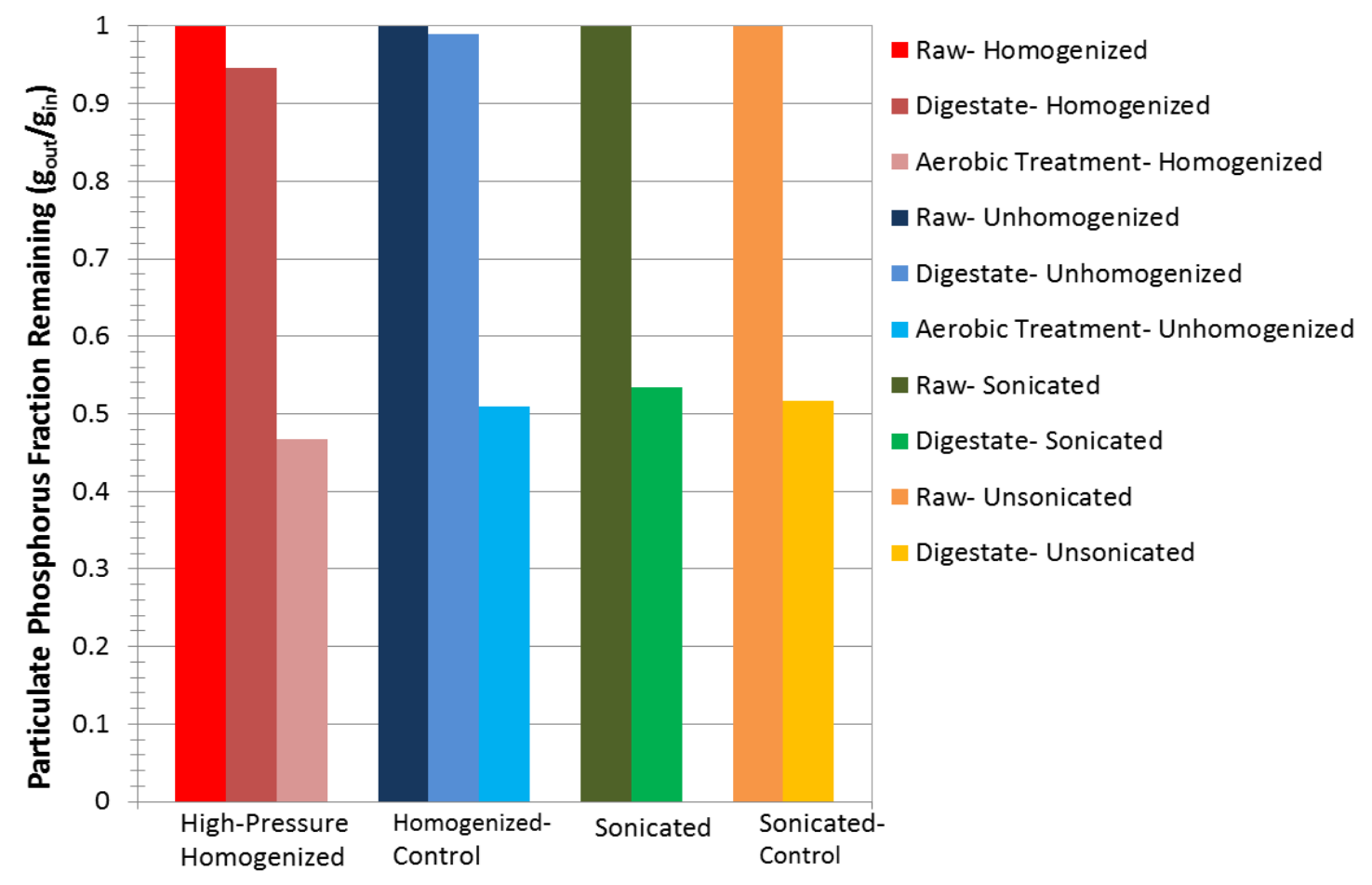

Figure 4-28: The effect of the pretreatment technologies on particulate phosphorus degradation during anaerobic digestion and aerobic digestion. The pretreatment technologies were highpressure homogenization and sonication. "Digestate" refers to the effluent of the anaerobic digesters 


\section{Conclusions}

The final chapter of this thesis summarizes the significant results of each experiment and limitations of the research. The main objective of the pond experiments was to evaluate the fate of nitrogen and phosphorus in raceway ponds fed primary clarifier effluent wastewater. Also included is a summary of the results discussing the effect of each lysing method on organic nitrogen and particulate phosphorus degradation from the compound anaerobic and aerobic digestion experiments discussed in Hill (2014) and Chang (2014), respectively.

\subsection{Experimental Conclusions}

The two separate ponds-in-series experiments will be presented first, followed by the two-day HRT pond experiment, and finally the summarized results from the anaerobic and aerobic digestion experiments.

\subsubsection{N and P Removal from Ponds-in-Series Experiment I and II}

Ponds-in-series Experiments I and II had similar process flows and goals but differed in the HRT of the Round 2 ponds and the influent conditions from Round 1 to Round 2 ponds. Both experiments tested the ability of raceway ponds operating in series to achieve low soluble nitrogen and dissolved reactive phosphorus levels.

\subsubsection{N and P Removal from Ponds-in-Series Experiment I}

Experiment I was a continuation of the ponds-in-series experiment presented in Rodrigues (2013). The triplicate Round 1 ponds operated at a 3-day HRT followed by triplicate Round 2 ponds at 4-day HRT. The Round 2 ponds were supplemented with $\mathrm{CO}_{2}$ via sparging which was programmed to turn on and off at $\mathrm{pH}$ set points of 8.4 and 8.5.

Round 1 ponds received primary clarifier effluent. The effluent from the triplicate Round 
1 ponds was pumped to its respective tube settler and the supernatant fed the triplicate Round 2 ponds via gravity drainage (Section 3.2.2). The total HRT after Round 1 and 2 treatment was 7 days. This duration of this experiment was from March 6, 2013 to June 13,2013 . It should be noted that this experiment was conducted only during the summer months.

The average Round 2 TAN effluent concentration of $0.1 \mathrm{mg} / \mathrm{L}-\mathrm{N}$, with minimums of $<0.1$ $\mathrm{mg} / \mathrm{L}-\mathrm{N}$ recorded for 7 out of the 14 weeks, and a maximum of $0.8 \mathrm{mg} / \mathrm{L}-\mathrm{N}$ (Table 5-1). Oxidized nitrogen levels remained lower in Round 2 effluent than Round 1 effluent, with averages of $10.1 \mathrm{mg} / \mathrm{L}-\mathrm{N}$ and $12.8 \mathrm{mg} / \mathrm{L}-\mathrm{N}$, respectively. Denitrification did not likely occur in Round 2 because DO levels remained above 30\% during nighttime; thus the nitrate removal in Round 2 was from assimilation after TAN was depleted. Round 2 effluent achieved soluble nitrogen $\left(\mathrm{TAN}+\mathrm{NO}_{2}{ }^{-}+\mathrm{NO}_{3}{ }^{-}\right.$) levels of less than $10 \mathrm{mg} / \mathrm{L}-\mathrm{N}$ for only four weeks out of $14.76 \%$ of the influent soluble nitrogen was converted to organic nitrogen by assimilation, while $6 \%$ of the influent ammonia was lost by volatilization. Average DRP concentrations in Round 1 and 2 effluent was $2.5 \mathrm{mg} / \mathrm{L}-\mathrm{P}$ and $1.2 \mathrm{mg} / \mathrm{L}-\mathrm{P}$, respectively. These resulted in removal efficiencies of $29 \%$ for Round 1 and $67 \%$ for Round 2, a $37 \%$ increase in Round 2.

Table 5-1: Significant TAN effluent concentrations and removal efficiencies in the triplicate Round 1 and Round 2 ponds and Influent.

\begin{tabular}{lccc} 
& Influent & Round 1 Effluent & Round 2 Effluent \\
\hline Avg. TAN (mg/L-N) & 39 & 4.8 & 0.1 \\
Avg. \% Removal & - & $88 \%$ & $\sim 100 \%$ \\
Standard Deviation of \% & 5 & $4.8 \%$ & $0.6 \%$ \\
removal & - & 4.5 & $<0.1$ \\
25th Percentile (mg/L-N) & - & 5.9 & 0.2 \\
75th Percentile (mg/L-N) & 31 & 2.3 & $<0.1$ \\
Min. TAN (mg/L-N) & & &
\end{tabular}




\subsubsection{N and P Removal from Ponds in Series Experiment II}

For Experiment II, the operation of triplicate Round 1 ponds did not change, but the triplicate Round 2 ponds were switched to a 3-day HRT. The effluent from Round 1 ponds was still pumped to their respective tube settler, but for this experiment the supernatant from the settlers gravity drained into a continuously mixed head tank that evenly distributed the water to each Round 2 pond (Section 3.2.2). The total HRT after

Round 1 and 2 treatment was 6 days, one day less than Experiment I. Both Round 1 and 2 ponds received $\mathrm{CO}_{2}$ sparging to programmed to turn on and off at $\mathrm{pH}$ set points of 8.4 and 8.5. The duration of this experiment was from June 26, 2013 to August 28, 2014. It should be noted that the results for this experiment were split between summer months (March - October) and winter months (November - February) due to treatment variability during periods of low solar radiation and average air temperatures.

The six days of treatment time resulted in average TAN effluent concentrations of 0.15 $\mathrm{mg} / \mathrm{L}-\mathrm{N}$ in the summer and $3.7 \mathrm{mg} / \mathrm{L}-\mathrm{N}$ in the winter, corresponding to average removal efficiencies of 100\% and 88\% (Table 5-2). Round 2 achieved TAN effluent concentrations of $0.0 \mathrm{mg} / \mathrm{L}-\mathrm{N}$ for 13 weeks out of 58 weeks of experimentation. During the winter months as solar radiation decreased below $150 \mathrm{~W} / \mathrm{m}^{2}$, the average removal efficiencies decreased $102 \%$ for Round 1 and $12 \%$ for Round 2 . Thus meaning the ponds in series operation was still significantly affected by seasonal variation in weather

(Figure 5-1). Unintentional interruptions in $\mathrm{CO}_{2}$ supplementation in both pond sets contributed to periods of lower TAN removal. Oxidized nitrogen concentrations 
increased in the winter for Round 2 effluent, which corresponded to periods when TAN levels were greater than $1 \mathrm{mg} / \mathrm{L}-\mathrm{N}$. Nitrate nitrogen concentrations could not be measured from January 8 to February 5, 2014 while the probe was being repaired. Round 2 effluent in the summer achieved soluble nitrogen levels of less than $10 \mathrm{mg} / \mathrm{L}-\mathrm{N}$ for $70 \%$ of the 43 weeks of experimentation during summer. $81 \%$ of the influent soluble nitrogen was converted to organic nitrogen by assimilation, and only $1 \%$ of the influent ammonia was lost by volatilization. Average DRP concentrations in Round 2 effluent was $1.3 \mathrm{mg} / \mathrm{L}-\mathrm{P}$ in the summer and $2.3 \mathrm{mg} / \mathrm{L}-\mathrm{P}$ in the winter, corresponding to removal efficiencies of $66 \%$ and $38 \%$.

Table 5-2: Summer and winter TAN effluent concentrations and percent removals for Influent and Round 1 and 2 effluent.

\begin{tabular}{lcccccc} 
& \multicolumn{2}{c}{ Influent } & \multicolumn{2}{c}{ Round 1 Effluent } & \multicolumn{2}{c}{ Round 2 Effluent } \\
\hline & Winter & Summer & Winter & Summer & Winter & Summer \\
\hline Avg. TAN (mg/L-N) & 34 & 37 & 20.1 & 5.6 & 3.7 & 0.15 \\
$\begin{array}{l}\text { Avg. \% Removal } \\
\text { Standard Deviation of \% }\end{array}$ & - & - & $41 \%$ & $84 \%$ & $88 \%$ & $\sim 100 \%$ \\
removal & 4 & 8 & $20.5 \%$ & $7.6 \%$ & $13.8 \%$ & $0.7 \%$ \\
25th Percentile (mg/L-N) & - & - & 14.7 & 3.9 & 1.0 & 0.04 \\
75th Percentile (mg/L-N) & - & - & 24.3 & 7.2 & 4 & 0.1 \\
Min. TAN (mg/L-N) & 27 & 22 & 9.1 & 2.1 & 0.3 & $<0.1$ \\
Max. TAN (mg/L-N) & 42 & 53 & 34 & 10.1 & 15.2 & 1.2 \\
\hline
\end{tabular}




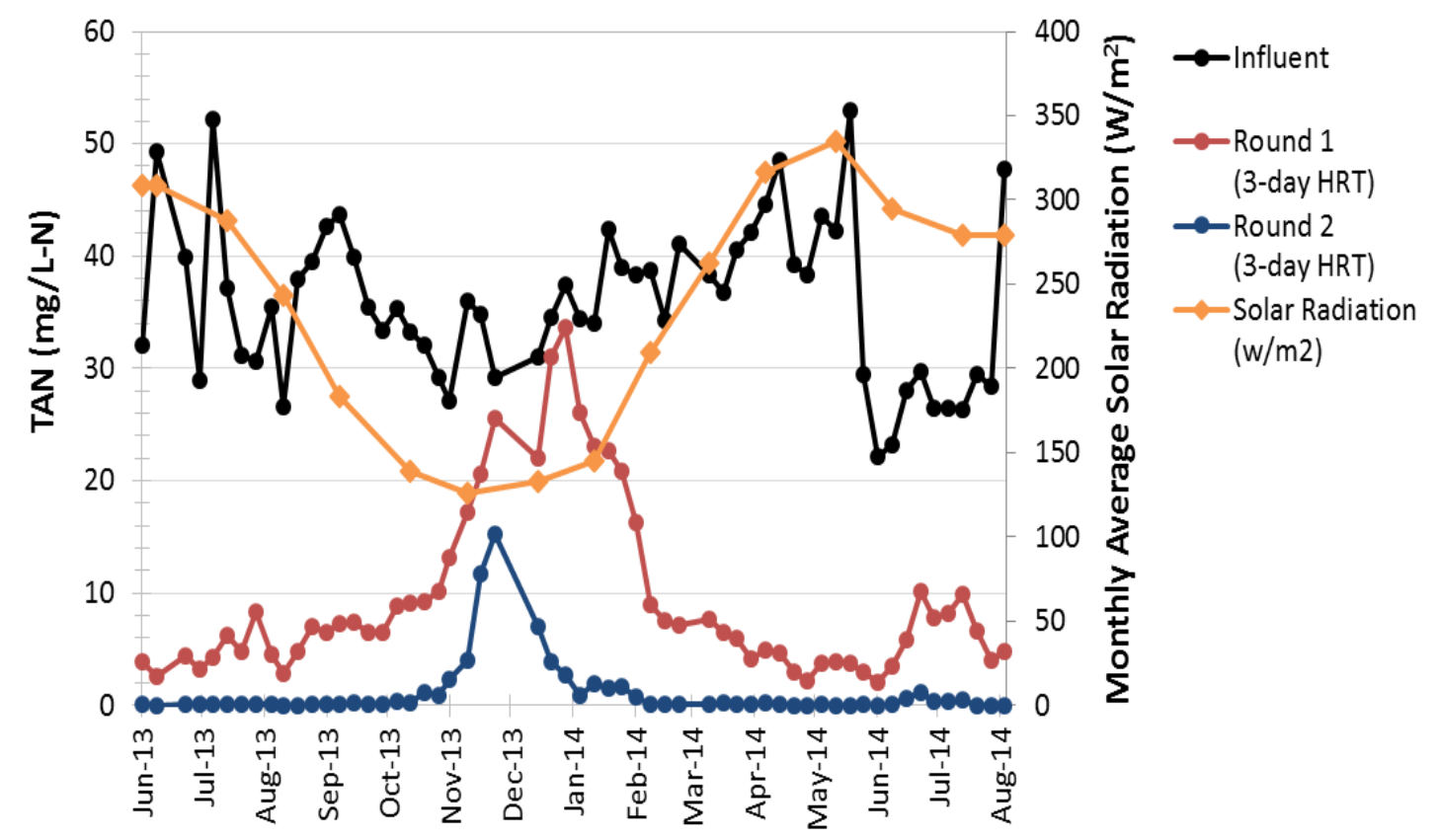

Figure 5-1: TAN concentrations from Round 1 and 2 effluent and Influent, presented as a time series with monthly average solar radiation.

\subsubsection{N and P Removal from Two-day HRT Raceway Ponds}

The two-day HRT triplicate ponds received primary clarifier effluent wastewater and did not have $\mathrm{CO}_{2}$ supplementation. This experiment tested the nitrogen and phosphorus removal capabilities of raceway ponds operating at a shorter HRT of two days. The duration of this experiment was from March 6, 2013 to August 28, 2014. The results were split up between summer months (March - October) and winter months (NovemberFebruary).

The two-day HRT ponds achieved $71 \%$ average TAN removal efficiency in the summer but decreased to $11 \%$ in the winter (Table 5-3). A TAN effluent concentration of less than $1 \mathrm{mg} / \mathrm{L}-\mathrm{N}$ was measured once during the experiment. The average oxidized nitrogen concentration was below $6.0 \mathrm{mg} / \mathrm{L}-\mathrm{N}$ for both summer and winter. Elevated levels of 
greater than $10 \mathrm{mg} / \mathrm{L}-\mathrm{N}$ corresponded with above average TAN removal efficiencies. The triplicate two-day HRT ponds achieved average soluble nitrogen levels of less than 10 $\mathrm{mg} / \mathrm{L}-\mathrm{N}$ for three weeks out of the 72 weeks of experimentation. Those three weeks corresponded to measured organic nitrogen composition in the biomass ranging from $12 \%$ to $14 \%$, indicative of above average nitrogen assimilation. $41 \%$ of the influent soluble nitrogen was converted to organic nitrogen by assimilation, while $3 \%$ was lost through ammonia volatilization. Dissolved reactive phosphorus removal was minimal for both summer and winter, with average removal efficiencies of $17 \%$ and $10 \%$, respectively.

Table 5-3: Winter and summer TAN effluent concentrations and removal efficiencies for the triplicate two-day HRT ponds, and the Influent.

\begin{tabular}{lcccc} 
& \multicolumn{2}{c}{ Influent } & \multicolumn{2}{c}{$\begin{array}{c}\text { Average two-day HRT } \\
\text { effluent }\end{array}$} \\
\hline & Winter & Summer & Winter & Summer \\
\hline Average TAN (mg/L-N) & 34 & 37 & 30.4 & 10.4 \\
Average \% Removal & - & - & $11 \%$ & $71 \%$ \\
Standard Deviation of $\%$ & 4 & 7 & $20 \%$ & $15 \%$ \\
removal & - & - & 25.1 & 6.3 \\
25th Percentile (mg/L-N) & - & - & 37.2 & 13.8 \\
75th Percentile (mg/L-N) & 27 & 22 & 17.5 & 0.6 \\
Min. TAN (mg/L-N) & 42 & 53 & 43 & 22.5 \\
Max. TAN (mg/L-N) & & & &
\end{tabular}

\subsubsection{Summary of sequential Anaerobic and Aerobic Digestion Experiments}

Lab-scale experiments of anaerobic digestion followed by aerobic digestion of harvested algal biomass were performed to quantify the rate and extent of organic nitrogen and particulate phosphorus degradation, which results in nutrient solubilization.

High pressure homogenization decreased the fraction of organic nitrogen remaining by $19 \%$ in the anaerobic digestion reactors. However, after aerobic treatment the fraction of 
organic nitrogen remaining was equal in both the homogenized control samples. Therefore the high pressure homogenization did not increase the fraction of organic nitrogen that is degradable. Sonication decreased the organic nitrogen degradation by $9 \%$ during anaerobic digestion. Aerobic digestion was not performed on the unsonicated control samples because of a lack of sample volume. Based on anaerobic digestion results, sonication did not increase the fraction of degradable organic nitrogen.

The sonication reactors and its unsonicated control reactors achieved $47 \%$ and $48 \%$ particulate phosphorus degradation, respectively. Total phosphorus was not performed on the aerobic digestion experiments for sonication so particulate phosphorus could not be measured. The high pressure homogenization and its unhomogenized control reactors achieved only $5 \%$ and $1 \%$ particulate phosphorus degradation, respectively. As described in Hill, 2014 the phosphorus data were deemed illegitimate because phosphorus precipitation occurred in the anaerobic digestion reactors. He concluded this was the cause for low degradation results. Aerobic digestion achieved $48 \%$ particulate phosphorus degradation in both the homogenized reactors and unhomogenized control reactors. Based on these results, sonication and high-pressure homogenization did not help increase the amount of degradable particulate phosphorus.

Ponds operating in series, each at a 3-day HRT, proved to achieve sufficient secondary treatment in the summer to meet common TAN and TN discharge limits set by the RWQCBs. Their treatment performance in the winter did not achieve the TAN and TN discharge limits. Longer HRTs or another pond set in series may provide the extra treatment in winter needed to meet those discharge limits. Anaerobic and aerobic digestion of untreated harvested algae achieved sufficient nutrient solubilization through 
biomass degradation. Recycling these solubilized nutrient is an important aspect to improve algal biofuels.

\subsection{Limitations of Study}

The pond operational, experimental, and laboratory limitations were as follows:

Pond operational limitations

1. Neptune data logger malfunctioned from March - September 2013, preventing the recorded pond $\mathrm{DO}, \mathrm{pH}$, and temperature readings.

2. The $\mathrm{pH}$ and $\mathrm{DO}$ probes malfunctioned periodically, producing unreliable $\mathrm{DO}$ and $\mathrm{pH}$ data for short periods of time.

3. Tube settler pumps intermittently failed, preventing feed to the Round 2 ponds.

Experimental limitations

1. Grab samples were only representative of the ponds at one time during the day.

2. Organic nitrogen and particulate phosphorus removed from harvested algae was not directly measured.

3. Carbon assimilation was not measured.

4. Polyphosphate and acid-hydrolysable phosphorus in the ponds was not measured.

Laboratory limitations

1. The nitrate ion selective electrode (Orion Model RO1-14563) was down for maintenance for $40 \%$ of the winter experimentation, preventing the measurement of nitrate.

2. Total phosphorus mass balances on the primary clarifier effluent and the ponds did not pass QC. The total phosphorus analytical test should be fine-tuned to achieve equal mass balances across the influent and the ponds. 


\subsection{Future Research}

To fully understand the nutrient removal performance in this study, additional research should be done on the following:

1. Measure all forms of phosphorus in the raceway ponds, not just dissolved reactive phosphorus. Also, the total phosphorus analytical test should be fine-tuned to achieve good mass balance data.

2. Investigate the nitrifying and denitrifying bacteria present in the raceway ponds.

3. Lower the $\mathrm{pH}$ set points that trigger the $\mathrm{CO}_{2}$ supplementation to reduce the chance of ammonia volatilization.

4. Measure carbon and iron assimilation by algae.

5. Measure the organic nitrogen and particulate phosphorus content in the harvested algae for mass balances on the settling units.

6. Determine the optimal amount of resolubilized nutrients to recycle into the raceway ponds to achieve consistently high algae growth. 


\section{REFERENCES}

Bohutskyi, P., Kula, T., Kessler, B., Chow, S., Liu, K., Bouwer, E., . . . Allnutt, F. (2014). Enhancing Performance and Assaying Nutrient Recycling Potential for a Sequential Photoautotrophic-Heterotrophic Algal Biofuel Production System.

CEC. (2005). California's Water-Energy Relationship. Sacramento: California Energy Comission.

Chang, M. (2014). Water and Nutrient Removal by High Rate Algae Ponds Fed Primary Treated Municipal Wastewater. San Luis Obispo.

Chinnasamy, S., Sood, A., Renuka, N., Prasanna, R., Ratha, S., Bhaskar, S., . . Lewis, D. (2014). Ecological aspects of algae cultivation in wastewaters for recycling of nutrients and biofuel applications. Biofuels, 1-4.

Eddy, M. \&. (2014). Wastewater Engineering Treatment and Resource Recovery. New York: McGraw-Hill Education.

EERE. (n.d.). Algal Biofuels. Retrieved from Office of Energy Efficiency \& Renewable Energy: http://www.energy.gov/eere/bioenergy/algal-biofuels

Hill, A. (2014). The Effect of Pretreatment Methods on Methane Yields and Nutrient Solubilization During Anaerobic Digestion of Microalgae. San Luis Obispo.

Hu, Z., Houweling, D., \& Dold, P. (2012). Biological Nutrient Removal in Municipal Wastewater Treatment: New Directions in Sustainability. Journal of Environmental Engineering, 1-4. 
Jewell, W., \& McCarty, P. (1971). Aerobic Decomposition of Algae. Environmental Science and Technology, 1023-1031.

Kendrick, M. (2011). Algal Bioreactors for Nutrient Removal and Biomass Production During the Tertiary Treatment of Domestic Sewage. Loughborough: Loughborough University.

Lundquist, T., Woertz, I., Quinn, N., \& Benemann, J. (2010). A Realistic Technology and Engineering Assessment of Algae Biofuel Production.

Mayo, A., \& Mutamba, J. (2005). Modeling nitrogen removal in a coupled HRP and unplaned horizontal flow subsurface gravel bed constructed wetland. Science Direct, 673-678.

NREL. (2014, April 22). Solar Maps. Retrieved from National Renewable Energy Labratory: http://www.nrel.gov/gis/images/map_pv_us_annual10km_dec2008.jpg

Nurdogan, Y., \& Oswald, W. (1995). Enhanced Nutrient Removal in High-Rate Ponds. Water Science Technology, 33-37.

Oswald, W. (1990). Advanced Integrated Wastewater Pond Systems. Supplying Water and Saving the Environment for Six Billion People (pp. 74-77). San Francisco: ASCE.

Oswald, W., Gotass, H., Ludwig, H., \& Lynch, V. (1953). Algae Symbiosis in Oxidation Ponds. Sewage and Industrial Wastes, 25.

Oswald, W., Shelef, C., \& Golueke, C. (1968). Kinetics of Algal Systems in Waste Treatment. Berkeley: College of Engineering and School of Public Health. 
Park, J., Craggs, R., \& Shilton, A. (2010). Wastewater treatment high rate algal ponds for biofuel production. Bioresource Technology, 1-6.

Park, J., Craggs, R., \& Shilton, A. (2011). Recycling algae to improve species control and harvest efficiency from a high rate algal pond. Water Research, 6637-6640.

Pitas, V., Fazekas, B., Banyai, Z., \& Karpati, A. (2010). Energy efficiency of the municipal wastewater treatment. Journal of Biotechnology, 1.

Porter, K. (1972). Enhancement of Algal Growth and Productivity by Grazing Zooplankton. Science, 1332.

Powell, N., Shilton, A., Chisti, Y., \& Pratt, S. (2009). Towards a luxury uptake process via microalgae - Defining the polyphosphate dynamics. Water Research, 42074213.

Powell, N., Shilton, A., Pratt, S., \& Chisti, Y. (2008). Factors Influencing Luxury Uptake of Phosphorus by Microalgae in Waste Stabilization Ponds. Environmental Science Technology, 5958-5962.

Roberts, A. (2014). Velocity Report. San Luis Obispo.

Rodigues, M. (2013). NUTRIENT REMOVAL USING MICROALGAE IN WASTEWATER-FED HIGH RATE PONDS. San Luis Obispo.

SSWM. (n.d.). Advanced Integrated Ponds. Retrieved from Sustainable Sanitation and Water Management: http://www.sswm.info/content/advanced-integrated-ponds 
Sutherland, D., Howard-Williams, C., Turnbull, M., Broady, P., \& Craggs, R. (2014). Enhancing microalgal photosynthesis and productivity in wastewater treatment high rate algal ponds for biofuel production. Bioresource Technology, 1-2.

SWRCB. (2010). Recycled Water Policy. Sacramento: California Environmental Protection Agency.

U.S. GAO. (2011). Energy-Water Nexus. Washington, DC: United States Government Accountability Office.

Venteris, E., Skaggs, R., Coleman, A., \& Wignosta, M. (2013). A GIS Cost Model to Assess the Vailability of Freshwater, Seawater, and Saline Groundwater for Algal Biofuel Production in the United States. Environmental Science and Technology, 4840-4849.

Woertz, I., Fulton, L., \& Lundquist, T. (2009). Nutrient Removal \& Greenhouse Gas Abatement with CO2 Supplemented Algal High Rate Ponds. San Luis Obispo: Cal Poly Digital Commons.

Yang, J., Xu, M., Zhang, X., Hu, Q., Sommerfield, M., \& Chen, Y. (2011). Life-cycle analysis on biodiesel production from microalgae: Water footprint and nutrients balance. Bioresource Technology, 159-165. 


\section{APPENDICES}

Appendix A: Pond pH, DO, and temperature data recorded by Neptune data logger

Appendix B: San Luis Obispo monthly precipitation, solar radiation, and air temperature data recorded by CIMIS

Appendix C: Organic nitrogen and particulate phosphorus data from the anaerobic + aerobic digestion experiments

Appendix D: List of operational changes at the AFS 


\section{Appendix A: Pond pH, DO, and temperature graphs}

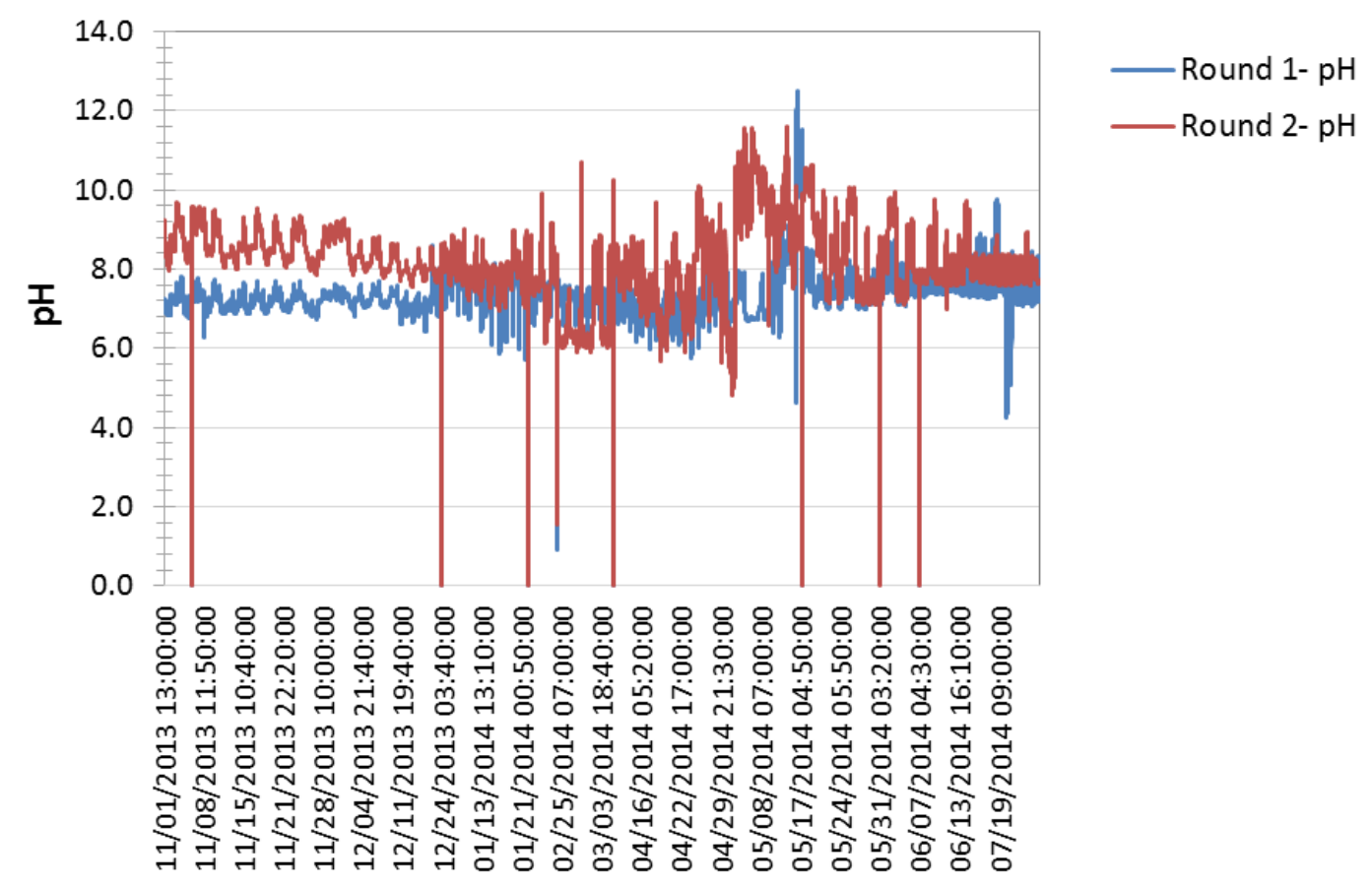

Figure 7-1: Recorded hourly $\mathrm{pH}$ measurements for Round 1 and 2 ponds during November 1, 2013 - August 28, 2014 of Ponds in series- Experiment II. The values displayed are an average of the triplicate Round 1 and 2 ponds. The outlier values (below pH 5 and above $\mathrm{pH}$ 12) correspond to time periods when the probes were down for maintenance or the data logger malfunctioned, and should be ignored. The Neptune data logger recorded these measurements. 


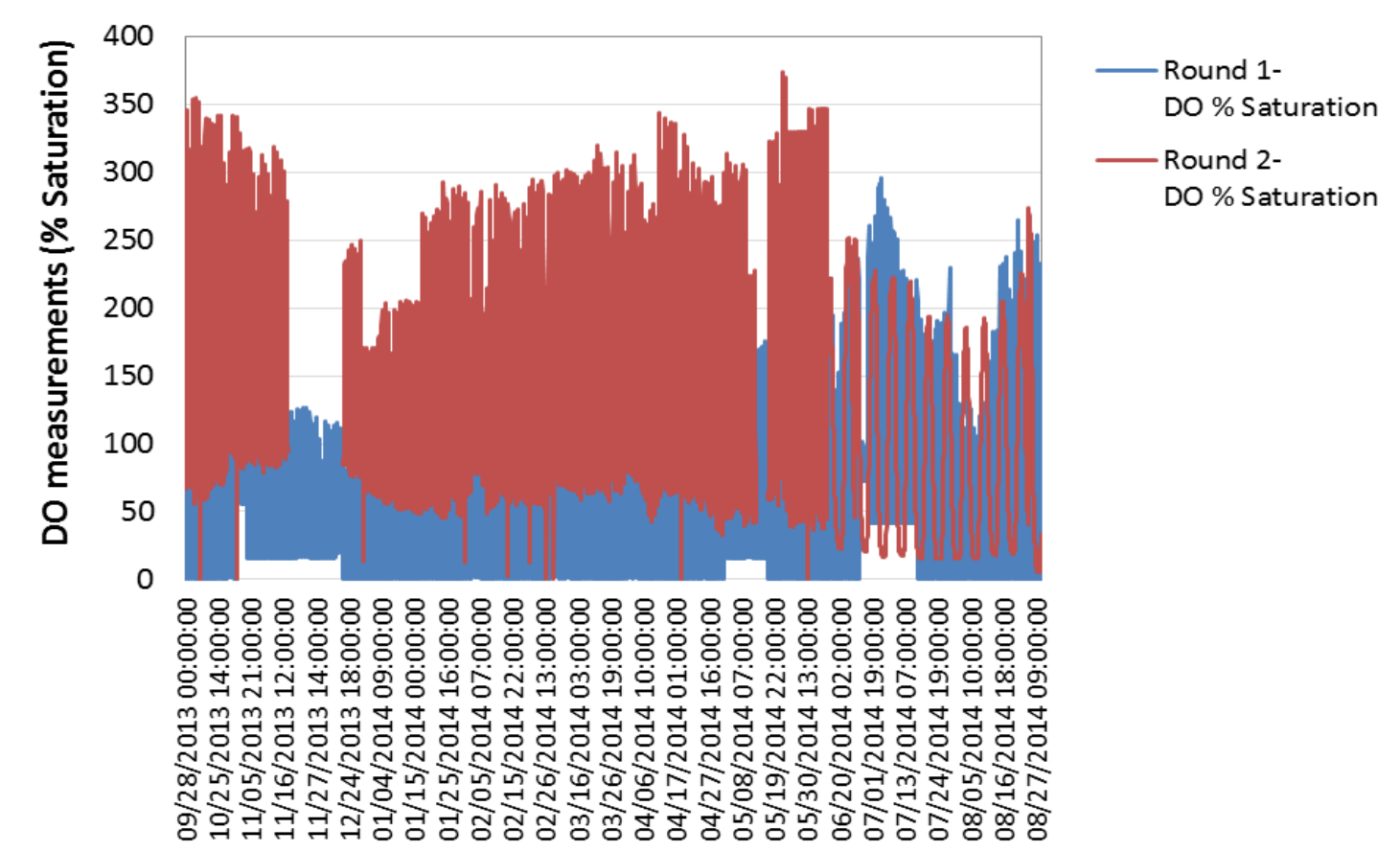

Figure 7-2: Recorded hourly DO measurements for Round 1 and 2 ponds during September 28, 2013 - August 28, 2014 of Ponds in series- Experiment II. The values displayed are an average of the triplicate Round 1 and 2 ponds. The Neptune data logger recorded these measurements. 


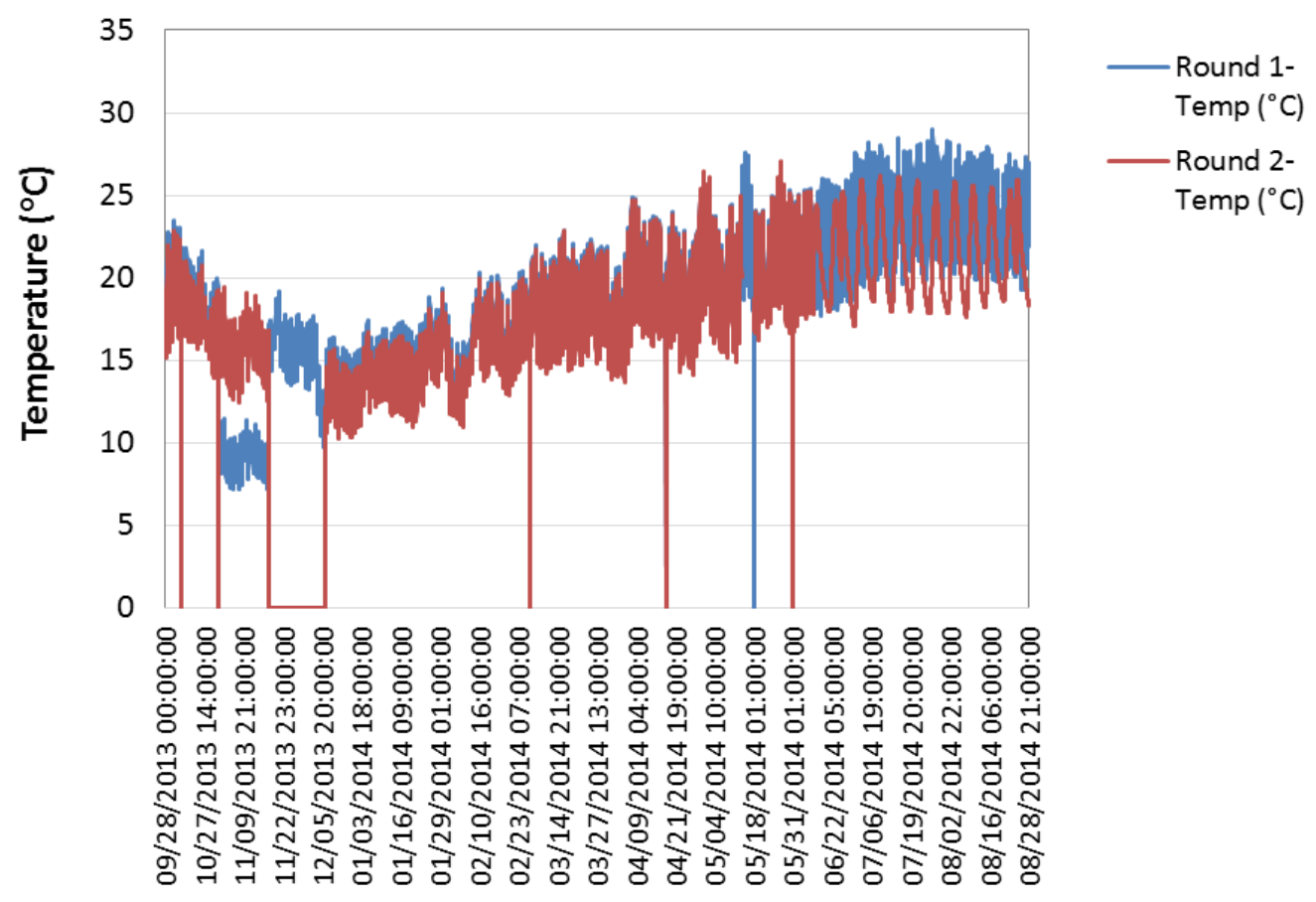

Figure 7-3: Recorded hourly temperature measurements for Round 1 and 2 ponds during September 29, 2013 - August 28, 2014 of Ponds in series- Experiment II. The values displayed are an average of the triplicate Round 1 and 2 ponds. The outlier values (temperatures of $0^{\circ} \mathrm{C}$ ) correspond to time periods when the probes were down for maintenance or the data logger malfunctioned, and should be ignored. The Neptune data logger recorded these measurements. 


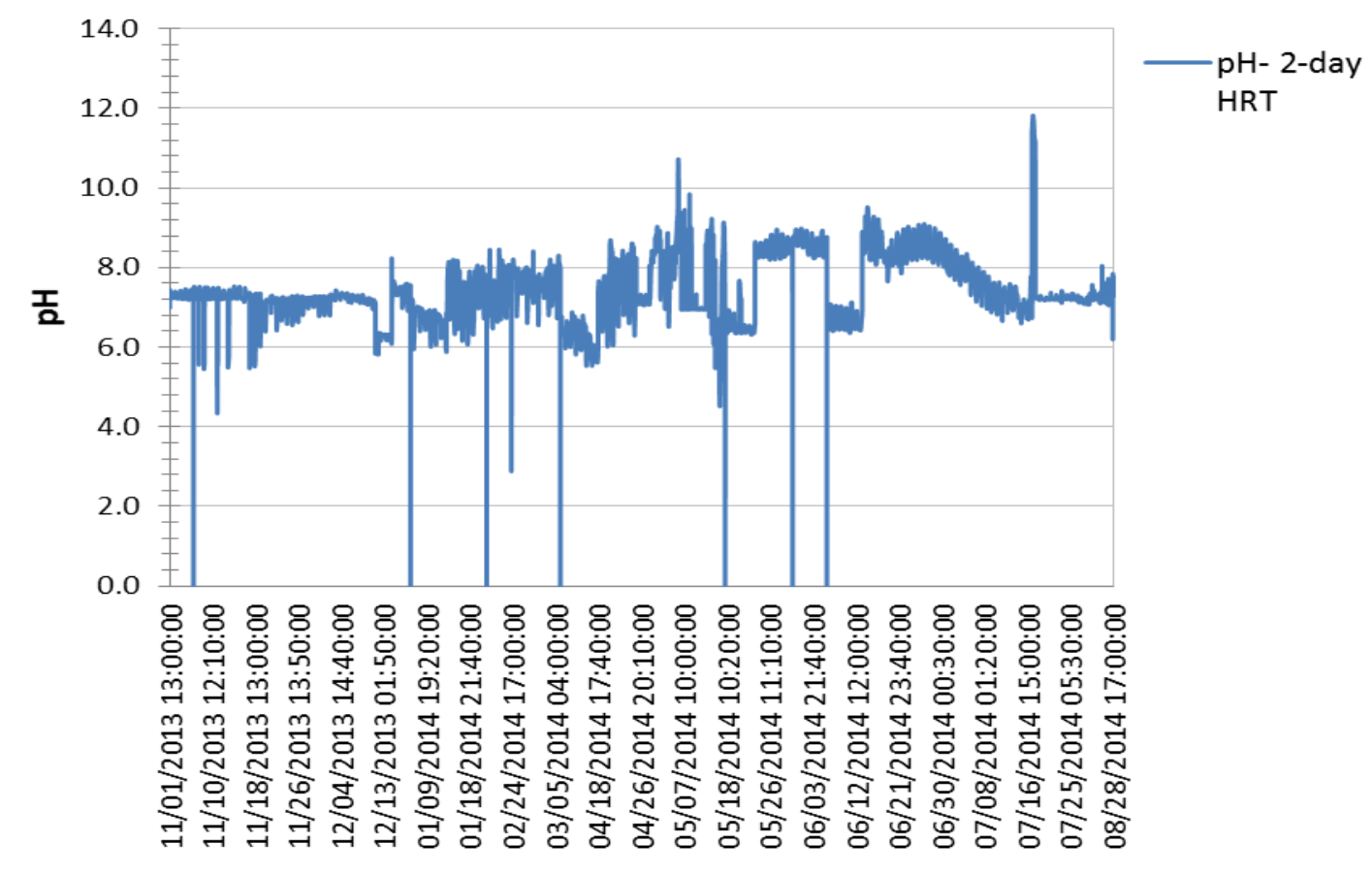

Figure 7-4: Recorded hourly $\mathrm{pH}$ measurements for the two-day HRT ponds during November 1, 2013 - August 28, 2014 of the Two-day HRT Raceway Ponds experiment. The values displayed are an average of the two-day HRT ponds. The outlier values (below $\mathrm{pH} 5$ ) correspond to time periods when the probes were down for maintenance or the data logger malfunctioned, and should be ignored. The Neptune data logger recorded these measurements 


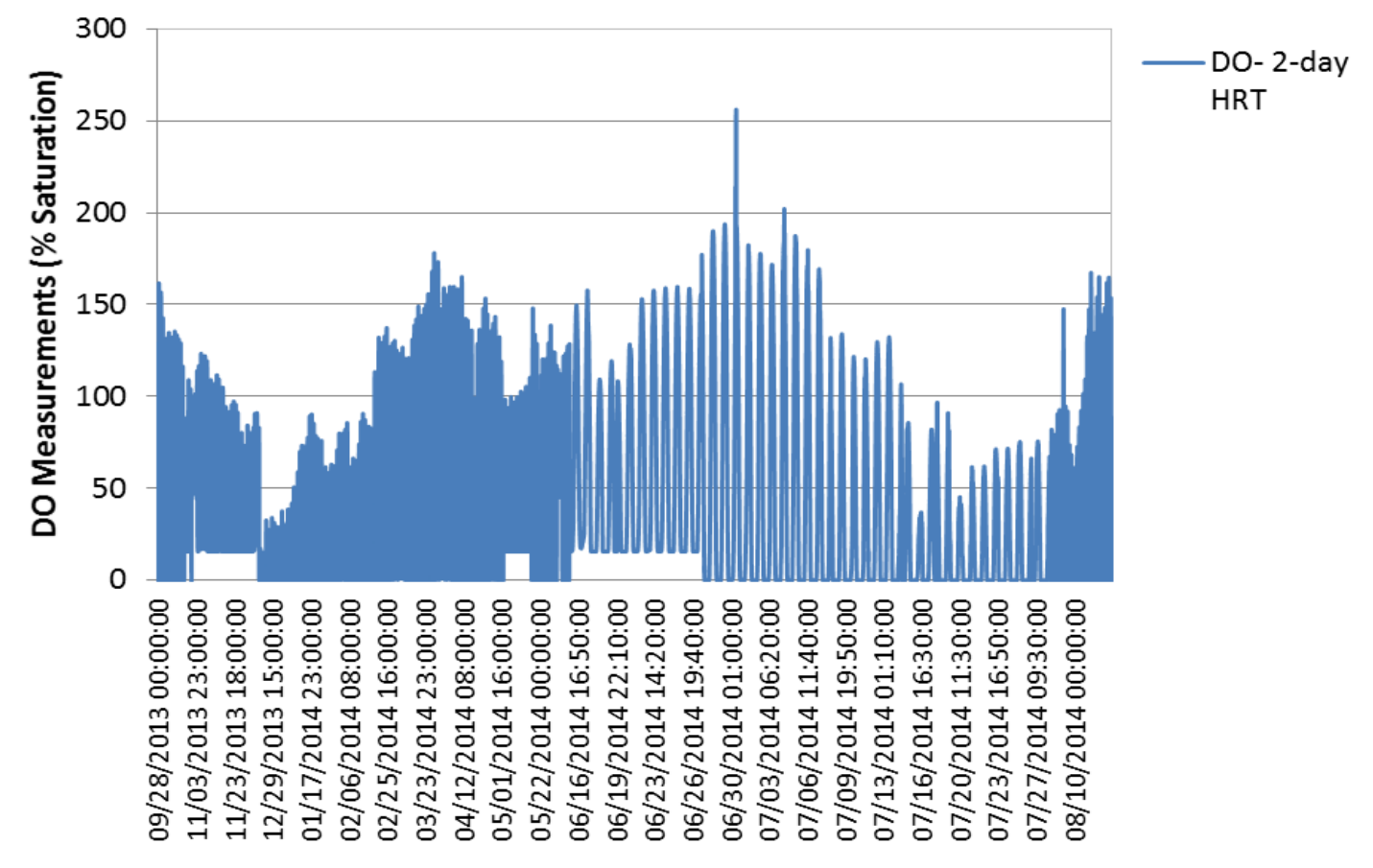

Figure 7-5: Recorded hourly DO measurements for the two-day HRT ponds during September 28, 2013 - August 28, 2014 of the Two-day HRT Ponds experiment. The values displayed are an average of the triplicate two-day HRT ponds. The Neptune data logger recorded these measurements. 


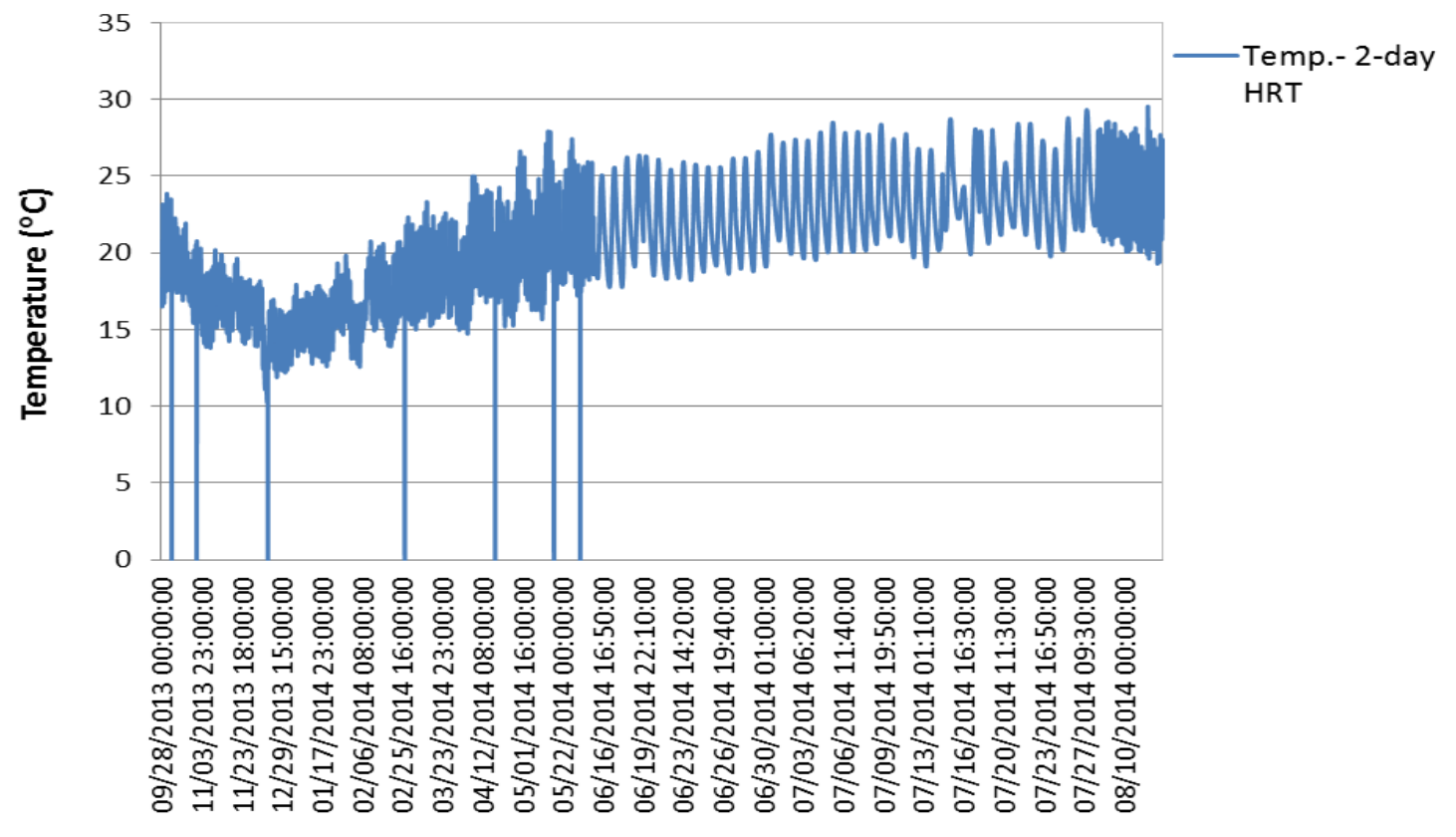

Figure 7-6: Recorded hourly temperature measurements for two-day HRT ponds during September 29, 2013 - August 28, 2014 of the Two-day HRT Ponds experiment. The values displayed are an average of the triplicate two-day HRT ponds. The outlier values (temperatures of $0^{\circ} \mathrm{C}$ ) correspond to time periods when the probes were down for maintenance or the data logger malfunctioned, and should be ignored. The Neptune data logger recorded these measurements 
Appendix B: San Luis Obispo monthly precipitation, solar radiation, and air temperature data recorded by the CIMIS weather station

Table 7-1: Monthly weather data recorded by the San Luis Obispo CIMIS weather station located approximately $6 \mathrm{~km}$ north of the AFS.

\begin{tabular}{cccc}
$\begin{array}{c}\text { Date } \\
\text { (yr-month })\end{array}$ & $\begin{array}{c}\text { Total Precipitation } \\
(\mathrm{cm})\end{array}$ & $\begin{array}{c}\text { Avg. Solar } \\
\text { Radiation }\left(\mathrm{W} / \mathrm{m}^{2}\right)\end{array}$ & $\begin{array}{c}\text { Avg. Air } \\
\text { Temperature }\left({ }^{\circ} \mathrm{C}\right)\end{array}$ \\
\hline 13-Mar & 1.7 & 215 & 13.0 \\
13-Apr & 0.3 & 277 & 13.4 \\
13-May & 0.6 & 305 & 15.2 \\
13-Jun & 0.1 & 308 & 17.4 \\
13-Jul & 0.0 & 308 & 16.9 \\
13-Aug & 0.0 & 288 & 16.9 \\
13-Sep & 0.0 & 244 & 18.1 \\
13-Oct & 0.9 & 184 & 15.2 \\
13-Nov & 0.8 & 139 & 13.9 \\
13-Dec & 0.7 & 126 & 11.6 \\
14-Jan & 0.1 & 133 & 13.8 \\
14-Feb & 13.4 & 145 & 13.2 \\
14-Mar & 6.0 & 210 & 14.0 \\
14-Apr & 0.6 & 263 & 14.2 \\
14-May & 0.0 & 316 & 16.7 \\
14-Jun & 0.0 & 335 & 15.6 \\
14-Jul & 0.0 & 294 & 18.6 \\
14-Aug & 0.0 & 279 & 18.2 \\
\hline
\end{tabular}




\section{Appendix C: Organic nitrogen and particulate phosphorus data from the sequential}

\section{Anaerobic and Aerobic Digestion Experiments}

Tables 7-2 to 7-9 were used to create Figures 4-36 and 4-37 in Sections 4.6.1 and 4.6.2.

Figures 4-36 and 4-37 analyzed the effect of the two separate pre-treatment technologies

on the fraction of degradable organic nitrogen and particulate phosphorus in the harvested

algae during sequential anaerobic and aerobic digestion experiments. The two

pretreatment technologies were high-pressure homogenization and sonication. Control

digesters were also tested, except for aerobic digestion in the sonication experiment.

Table 7-2: The mass of organic nitrogen in the anaerobic and aerobic digesters for the sequential anaerobic and aerobic digestion experiments in Section 4.6. The pre-treatment technology was high-pressure homogenization. "Raw" refers to the pre-treated sample in the anaerobic digestion on day 0 . "Digestate" and "aerobic treatment" refers to the effluent of the anaerobic digesters and aerobic digesters, respectively.

Organic nitrogen decay- mass basis (High-pressure homogenized)

\begin{tabular}{ccc}
\hline Stage & Organic N $(\mathrm{mg})$ & Organic N Fraction Remaining $(\mathrm{g} / \mathrm{g})$ \\
\hline Raw & 1686.2 & 1.0 \\
Digestate & 544.2 & 0.3 \\
Aerobic Treatment & 218.0 & 0.1 \\
\hline
\end{tabular}

Table 7-3: The mass of organic nitrogen in the anaerobic and aerobic digesters for the sequential anaerobic and aerobic digestion experiments in Section 4.6. No pre-treatment technology was used for the control samples. "Raw" refers to the sample in the anaerobic digestion on day 0.

"Digestate" and "aerobic treatment" refers to the effluent of the anaerobic digesters and aerobic digesters, respectively.

Organic nitrogen decay- mass basis (Homogenized-control)

\begin{tabular}{ccc}
\hline Stage & Organic N $(\mathrm{mg})$ & Organic N Fraction Remaining $(\mathrm{g} / \mathrm{g})$ \\
\hline Raw & 1785.2 & 1.0 \\
Digestate & 911.2 & 0.5 \\
Aerobic & 176.9 & 0.1 \\
Treatment & & \\
\hline
\end{tabular}

Table 7-4: The mass of organic nitrogen in the anaerobic and aerobic digesters for the sequential anaerobic and aerobic digestion experiments in Section 4.6. The pre-treatment technology was sonication. "Raw" refers to the pre-treated sample in the anaerobic digestion on day 0. 
"Digestate" and "aerobic treatment" refers to the effluent of the anaerobic digesters and aerobic digesters, respectively.

\begin{tabular}{ccc}
\multicolumn{3}{c}{ Organic nitrogen decay- mass basis (Sonicated) } \\
\hline Stage & $\begin{array}{c}\text { Organic N } \\
(\mathrm{mg})\end{array}$ & Organic N Fraction Remaining $(\mathrm{g} / \mathrm{g})$ \\
\hline Raw & 545.0 & 1.0 \\
Digestate & 88.0 & 0.2 \\
Aerobic Treatment & 31.0 & 0.1 \\
\hline
\end{tabular}

Table 7-5: The mass of organic nitrogen in the anaerobic digesters for the sequential anaerobic and aerobic digestion experiments in Section 4.6. No pre-treatment technology was used for the control samples. "Raw" refers to the sample in the anaerobic digestion on day 0. "Digestate" refers to the effluent of the anaerobic digesters.

\begin{tabular}{ccc}
\multicolumn{3}{c}{ Organic nitrogen decay- mass basis (Sonicated- control) } \\
\hline Stage & Organic N (mg) & Organic N Fraction Remaining $(\mathrm{g} / \mathrm{g})$ \\
\hline Raw & 451.0 & 1.0 \\
Digestate & 32.0 & 0.1 \\
\hline
\end{tabular}

Table 7-6: The mass of particulate phosphorus in the anaerobic and aerobic digesters for the sequential anaerobic and aerobic digestion experiments in Section 4.6. The pre-treatment technology was high-pressure homogenization. "Raw" refers to the pre-treated sample in the anaerobic digestion on day 0. "Digestate" and "aerobic treatment" refers to the effluent of the anaerobic digesters and aerobic digesters, respectively.

Particulate phosphorus decay- mass basis (High-pressure homogenized)

\begin{tabular}{ccc}
\hline Stage & Particulate P $(\mathrm{mg})$ & Particulate P Fraction Remaining $(\mathrm{g} / \mathrm{g})$ \\
\hline Raw & 402.0 & 1.0 \\
Digestate & 380.0 & 0.9 \\
Aerobic Treatment & 187.9 & 0.5 \\
\hline
\end{tabular}

Table 7-7: The mass of particulate phosphorus in the anaerobic and aerobic digesters for the sequential anaerobic and aerobic digestion experiments in Section 4.6. No pre-treatment technology was used for the control samples. "Raw" refers to the sample in the anaerobic digestion on day 0. "Digestate" and "aerobic treatment" refers to the effluent of the anaerobic digesters and aerobic digesters, respectively.

Particulate phosphorus decay- mass basis (Homogenized Control)

\begin{tabular}{ccc}
\hline Stage & Particulate P $(\mathrm{mg})$ & Particulate P Fraction Remaining $(\mathrm{g} / \mathrm{g})$ \\
\hline Raw & 402.0 & 1.0 \\
Digestate & 398.0 & 1.0
\end{tabular}


Table 7-8: The mass of particulate phosphorus in the anaerobic digesters for the sequential anaerobic and aerobic digestion experiments in Section 4.6. The pre-treatment technology was sonication. "Raw" refers to the pre-treated sample in the anaerobic digestion on day 0.

"Digestate" refers to the effluent of the anaerobic digesters.

Particulate phosphorus decay- mass basis (Sonicated)

\begin{tabular}{ccc}
\hline Stage & Particulate $\mathrm{P}(\mathrm{mg})$ & Particulate P Fraction Remaining $(\mathrm{g} / \mathrm{g})$ \\
\hline Raw & 146.0 & 1.0 \\
Digestate & 78.0 & 0.5 \\
\hline
\end{tabular}

Table 7-9: The mass of particulate phosphorus in the anaerobic digesters for the sequential anaerobic and aerobic digestion experiments in Section 4.6. No pre-treatment technology was used for the control samples. "Raw" refers to the pre-treated sample in the anaerobic digestion on day 0. "Digestate" refers to the effluent of the anaerobic digesters.

Particulate phosphorus decay- mass basis (Sonicated- control)

\begin{tabular}{ccc}
\hline Stage & Particulate P $(\mathrm{mg})$ & Particulate P Fraction Remaining $(\mathrm{g} / \mathrm{g})$ \\
\hline Raw & 118.0 & 1.0 \\
Digestate & 61.0 & 0.5 \\
\hline
\end{tabular}




\section{Appendix D: List of operational changes at the AFS}

The operational changes made of the AFS during the course of the pond experiments are outlined in Table 7-10.

Table 7-10: List of operational changes at the AFS during the course of the experiments (March 6, 2013 - August 28, 2014).

\begin{tabular}{cc} 
Date & Operational change \\
\hline $3 / 6 / 2013$ & Grab samples started \\
6/1/2013 & $\begin{array}{c}\text { Round 2 ponds were switched to a } \\
\text { 3-day HRT and } \mathrm{CO}_{2} \text { sparging was } \\
\text { installed in the Round 1 ponds. }\end{array}$ \\
& $\begin{array}{c}\text { Ramped standpipes were installed } \\
\text { in Ponds 1, 2, 4, 5, 8, and 9. 4-inch } \\
\text { vertical standpipes were installed } \\
\text { in Ponds 3, 6, and 7. }\end{array}$ \\
\hline
\end{tabular}

